\title{
Data collection systems and methodologies for the inland fisheries of Europe
}

\author{
Vehanen, Teppo; Piria , Marina ; Kubeka, Jan ; Skov, Christian; Kelly, Fiona; Pokki, Heidi ; Eskelinen, \\ Päivi ; Rahikainen, Mika; Keskinen, Tapio ; Artell, Janne \\ Total number of authors: \\ 26
}

Link to article, DOI:

10.4060/ca7993en

Publication date:

2020

Document Version

Publisher's PDF, also known as Version of record

Link back to DTU Orbit

Citation $(A P A)$ :

Vehanen, T., Piria, M., Kubeka, J., Skov, C., Kelly, F., Pokki, H., Eskelinen, P., Rahikainen, M., Keskinen, T., Artell, J., Romakkaniemi, A., Sui, J., Adámek, Z., Heimlich, R., Chalupa, P., Ženíšková, H., Lyach, R., Berg, S., Birnie-Gauvin, K., ... Arlinghaus, R. (2020). Data collection systems and methodologies for the inland fisheries of Europe. Food and Culture Organization of the United Nations. F A O Fisheries and Aquaculture Technical Paper No. 649 https://doi.org/10.4060/ca7993en

\section{General rights}

Copyright and moral rights for the publications made accessible in the public portal are retained by the authors and/or other copyright owners and it is a condition of accessing publications that users recognise and abide by the legal requirements associated with these rights.

- Users may download and print one copy of any publication from the public portal for the purpose of private study or research.

- You may not further distribute the material or use it for any profit-making activity or commercial gain

- You may freely distribute the URL identifying the publication in the public portal 
Food and Agriculture

\section{9}

\section{Data collection systems and methodologies for the inland fisheries of Europe}


Cover photo: Fishing trawler in Lake Oulujärvi, Finland. OPekka Hyvärinen. 


\section{Data collection systems and methodologies for the inland fisheries of Europe}

by

\section{European Inland Fisheries and Aquaculture Advisory Commission (EIFAAC) institutions:}

Teppo Vehanen
Senior Scientist
Natural Resources
Institute Finland
Helsinki, Finland
Marina Piria
Professor
University of Zagreb
Zagreb, Croatia
Jan Kubečka
Director
Institute of Hydrobiology
České Budějovice, Czech
Republic
Christian Skov
Associate Professor
DTU Aqua
Silkeborg, Denmark
Fiona Kelly
Senior Research Officer
Inland Fisheries Ireland
Dublin, Ireland
Heidi Pokki
Research Scientist
Natural Resources
Institute Finland
Helsinki, Finland
Päivi Eskelinen
Research Scientist
Natural Resources
Institute Finland
Jyväskylä, Finland

Mika Rahikainen

Senior Statistician

Natural Resources

Institute Finland

Helsinki, Finland

Tapio Keskinen

Research Scientist

Natural Resources

Institute Finland

Helsinki, Finland

Janne Artell

Senior Scientist

Natural Resources

Institute Finland

Helsinki, Finland

Atso Romakkaniemi

Senior Scientist

Natural Resources

Institute Finland

Oulu, Finland

Josip Suić

Senior Officer

Ministry of Agriculture

Zagreb, Croatia

Zdeněk Adámek

Researcher

University of South

Bohemia in České

Budějovice

Brno, Czech Republic
Roman Heimlich

Head of Department

Ministry of Agriculture

Prague, Czech Republic

Petr Chalupa

Officer

Ministry of Agriculture

Prague, Czech Republic

Hana Ženíšková

Officer

Ministry of Agriculture

Prague, Czech Republic

Roman Lyach

Associate Researcher Institute for Evaluations and Social Analyses

Prague, Czechia

\section{Søren Berg}

Senior Adviser

DTU Aqua

Silkeborg, Denmark

Kim Birnie-Gauvin

PhD student

DTU Aqua

Silkeborg, Denmark

Niels Jepsen

Senior Researcher

DTU Aqua

Silkeborg, Denmark
Anders Koed

Vice Director

DTU Aqua

Silkeborg, Denmark

Michael Ingemann

Pedersen

Researcher

DTU Aqua

Silkeborg, Denmark

\section{Gorm Rasmussen}

Emeritus

DTU Aqua

Silkeborg, Denmark

Patrick Gargan

Senior Research Officer Inland Fisheries Ireland

Dublin, Ireland

William Roche

Senior Research Officer Inland Fisheries Ireland

Dublin, Ireland

Robert Arlinghaus

Professor

Leibniz-Institute of

Freshwater Ecology and Inland Fisheries

Humboldt-Universität

zu Berlin

Berlin, Germany 
Required citation:

Vehanen, T.; Piria, M.; Kubečka, J.; Skov, C.; Kelly, F.; Pokki, H.; Eskelinen, P.; Rahikainen, M.; Keskinen, T.; Artell, J.; Romakkaniemi, A.; Suić, J.; Adámek, Z.; Heimlich, R.; Chalupa, P.; Ženíšková, H.; Lyach, R.; Berg, S.; Birnie-Gauvin, K.; Jepsen, N.; Koed, A.; Pedersen, M. I.; Rasmussen, G.; Gargan, P.,Roche, W. \& Arlinghaus, R. 2020. Data collection systems and methodologies for the inland fisheries of Europe. FAO Fisheries and Aquaculture Technical Paper No. 649. Budapest, FAO. https://doi.org/10.4060/ca7993en

The designations employed and the presentation of material in this information product do not imply the expression of any opinion whatsoever on the part of the Food and Agriculture Organization of the United Nations (FAO) concerning the legal or development status of any country, territory, city or area or of its authorities, or concerning the delimitation of its frontiers or boundaries. Dashed lines on maps represent approximate border lines for which there may not yet be full agreement. The mention of specific companies or products of manufacturers, whether or not these have been patented, does not imply that these have been endorsed or recommended by FAO in preference to others of a similar nature that are not mentioned.

The views expressed in this information product are those of the author(s) and do not necessarily reflect the views or policies of FAO.

ISBN 978-92-5-132256-7

ISSN 2070-7010 (print)

(ㄷ) FAO, 2020

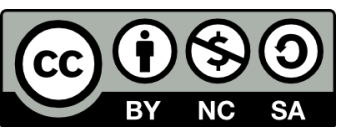

Some rights reserved. This work is made available under the Creative Commons Attribution-NonCommercial-ShareAlike 3.0 IGO licence (CC BY-NC-SA 3.0 IGO; https://creativecommons.org/licenses/by-nc-sa/3.0/igo/legalcode).

Under the terms of this licence, this work may be copied, redistributed and adapted for non-commercial purposes, provided that the work is appropriately cited. In any use of this work, there should be no suggestion that FAO endorses any specific organization, products or services. The use of the FAO logo is not permitted. If the work is adapted, then it must be licensed under the same or equivalent Creative Commons licence. If a translation of this work is created, it must include the following disclaimer along with the required citation: "This translation was not created by the Food and Agriculture Organization of the United Nations (FAO). FAO is not responsible for the content or accuracy of this translation. The original [Language] edition shall be the authoritative edition."

Disputes arising under the licence that cannot be settled amicably will be resolved by mediation and arbitration as described in Article 8 of the licence except as otherwise provided herein. The applicable mediation rules will be the mediation rules of the World Intellectual Property Organization http://www.wipo.int/amc/en/mediation/rules and any arbitration will be conducted in accordance with the Arbitration Rules of the United Nations Commission on International Trade Law (UNCITRAL).

Third-party materials. Users wishing to reuse material from this work that is attributed to a third party, such as tables, figures or images, are responsible for determining whether permission is needed for that reuse and for obtaining permission from the copyright holder. The risk of claims resulting from infringement of any third-party-owned component in the work rests solely with the user.

Sales, rights and licensing. FAO information products are available on the FAO website (www.fao.org/publications) and can be purchased through publications-sales@fao.org. Requests for commercial use should be submitted via: www.fao. org/contact-us/licence-request. Queries regarding rights and licensing should be submitted to: copyright@fao.org. 


\section{Preparation of this document}

This document is a technical paper contributing to the regional results under an FAO Technical Cooperation Programme project (TCP/RER/3701) on "Systems and methodologies of data collection in inland fisheries of Europe", financed by the FAO Regional Office for Europe and Central Asia (REU). This work is facilitated by the European Inland Fisheries and Aquaculture Advisory Commission (EIFAAC), a pan-European network of research institutions, and through a Letter of Agreement between FAO and the Natural Resources Institute Finland (LUKE). Mr Teppo Vehanen (LUKE), as Chair of the EIFAAC Technical and Scientific Committee (TSC), provided direct supervision of the co-authors from various EIFAAC research institutions. FAO technical oversight was provided by Ms Victoria Chomo, Secretary of EIFAAC and Senior Fisheries and Aquaculture Officer of FAO and Ms Eva Kovacs, FAO Consultant on inland fisheries. This paper makes a significant contribution to knowledge on the inland fisheries data systems of Europe, providing examples of good practices to guide evidence-based policy, as well as documenting the challenges facing management of inland fisheries resources. The main objective of this paper is to produce an up-to-date report on catch data collection and the methodologies used for fisheries (commercial and recreational) in European rivers and lakes. There are five detailed country examples of inland fisheries data collection systems and a short review of the remaining European countries. The other institutes involved, and responsible for their country examples, were Inland Fisheries Ireland, University of Zagreb (Croatia), DTU Aqua (Denmark) and Biologicke centrum AV CR (Czech Republic). The useful comments and suggestions from stakeholders were valuable and improved the quality of the paper. The final version was reviewed by the EIFAAC TSC and approved by the EIFAAC Management Committee. 


\section{Abstract}

Inland fisheries are important sources of ecosystem services contributing to human diet, health, well-being and economies. The evaluation of the importance and value of inland fisheries is one of the biggest challenges for its development. To develop the inland fisheries data collection, we reviewed the current status of data collection in European countries and provided five detailed country examples.

The level and methods of inland fisheries data collection in Europe were highly variable. Some countries did not collect any data on recreational fishing, or it was collected only from specific areas, or only the number of licenses sold was recorded. Data collection from catches of diadromous species was most common and harmonized among countries and in particular, Atlantic salmon Salmo salar were recorded. When data from other fish species were also nationally collected, the methods used included postal or telephone recall surveys using a sample of citizens of the country. More detailed surveys were used to assist national surveys, or were used independently, in specific sites of importance using various methods, like postal surveys targeted to fishing license holders, online reporting of catches, or catch reports and logbooks. Many countries provided fishing license buyers with catch return forms or logbooks to be filled at fishing occasions and/or returned in the end of the fishing season.

Commercial inland fisheries did not exist, or were very limited, in many European countries. In countries where commercial fishing was important, in most cases the fishers were registered and obliged to report their catches. The reliability of self-reporting of commercial catches was questioned in some cases. There was a trend towards webbased online reporting of inland fisheries data, which some countries were already using. The specific country examples give detailed description of data collection, focusing on: 1) country-wide postal survey (Finland) and 2) web-based survey and development of citizen science approach (Denmark). Example 3) from Ireland focuses on recreational salmonid fishing and conservation limits. There are two examples based on logbook returns: 4) one strict system, which is considered to work well (Czech Republic) and 5) one less controlled system, currently not producing reliable results, and under development (Croatia). Case studies were provided in each country example.

Finally, the authors discuss the important aspects of inland fisheries data collection and review the methods to provide recommendations. 


\section{Contents}

Preparation of this document $\quad$ iii

Abstract iv

1. INTRODUCTION

2. Overview of the current situation of inland fisheries data collection in Europe

2.1 Northern Europe 3

2.2 Western Europe $\quad 8$

$\begin{array}{ll}2.3 \text { Southern Europe } & 10\end{array}$

2.4 Eastern Europe 13

3. Country examples: Finland 15

$\begin{array}{ll}\text { 3.1 Data collection for statistics } & 15\end{array}$

3.2 Case study: Lake Oulujärvi - large lake with commercial and
recreational fishing

3.3 Case study: Examples of socio-economic valuation $\quad 24$

$\begin{array}{ll}3.4 \text { Legal background } & 25\end{array}$

3.5 Environmental issues and conflict with other water uses 27

3.6 Commercial fishing in inland waters $\quad 30$

$\begin{array}{ll}3.7 \text { Recreational fishing in inland waters } & 31\end{array}$

$\begin{array}{ll}3.8 \text { Monitoring system } & 34\end{array}$

3.9 International cooperation case study: River Tornionjoki salmon
fishing - border river between Finland and Sweden

4. Country examples: Croatia 43

4.1 Data collection for statistics 43

4.2 Case study: The Sava River fishing area with commercial and
recreational fishing

4.3 Case study: Socio-economic valuation of recreational and commercial fishers 51

4.4 Legal background $\quad 56$

4.5 Fishing restrictions $\quad 58$

4.6 Environmental issues and conflicts with other water uses 61

4.7 Commercial fishing in inland waters 64

4.8 Recreational fishing in inland waters 66

4.9 Management and monitoring of inland waters 68

4.10 International cooperation $\quad 69$

5. Coutry examples: Czechia 71

$\begin{array}{ll}\text { 5.1 Data collection for statistics } & 71\end{array}$

$\begin{array}{ll}5.2 \text { Legal background } & 73\end{array}$

$\begin{array}{ll}5.3 \text { Fishing rights } & 74\end{array}$

$\begin{array}{ll}5.4 \text { Fishing restrictions } & 75\end{array}$ 
$\begin{array}{ll}5.5 \text { Recreational fishing } & 77\end{array}$

$\begin{array}{ll}5.6 \text { Commercial fishing } & 78\end{array}$

$\begin{array}{ll}5.7 \text { Management and monitoring } & 79\end{array}$

5.8 Environmental issues and conflict with other water uses $\quad 80$

$\begin{array}{ll}5.9 \text { Diadromous species } & 80\end{array}$

5.10 Case study: Lipno Reservoir - large lake with extensive recreational fishing

5.11 International cooperation: Border streams and fishing grounds $\quad 85$

6. Country example: Denmark 87

6.1 Data collection for statistics $\quad 87$

6.2 Legal Background $\quad 89$

$\begin{array}{lr}6.3 \text { Recreational fishing } & 95\end{array}$

6.4 Commercial fishing 103

$\begin{array}{ll}\text { 6.5 Monitoring of inland waters } & 104\end{array}$

6.6 Management Case: Status and management of Atlantic salmon
populations in Denmark

$\begin{array}{ll}6.7 \text { International cooperation } & 107\end{array}$

6.8 Challenges for Danish inland fisheries management, conflicts with
other water uses

7. Country example: Ireland 111

$\begin{array}{ll}\text { 7.1 Data collection for statistics } & 111\end{array}$

7.2 Case study: Erriff River - recreational fishing only 113

7.3 Case study: Salmon and sea trout recreational angling, data collection and statistics in Ireland 115

7.4 Case study: a long-term cross-border angling species data collection scheme

$\begin{array}{ll}7.5 \text { Case study: socio-economic studies } & 121\end{array}$

$\begin{array}{ll}7.6 \text { Legal background } & 124\end{array}$

7.7 Environmental issues and conflicts with other water users 129

$\begin{array}{ll}7.8 \text { Monitoring fish } & 131\end{array}$

7.9 Commercial fishing in inland waters 132

7.10 Recreational fishing in inland waters 133

$\begin{array}{ll}7.11 \text { International cooperation } & 134\end{array}$

8. Methodologies suitable for data collection in inland fisheries 137

8.1 Different methods used to collect data from inland fisheries 138

9. Acknowledgements 149

10. References 151

11. Other sources of information 163 


\section{Figures}

FIGURE 1. Main parts of the Finnish water protection legislation

FIGURE 2. Permit procedure for water permit and environmental permit in Finland (Keto, 2019)

FIGURE 3. Catch of vendace and other fish species from Finland inland waters 1980-2017.

FIGURE 4. Number of recreational fishers by age group in inland waters and sea areas

FIGURE 5. Number of fishers using different types of gear in both inland waters and sea areas

FIGURE 6. Most common species of fish catches in inland waters

FIGURE 7. Above: Map of Tornionjoki River between Finland and Sweden and its main rivers. Below: The statistical fishing areas in the Bothnian Bay.

FIGURE 8. The estimated amount of salmon smolts migrating from Tornionjoki River to the Baltic Sea 1996-2018

FIGURE 9. The annual numbers of upstream migrating adult salmon in Tornionjok River 2009-2018

FIGURE 10. The salmon juvenile densities (all age groups combined, mean for three years) in different parts of the Tornionjoki River from 1986 to 2018

FIGURE 11. Map of Croatia with indicated bordering area of the Sava and Danube rivers

FIGURE 12. The number of anglers and the annual catch per angler $(\mathrm{kg})$ in the Sava River fishing area from 2008 to 2017 year

FIGURE 13. Catch of recreational fishers ( $\mathrm{kg} / \mathrm{year}$ ) at the Sava River fishing zone from 2008 to 2017

FIGURE 14. Average annual share of species in total catch (\% kg) by recreational and commercial (artisanal) fishers in the Sava River 51

FIGURE 15. Anglers dependency on fishing location and the catch content

FIGURE 16. Part of the profit from fishing in total personal income and in household income

FIGURE 17. The Sava River fishing zones

FIGURE 18. Total catch of commercial fishers for the Danube River in Croatia in 2017

FIGURE 19. Total catch of commercial fishers for the Sava River in Croatia in 2017

FIGURE 20. The total number of fishers and total catch from 2015-2018 in Croatia

FIGURE 21. Catches $(\mathrm{kg})$ of most common species of fish in 2018

FIGURE 22. Catches $(\mathrm{kg})$ of other fish species which should be reported in fish logbooks for 2018

FIGURE 23. Schematic presentation of the international fisheries data collection in the Czech Republic

FIGURE 24. The dynamics of yearly eel catches in fishing grounds of the Czech Anglers' Union

FIGURE 25. The development of angler catch biomass in the Lipno Reservoir from 1958 to 2018 
FIGURE 26. Biomass composition of multi-mesh sizes gillnet catch in the Lipno reservoir in all benthic and pelagic habitats

FIGURE 27. Number of daily, weekly, and annual angler licenses (top) and and standing gear fisher licenses (bottom) sold between 2005 and 201896

FIGURE 28. Number of annual, weekly and daily angler licenses sold to people who reside outside Denmark

FIGURE 29. A flow chart of the management model for inland recreational fisheries in Denmark.

FIGURE 30. Restocking of young eels $(2-5 \mathrm{~g})$ in lakes and rivers from 1987-2017,

100

FIGURE 31. Until the 1920s, Atlantic salmon populations existed in one eastern and eight western Jutland rivers.

FIGURE 32. Estimated spawning population of Atlantic salmon in rivers Storå, Skjern and Varde over the years

FIGURE 33. Estimated spawning population of Atlantic salmon in rivers Storå, Skjern and Varde over the years

FIGURE 34. Map of Ireland showing the Republic of Ireland and Northern Ireland,

FIGURE 35. The River Erriff Fishery, Co. Mayo 114

FIGURE 36. Summary of fishing catches in the Erriff Fishery 1975 to $2018 \quad 114$

FIGURE 37. Salmon and sea trout gill tags 116

FIGURE 38. The scientific process to provide catch advice for salmon in Ireland 118

FIGURE 39. Lough Melvin and Drowes Fishery 135

FIGURE 40. A conceptual figure of the data flow from an angler app. 144

\section{Tables}

Table 1. Summary of fishing and catches in Lake Oulujärvi between 1987-2015 according to postal fishing questionnaire surveys (Pöyry, 2015)

Table 2. Catch sizes and closed seasons. Restrictions on quantity or size of fish and on fishing activity when spawning in Finland

Table 3. Catches of Baltic salmon in the coastal commercial fishing near the mouth of the Tornionjoki River 2005-2018

Table 4. Catches of Baltic salmon in recreational fishing in the Tornionjoki River 1997-2018

Table 5. Fish species set by Ministry of Agriculture for data collection

Table 6. Fish species set by Ministry of Agriculture for data collection

Table 7. Number of licences issued to commercial fishers for the Sava River fishing area from 2006 to 2017

Table 8. Total annual catch and percentage of total permitted catch quota of commercial fishers on the Sava River from 2007-2017

Table 9. Number of commercial fishers and total catch by fishing zones in 2017 for the Sava River

Table 10. Total annual catch, catch per important fish species $(\mathrm{kg})$, catch per unit effort (CPUE) and number of commercial fishers at the Sava River for period 2005-2017 
Table 11. Structure of authorized fishing gear registered by the owners in Rivers Sava and Danube, Croatia

Table 12. How much do you agree with the mentioned statements (\%)

Table 13. Closed season for particular fishing area and the smallest fishing size allowed

Table 14. Fish species strictly protected by the Natural Protection Act

Table 15. Permitted annual catch quota $(\mathrm{kg})$ of commercially-important fish species for the Sava and Danube River fishing areas

Table 16. An example of annotated yearly fishing ground summary sheet in Czech Republic (Lipno Reservoir 2018).

Table 17. General fishing restrictions (legal sizes and closed seasons) in the Czech Republic.

Table 18. The annual total catch in 2017 from the recreational inland fisheries in the Czech Republic, according to the Ministry of Agriculture.

Table 19. Minimum harvest size and closed seasons of some important species for inland fisheries.

Table 20. Examples of some of the fishing restrictions for brown trout in Ireland

Table 21. Main Irish legislation and EU Directives relating to water

Table 22. Overview of more or less frequently used methods used to sample recreational fisheries data from European inland waters and country examples

\section{Boxes}

BOX 1. Examples of fisheries regulations in inland water(general rules only) 91

BOX 2. Brown trout stocking plans based on stream monitoring 94

BOX 3. The email query that was sent to the European countries 137 



\section{INTRODUCTION}

Inland fisheries are important sources of ecosystem services contributing to human diet, health, well-being, rural community livelihoods and economies (UNEP 2010, Cooke et al., 2016). The importance of inland fisheries is often undervalued and has been largely overlooked in policy discussions and the global sustainable development agenda as the discussions have mainly focused on the marine environment (FAO, 2018). In European countries, the role of inland fisheries has increasingly provided recreational services, biodiversity conservation, and eco-tourism. The value of recreational fishing in terms of economic contribution has grown significantly (FAO 2012). It is expected that the importance of inland fisheries, and thus the need for improvements in monitoring and management, further increases as food security becomes a major global concern (Suuronen and Bartley 2014). Processing fish to added-value products increases the value of the catch as fish provide important micronutrients and essentially fatty acids (Cooke et al., 2016). The challenge from climate change, lower carbon emissions, can be better met by low environmental impact food production, such as freshwater aquaculture and inland fisheries. Sustainable inland capture fisheries also contribute positively to several UN Sustainable Development Goals (Lynch et al., 2017). The many other benefits of sustainable inland fisheries to social, economic, and environmental systems are summarized by Arlinghaus et al. (2002), Lynch et al. (2016) and Funge-Smith (2018).

Global inland fisheries catch was 11.47 million tonnes in 2015 (FAO, 2018), contributing slightly more than 12 percent to annual global fisheries catch. In many of the countries reporting catch from inland fisheries, those catches have been increasing. It is, however, unclear whether this is real development or due, for example, to better reporting of inland catches. Moreover, recreational landings are usually not tracked. Typically, inland fisheries are described as small-scale fisheries, but also some large-scale inland fisheries exist (Newman, 2014, Funge-Smith, 2018). Management of inland fisheries is variable, and many freshwater fisheries are managed without use of any stock assessments, which complicates the development of sustainable harvesting strategies (Lorenzen et al., 2016).

Regionally, Asia has the highest inland fishery catch followed by Africa. European catch is relatively low at 150017 tonnes annually (FAO, 2018). According to Cowx (2015), commercial fisheries have declined throughout Europe. Data on inland fisheries from Europe is scarce, and data collection is highly variable, and not necessarily comparable (Newman, 2014). It is suggested that the catch statistics underestimates the value of inland fisheries, as the actual yield may be much greater due to underreporting (Bartley et al., 2015). The versatile status of fisheries data collection in Europe is due to the fact that countries manage inland fisheries individually without common guidelines, for example among the European Union (EU) member counties.

There is no European-wide socio-economic assessment of inland recreational fisheries, although country-level socio-economic studies have been conducted. Ernst and Young (2011) reported the number of commercial fishers in the EU member countries and employment in the sector. Commercial inland fisheries are practiced in 22 of the 28 member states. The number of fishers is estimated to be 17000 and the total annual commercial catch was 35000 tonnes (average from 2007-2008). Ernst and Young (2011) considered the contribution of commercial inland fishing catch to European market supply as "negligible". The European Inland Fisheries and Aquaculture Advisory Commission (EIFAAC) estimated commercial inland fishing total catch at 90000 tonnes and about 30000 commercial fishers in 33 EIFAAC member countries, including some countries also outside of the EU (Mitchell et al., 2010). Not all European countries routinely collect data on inland recreational fisheries catch. Ernst and Young (2011) estimated that there were around 15.8 million recreational fishers in $21 \mathrm{EU}$ member countries and their socio-economic 
importance was higher compared to commercial fishing. According to Arlinghaus et al. (2015), on average slightly less than 11 percent of the population in Europe participated in recreational fishing, but participation rates vary widely, with over 30 percent in Norway and three percent in Belgium. Information about the socio-economic importance of inland fisheries is scarce and socio-economic evaluation is one of the biggest challenges for the development of inland fisheries (Lucas and Marmulla, 2000, Arlinghaus et al., 2002).

Inland fisheries are one part of the multipurpose use of inland waters, competing with other water uses such as abstraction, hydropower and navigation (Arlinghaus et al., 2002, Cowx 2015). As long as the data on the importance and socio-economic value of inland fisheries is unrecorded or under-reported, decision makers may value other water uses with known value to the economy over the fisheries sector. In some European countries, anglers' associations are well organized and influential, but generally there is insufficient coordination amongst fishers in Europe, especially among commercial fishers. Insufficient coordination hinders the inland fisheries to have a strong effect on planning and management of freshwater resources (Newman, 2014). There are also conflicts between recreational and commercial fishers on the use of fish resources decentralizing the influence of the whole sector. The small scale of fisheries in the inland fisheries sector together with low funding for fisheries research and management of inland waters is a threat for the sector (Arlinghaus et al., 2002). Finally, environmental degradation and climate change result in loss of habitat and form a threat for inland fisheries.

Global warming due to climate change affects fish biology such as growth pattern and age at maturity. Sufficient monitoring of freshwater fish stocks is necessary to ensure sustainable fisheries management. This challenge emphasizes the need for proper data collection in freshwater lakes, ponds and rivers across Europe.

The future of inland fisheries is linked with the successful management of rivers and lakes and their surrounding basins (UNEP, 2010). Inland fisheries are most commonly managed on a site-by-site basis which is inadequate when we consider the nature of European rivers crossing international borders and shared fish stocks in lakes bordering more than one country. The management of inland fisheries should be placed on a larger environmental and socio-economic scale. There is strong support from the scientific community towards a wider perspective in fisheries management, such as the ecosystem approach to fisheries (EAF) (Arlinghaus et al., 2002, FAO, 2003, Garcia et al., 2003, Garcia and Cochrane 2005). Implementing EAF for fisheries has been suggested to improve inland water management (Beard et al., 2011, Suuronen and Bartley, 2014, Cooke et al., 2016). Through this approach, inland fisheries could be better evaluated for their contribution to food security and livelihoods and recognized in broader water resource decision-making (Cooke et al., 2016). The effective implementation of EAF in inland fisheries management requires reliable, comparable and up-to-date data collection from inland fisheries and their efficient analysis. The purpose of this research is to form a baseline of information on current methodology and systems for data collection, monitoring and evaluation of inland fisheries. Challenges are identified and recommendations provided from country case studies.

The Food and Agriculture Organization of the United Nations (FAO) describes inland fisheries as "any activity conducted to extract fish and other aquatic organisms from inland waters" (http://www.fao.org/inland-fisheries/en/). In this report, the authors focus on commercial and recreational freshwater fishing in Europe: commercial fishing is considered as an activity where fish are caught for the purpose of sale or where a caught fish or part of it is sold; recreational fishing means fishing for recreation and domestic needs including the use of both passive and active fishing gear. Examples are provided from five European countries on data collection and use of recreational and commercial inland fisheries data. Those countries are: Croatia, Czech Republic, Denmark, Finland and Ireland. Literature and personal communications were used to collect information from other European countries. The aim of the study is to describe current systems used in inland fisheries data management, and to identify good practices and the main problems regarding data collection for management of inland fisheries resources in Europe. 


\section{Overview of the current situation of inland fisheries data collection in Europe}

The information on the current status of inland fisheries data collection in European countries was developed using personal communications, literature and web sources. Countries are grouped according to the United Nations geoscheme for Europe.

\subsection{NORTHERN EUROPE}

In Finland, recreational fishing data for the whole country is collected by postal fisheries questionnaires using a large sample drawn from the population register maintained by the Population Register Centre (see Chapter 3). The Advisory Board of the Official Statistics of Finland and the Ministry of Agriculture and Forestry determine the criteria for data collection which is collected by the National Resources Institute Finland. The data accuracy of the national study is not enough to expose the catch statistics of individual water bodies, rivers and lakes. Therefore, separate surveys are conducted on specific water bodies, like important salmonid rivers and large lakes. These separate surveys can include different methods like online reporting of salmon catches or using information of the fishing licence holders to target the postal questionnaire specifically to licence holders. Inland commercial fishers are registered and are obliged to report their fishing activities and catches to the authorities (Chapter 3). For the stock assessment, biological sampling is done in specific areas of interest.

In Sweden, national statistics on recreational fishing is also collected by postal questionnaire surveys. The Swedish Agency for Marine and Water Management is responsible for the survey and carried out by Statistics Sweden. Since 2013, it has been an annual survey, including Swedish residents between 16 and 80 years old. Fishing carried out by visitors to Sweden is not included. The questionnaire is sent out three times a year and includes questions regarding fishing activities such as geographical area, gears used, number of fishing occasions, species caught and released, as well as travel distance and associated costs. The survey defines recreational fishing as all fishing activities carried out by those without a commercial fishing license. The survey covers both public and private waters. In lakes and rivers, catches sold from recreational fishing are also included. In addition to the national survey, regional collection programmes and surveys are conducted for both national and international reporting, to a large extent collated by the Swedish University of Agricultural Sciences, Department of Aquatic Resources (SLU Aqua). These surveys are based on a variety of methods, including both on- and off-site techniques, depending on local conditions. Inland commercial fishing in Sweden is mainly concentrated on the large lakes. Registered commercial fishers are required to log their fishing activities and catches and report them to the Swedish Agency for Marine and Water Management.

In Norway, the Ministry of Climate and Environment and the Norwegian Environment Agency are responsible for the inland fisheries data collection. For anadromous species in rivers and in the sea, catch data are available for every nationally registered salmon river. This is based on an obligatory reporting system, where river owners or river management organizations must report detailed data gathered from anglers. For bag net and bend net fishing for anadromous salmonids in the sea, this is obligatory for every fisher. The number of anglers in the rivers and netsmen regarding 
anadromous salmonids is collected through the obligatory national licencing system, except for those fishing for anadromous salmonids with rod and line in the sea, where no detailed data exist. For the freshwaters (inland waters) outside anadromous salmonid watersheds, there is no national method to collect catch data. National data of fishing as an outdoor activity in Norway is collected through household surveys, which gives an indication of the trend of people participating in inland fishing. Normally, such approaches overestimate catches and activity levels. There is limited inland commercial fishing in Norway. To the extent it exists, it is limited to some seasonal whitefish (Coregonus lavaretus) fisheries in the larger lakes in Eastern Norway and some smallscale wild brown trout fisheries in the mountains.

In Denmark, catch registration from commercial fishery in inland waters has been collected since 1903 and it is the responsibility for the individual commercial fishers to report their catch annually. Today, commercial fishing is scarce in Denmark and takes place in less than ten lakes. In general, there are no mandatory obligations for recreational fishers to report their catches. The only exception includes Atlantic salmon in rivers, where both harvested and released salmon are reported. In 2016, a citizen science approach, centred on smartphone technology, was introduced for catch data collection as well as CPUE data from anglers. There are examples which indicate that data obtained via self-reporting from anglers can have potential, but further evaluations of the quality of collected data are needed for example to understand temporal and spatial stability. As part of the EU data collection framework, biannual recall surveys are conducted twice a year. Although the survey focuses on marine catches, respondents are also asked about temporal patterns (quarterly) of harvest of eel and brown/sea trout in freshwater. The survey is web based, where potential participants are recruited via mail. The sampling frames are recreational fishers who are Danish residents and hold a valid annual license for recreational fishing.

In Iceland, it is mandatory by law for the owners of fishing rights to register and report their catch. The Ministry of Fisheries and Agriculture has overall responsibility and the information is collected by the Marine and Freshwater Research Institute. Rod fishery is reported in logbooks located in fishing lodges in a form that have been running since 1946. Atlantic salmon catch is registered on single fish and data is available in electronic form from 1974 to date. With a national poll survey, the Marine and Freshwater Research Institute has estimated less than two percent of Atlantic salmon and approximately 40 percent of Arctic charr and brown trout catch is unregistered. More general statistics of Iceland's inland recreational fisheries are not collected. Commercial fishery for salmon is registered on a daily basis (number and weight) in only a few glacial rivers. The Institute of Economic Studies analyses and reports the value of salmon and trout angling in Iceland http://www.hhi.hi.is/ sites/hhi.hi.is/files/sjz/virdi_lax-_og_silungsveidi_16.11.2018_0.pdf. Total expenditure on salmon and trout angling permits in Iceland in 2018 was valued at approximately 4.9 billion Icelandic krona, of which 2.8 billion goes to the owners of the rivers or lakes (landowners) where angling takes place.

In Estonia, the Ministry of Environment is responsible for the collection of recreational fisheries data. National surveys (e.g. phone interviews) covering the inland and sea recreational fisheries are done from time to time. There is a fishing card system for some certain fishing gear like gill net, longline, harpoon and trap net and also for certain species like salmon, sea trout and brown trout in specific rivers. Fishers using the fishing card must submit a catch report. There is no requirement to report catches from angling, apart from particular areas. Catch data can be submitted online at the address www.pilet.ee or www.kala.envir.ee to the Environmental Board by signing the data. However, much goes unreported and the figures do not cover the whole recreational catch. The data is stored in the Estonian Fisheries Information System, which can be accessed online. The Estonian Veterinary and Food Board is responsible for the 
collection of inland commercial fisheries data. All commercial fishers are registered in the Commercial Fishing Register; they must have fishing permits and they are obliged to report their catches at least once a month. Catches can be reported electronically to the Commercial Fishing Register through a specific application (PERK, Estonian abbreviation for "electronic reporting of catch data for coastal fisheries") on a daily basis. Fishers can also fill in fishing logbooks in paper format. The logbook is filled in on a daily basis and delivered monthly to the Veterinary and Food Board's Fishery and Market Regulation department's local office. Fishers can send the paper logbook to the Commercial Fishing Register electronically and Veterinary and Food Board specialists enter the data into the Register. Commercial fishers fishing in Lakes Peipus, Lämmijärv and Pihkva (the large lakes on the Estonian-Russian border) must report their catches and landing data to the Environmental Inspectorate by phone or by the PERK application at least one hour before they return to the landing site. Fishing trips are followed by a GPS vessel monitoring system.

In Latvia, purchase of an angling licence allows general angling in all public and private lakes and rivers, fishponds and the sea. Latvia does not collect data about the catches of anglers on a regular basis. The exceptions are salmon and sea trout caught in rivers where angling of these species is carried out with a special permit. In limited access waters, where angling is organized by the fishing right owners and special angling permits are sold, the organizers are responsible for collecting catch data. The data is sent to Institute of Food Safety, Animal Health and Environment (BIOR). However, not all fishing organizers deliver the data. Anglers' catches have been estimated by several methods: questionnaires, interviews, number of angling cards sold, and returned licences which contain information on catches. However, the total inland anglers' catch is poorly known. Recreational fishers using passive gears need a gear-specific license and catch cannot be sold. Recreational fishers using commercial gears are obliged to report all their catches in the same way as commercial fishers. Fishing operations have to be reported daily by filling in the fishing logbook. Logbooks are collected by the State Environmental Service which hands them over to BIOR for analysis.

In Lithuania, the Ministry of Environment is responsible for the distribution of recreational fishing licences (Coalition Clean Baltic, 2017), which are needed for general angling. Licences allow recreational fishing both inland and at sea, it is difficult to estimate fishing efforts for each (Coalition Clean Baltic, 2017). The large majority of recreational catches are from inland waters. The Fisheries Service under the Ministry of Agriculture is the main institution involved in recreational fisheries data collection, particularly the Division of Fisheries Research and Science (Coalition Clean Baltic, 2017). There is no regular monitoring of recreational catches from inland waters. Previously, data on recreational fisheries was collected by recall questionnaires providing estimates for catch per unit effort (CPUE) and regional surveys. Most of the inland fisheries catch comes from the Curonian Lagoon, a freshwater lagoon of the southeastern part of the Baltic Sea. The Curonian Lagoon is also the main water body for inland commercial fishing.

In England and Wales, the Environment Agency (EA), guided by the Department for Environment, Food and Rural Affairs (DEFRA), is responsible for the collection of the inland fisheries statistics. Freshwater recreational fishing is mainly angling, and the EA works in close cooperation with its partners, such as anglers' associations. The EA sells fishing licences, keeps track and reports annual sales. Salmon and sea trout rod licence holders are legally required to submit a full and accurate catch return to the EA every year (by 1 January of the following year). Commercial net and fixed engine licence holders must submit their catch return logbook within 14 days of the end of their respective fishing seasons. EA sends reminders to licence holders who have not declared their catches. The reporting can occur electronically as the EA introduced an online reporting system in 2015. 
In Scotland, fisheries management and legislation is predominantly focused on Atlantic salmon and sea trout, but there are important fisheries for wild brown trout and some fisheries for coarse fish species and rainbow/brown trout (Radford et al., 2014, PACEC, 2017). Laws governing fisheries for Atlantic salmon in Scotland are more complex than elsewhere in the UK, and probably Europe. They are based on the Feudal System - where all rights of salmon fishing must be traceable to the crown. The law of heritable Property in Scotland means that all salmon fishing (in Scottish law 'salmon' refers to both Atlantic salmon and sea trout) are a separate heritable estate. A landowner whose property is bounded by or includes a salmon river does not necessarily own the right to fish for them. Salmon fisheries are managed, on a day-to-day basis by a network of District Salmon Fishery Boards, and many of these are supported by a similar network of local Fishery Trusts who provide scientific and monitoring support. Brown trout, by contrast, is the most common and widespread freshwater fish in Scotland and is the subject of many sport fisheries in both standing and running waters in all parts of the country. Some fisheries are exclusive, closely managed, private fisheries, while others are easily accessed by the public, with or without permission from the landowner. Coarse fisheries are fewer than those available for salmonids and, apart from native pike, roach, perch and eel, most coarse fish which are angled in Scotland are introduced species. The majority of coarse fisheries in Scotland occur within the Central Belt or southern Scotland and are found in a wide variety of waters, both standing and running. It is traditional among coarse anglers to practice 'catch and release' for all fish and these operate throughout the year. Many individuals and clubs are associated with the Scottish Federation for Coarse Angling which is the leading organization for the sport in Scotland. There are also specialist clubs for individual species, for example the Pike Anglers Club of Great Britain, the National Anguilla Club and the Carp Anglers Group. In 'put-and-take' fisheries, the dominant species stocked is mainly farmed rainbow trout, although brown trout sourced from commercial suppliers are often used. The Association of Scottish Stillwater Fisheries is the representative body for this sector.

Scottish net fisheries, which have declined substantially in recent years, are also dominated by Atlantic salmon and Sea trout and a three-year moratorium is in place to limit the impact of mixed stock coastal net fisheries. The Salmon Net Fishing Association is the representative body for this sector. Marine Scotland Science (MSS) collects Atlantic salmon and sea trout fishery data annually. These are provided by the proprietors, occupiers or agents of salmon and sea trout fisheries throughout Scotland. Since 2018, MSS has asked fisheries to start recording fishing effort as rod days for the 2019 season onwards. It is a legal requirement that catch forms are completed accurately and returned. There is no requirement for coarse fisheries or put and take (PandT) stillwater fisheries (for rainbow trout) to submit formal catch returns. However, since 2008 all fishery managers are required to apply for a licence to introduce fish to their waters, and licences are issued according to the carrying capacity of the water body into which the fishery managers want to stock fish. Marine Scotland Science is the Scottish Government body responsible for assessing applications and issuing the licence to stock. If the water body is protected for nature conservation or lies within the boundary of a site designated for nature conservation, then Scottish Natural Heritage (SNH) will also be consulted. SNH routinely asks that catch records be maintained, and these should be available for inspection when licence renewals are sought.

There is no single management body for freshwater fisheries in Scotland. A variety of organizations are currently involved in various aspects of management of fisheries. Because Atlantic salmon fisheries dominate in terms of income and profile, the major driver is Atlantic salmon, and these are managed on a local basis by a network of District Salmon Fishery Boards which span almost all of the country. Overall, Marine 
Scotland Science takes the lead in collating Atlantic salmon and sea trout catch statistics from both anglers and netsmen, through a system of mandatory annual catch return forms. There is no parallel management body for other freshwater fisheries (e.g. coarse fisheries and PandT fisheries for rainbow trout). There are a number of representative bodies which lobby on behalf of their members but take no overall management role. These include the Scottish Federation of Coarse Anglers (for the coarse angling sector) and the Association of Scottish Stillwater Fisheries (for PandT Rainbow and Brown trout PandT fisheries).

MSS collects Atlantic salmon and Sea trout fishery data annually. These are provided by the proprietors, occupiers or agents of salmon and Sea trout fisheries throughout Scotland and includes both rod fisheries and netsmen. There is no systematic collection of catch data from coarse fisheries or PandT fisheries, although stocking data will be retained by the licensing body (which is also MSS). The sale of wild caught Atlantic salmon or Sea trout that have been captured by rod-and-line is illegal in Scotland and there is legislation in place to prevent the killing of spring stock of all Atlantic salmon populations, and rod-caught Atlantic salmon can only be killed legally in rivers which have achieved, or are likely to achieve, their conservation limit. Proprietors are required to declare the number of fish killed in their annual catch return questionnaire to MSS. Commercial netsmen are also legally obliged to report catches to Marine Scotland Science.

Inland Fisheries Ireland (IFI) is responsible for collecting fishery statistics in the Republic of Ireland except for two cross-border areas (between Republic of Ireland and Northern Ireland - i.e. Foyle and Carlingford area). Statistics for these two areas are collected by a cross-border agency - the Loughs Agency. IFI was established in 2010 (after the amalgamation of seven regional fishery boards and a central fisheries board into a single agency) and is responsible for the conservation, protection and management of the Inland fisheries resource, including sea angling (see Chapter 7). IFI is funded by the Department of Communications, Climate Action and Environment and is responsible for the day-to-day management of the inland fisheries resource including setting salmon conservation limits, issuing fishing licences and acting on reports of pollution and poaching. Ireland has over 74000 kilometres of rivers and streams and 128000 hectares of lakes, all of which fall under the jurisdiction of IFI. IFI is also the main fisheries research organization in Ireland. Angling is the only freshwater recreational fishing (see Chapter 7). Commercial inland fishing in the Republic of Ireland is limited to one lake fishery in the midlands and catches by each fisher are reported to IFI on an annual basis. Fisheries statistics are available for salmon and sea trout angling for every salmon river in each fishery district; however, there is no national method to collect statistics for other fish species in the Republic of Ireland. As there is no national method for collecting catch separate surveys are undertaken in specific water bodies (e.g. salmon rivers and large lakes) to assess the status of fish stocks (Chapter 7).

The Department of Agriculture, Environment and Rural Affairs (DAERA) is responsible for collecting statistics relating to fisheries in Northern Ireland (excluding two cross-border areas - see below). DAERA provides funding to the Agri-Food and Biosciences Institute Northern Ireland (AFBI NI) to collect data and carry out research. A rod licence (game and coarse) is required by law for any angler over 12 years of age on waters covered by DAERA. Information on the demographics of anglers is available from the DAERA 2012/2013 to 2016/17 (https://www.daera-ni. gov.uk/publications/continuous-household-survey). Information on fishery statistics is available through a Fisheries Digest published annually on the DAERA website (https://www.daera-ni.gov.uk/articles/angling-and-inland-waterway-statistics. Data are collected by DAERA and AFBI NI. 
The Loughs Agency (LA), a cross-border (Northern Ireland and Republic of Ireland) body established under the British Irish Agreement Act 1999 between the Government of the United Kingdom of Great Britain and Northern Ireland and the Government of Ireland, is responsible for collecting fisheries statistics in two cross border catchments (19 rivers) (i.e. Foyle and Carlingford). The Agency operates under the co-sponsorship of the Department of Communications, Climate Action and Environment in the Republic of Ireland and the Department of Agriculture Environment and Rural Affairs in Northern Ireland. A rod licence (game or coarse fish) is required by law for salmon, sea trout and coarse fishing in the LA area. Fisheries statistics are available for salmon and sea trout angling in the LA area. A similar tagging and data collection scheme to the Republic of Ireland is implemented by the LA.

\subsection{WESTERN EUROPE}

In France, reporting of salmon catches is mandatory for anglers. There is an obligation to report each fish caught, when the fisher does not release it, to the CNICS (Centre national d'interprétation des captures de salmonidés migrateurs). There is a specific procedure to report the information and tag the fish with an identification ring (http://www.generationpeche.fr/3535-la-peche-des-salmonides-migrateurs.htm). Reporting is monitored by French Agency for Biodiversity (an institute of the Ministry of Environment) and Fédération Nationale de la Pêche en France. Currently data is collected by postal return, but the process is changing to online reporting in 2020. Sea trout catch reporting follows the same procedure as for salmon. But because the reporting is not mandatory, results are much less accurate.

For anglers, eel catches must be reported on a form. But because of lack of followup, catches are not compiled and are not reported further. For all the other species of angling interest (mainly pike, sander, brown trout), anglers' catch reports are only monitored in a few cases (some lakes, some river sections) and often for limited time. There is no national compilation for these data.

In France, fisher categories are:

- anglers (as explained above);

- professional ; and

- amateur fishers (with fishing gears).

In France, inland commercial fishers and fishers catching eels must report data on their catches. The Ministry of Ecology (MTES (Ministère de la transition écologique et solidaire)) is responsible for commercial fisheries data. The French Agency for Biodiversity (AFB) (www.afbiodiversite.fr) provides technical service for the Ministry. Inland commercial fishers needs to be registered with the national register - SNPE (Suivi national des pêcheurs aux engins). Information is also collected from local and the national professional fishers' associations (AAIPPED - Association agréée interdépartementale des pêcheurs professionnels Rhône aval - Méditerranée) and CONAPPED - the French national committee of inland professional fishers. They need to send a catch report each month (Fiche de déclaration de captures d'anguilles the CERFA administrative form) to AFB. Essentially, the same form of catch reporting is done by recreational fishers using gill nets or other standing gear. CONAPPED is co-developing an online reporting system with $\mathrm{ABF}$, which should be operational at the end of 2019.

In Germany, the Institute of Inland Fisheries Potsdam-Sacrow collects information about inland recreational and commercial fishery by sending questionnaires to fisheries authorities in the 16 German Federal States. These Federal State authorities report to the Ministry responsible for fisheries in the respective Federal State (primarily the Ministry for Agriculture and Rural Development). They provide their answers aggregated to the State level based on the information and statistics available to them. 
Although production from commercial inland fisheries is often known with certainty, certain data on recreational fisheries (e.g. landings) are not regularly surveyed and thus based on "best guess" basis. Despite these data gaps, a state-wide overview is compiled by the Institute of Inland Fisheries and published annually.

The fishing rights for inland waters belong to the owner of the water body. In public waterways, this is the Federal State, but many lakes are owned by private people, farmers, associations and enterprises. Fishing rights are usually rented out to fishers or angling associations/clubs. While fishing rights holders may be obliged to report catches to the authorities, this is usually only followed up for commercial fisheries. There are about 10000 angling clubs in Germany, and although catches and other data may be generated within each of these clubs, these data are rarely, if ever, aggregated and communicated to the authorities. Under-reporting is also very common in commercial fisheries. All available catch statistics, or in some cases expert judgement, become part of the aggregated data reported by the authorities. Importantly, however, for many privately-owned waters, as well as those owned by municipalities, churches, private people or angling clubs, there are typically no valid statistics available to authorities. In these cases, the authorities would normally produce a "qualified guess" used to top up the statistics for the waters in a Federal State. The majority of commercial fisheries are based on larger water bodies, while angling clubs mainly own smaller sized waters. Because larger lakes and river stretches are often owned by Federal States, aggregated catches reported by fisheries authorities are to some extent based on real catch statistics, but uncertainty is high and catches are usually not available by size class or age class, which substantially limits the usefulness of the data for stock assessments. Moreover, as most inland fisheries are today of a recreational nature in Germany, the bulk of catches are not recorded at all. In most cases, authorities assume an average catch per angler (variation of 3-14 kg/head depending on the Federal State) and multiply this with the number of fishing licenses in that Federal State. Yet, this approach is also very error prone as anglers from neighbouring states can obtain angling permits in other states. There are no statistics for regular effort available, and there is no routine scientific social survey of anglers at state level and thus the situation is extremely data-poor.

There is also no formal obligation for commercial inland fishers to register and report catches. However, registration and reporting is required for fishers when:

- renting fishing rights are owned by Federal States;

- fishing takes place in a Federal State, where a submission (and confirmation) of plans on how to manage and protect fish stocks (Hege dyty) is compulsory. This is the case in less than half of the 16 Federal States;

- financial support is received (e.g. for eel stocking); and

- waters are managed under special regulations (e.g. Lake Constance).

In such cases, fishers are obliged to report catches to the Fisheries authorities of the respective Federal State.

In Austria, there is no central institution that collects data on recreational fisheries. Data are collected by Landesfischereiverbände (fishing associations of the different Austrian provinces). The extent and accuracy of data collection differs between the provinces. Inland commercial fisheries exists in Austria and fishers are registered - or more precisely - the Fischereirechte (fishing rights) are registered. In Austria there are no exact catch statistics - only estimates are made, based on the number of fishing rights and productivity for each lake. The main fish species exploited commercially in the Austrian Alpine lakes is whitefish, and accordingly, whitefish stocks are subject to high fishing pressure. A pilot study for data collection and management is ongoing together with the fishery rights owners.

In Switzerland, recreational fisheries data are collected annually by the cantons and sent to the federal authorities. The responsible authorities are the fishery offices of the cantons and the Water Habitats division of the federal government (BAFU). 
As per the fishing laws, the cantons collect the data and deliver them to the federal authorities in a digital database format (.xlsx tables which meets the database format). Data are collected from all the water bodies. Professional fishers have to be registered by the canton in order to practice their activity. The federal authorities have a regularly updated list of active professional fishers and their category of employment: full time ( $90 \%$ of their income or working time), part time ( $>30 \%<90 \%)$, occasional $(<30 \%)$ ).

In Holland, the Ministry of Agriculture, Nature and Food Quality is responsible for the collection of inland recreational fisheries data. The Ministry has contracted Wageningen Marine Research to carry out aerial surveys to monitor the number of recreational anglers. Wageningen Marine Research also sends a questionnaire to thousands of recreational fishers who provide information on their catch and effort on a voluntary basis - via a logbook survey (van der Hammen et al., 2016). Recreational fishers are not obliged to report catches to the authorities. All commercial inland fishers are registered and require a public permit; next they need a private authorization from the local owner of the water or fishing rights. They must report their catches of eel weekly. Only for the IJsselmeer area (closed inland bay), fishers using nets are obliged to report catches of pike-perch, perch, roach and bream on a quarterly basis. Catch reports are sent to the Ministry of Agriculture, Nature and Food Quality and the Wageningen Marine Research.

In Flanders and Wallonia in Belgium, there are no commercial inland fisheries. Recreational fisheries data is not compiled from inland fishing. Recreational anglers' organizations collect data for example from angling competitions: such as https://www.sportvisserijvlaanderen.be and http://www.parcoursdepeche.be/

\subsection{SOUTHERN EUROPE}

In Spain, the Autonomous Communities of Spain ${ }^{1}$ are responsible for regulating inland fisheries, with the exception of areas under the jurisdiction of the Secretaries of Fisheries (Secretarias de Pesca) (Mitchell et al., 2010, Morales-Nin and Lobon-Cervia, forthcoming). The catch technique preferred by Spanish fishers is the traditional rod and line. Most fishers conform to the techniques of capture, to the preferred species and the areas or regions where they fish. In inland waters, the number of species of recreational fishing interest is low, it is essentially limited to salmon Salmo salar and to trout Salmo trutta, in addition to some introduced species such as pike Esox lucius and black bass Micropterus salmoids and to a much lesser extent, some cyprinids and crabs (Morales-Nin and Lobon-Cervia, forthcoming). Inland recreational fishing is not subject to similar or comparable evaluations to those carried out in marine fisheries, as information is collected on catches of only three species whose populations are in a state of recession (Morales-Nin and Lobon-Cervia, forthcoming). Anguilla juveniles known as elvers Anguilla Anguilla, that are captured in mouths and estuaries of the rivers, sea bass Dicentrarchus labrax and Atlantic salmon catches must be all registered, measured and labelled (Morales-Nin and Lobon-Cervia, forthcoming). Information of the number of fishing licences sold is collected by the Autonomous Communities. There are some differences and problems with the comparability of the numbers among the Communities, In some areas, the licence does not have to be annual, but can valid up to four years, which means the number of licences issued annually do not coincide with the actual numbers in force (Morales-Nin and Lobon-Cervia, forthcoming). Also, there are some licences that authorize fishing in several Autonomous Communities so that fishers can make excursions to other Communities. Another additional problem is related to fishing from boats in which licenses are issued for each boat in particular, but do not specify the number of authorized fishers that may vary remarkably depending on the length of the boat (Morales-Nin and Lobon-Cervia, forthcoming). In other

Catalonia, Balearic Islands, Galicia and Basque Country 
cases, such as in Catalonia, fishing licenses serve both inland and marine waters, and separation between the two is not possible (Morales-Nin and Lobon-Cervia, forthcoming). Inland commercial fishing in Spain is very limited (Mitchell et al., 2010).

In Greece, according to law (p.d. 99/2003 A' 94), the use of vessels for recreational fishing is not allowed and only the use of line gears is allowed, with the exception of longlines. Recreational fishers are allowed to fish either three fish or a maximum of two kilograms per day. Total catches are relatively small quantities so a special system of collection does not apply. Almost all Greek commercial fishing fleets operate at sea. Production from inland waters in Greece is negligible (less than $3000 \mathrm{t}$ ). Inland fisheries have always been of relatively low interest to the country, given the limited area of inland waters and, consequently, the small income it produces. Commercial fishery in Greece is only conducted in a few large lakes located in western and northern Greece (e.g. Lake Kastoria, Trichonida, Polyphytoy etc.), and not at all in rivers and streams. Catch data are collected from the Regional Units of Fisheries Departments in each Prefecture (13 Prefectures in total). Data is based on reporting by fishers, and there are some concerns about the reliability of the data. For recreational and commercial inland fisheries, the number of licenses sold are collected. The responsible institution for providing these licences is the Ministry of Rural Development and Food (http://www.minagric.gr/index.php/en/). Recently, there has been an ongoing effort to collect more production data from professional inland fishing vessels.

In Portugal, in most cases, catch data from recreational fisheries is not reported as it is not a legal requirement. Anglers need to register to buy an annual licence for recreational fishing. Some records are collected from angling clubs and competitions, and this data is managed by the Portuguese Institute for Nature Conservation and Forests (ICNF - www.icnf.pt). Inland commercial fisheries in Portugal focus mostly on anadromous fish species (especially shad and sea lamprey) and fishers must register and acquire a specific licence for this activity. This fishing activity only occurs in specific river stretches defined as Commercial Fisheries Areas. Commercial fishers must keep a capture per night logbook which is then collected by the authorities. There are some projects, developed by Universities and Research Centres (mostly the University of Évora and MARE centre) that are currently collecting commercial fisheries data on anadromous species at a national level through fishers' surveys. Long-term catch data for inland commercial fisheries is managed by the ICNF institute.

In Italy, management of freshwater fisheries exists at national and local level. National legislation covers the general fisheries policy framework and the quality of inland waters, while regional legislation covers general fishing rules (minimum fish size, gear permitted, fishing periods, etc.) and allows for more restrictive modifications from local administrations. In Italy, the absence of a unified licensing system makes it difficult to estimate the number of recreational fishers and their catches. The legislation does not require reporting of the catches. Commercial inland fisheries in Italy are mainly located in the northern and central regions. The majority are in the north lake district in the large glacial lakes. Commercial inland fisheries and recreational fisheries data are only available at regional level.

In Croatia, inland recreational and commercial fishers' data is collected by fish logbooks prescribed by national legislation (see Chapter 4). Recreational fishing is only permitted for running and standing waters under concession of the fishing right owner. Commercial fishers should possess licenses for commercial fishery and fishing is allowed only in the Sava and the Danube rivers. Accordingly, data on recreational fishery is only collected for standing and running waters which are under state concession, and for commercial fishery only at authorized fishing zones. Compiled logbooks for recreational fishery are collected and aggregated yearly by the Croatian Sports Fisheries Association which then sends it to the Ministry of Agriculture. Commercial fishers return filled logbooks directly to the Ministry of Agriculture. The new Freshwater Fisheries Act 
should be released in 2019, and data collection will be managed digitally. At present, data collected does not reflect the real catch (see Chapter 4).

In Bosnia and Herzegovina, recreational fisheries data are collected by the Ministry of Agriculture, Forestry and Water management. The Ministry of Agriculture, Forestry and Water management has an office in each county. Currently, data collection is not fully operational. Each fishing association should inform the Ministry about their activities at the end of each year. The form and method of reporting is not fully defined, and data collection is incomplete. Commercial fisheries do not exist in Bosnia and Herzegovina.

Albania does not collect inland recreational fisheries data. Inland commercial fisheries data are reported mainly for the lakes (e.g. Shkoder and Oher lakes) by the fisheries management organization of the lake. Generally, the commercial fisheries landing statistics are collected by the fisheries inspectorate in each of the Albanian regions.

In Montenegro, the Ministry of Agriculture and Rural Development is responsible for the collection of data from commercial and recreational fish catches. Both anglers and commercial fishers are obliged to report the same data in e-logbooks. The year 2019 is designated as a transition year for the use of e-logbooks and the implementation of the new law on freshwater fishery and agriculture. Full implementation of the law will take place in January 2020. Commercial fishery exists only at Lake Skadar (bordering lake with Albania). Fishery on Skadar Lake is organized by the Skadar Lake National Park. Both commercial and recreational fishers can buy licences. The Skadar Lake National Park ranger service is in charge of fishery controls (i.e. enforcement of fisheries rules and regulations).

Slovenia prohibits commercial fishing in inland waters; only non-commercial fishing with fishhooks is allowed, in accordance with fishery arrangements regarding individual water bodies and individual fish species (http://www.mkgp.gov.si/en/ areas_of_work/fisheries/). In some regions, sport fishing is of great importance for tourism. Rainbow trout Oncorbynchus mykiss and brown trout Salmo trutta are the main targets for sport fishing and the Fisheries Research Institute of Slovenia collects fishing data. The biological database of the Fisheries Research Institute of Slovenia (Bios) is an open source database used to collect data from inland fisheries.

In the Republic of North Macedonia, inland fisheries data are collected. Each angler buys a license and receives a record sheet with the licence to report back the information and catch of the fishing process. This record sheet should be filled in and at the end of year sent to the angling association (concessionaire). Angling associations collect all these records and send them to the Ministry of Agriculture. In practice, the level of reporting is low, and the data is incomplete. The Macedonian Fishing Association is responsible for the data collection and its delivery to the Ministry of Agriculture. Commercial fishing takes place in three natural lakes (Ohrid, Prespa, Dojran) and on two artificial lakes (Tikvesh and Shpilje). Commercial fishers must pass an examination and are then registered by the Ministry. The examination is prepared by the commercial fishers' association (concessionaire). The concessionaire collects the commercial fisheries data (daily, monthly and annual catch and effort) and sends this data to the Ministry of Agriculture.

In Serbia, recreational fishers purchasing the annual fishing license acquire a booklet to report their fishing activities and catches. By law, catch statistics for each fishery district is reported annually. Fishers record each fishing occasion and catch by species and size. Fisheries managers are obliged to collect all booklets when issuing the annual fishing license to the recreational fishers for the next year. They also need to analyse catch records and to report the results in the fishing district's annual report which they are obliged to prepare and deliver to the Ministry of Environment Protection. The Ministry is in charge of sustainable use of fish stocks. Commercial fishers from the large lowland rivers (Danube, Sava and Tisa) deliver their monthly-recorded catches 
to the fishery district managers. Fishery districts compile and summarize them at the end of year and report in the annual report to the Ministry of Environment Protection. The collected data should be used to serve the fisheries management in annual fishery management plans. If catches do not exceed the plan, then the projected fishing regime can be continued. In practice, the system is not fully working, the level of reporting is low and there are concerns about the reliability of the data available from both recreational and commercial fisheries. The control of catch by guarding services in the field is very sparse. The Ministry in charge, or Agency for Natural Protection, delivers the summary of the results in gross form to the Annual Statistics Almanac of the Republic of Serbia.

In Turkey there is no collection of data from recreational inland fishing as freshwater recreational fishing is not very common in Turkey. Commercial fishing data is collected from registered fishing cooperatives wherever they exist. They are common especially in large natural lakes and reservoirs where fish stocks are large enough to be commercially utilized. Commercial cooperatives have to report directly to the Ministry of Agriculture, Fisheries department and the Turkish Statistic Institute keeps all the data logs. Catch is given as metric tonnes of commercial and economic fish (for each species) such as common carp (Cyprinus carpio) and pike (Esox lucius). There are, however, some concerns that the data gathered from fishers through cooperatives are unreliable.

\subsection{EASTERN EUROPE}

In Poland, fisheries management is under the responsibility of the Ministry of Maritime Economy and Inland Navigation. The Inland Fisheries Institute is the main research institute for carrying out research in the field of inland fisheries and inland fisheries economics. Recreational fishing is the main fishing activity in the inland waters of Poland while commercial inland fisheries are important in the lake area in the northern part of the country. The inland waters are controlled by the Polish Angling Association (PAA), water companies, fisher cooperatives and by private persons. Public Inland waters are owned by the Polish State Treasury and managed by regional boards of National Water Management Authority. The Polish Angling Association (PAA), the largest fishery stakeholder, manages almost 36 percent of the total inland water area of Poland (Kaczkowski and Grabowska, 2016). The PAA has at its disposal 66 percent of the total river area, 88 percent of impoundment surfaces and 21 percent of total lake area. From 2004, concessions for fishery management were obtained from the Regional Water Management Authority at fishing ground auctions (Kaczkowski and Grabowska, 2016). Management is strictly regulated for 10-year periods according to the statements in fishery plans that were submitted for auction. Generally, management is focused on stocking and the stocking rate is the basic issue taken into consideration during fishing ground auctions (Kaczkowski and Grabowska, 2016). Currently, the main source of information on the level of angling catches is catch registers (anglers return their catch data) maintained by particular PAA districts. The PAA has also tested the portal for online registration of angler catches. Generally, the data obtained from the records are incomplete, due to the different level of records in particular districts, the lack of information on catches of visiting anglers and the problem of reliability of data entered into registers. There are special questionnaires such as RRW22 - for aquaculture enterprises and RRW-23 - for inland fisheries enterprises (private companies and the Polish Angling Association). However, a large part of recreational catches are not registered in Poland. Commercial fishers are obliged to report their catches. The present knowledge of commercial and recreational fisheries is either limited by the area and time of particular scientific surveys, or by the scope of official documentation issued by commercial and recreational fisheries organizations and enterprises. Lakes make up the greatest surface area (64 percent) of commercial fishing 
grounds compared to rivers (21 percent) and reservoirs (15 percent) (Kaczkowski and Grabowska, 2016).

In Hungary, the National Food Chain Safety Office (NEBIH), belonging to the Ministry of Agriculture is responsible for the collection of recreational inland fisheries data. The data are collected on a national level. All recreational anglers or fishers, regardless of the type of water, must keep an official logbook where they immediately record all caught (and kept) fish. The logbook must be submitted to the angler's association (in Hungary all anglers must be members of an angling association) at the end of the year (and no later than 28 February of the subsequent year). The logbook data are summarized by the National Food Chain Safety Office (NÉBIH), which produces natural water fishing statistics. Aquaculture data collection is done by the Research Institute for Agricultural Economics, National Agricultural Research and Innovation Centre (NAIK AKI), which is also one of the sectoral research institutes belonging to the Ministry of Agriculture. The statistical data from NÉBIH and NAIK AKI are compiled into the official fisheries and aquaculture production statistics by the Department of Fisheries of the Ministry of Agriculture, which provides the statistical data to both the Hungarian Central Statistical Office, FAO and OECD. Hungary has stopped all commercial fishing on its waters with effect on 1 January 2016.

In the Czech Republic, the Ministry of Agriculture is the central authority for the state administration of fisheries (see Chapter 5). The Ministry of Agriculture produces annual reports about inland fisheries prospects. The recreational fishing of Czechia is organized mostly by the Czech Anglers' Union based in Prague https://www.rybsvaz.cz/beta/ index.php and the Moravian Anglers' Union based in Brno http://www.mrsbrno.cz/ (see Chapter 5). In Czechia, commercial fishery from open waters (excluding aquaculture) is of a negligible extent (landing less than 50 metric tonnes). Recreational fishery catches are three orders of magnitude higher. All 315000 recreational anglers are required to write down and report every fish retained. The information is then integrated into fishing ground-specific catch summary for each angler. Yearly logbooks are collected by local anglers' unions and are summarized for individual fishing grounds. Summaries are forwarded to the Ministry of Agriculture which issues the nationwide fishery statistics. Also, recording the number of angling visits, irrespective of the catch, is as a compulsory proxy for fishing efforts (see Chapter 5).

Bulgaria has both recreational and commercial inland fishing. Commercial fishing takes place especially in the Danube and in some reservoirs. The responsible agency for data collection is NAFA (National Agency for Fisheries and Aquaculture) for the Ministry of Agriculture, Foods and Forestry. Reporting is done as follows: recreational fishers should note every catch on their fishing licence. This can be monitored in situ at the fishing site. Typically, the catch report in the licence is not returned at the end of the year as it is not obligatory. Commercial fishers keep a diary of their catches and report to NAFA. Afterwards NAFA collects the data into the national catch statistics. In practice, however, there are only limited data for recreational fishing and there are concerns about the reliability of the commercial fishing data. 


\section{Country examples: Finland}

\subsection{DATA COLLECTION FOR STATISTICS}

\subsubsection{Recreational fishing}

The recreational fishing statistics of Finland (OSF, 2017) is produced by the Natural Resources Institute Finland (Luke). Producing statistics is one of the continuous basic duties laid down by law for the research institute which is funded from the central government budget. The statistics on recreational fishing includes both inland and marine fishing and the statistics present the number of fishing households and persons, the number of those using different gear types, the number of fishing days and the catch by species, by gear type and by fishing area. The Advisory Board of the Official Statistics of Finland determines criteria for the statistics. The quality description of the recreational fisheries statistics are in line with the recommendations by the Advisory Board. Further information on the statistics and quality description can be found at: https://stat.luke.fi/en/recreational-fishing.

Recreational fishing statistics are used to monitor the state of fish stocks at sea and trends in recreational fishing. The data are also needed to evaluate the social significance of recreational fishing. One part of the presented catch estimates includes meeting the obligations of EU data collection of fisheries (Council Regulation No. 2017/1004, Commission Regulation No. 665/2008). The catch estimates of recreational fishing are also included in the statistical programme of FAO.

Apart from official statistics, recreational salmon catches in Finnish salmon rivers are estimated separately. In the Tornionjoki (see Chapter 3.9) and Simojoki rivers, catches are estimated on the basis of surveys conducted by Luke of fishers who purchased fishing licenses in those rivers. In the Tenojoki and Näätämönjoki rivers, fishers are, according to fishing rules, obliged to report their catches through an online website. The statistics are used to monitor the status of fisheries and the fish stocks. Statistical data are also needed to assess the societal significance of the fisheries, the financial state of fishing companies or the impact of environmental changes on the fisheries.

Complementary to the recreational fishing statistics collection, Luke (and its predecessor, the Finnish Forest Research Institute, METLA) and Statistics Finland collect information linking recreational fishing to other outdoor recreation activities and nature-based tourism on a national scale every decade. Two previous national outdoor recreation inventory studies (LVVI, https://www.luke.fi/en/natural-resources/ recreational-use-of-nature/) were conducted during 1998-2000 (approximately 10600 respondents) and 2009-2010 (approximately 8900 respondents). The third study is scheduled to take place between 2019 and 2021.

\subsubsection{Data collection}

The data is collected by postal questionnaire using a sample drawn from the population register maintained by the Population Register Centre. The statistical unit in the recreational fishing statistics is the household-dwelling. The term recreational fishing includes all fishing practiced by Finnish household-dwellings with the exception of that carried out by professional/commercial fishers and their households. The statistics do not include fishing by foreign visitors or by Finns living abroad.

Fishing is included in the statistics when a person has used gear of some kind at least once a year. The definition of a fishing day depends on the type of gear used. In the case of rod and line, a fishing day means that one person has used a certain type of 
rod on one day. In the case of gill nets, fish traps, crayfish traps and trap nets, a fishing day means that the person has inspected the gear in question on one day. The regional division is based on the Fisheries Units of the Centres for Economic Development, Transport and the Environment (ELY Centres). In addition, regions in inland waters are divided on the basis of Regional State Administrative Agencies and in marine areas on the basis of regional borders between Uusimaa - Southwest Finland, Southwest Finland - Satakunta and Ostrobothnia - Central Ostrobothnia. This division differs slightly from the previously used regional division of the International Council for the Exploration of the Sea (ICES).

\subsubsection{Compiling statistics}

Fishing days are calculated statistically by gear type. Catches are reported as un-gutted weight and are allocated by species to the statistical areas according to the most important fishing area for the species. Catch value is calculated using the average prices paid to commercial fishers using the official statistics of prices for fish produced by Luke (https://stat.luke.fi/en/producer-prices-fish). If there are no prices for certain species available, price of a similarly priced species is used (e.g. the price of whitefish (Coregonus lavaretus s.l.) is used for grayling (Thymallus thymallus), that of sea salmon for landlocked salmon and that of Baltic herring (Clupea harengus membras) for sprat (Sprattus sprattus)). The prices are those paid to marine commercial fishers, with the exception of vendace (Coregonus albula). For grayfish, the prices are collected from wholesalers.

The catch values are rough proxy estimates, because recreational fishers rarely sell their catch. Mostly recreational fishing is subsistence fishing; the catch is consumed by the fisher's own household or it is given free of charge to relatives, friends and neighbours. Catch and release fishing has also become more and more popular, especially salmonids, big pikes and also small ice-fished perch are released. The monetary value of catch in candr fishing is difficult to value, but the recreational value of fishing for fishers is certainly great. Also, crayfish catch is used mostly by fishers' own households. One part of crayfish catch is sold for example to restaurants or to other households. Small crayfish are also sold for stocking in lakes and rivers.

The sample for recreational fishing statistics comprises 7500 household-dwelling units randomly selected from the Finnish population register combined with the fisheries management fee register. One household-dwelling unit consists of the persons living permanently in the same household. The sampling is targeted at persons aged 18-74 years and the sample design is stratified sampling. The strata are formed by taking into account the payment of the fisheries management fee, the location of the person's municipality of residence, the type of municipality and the location of the municipality in relation to the sea.

The four-page questionnaire focuses on the age and gender of fishers, the importance of fishing as a hobby, fishing activity by fishing area, and catch sizes. The survey is conducted biannually at the beginning of the year following the reference year. Salmon, cod and eel are caught by very few fishers, and the variation of these uncommon catches among fishers is high. Because of this, the confidence intervals of those catch estimates are wide, even in the case of large sample sizes.

Post-sampling for non-respondents is applied to correct the bias resulting from the differences between respondents and non-respondents. If the bias is not taken into account, the catch and number of fishers would be overestimated. The purpose of postsampling is to establish the proportion of fishing household-dwellings among nonresponders. For the computation, a weighting factor is applied for each statistical unit, or household-dwelling. The survey data (e.g. catch size) for the household-dwelling are then multiplied by that factor. The weighting factor is formed from the inverses of the inclusion probability and response probability of the sampling unit, that is, householddwelling unit, and from the calibration weight. 
The bias caused by non-response is corrected using the homogeneous response group model. The sample is divided by stratum into two homogeneous response group sets within which the probability of responding is considered to be constant. The first group comprises those responding to the questionnaire at first and second contacts, and the second group - those responding at the third contact. In the calibration, the distributions to be calculated from the sample can be made to correspond to the marginal distributions. Such marginal distributions are the number of householddwellings in household-dwelling groups and the number of household-dwellings by the Fishing Industry Unit obtained from Statistics Finland, the age distribution of men and women and the number of men and women by the Fishing Industry Unit obtained from population statistics, and the number of fishing household-dwellings by strata estimated using both postal questionnaire and telephone interview data. The household-dwelling groups are formed according to the size and age distribution of the inhabitants. The calibration corrects the bias in the estimates arising from nonresponse, as the size, structure and place of residence of the household-dwelling all have an effect on response activity. The partial loss due to missing data items is taken into account using hierarchical imputation, in which the missing item is replaced with a value obtained from the data record.

In practice, the estimation is carried out with SAS software and the SAS macro CLAN97 developed by Statistics Sweden. Imputation of the partial loss is done with SOLAS software. Reliability is depicted by the 95 percent confidence interval and the coefficient of variation. The reliability of a certain catch estimate depends on how many households engaging in fishing have caught the species in question and on how great the differences are between the catches of various households. Thus, the most unreliable estimates refer to catches of species taken by only a few households or to catches with great variation.

\subsubsection{Data availability}

The recreational fishing statistics are published biennially on Luke's statistical services webpages: https://stat.luke.fi/en/recreational-fishing. The recreational fishing statistics are published by the end of October of the year following the statistical year. No preliminary information on the recreational fishing statistics is published. Data is available from Luke's statistical database from 1998 onwards: http://statdb.luke.fi/ PXWeb/pxweb/en/LUKE/?rxid=99b449a0-9547-4142-b454-6de6d68a95d3

From 1975 to 1986, the statistics for recreational fishing were published in the Suomen Kalatalous series, from 1988 to 1996 in the Environment series, and since 1998 in the Agriculture, Forestry and Fishery series of the Official Statistics of Finland. The time series statistics for recreational fishing for 1986-1998 are provided in the Finnish Fishery Time Series (Official Statistics of Finland: Agriculture, Forestry and Fishery 2001:60) publication. The data used for calculating the statistics is stored at the Natural Resources Institute Finland (Luke).

\subsubsection{Commercial inland fishing}

The statistics of commercial inland fishery (OSF, 2018) provides estimates about the volume and value of catch, and the number of commercial fishers. Estimates are disaggregated by fish species, year, month, area, gear, and fisher group.

The code of conduct for the statistical production model requires the provision of a general description (https://stat.luke.fi/en/tilasto/4474/kuvaus/7237) and a quality description (https://stat.luke.fi/en/tilasto/4474/laatuseloste/7240) to support correct interpretation of the statistics. 


\subsubsection{Data collection}

Starting from 2016, all commercial fishers have a statutory obligation to register therefore since then, and for the first time, a comprehensive register is available. The statistics for commercial inland fishery is based on a census survey and its frame population is the commercial fishers in the register of commercial fishers at the end of the year. The register is maintained by the ELY Centre for Southwest Finland. A commercial fisher can be a person (person or one-man business) or a legal person (limited liability company, limited partnership or general partnership).

In inland waters, fishers other than commercial fishers cannot engage in the direct sale of the fish they have caught, apart from the occasional sale of minor fish or crayfish catches to consumers. However, family members or hired labour who take part in fishing activities are not regarded as commercial fishers, unless they are listed in the register.

The information is based on data provided by commercial fishers. They are obliged to maintain a journal of fishing activities and to report their catches. Fishers must submit an electronic or paper fishing journal to the Natural Resources Institute Finland (Luke) by the end of February following the statistics year. Fishers record data on a monthly basis in the journal. There is a paper journal available for fishers who are not willing to use an electronic journal. The paper journal is sent to the fishers by post at the beginning of a calendar year. The reporting obligation also applies to crayfish, European river lamprey and to the amount of roe. The obligation of commercial fishers to report the data to Luke is based on the Fishing Act (379/2015) and the Act on Food and Natural Resource Statistics (562/2014).

Telephone interview data are used in addition to the actual responses to estimate the number of active fishers by fisher group and fishery unit. When estimating the number of fishers, they are allocated into two categories based on the value of their catches. Fishers whose average revenue from the sale of the fish they have caught, or fish products processed from their catch over the past three financial years exceeds EUR 10000 are in group I - other fishers are in group II.

The Natural Resources Institute Finland maintains the database and publishes annual official statistics (https://stat.luke.fi/en/commercial-inland-fishery) about the commercial inland fisheries. The statistics were published every other year in 1998-2014.

\subsubsection{Compiling statistics}

The concepts, classifications, and applied methods are reported in the quality description of the statistics (https://stat.luke.fi/en/tilasto/4474/laatuseloste/7240).

Protecting the identity of the respondents is a fundamental principle of statistics production. It usually limits the dimensions of any output matrix so that the level of disaggregation has to respect a threshold criterion and a dominance criterion which are implemented to avoid identification of any single respondent unit in the statistical output. The threshold criterion indicates that any combination in the output matrix has to be based on data about at least three independent respondents. The dominance criterion indicates that the major respondent should not exceed 50 percent of the measured quantity, or the two major respondents should not exceed 80 percent of the measured quantity.

Within the fisher groups, it is assumed that the proportion of fishers who did not respond to the survey is the same as that of fishers who responded to telephone interviews. In addition, the resulting weights are calibrated according to the number of registered fishers in each group as per fishery units in the respondent's habitual residence.

The reported catches are expanded to cover the estimated number of fishers per fisher group. The weights are calibrated by the estimated number of active fishers as per fishery units in each ELY Centre region. 
Any joint ventures formed by fishers are processed on a fisher basis. The reported total catch is divided between each partner before the calculation.

The value of the catch is calculated on the basis of annual species-specific average prices reported by fishers. Salmon and trout are sold gutted, and the value of the catch is usually indicated as gutted fish. It is converted into the price of a full fish using a conversion factor, which is 1.11 for salmon and trout. Where values from previous years are used, they have been converted into the current year's prices using the index of consumer prices.

Precision and accuracy of any statistics is a function of the sampling ratio and response rate. In Finland, all commercial inland fishers do not report their fishing data as required by legislation. The response rate among fishers in group I was roughly 60 percent in 2016 and 2017, whereas it was 40 percent among fishers in group II. Telephone interviews were conducted in 2018, including a sample of fishers in group II and all fishers in group I. They were asked whether they were engaged in fishing activities and whether they sold the fish they caught in 2016 and 2017.

\subsubsection{Data availability}

An estimate of the previous year's catch is published at the end of October. The date is announced in a statistical release calendar (https://stat.luke.fi/en/ julkistamiskalenteri\#seuraava-julkaisu). The statistics are published in Luke's online service at stat.luke.fi.

Customers can order separate reports from the data, within the scope permitted by the basic material and privacy rules. The questionnaire and calculation data of the statistics are stored by Luke.

Any errors in the statistics will be corrected as quickly as possible in accordance with the recommendations issued by the advisory council of the Official Statistics of Finland (OSF). Errors will be corrected in statistical databases, and corrected data are published on the statistics website.

\subsection{CASE STUDY: LAKE OULUJÄRVI - LARGE LAKE WITH COMMERCIAL AND RECREATIONAL FISHING}

Lake Oulujärvi in northern Finland $\left(27^{\circ} 10^{\prime} \mathrm{E}, 64^{\circ} 20^{\prime} \mathrm{N}\right)$ is the fifth largest lake in the country. Its surface area is $928 \mathrm{~km} 2$, mean depth $7.6 \mathrm{~m}$, and mean elevation above sea level $121 \mathrm{~m}$. It is the central lake of the Oulujoki water system, which drains into the Bothnian Bay in the Baltic Sea. The lake is covered with ice from November to May and in summer the surface water temperature reaches as high as $20^{\circ} \mathrm{C}$. The water has a brownish colour (30-80 mg Pt L-1), secchi desk depth about 2-3 m, a low content of organics (COD 10-13 mg O2 L-1), and can be classified as dysoligotrophic.

Lake Oulujärvi has been regulated since 1951 for hydropower production and flood prevention. Yearly maximal range of water level fluctuation is $2.7 \mathrm{~m}$, but in practice the yearly mean has been $1.7 \mathrm{~m}$ (Table 1). Due to damming and dredging of spawning rivers, natural reproduction of brown trout (Salmo trutta) has collapsed. In addition, water level regulation has changed the fish community, for example by increasing the mortality of whitefish eggs. The hydropower company in charge of the water level regulation must legally monitor the effects of the regulation on fish stocks and fishing. In addition, several research projects have collected data on fish catches and fishing. The list of reports published and links to national fisheries statistics starting from 1986 can be found in the website of the Kainuu Fisheries Research Station (http://www.kfrs. fi/sitenews/view/-/nid/41/ngid/5).

\subsubsection{Data collecting}

Catch statistics from Lake Oulujärvi have been collected since 1973 (Salojärvi, 1991, 1992). Previously the statistics was collected on a yearly basis but since 1991 catches 
TABLE 1

Summary of fishing and catches in Lake Oulujärvi between 1987-2015 according to postal fishing questionnaire surveys (Pöyry, 2015)

\begin{tabular}{|c|c|c|c|c|c|c|c|c|}
\hline & 1987 & 1988 & 1990 & 1995 & 2000 & 2005 & 2010 & 2015 \\
\hline \multicolumn{9}{|l|}{ Households fishing } \\
\hline Recreational & 3400 & 4900 & 3800 & 3700 & 2300 & 2250 & 2310 & 1830 \\
\hline Commercial & 64-101 & 85 & $60-97$ & 50 & 64 & 51 & 53 & 58 \\
\hline \multicolumn{9}{|l|}{ Fishing gear (pcs) } \\
\hline Trawl groups & 7 & 7 & 11 & 9 & 9 & 8 & 5 & 5 \\
\hline Winter seine groups & 5 & 4 & 9 & 8 & 8 & 5 & 1 & 1 \\
\hline Fyke nets & 40 & 43 & 19 & 22 & 34 & 31 & 47 & 59 \\
\hline Other traps & 600 & .. & 720 & 350 & 320 & 140 & 110 & 71 \\
\hline Vendace nets & 7070 & .. & 6430 & 5350 & 3600 & 2300 & 1300 & 1100 \\
\hline Gill nets & 18150 & .. & 16790 & 17430 & 14100 & 10300 & 10100 & 8200 \\
\hline \multicolumn{9}{|l|}{ Catch (tonnes) } \\
\hline Vendace & 178 & 202 & 187 & 352 & 252 & 154 & 67 & 60 \\
\hline Whitefish & 77 & 65 & 51 & 77 & 27 & 9 & 7 & 6 \\
\hline Brown trout & 10 & 15 & 10 & 12 & 8 & 6 & 5 & 1 \\
\hline Pike & 88 & 92 & 82 & 87 & 86 & 98 & 106 & 77 \\
\hline Perch & 73 & 77 & 56 & 95 & 61 & 64 & 53 & 50 \\
\hline Pike-perch &.. & .. & 0,3 & 4,6 & 13 & 77 & 106 & 86 \\
\hline Burbot & 41 & 44 & 38 & 35 & 28 & 23 & 17 & 17 \\
\hline Roach & 32 & 31 & 32 & 59 & 24 & 15 & 22 & 26 \\
\hline Smelt, others & 88 & 60 & 74 & 90 & 19 & 10 & 8 & 31 \\
\hline Total catch & 590 & 600 & 540 & 818 & 522 & 456 & 391 & 354 \\
\hline Commercial catch & 273 & 365 & 282 & 415 & 328 & 239 & 181 & 223 \\
\hline
\end{tabular}

from commercial and recreational fishing are collected in five-year intervals. These intervals have proven to be too long to properly identify changes in fish stocks. However some bookkeeping fishers also kept records during the intermittent years and catch trends during these years can to some extent be estimated from the catch per unit effort (CPUE) data.

The most recent catch statistics are from 2015 (Pöyry, 2015). This was before the current Finnish system, where all professional fishers are now in a common register. Postal surveys were used to collect data on commercial fishing, assisted with personal interviews. A fishing questionnaire survey was sent to all households with professional fishing licences fishing with trawls, large fyke nets, winter seining or gill nets (gill net catch more than $500 \mathrm{~kg}$ ). Commercial fishers fishing with fyke nets were also personally interviewed.

In privately-owned waters, catch statistics for recreational fishing in the lake were collected by sending a survey questionnaire to a sample of fishers who had bought a license from the local fisheries regions. When the license is sold, the fisheries region collects the names and addresses of the buyers. Open parts of major lakes in Finland are public water areas managed by the state (Metsähallitus). A survey questionnaire was also sent to fishers who had bought a license from Metsähallitus to fish in these public waters. Furthermore, it is possible to buy a license that covers the whole lake for angling or trolling with more than one rod. These license buyers were also included in the sample. The overall sample size was 1344 fishers -49 percent of the licenses sold. Catches based on common fishing rights (i.e. hook and line, ice fishing, angling with one rod only) could not be included in the survey. The query was repeated once to fishers who hadn't responded, leading to a high final response rate h (75 percent). 
To estimate the age and size distribution of the fish populations gear-specific random samples are collected catches of Lake Oulujärvi. Currently, the monitoring programme of the lake includes samples from pike-perch and whitefish. In 2015, a total of 298 whitefish and 307 pike-perch (Stizostedion lucioperca) scale samples were collected. From the whitefish samples, gill raker numbers are calculated to separate the different whitefish forms. Pike-perch heads are collected to separate the natural individuals from the stocked ones (Alitsarin Red-s marked). Previously, samples have been collected also from other fish species including vendace, pike and brown trout.

There were 22 bookkeeping fishers in Lake Oulujärvi in 2015 using gill nets and fyke nets. In addition, catch per unit effort was obtained from trawlers $(\mathrm{N}=7)$. Bookkeeping has been an ongoing practice since 1986 and catch-effort data has been used to calculate species and gear-specific indices as catch per lift or catch per time. These indices have been used to estimate the status and trend of fish stock and to assist in catch data estimation in years when fisheries questionnaire surveys are not made. The results of the bookkeeping fishers are not presented here.

To compensate for the adverse impacts of construction, water-level regulation, and pollution loading, predatory and planktivorous fish are annually stocked in the lake. The number of stocked one-summer-old northern densely rakered whitefish has varied widely, from more than one million to about 200000 annually. The brown trout are mostly stocked as two- to three-year-old smolts directly in the lake. Due to weak catches from the stock, the number of stocked brown trout smolts has diminished. Pike-perch stock in Lake Oulujärvi collapsed during the 1950s to 1960s, probably due to overfishing and a slight cooling in temperature (Colby and Lehtonen, 1994). Stocking of pike-perch fingerlings was initiated on a larger scale during the mid-1980s. In recent decades, stocking of pike-perch fingerlings has been around 600000 annually, and in recent years between 200000 and 400000 annually.

\subsubsection{Fishing restrictions}

No management measures are taken to regulate total catches in Lake Oulujärvi, and fishing effort is practically unlimited (Vehanen et al., 2002). Size limits are not applied in whitefish fisheries, but the minimum size limit for pike-perch is $450 \mathrm{~mm}$. The minimum size limit of adipose clipped (hatchery) brown trout is $500 \mathrm{~mm}$, brown trout with adipose fin (natural) $600 \mathrm{~mm}$, and for the grayling it is $350 \mathrm{~mm}$. Recreational fishers can use only two gill nets simultaneously with mesh sizes between 20-54 mm in privately-owned waters and they are totally banned in state-owned waters. This restriction is mainly to protect undersized pike-perch. The Finnish Fishing Act establishes that recreational fishers can simultaneously use eight nets with a maximum total length of $240 \mathrm{~m}$. Other gears are not regulated. There are few, relatively small-sized areas on the lake, where fishing with gill nets is either prohibited or recommended to avoid fishing with standing gears.

\subsubsection{Fishing and catches}

The number of households taking part in the recreational fishing in Lake Oulujärvi was 1830 in 2015 (Table 1). On average 1.8 persons per household took part in fishing, so the total number of persons engaged in recreational fishing was 3 300. Gill-netting was the most popular form of fishing among recreational fishers. Recreational fishers in Lake Oulujärvi used altogether 6300 gill nets, Most of these nets had mesh sizes over $40 \mathrm{~mm}$ (70 percent), vendace nets were 17 percent and mesh sizes $27-40 \mathrm{~mm}$ and 13 percent ("whitefish-nets"). Trolling was exercised among 57 percent of the fishers with 1150 motorboats and 230 rowing boats. Altogether, 5300 fishing rods were used by trolling boats and 500 rods in cast fishing. Recreational fishers also used pike-traps, winter fishing, hooks and fishing rods with hook and line. 
A total of 58 households were involved in commercial fishing (Table 1). There were five trawl groups (including seven persons) and only one group performing winter seining. Overall, 59 large fyke nets were used and 70 smaller trap nets. Commercial fishers used 9300 nets in 2015.

The total catch in 2015 for Lake Oulujärvi was 354 tonnes. Commercial fishers caught two thirds of the total catch (Table 1). Total catch consisted mostly of pikeperch 24 percent $(86 \mathrm{t})$, pike 22 percent $(77 \mathrm{t})$, vendace 17 percent $(60 \mathrm{t})$ and perch 14 percent $(50 \mathrm{t})$. Whitefish and brown trout catches were low (Table 1). Roach (Rutilus rutilus) and common bream (Abramis brama) catch made up for one fifth of the catch of the commercial fishing.

Generally, there have been many changes and trends in fishing and catches over the past two decades in Lake Oulujärvi. Whitefish and brown trout catches have ceased while pike-perch has become the most valuable catch for both commercial and recreational fishing. The vendace stock has varied widely and the trawl fishing effort seems to have an important effect on this variation (Huusko and Hyvärinen, 2012). In gill net fishing, the trend is toward larger mesh sizes as fishers especially target pikeperch and less whitefish. The use of gill nets and vendace nets has reduced.

\subsubsection{Scientific use of catch statistics}

Several papers have drawn on the catch statistics from Lake Oulujärvi and generated scientific advice which has been used in fisheries management of the lake. Here are some highlights from the full list of papers: http://www.kfrs.fi/sitenews/view/-/ $\mathrm{nid} / 41 /$ ngid/5.

Catch statistics were used in the Virtual Population Analysis (VPA) to model the fluctuations in numbers of vendace, whitefish, pike-perch and brown trout in 1973-1995. A computer model was established to study the interactions between the species. Postal questionnaires and personal interviews were used to reveal the opinions and possible conflicts between the groups of fishers (commercial and recreational). Economic analysis was done to estimate the cash flow in Lake Oulujärvi fisheries 1995. The study showed that the amount of its primary prey in the lake - vendace - largely determined the success of brown trout stocking. Stocking of whitefish with high stocking rate used was unsuccessful. Fishers identified that conflicts existed between trawling and use of other fishing gear. Of the fishing restrictions, the ban of gill net with mesh sizes $27-40 \mathrm{~mm}$ was accepted by commercial fishers while local recreational fishers opposed. The annual cash flow of Lake Oulujärvi fisheries was estimated to be EUR 3.36 million and was a locally important revenue? in 1995. (Vehanen et al., 2002).

Several models and cost-benefit analyses were used to assess the ecological, economic, and social impacts of three alternative management strategies. The results emphasized that when determining stocking levels and fishing regulations, the system should be considered as a whole, and impacts on major fish species and different groups of fishers should be assessed. The stocking policy and fishing regulations should also be flexible to accommodate changing biotic and societal conditions. The key questions in applying the adaptive management process in Oulujärvi fisheries was how to determine clear objectives for fisheries management, identify a fisheries management structure that provides workable interactions between different stakeholders, and arrange cost-effective monitoring. The lessons learned from the Oulujärvi experience and recommendations for fisheries management were found relevant to other lakes with conflicting stakeholder objectives. (Marttunen and Vehanen, 2004).

Catch and stocking statistics from Lake Oulujärvi were used to study the factors affecting long-term variation in brown trout, Salmo trutta, stocking success. The biomass of the vendace population (prey) at release time had the largest positive effect on stocking success. There was an increasing trend of predator-catch-per-unit-effort (CPUE) - combined CPUE of northern pike, burbot Lota lota and pike-perch - 
through the study period, suggesting strengthening predator stocks in the lake. This predator CPUE had a negative effect on trout stocking success. (Hyvärinen and Huusko, 2005).

This study demonstrated, using catch statistics and a population dynamics model from Lake Oulujärvi, that changes in the harvesting rate of vendace also changed the population dynamics. The high fishing pressure, especially from trawling, changed the long-term oscillation in stock dynamics and recruitment (i.e. strong year class was born and recruited to fishery only once in several years) into two-year cycling (strong year class is born every second year). The high harvest rate evidently simplified the spawning population structure from a multi-generation state to an almost total singlegeneration state. The results support a precautionary policy in harvesting and stress the importance of understanding the basic mechanisms of population dynamics in order to gain sustained yields from the population. (Huusko and Hyvärinen, 2005).

Food consumption and prey orientation of stocked brown trout and pike-perch were studied in Lake Oulujärvi. Virtual Population Analysis based on catch statistics was used to model the fluctuations in age-specific fish numbers. Stomach samples were collected and analysed and a bioenergetics model was used to calculate consumption. The results stressed that the adjustment of the stocking rate of predators to correspond to the abundance of prey fish was one of the key factors in lake fisheries management. (Vehanen et al., 2007).

The study used Lake Oulujärvi fisheries statistics to reveal the importance of different minimum size limits (MSL) on the yield from pike-perch stocking. An age-, size-, and maturity-structured evolutionary model was parameterized for Lake Oulujärvi pike-perch. The study found that at the current level of harvesting (fishing mortality rate, $\mathrm{F}=0.7$ ) and stockings (430 000 year-1), and assuming strongly, density-dependent growth, the nation-wide MSL of $370 \mathrm{~mm}$ does not prevent severe recruitment overfishing under further increased fishing pressures or stochasticity in recruitment success. The recently imposed, local MSL of $450 \mathrm{~mm}$ better ensures stable yields, and even increases them if individual growth is density-independent - but further increase of MSL to $500 \mathrm{~mm}$ would already reduce yield especially if there was discard mortality for undersized fish. Results supported the intentions to increase MSLs in order to improve both ecological and evolutionary sustainability of recreational fisheries. (Vainikka and Hyvärinen, 2012).

The study assessed the stock of each morphologically distinguishable whitefish form (native lesser sparsely-rakered whitefish, native blue whitefish and stocked northern densely-rakered whitefish) in Lake Oulujärvi during 1973-2014, and related temporal variations in population dynamics to environmental data and catch per unit of effort (CPUE) data on other species having fisheries significance. The results demonstrated a synchronous major decline in the abundance of the native whitefish forms and a decline in the length-at-age of all forms. During the study period, summertime water temperature increased, and surface water phosphorous concentration decreased. Recruitment in all whitefish forms showed Ricker-type dependence on spawning stock biomass but little residual correlation with the environmental parameters. Crosscorrelation analyses suggested that the re-establishment of pike-perch population negatively affected both the recruitment and biomass of whitefish, but the exact effect mechanisms requires further assessment. The results exemplified that ecosystem-based fisheries management in inland waters must take into account both natural and humaninduced environmental changes as well as stockings, and that knowledge-based inland fisheries management is inherently data-intensive. (Vainikka et al., 2017). 


\subsection{CASE STUDY: EXAMPLES OF SOCIO-ECONOMIC VALUATION}

The following valuation cases refer to studies that look into the economic values for individual fishers from a utility theoretic viewpoint ${ }^{2}$. These values exceed actual expenditures on fishing - they represent the maximum willingness to pay for fishing activities or a change in their provision. Typically, the estimated values are also only for using the fisheries for fishing activities, i.e. use values, but leave out non-use values of inland fisheries. The population that does not fish may have value for the option to fish at some point in time, but also value in the existence of recreational fisheries per se. The report by Parkkila et al. (2010) explains the different facets of economic valuation and the assessment methodology.

Several valuation studies have looked into the economic value of recreational fishing in Finland, where most of these studies have concentrated on inland recreational fisheries. In a recent study on angling in River Teno, a travel cost recreation demand model was used to estimate the recreational value of salmon fishing. Following a twostep estimation procedure, Pokki et al. (2018) showed that the estimated consumer surplus per trip ranged from EUR 222 to 338, and the estimated total recreational value of salmon fishing in the area was EUR 2.4 to 3.7 million in 2011. The study suggested that the number of fishing trips per angler is strongly affected by the angler's previous salmon catch.

The value of recreational angling in the River Simojoki was evaluated by Parkkila (2005). In this study, fishers were asked how much they were willing to pay for a doubling of the salmon catch in the river. In 2009, a contingent valuation study on recreational fishing in the River Tornionjoki was conducted (Riista- ja kalatalouden tutkimuslaitos, 2009), where a higher probability of catching salmon increased both the willingness to pay and the fishing effort of fishers. Parkkila, Haltia, and Karjalainen (2011) studied the benefits of restoring the salmon stocks in the River Iijoki with the contingent valuation method. This study searched for a potential fish restoration payment that fishers would be willing to pay for salmon stock restoration in the River Iijoki. In addition, the economic value of recreational fisheries in the Evo hiking area in southern Finland was estimated by Ovaskainen (1999) using the individual TCM with on-site data.

Economic aspects of recreational fisheries also look at how much fishers spend on their hobby. In a recent study on entrepreneurship of recreational fishing and fishery tourism, spending of fishers who had paid the fisheries management fee was estimated (Pohja-Mykrä et al., 2018) and revealed that the total was about EUR 249 million a year. Most of that money was used in the domestic market. Apart from fisheries management fees, the greatest expenses were boats, fishing equipment and fishing licenses. Spending on fishing guide services is minor in Finnish recreational fishery at the moment.

Toivonen et al. (2004) studied the value of recreational fisheries in the Nordic countries (Denmark, Finland, Iceland, Norway and Sweden). Recreational fishers described their current expenditure on fishing and the amount of additional costs that would make fishing prohibitively expensive, all things equal. This allowed for determining the use-value for national recreational fisheries, roughly USD 280 million, consisting of USD 201 million (1999) on actual expenses and USD 82 million (1999) of maximum willingness to pay in addition to actual costs to retain current level of recreation (i.e. consumer surplus).

\footnotetext{
As a disambiguation of the socio-economic "value" of fishing, we focus on consumer preferences that build the economic value for the individual under a budget constraint (i.e. income). Apart from value estimations for the individual, the effects of fishing on the regional economy can also be analysed. Regional economic analysis takes into account how the inflow of money from fishers enriches the local economy, e.g. through service development and employment.
} 
Vesterinen et al. (2010) employed the LVVI database on outdoor recreation to assess the value of one-day water recreation split into swimming, fishing and boating activities based on travel costs. While the data did not allow for assessing the value for each activity separately, daily water recreation trips were jointly valued (consumer surplus) between EUR 6.30 and 18.98 per water recreation trip. It is worth noting that underlying the analysis, the distances and time taken to travel to one-day trips and hence their costs per person were reported higher for fishing than for swimming or boating. With roughly 30 annual one-day fishing trips by little less than one half of the population led to a value assessment of between EUR 272 and 819 million (2010) annually for daily fishing trips by the Finnish adult population. Further, local water clarity was found to affect fishing participation and frequency where an increase (decrease) in average water clarity by 1 metre on the national average could increase (decrease) the fishing trip values by EUR 43 to 129 (38 to 113) million.

In research concerning fishers' profiles (Pellikka and Eskelinen, forthcoming), annual national expenditure by fishers on the fisheries management fee was EUR 240 million. About half of the fishers bought fishing equipment during the last year and about 60 percent of them used money to travel, stay overnight or restaurant services during fishing trips.

The multiplicative effects of fishers' spending are greater than the direct effects as seen in the river fishing examples above.

\subsection{LEGAL BACKGROUND}

\subsubsection{Data collection and statistics}

In Finland, as of 1 January 2015, the Natural Resources Institute Finland (Luke) has been responsible for compiling statistics on Finnish food and natural resources, including data on fish resources and fisheries. The research institute produces official statistics for Finland in its own field.

The legal basis for the collection of fisheries statistics is the Natural Resources Institute Finland Act (561/2014), which defines the production of statistics as one of the tasks in Luke's scope of activities. The food and natural resource statistics Act (562/2014) and the Statistics Act (280/2004) lay down provisions on the liability of information providers to disclose data, processing of information, and the quality and accessibility of statistical data.

EU legislation obliges Finland to gather detailed data on its fishery industry. The EU programme for fisheries data collection seeks to gather biological, economic, and statistical data on fisheries to support the Common Fisheries Policy. The information is used, for example, as the basis for the fishing quota decisions of the International Council for the Exploration of the Sea (ICES). The EU's data collection programme produces valuable information, which is used as the basis for the majority of marine research projects.

The EU programme for fisheries data collection is governed by Regulation (EC) No. 2017/1004. Detailed regulations, specifications, and requirements are laid down in Commission Regulation (EC) No 665/2008 and Commission Decision No. 2016/1251/EU.

Data protection has to be considered when data is collected and registered. The Constitution of Finland (731/1999) protects individual privacy and the Openness of Government Activities Act (621/1999) guides the authorities on good practice for information management and document secrecy. The Data Protection Act (1050/2018) specifies and adds to Regulation (EU) 2016/679 of the European Parliament and of the Council on the protection of individuals with regard to the processing of personal data and on the free movement of such data. 


\subsubsection{Fishing rights}

The Finnish Fishing Act (379/2015) defines two types of common fishing rights. Angling, jigging, ice fishing and fishing Baltic herring with a rod and vertically moved hooks attached to a line ("silakkalitka") is allowed without a fishing permit. Angling free of charge means fishing with one rod and hook without a lure and a reel suitable for spinning. Jigging and ice fishing free of charge means fishing with one short rod and vertically moved jig attached to a line. Common fishing rights do not, however, allow angling and ice fishing in areas where fishing is prohibited. The common fishing rights are part of the general public's right, "Everyman's right", which allows access by anyone living in or visiting Finland the freedom to roam the countryside and enjoy the recreational use of natural areas. Everyman's rights are largely based on individual rights described in the Constitution of Finland (731/1999).

Chargeable common fishing rights are based on the fisheries management fee. The fee is based on the Fishing Act (379/2015) and the fee system is managed by the Ministry of Aquaculture and Forestry. Fishers aged less than 18 or older than 64 years are exempted from the fee, those fishing other than angling, jigging and ice fishing must pay a fisheries management fee to the state. Everyone who has paid the fisheries management fee and all those under 18 or at least 65 years of age have the right to engage in lure fishing with one rod and lure in the whole country, except in rapids and currents in waters containing migratory fish or waters where fishing is prohibited under another provision.

Fishing right owners in Finland are the owners of waters, which is related to land and property ownership. Fishing rights holders are primarily responsible for organizing fishing and fisheries management in their waters in accordance with the principle of sustainable use. In state-owned waters fishing-related issues are the official duties of Metsähallitus (the Finnish Forest and Park Service, Metsähallitus Act 1378/2004). Metsähallitus sells fishing permits for rod and trap fishing as well as crayfish-fishing in state-owned waters for recreational fishing (www.eraluvat.fi). For private-owned waters, a permit from the fishing rights owner is also needed for trap fishing and fishing with several rods. According to Fishing Act 379/2015), fishing rights holders can be:

a) a body of joint owners of a jointly-owned water area;

b) an owner of a water area not belonging to a body of a joint owner;

c) owner of a property - if the property has fishing benefits resting on special grounds;

d) a natural or legal person holding fishing rights based on a fishing servitude or other legal grounds; or

e) a natural or legal person holding a fishing right based on a lease agreement.

The owners generally form bodies of joint owners to combine, for example, one lake or river into a single fishing area. They can also form wider partnerships to create larger fishing grounds under the same joint fishing licenses. The right to the use of the water area of a body of joint owners is determined on the basis of fishing gear units, which are typically divided according to the shares of the water area of the owners.

State-owned waters, managed by Metsähallitus, make commercial fishing activities potential in many regions of Finland. Persons intending to fish commercially in stateowned waters must apply and pay for a separate commercial fishing permit from Metsähallitus for each trap and net. The prices for commercial fishing permits are set by a Decree from the Finnish Ministry of Agriculture and Forestry (888/2017). Fishing Act (379/2015) also sets out that commercial fishers are persons or corporations whose turnover from the sale of fish or fish products exceeds a certain sum of money (laid down in section 3(1) of the Value Added Tax Act (1501/1993). Only commercial fishers have the right to use fishing gear intended for commercial fishing, like trawls or large bow nets.

In private waters, commercial fishers can be fishing rights owners themselves or purchase licenses for commercial fishing from the fishing rights holders. In certain 
cases, when there is no agreement between the fishing rights holders and commercial fishers, the local authority - the Centre for Economic Development, Transport and the Environment - may grant a commercial fisher a permit to engage in commercial fishing for a maximum of five years. As a pre-requisite, the water area must be designated as well-suited to commercial fishing in the management plan and the status of the fish stocks in the water area enables their utilization for commercial fishing (379/2015). A reasonable compensation must be paid to the fishing rights holder.

In private waters, fishing tourism enterprises or fishing guides can be fishing rights owners themselves or purchase licenses for their business from the fishing rights owners. If no licenses can be purchased and the water areas are especially suitable for fishing tourism, the Centre for Economic Development, Transport and the Environment may grant a permit to operate with no more than six fishing tourists at a time. Fishing is permitted with hook and line, jig or spinning rods and the permit runs for five years and costs EUR 100 per year.

\subsubsection{Fishing restrictions}

Common fishing rights, both chargeable and free of charge, are subject to certain restrictions. There are numerous different kinds of prohibited areas where fishing may not be practiced, like fast-flowing sections of watercourses where migratory fish salmon and whitefish are found, or other protected areas. The Finnish Fishing Act specifies that the Centre for Economic Development, Transport and the Environment may prohibit fishing based on the common fishing rights in specific areas. Decisions concerning such prohibited areas and the related maps are available from the fisheries units of the Centres for Economic Development, Transport and the Environment and on website kalastusrajoitus.fi, but only in Finnish and Swedish.

Only commercial fishers have the right to fish with trawl and, in waters north of the $67^{\circ} 00^{\prime} \mathrm{N}$ latitude, with nets whose total length per fishing or boating party exceeds $240 \mathrm{~m}$.

The general fishing restrictions, catch sizes, closed seasons and restrictions on quantity or size of fish and on fishing activity when spawning are shown in Table 2. These restrictions are issued in fishing decree (1360/2015). The facts that form the basis of these restrictions aim to protect endangered fish species (Urho et al., 2019) or ensure the sustainability of fishing. In addition to that, fishing rights holders (e.g. bodies of joint owners) can restrict fishing gear units and mesh sizes of nets or even set more closed seasons for their water areas.

The Saimaa ringed seal, a sub-species of ringed seal is classified as an endangered (EN) species which lives in parts of the lake area of Saimaa. Therefore, net fishing, except vendace nets, is prohibited in the its main habitats from $15^{\text {th }}$ April to $30^{\text {th }}$ June and there are also all-year restrictions on certain types of fishing gear.

In case of fishing offences on endangered fish species, if a fisher illegally, against specified closed seasons, catch sizes or quotas catches a salmon, landlocked salmon, eel, lamprey, sea trout, brown trout, grayling, arctic char, noble crayfish or whitefish in rivers and brooks flowing into the sea, he/she will be penalized and, subject to a court order, has to pay the state the value of the fish as a representative of the species. The values are set out in the government decree and range from 50 euros to 7510 euros, depending on the degree of endanger, population size and reproduction possibilities of the species.

\subsection{ENVIRONMENTAL ISSUES AND CONFLICT WITH OTHER WATER USES}

The interests of inland fisheries are supported at state level by the Ministry of Agriculture and Forestry, Centres for Economic Development, Transport and the Environment, and Metsähallitus (state-owned waters). The major national associations for recreational fishers (Finnish Federation for Recreational Fishing and 
TABLE 2

Catch sizes and closed seasons. Restrictions on quantity or size of fish and on fishing activity when spawning in Finland

\begin{tabular}{|c|c|c|}
\hline Species & Closed seasons & Catch sizes/quotas \\
\hline Trout with adipose fin & $\begin{array}{l}\text { Fully protected in all marine areas. } \\
\text { Fully protected in inland waters south } \\
\text { of latitude } 6400 \text { 'N. Not applicable to } \\
\text { trout caught from brooks or ponds } \\
\text { with no migratory connection from the } \\
\text { sea or a lake. } \\
\text { Rivers and brooks } 1 \text { Sept to } 30 \text { Nov }\end{array}$ & $\begin{array}{l}\text { Minimum } 50 \mathrm{~cm} \text { in waters north of } \\
\text { latitude } 6700^{\prime} \mathrm{N} \text {. } \\
\text { Minimum } 60 \mathrm{~cm} \text { in other areas where } \\
\text { fishing is permitted. } \\
\text { Maximum } 45 \mathrm{~cm} \text { in brooks or ponds } \\
\text { with no migratory connection from the } \\
\text { sea or a lake. }\end{array}$ \\
\hline Adipose fin-clipped trout & Rivers and brooks 1 Sept to 30 Nov & Minimum $50 \mathrm{~cm}$ \\
\hline Salmon & Rivers and brooks 1 Sept to $30 \mathrm{Nov}$ & $\begin{array}{l}\text { Minimum } 60 \mathrm{~cm} \text {, in Bay of Bothnia } \\
\text { north of latitude } 63^{\circ} 30^{\prime} \mathrm{N} 50 \mathrm{~cm} \\
\text { Quota for recreational fishing } 2 \\
\text { salmon/day/person. }\end{array}$ \\
\hline Adipose fin-clipped salmon & & $\begin{array}{l}\text { Minimum } 60 \mathrm{~cm} \text {, in Bay of Bothnia } \\
\text { north of latitude } 63^{\circ} 30^{\prime} \mathrm{N} 50 \mathrm{~cm}\end{array}$ \\
\hline Landlocked salmon with adipose fin & $\begin{array}{l}\text { Fully protected in the Vuoksi and } \\
\text { Hiitolanjoki river basins rivers and } \\
\text { brooks } 1 \text { Aug to } 30 \text { Nov }\end{array}$ & Minimum $60 \mathrm{~cm}$ in other waters \\
\hline Adipose fin-clipped landlocked salmon & $\begin{array}{l}\text { Vuoksi and Hiitolanjoki waters } \\
\text { specified in the map annexed to the } \\
\text { Fishing Degree } 1 \text { June to } 31 \text { Aug. } \\
\text { Rivers and brooks } 1 \text { Aug to } 30 \text { Nov. }\end{array}$ & $\begin{array}{l}\text { Minimum } 60 \mathrm{~cm} \text {. } \\
\text { Quota for recreational fishing } 1 \\
\text { salmon/day/person in the Vuoksi river } \\
\text { basin. }\end{array}$ \\
\hline Arctic char & $\begin{array}{l}\text { Fully protected in Lake Kuolimo and } \\
\text { in Lake Saimaa in the area between } \\
\text { Puumalansalmi and Vuoksenniska. } \\
\text { Elsewhere in the Vuoksi river basin } 1 \\
\text { Sept to } 30 \text { Nov }\end{array}$ & $\begin{array}{l}\text { Minimum } 60 \mathrm{~cm} \text { elsewhere in the } \\
\text { Vuoksi river basin. } \\
\text { Minimum } 45 \mathrm{~cm} \text { in Lake Inari. }\end{array}$ \\
\hline Grayling & $\begin{array}{l}\text { Fully protected in marine areas. } \\
\text { Inland waters south of latitude } 6700^{\prime} \mathrm{N} \\
1 \text { April to } 31 \text { May }\end{array}$ & $\begin{array}{l}\text { Minimum } 35 \mathrm{~cm} \text { south of and } 30 \mathrm{~cm} \\
\text { north of latitude } 6700^{\prime} \mathrm{N}\end{array}$ \\
\hline Whitefish & $\begin{array}{l}\text { Rivers and brooks flowing into the sea } \\
1 \text { Sept to } 30 \text { Nov }\end{array}$ & - \\
\hline Lamprey & 1 April to 15 Aug & - \\
\hline Zander/pike-perch & - & Minimum $42 \mathrm{~cm}$ \\
\hline Eel & 1 Oct to 31 Jan & - \\
\hline $\begin{array}{l}\text { Noble crayfish, signal crayfish, narrow- } \\
\text { clawed crayfish }\end{array}$ & 1 Nov to 21 July at 12 noon & - \\
\hline
\end{tabular}

Federation of Finnish Fisheries Associations), commercial fishers (Finnish Fishers' Association, Finnish Inland Fishers' Association) or for the whole industry (Pro Fish Association) have an important role in promoting the interests of inland fisheries. Nature conservation associations (WWF Finland, the Finnish Association for Nature Conservation, Natur och Miljö) can, for example, campaign for the sustainable use of local inland fish stocks while the research institute (Natural Resources Institute Finland) provides the scientific knowledge. There are also many regional associations working on local environmental issues, mainly on water quality, but also on improving fish production, connectivity and knowledge about the importance of inland fisheries. These can be relatively large associations paid by stakeholders (industry, communes) or smaller, more on a voluntary basis.

Many other water uses (hydropower, industrial and community wastewaters, agriculture diffuse loading) conflict with the interests of inland fisheries. The water protection legislation in Finland is supervised by the Ministry of the Environment. The water protection legislation and environmental conservation legislation can be found on the pages of the Ministry of the Environment: https://www.ym.fi/en-US/Nature/ 


\begin{tabular}{|c|c|c|}
\hline $\begin{array}{l}\text { Water Act } 2011 \\
\text { Use of water } \\
\text { resources } \\
\text {-Water abstraction } \\
\text {-Water regulation } \\
\text {-Hydropower } \\
\text {-Water related } \\
\text { construction work }\end{array}$ & $\begin{array}{c}\text { Environmental } \\
\text { Protection Act } \\
\mathbf{2 0 1 4} \\
\text { Water pollution } \\
\text {-Urban waste water } \\
\text {-Industry } \\
\text {-Peat production } \\
\text {-Agriculture }\end{array}$ & $\begin{array}{l}\text { Specific Acts or } \\
\text { Decrees on: } \\
\text {-River basin management } \\
\text {-Flood risk management } \\
\text {-Water services } \\
\text {-Discharge of nitrates } \\
\text {-Waste water on rural } \\
\text { areas } \\
\text {-Discharges from farms } \\
\text { into water bodies etc. }\end{array}$ \\
\hline
\end{tabular}

Legislation/Legislation_on_the_protection_of_water_and_the_sea. The legislation is sectorial and the main elements are presented in Figure 1.

According to Finland's water legislation, water permits are required for all activities affecting constructions in water or the water supply, and according to the environmental protection legislation, permits are needed for all activities involving the risk of water pollution. One important condition for permits is that emissions are limited to the levels obtainable by using Best Available Techniques (BAT).

Applications should be submitted to the relevant Regional State Administrative Agency or to the relevant authority, as defined in the Environmental Protection Act and Decree. The authority will then make the application public as appropriate, giving the relevant authorities and anyone affected by the plans time to comment and make proposals concerning the requirements for the permit (Figure 2). Complaints against any permit decisions may be made to the Administrative Court of Vaasa, then to the Supreme Administrative Court.

In the Environmental Impact Assessment (EIA), the environmental impact of the project is assessed at the preparation stage, before any decisions are made and when the forthcoming solutions can still be influenced. The EIA procedure is a project planning tool, and its results must be taken into account when granting permits for projects. The developer of the project is responsible for conducting the necessary environmental investigations and producing the scoping document and Environmental Impact Assessment Report. Developers can be individual companies or public actors, such as municipalities or government agencies. The procedure is supervised and monitored by the Centres for Economic Development, Transport and the Environment, who act as competent authorities. The public and the authorities affected by the project can participate in the EIA procedure. The nature of the procedure is participatory and open.

The EU Water Framework Directive (WFD) states that member states should aim to preserve and achieve good status in all surface water bodies. The national legislation based on WFD has an impact also on the permit procedure. River Basin Management Plans must be taken into consideration when authorities assess permit application in accordance of the provisions in the Environmental Protection Act and the Water Act. 


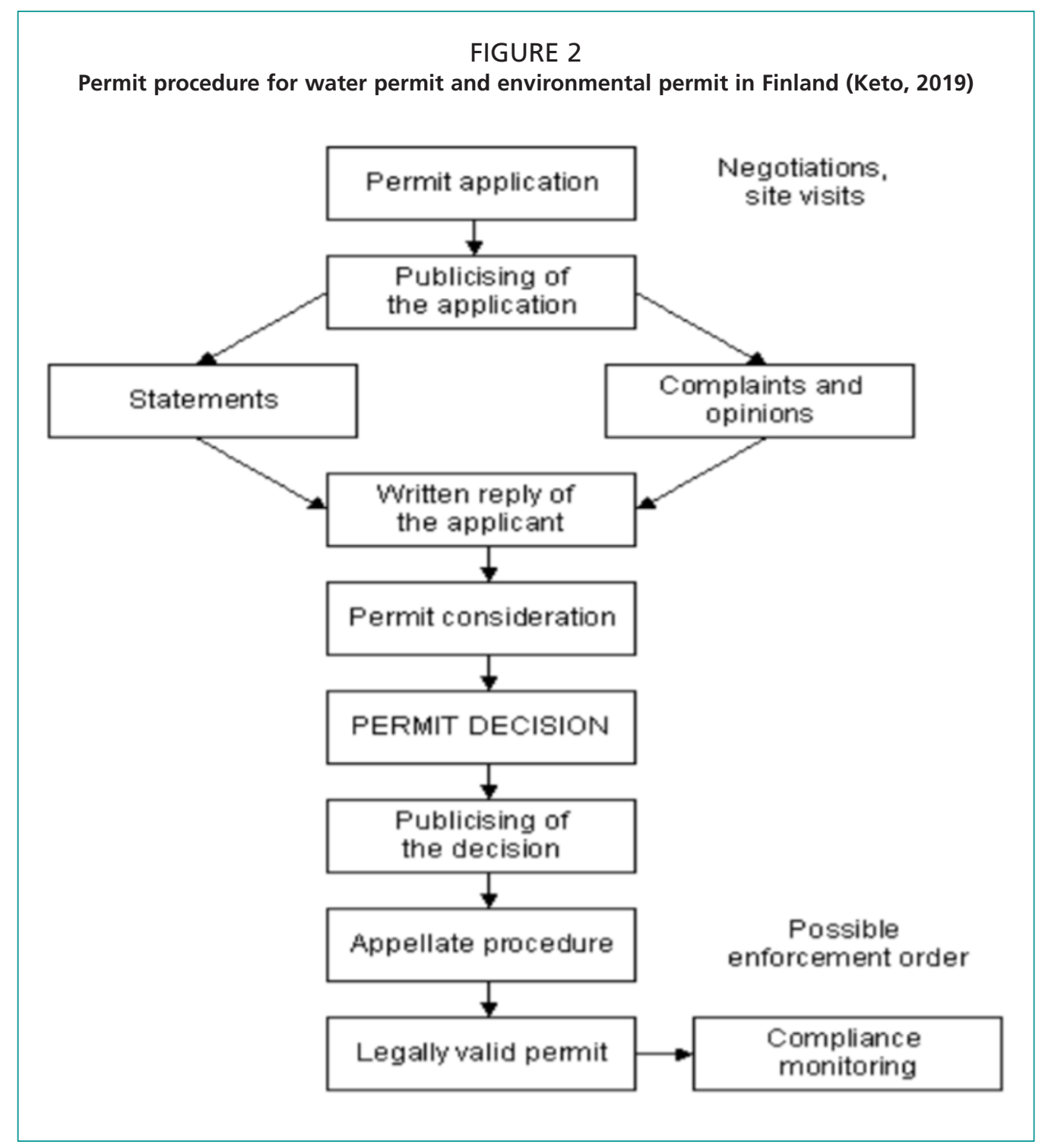

\subsection{COMMERCIAL FISHING IN INLAND WATERS}

In Finland, inland waters extend over $35000 \mathrm{~km}^{2}$. Earlier fishing for household purposes has been an important livelihood but during recent decades the recreational aspects of fishing have become more prominent. However, during the same time, commercial fisheries have remained as livelihoods.

Comparing the number of commercial fishers over the years is difficult due to changes in legislation and registration rules. The estimated number of full-time fishers in Finland (e.g. whose main source of income is fisheries) has been around 300-500 during this century. In the beginning of 2019, there were about 1800 inland fishers officially registered. Over 300 of them belong to group I - their annual turnover is more than EUR 10 000. The remainder are classified in group II. These part-time fishers (group II) sell their catch occasionally and fishing is not their main source of income. The number of gill nets is restricted to eight for recreational fishers. Registration for commercial fishers is simple and thus many people use it as a way to obtain more licenses for gill nets without actually being a proper commercial fisher.

The latest statistics of inland waters catch are from years 2017 and 2018. Vendace is the most important fish species for commercial inland fisheries in Finland. In recent years, commercial vendace catch has been 2.5-3.2 Mkg which is 48-64 percent of total commercial inland catch (OSF, 2018, 2019). Pike-perch and roach catch are under $1 \mathrm{Mkg}$, 
being the second largest volume of species caught. The most important trend during this decade has been the strong increase of pike-perch catch.

Trawl and seine are the main gears in commercial vendace fishing producing about 90 percent of annual vendace catch. For other species the importance of gears varies. Gill nets are the most important for pike-perch ( $>80$ percent) and whitefish ( $>50$ percent). Trap net, gill net and seine are almost equal in importance for perch.

According to catch value, pike-perch was the second most important inland fish species (EUR 4.5 million) and that value has nearly doubled since 2014. These two species accounted for 75 percent of the total value of the commercial inland fish catch. The third most valuable inland species was signal crayfish (Pacifastacus leniusculus). In total, the economic value of inland commercial catch has more than doubled in the last ten years.

About 27 percent of total human fish consumption in Finland comes from commercial fisheries (inland and Baltic Sea) and about 70 percent of commercial fisheries value is from inland waters (vendace, pike-perch).

The Finnish political-administrative fisheries system is complex with property rights, fishery legislation, fishery associations and fishery regions (Sipponen, 1999, see Chapter 3.4). As a consequence, license policy for commercial fishing has varied. The most common case is that commercial fishers own or rent units of statutory fishery associations and have access to fishing grounds this way. Statutory fishery associations can also sell licenses for commercial fishing. In some cases, statutory fishery associations and fishery regions have made agreements that the fishery region takes care of commercial fishing licenses. In some large lakes, there are public water areas where Metsähallitus can sell licenses for commercial fishing. Despite or because of multiple license systems, in many cases commercial fishers do not have enough legal areas for fishing. One reason for that is fragmented ownership of fishing rights. Units can be small, and one lake can include several fishing right owners. In the new Fishing Act (2016) there are some amendments to the commercial fishing license system. In management plans, areas well suited for commercial fishery are defined. If the commercial fisher and fishing rights owner do not agree, fishing license authorities have the right to grant licenses for commercial fishing subject to certain conditions. This possibility has not yet been used because management plans are still under preparation.

\subsection{RECREATIONAL FISHING IN INLAND WATERS}

The estimated number of recreational fishers in Finland was about 1.5 million in 2016 (OSF, 2017). The number has decreased by half a million fishers in the last decade. Still, about 28 percent of Finns participate in recreational fishing, of whom 34 percent are men and 19 percent are women. Of course, the intensity of fishing as a hobby varies a lot, some only participate as assistants by rowing or driving a fishing boat and others see fishing as their most important hobby. Fishers are found in all age groups (Figure 4), social groups and their places of residence range from north to south and cities to sparsely populated areas (Sievänen and Neuvonen, 2011).

The most popular gear used is angling with one rod and hook, with almost 60 percent of all fishers using that method (Figure 5). The next most popular is fishing with spinning rod, used by 50 percent of all fishers. Compared to the beginning of the 2000s, the popularity of rod and hook has decreased by almost half a million fishers. About one quarter of fishers used gill nets and these fishers are older than other fishers. The overall number of fishers using gill nets has decreased in all age groups, except among people aged over 64 years who make up one third of all gill net users.

The total catch for recreational fishers was approximately 30 million $\mathrm{kg}$ in 2016 (OSF, 2017). Over 80 percent of the total catch came from inland recreational fishery. Net fishing accounted for 40 percent of the total catch and spinning rod and trolling accounted for 26 percent. Perch and pike were the most common species in catches (Figure 6). Pike-perch catches have increased since 2000, and catches of all other common species have decreased. 


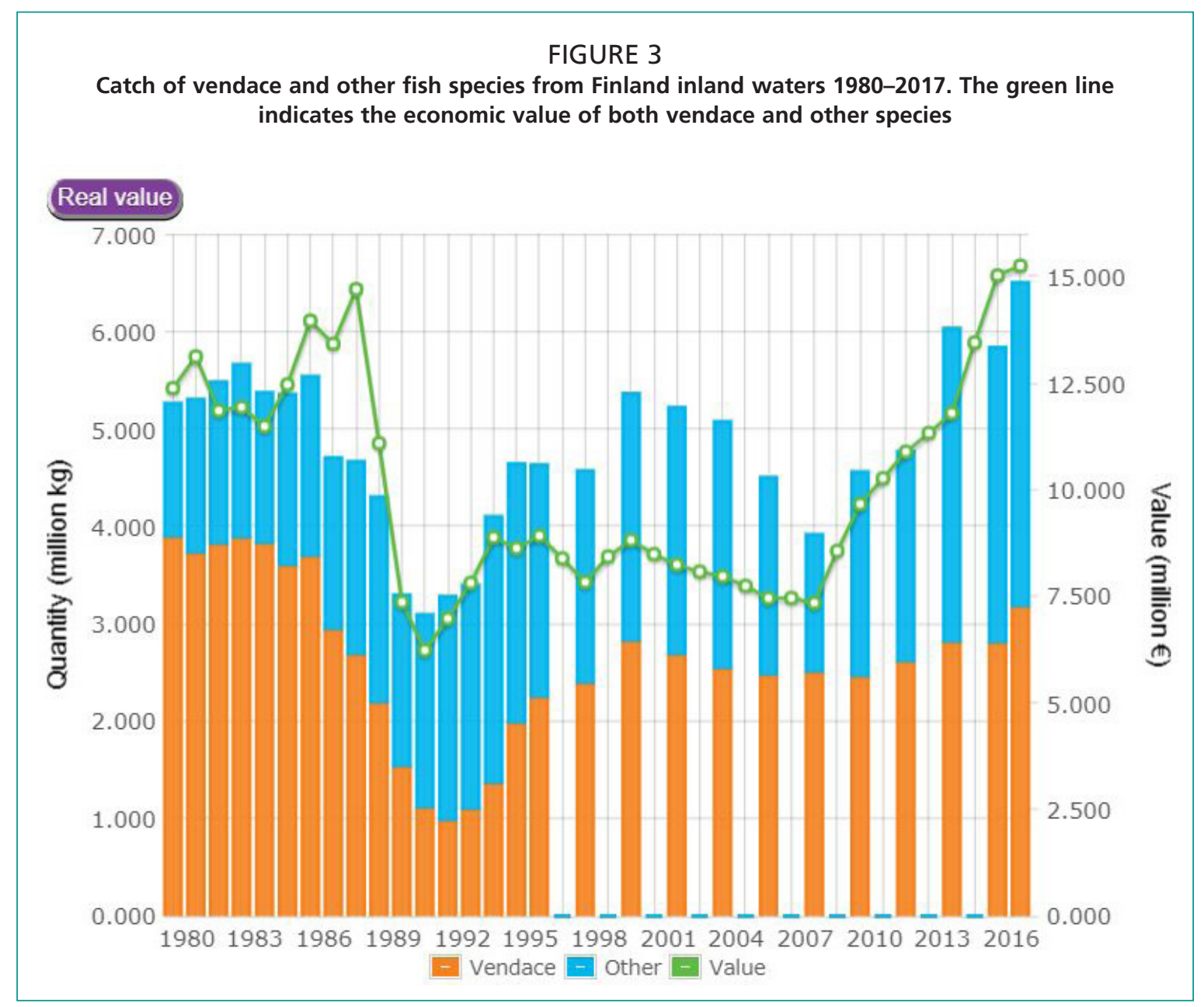

Source: OSF. Natural Resources Institute Finland, Commercial inland fishery.

FIGURE 4

Number of recreational fishers by age group in inland waters and sea areas (Natural Resources Institute Finland, 2018)

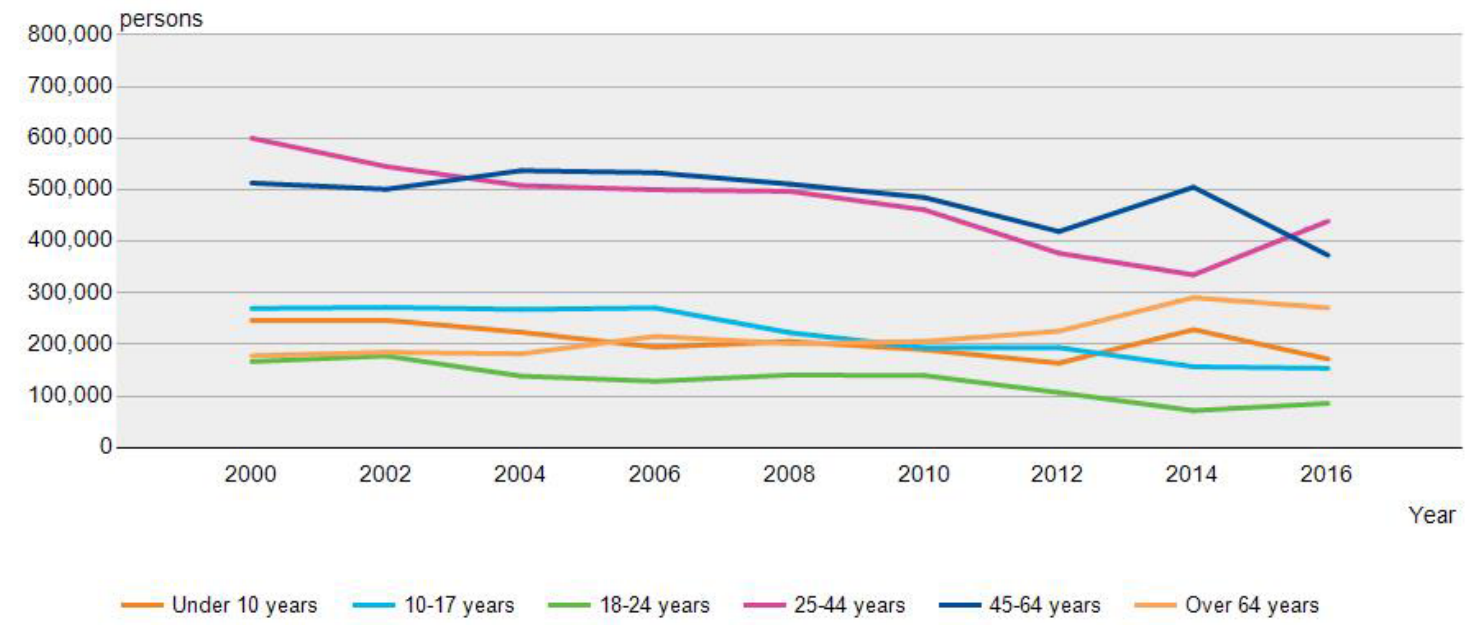




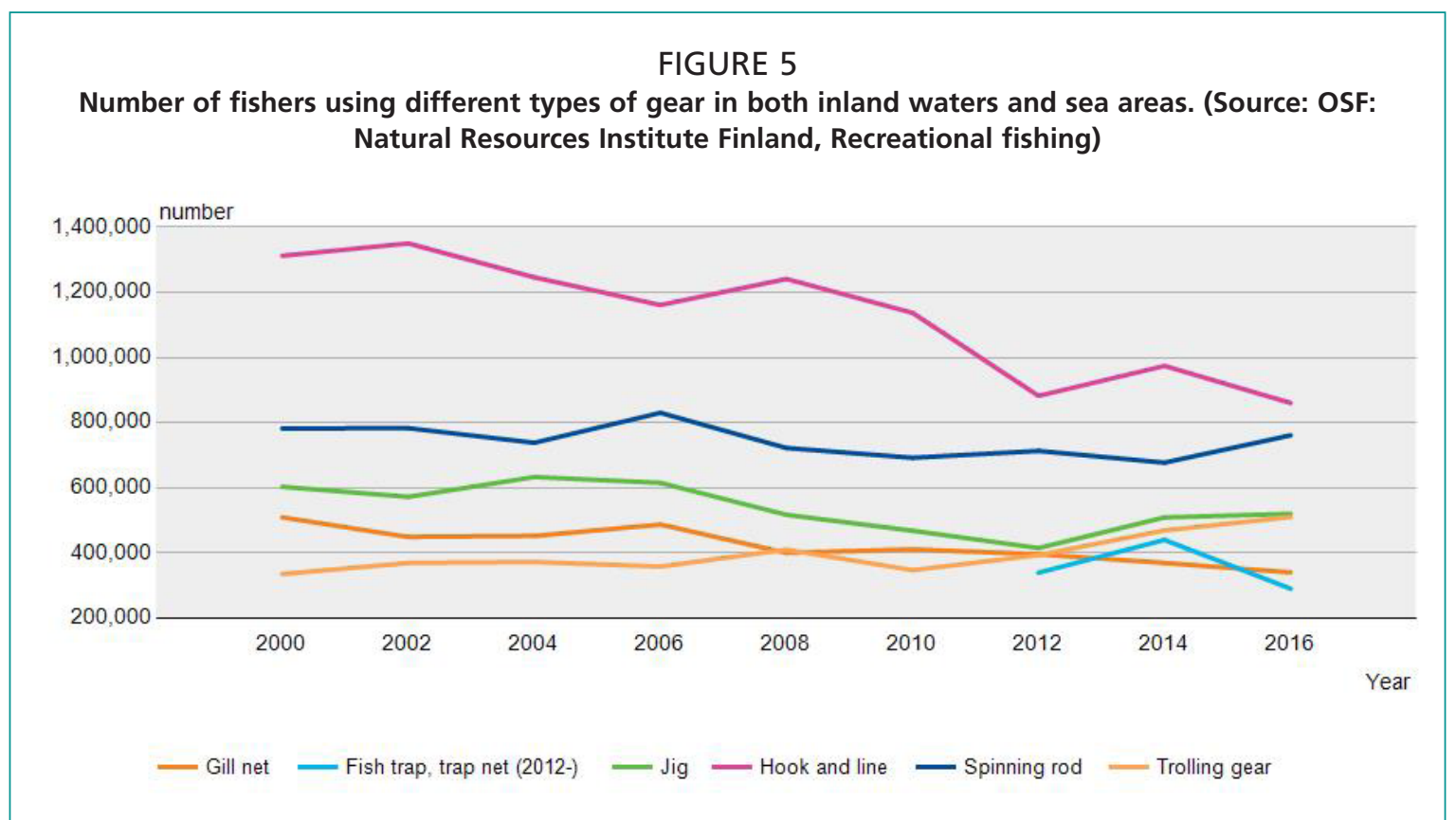

Source: OSF. Natural Resources Institute Finland, Recreationa fishing.

FIGURE 6

Most common species of fish catches in inland waters (Natural Resources Institute Finland, 2018)

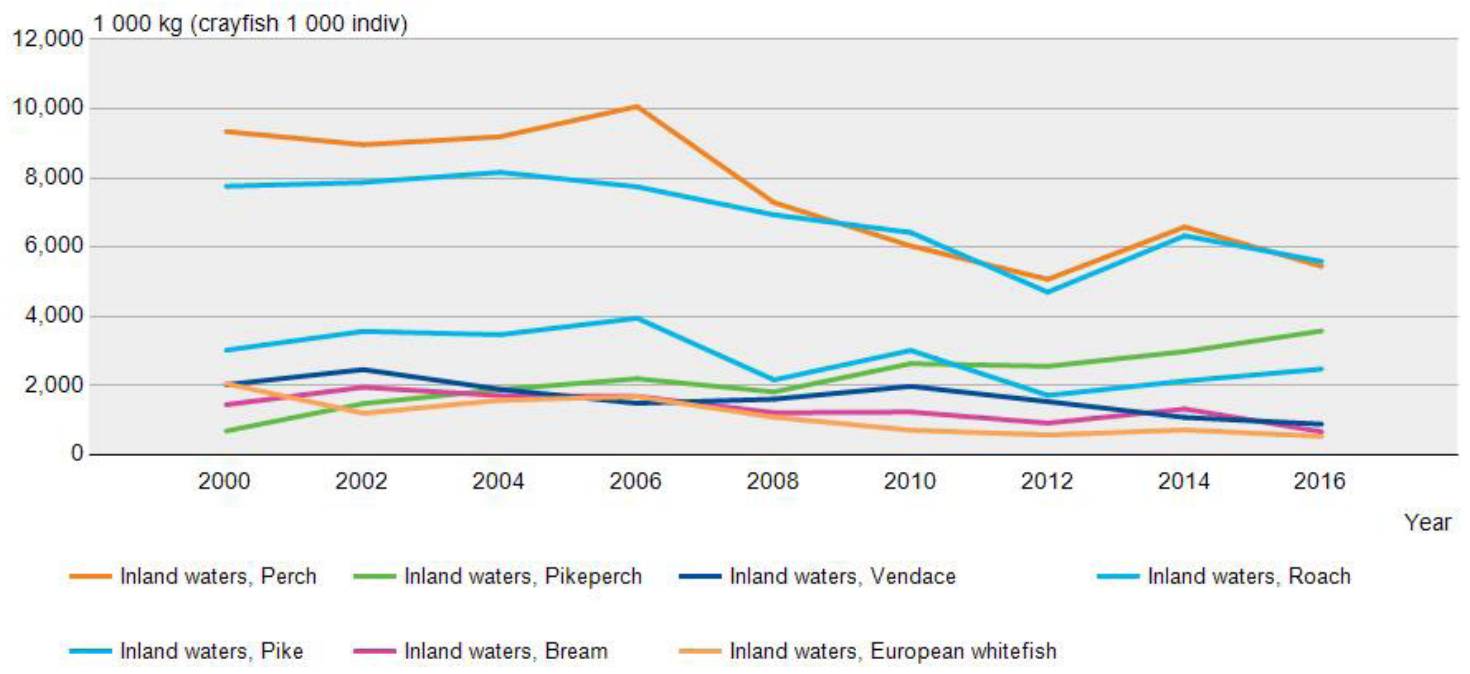

Source: OSF. Natural Resources Institute Finland, Recreationa fishing.

The fisheries management fee can be paid for one day, seven days or a whole year. About 240000 fishers paid some type of fisheries management fee in 2018, which brought in EUR 8.6 million for fisheries. The amount of fees paid decreased slightly from the previous year, but total revenue increased by half a million. No nationwide statistics about other types of fishing permits exist.

Fishing tourism is part of recreational fisheries in the Finnish administrative context. Fishing tourism belongs to nature tourism and there is a great variety among fishing tourism enterprises with some concentrating solely on fishing activities or fishing is included in their package of offerings. In a recent study, Pohja-Mykrä et al. (2018) found there are 547 fishing tourism enterprises in Finland; 180 of them received half of their income from fishing tourism. Finnish fishing tourism enterprises are quite small, 
and directly employ 935 person-years with a yearly revenue of about EUR 20 million. The average income from fishing tourism was estimated to be EUR 159 per customer. Annually, 132500 customers are estimated to have used fishing tourism services. A large portion of customers were foreign tourists from Russia and Central Europe. Two thirds of customers prefer catch and release fishing, and close to 70 percent of all catch was released. Finnish fishers are self-taught, they very seldom use fishing guides or fishing tourism services but may use accommodation and boat renting services (Pohja-Mykrä et al., 2018, Pellikka Eskelinen, forthcoming).

Though fishing tourism today is not a very big part of nature-based tourism business, the majority of fishing guides and fishing tourism entrepreneurs considered that their turnover will increase in coming seasons. Fishing can be seen as a permanent hobby among Finnish recreational fishers (Pellikka and Eskelinen, forthcoming) and most of those who paid the fisheries management fee for the whole year in 2018 indicated that they will renew for the following year. Fishers do not largely have plans to change their fishing methods, but about 40 percent of them are going to take a (self-guided) fishing trip in Finland. On the other hand, gill net fishing may lose popularity in the future because of the age structure of fishers using that gear type (OSF, 2017).

\subsection{MONITORING SYSTEM}

The Fishing Act (379/2015) sets out fisheries management goals: "to use the best available information to ensure ecologically, economically and socially sustainable management of fish resources in such a way as to secure a sustainable and diversified return on fish resources, the natural life cycle of fish stocks, and the diversity and protection of fish resources and other aquatic flora and fauna." Fishing Decree (1360/2015) includes more detailed provisions on, for example, use of fishing gear and the practice of fishing, legal size limits, protected fish species, state fishing waters and fisheries control.

The state's highest fishery authority is the Ministry of Agriculture and Forestry. The Ministry is responsible for the preparation of fishing laws and national plans for the management of fish resources. The national fish resource management plans take into account the regional fisheries management plans. The Ministry provides technical provisions on the structure and mode of use of fishing gear in specific waters. It also prepares strategies and programmes to secure the conditions for recreational fishing, commercial fisheries and the management of fishing waters, and ensures that Finland fulfils its international obligations.

The Centres for Economic Development, Transport and the Environment are the regional state fisheries authorities, which have a broad mandate ensure fisheries administration by the state. Centres supervise the general fishery interest and promote sustainable fishing and management of fish resources. They work with the fishery regions to provide expert assistance and ensure that they comply with the law, rules and accept the regional fisheries management plan. The funds from the state fisheries management fee are transferred to the water owners as compensation, and the Centres supervise fisheries management work using these state funds. Centres implement the fisheries regulation measures as agreed in the regional fisheries management plan, and can, to some extent ( 20 percent) change the legal-size limits for fish. They can also limit the fishery of fish stock at risk of overharvesting or protect fish stock of special importance.

Official fishery duties at state level are also managed by Metsähallitus and Natural Resources Institute Finland. Metsähallitus manages and controls fisheries in all stateowned waters and also collects the state fisheries management fee. Natural Resources Institute Finland collects and analyses fishery statistics and produces scientific information about the status of fish stocks. 
In privately-owned waters, body of joint owners or owners of water areas not belonging to a body of joint owners is responsible for fishery management. They decide on fishing that does not belong to common fishing rights, fishing with stationary fishing gear or with multiple rods. Fishing rules such as mesh sizes used in gill netting, and management actions such as fish stocking must be in line with the regional management plan. Joint owner bodies also decide on the fishing rights and allocate them to owners typically based on the size of the area owned.

Finnish waters are divided into 118 fishing zones including all inland waters. The purpose of the fishing zone system is to promote and standardize water management and exploitation beyond the limits of ownership. When determining an area belonging to a fishery region, the life cycle of migratory fish, appropriate organization of fishing, division of catchment areas and the division of water areas into water resources management areas are specifically taken into account. The geographical boundaries of the fishery regions are confirmed by the Centre for Economic Development, Transport and the Environment. The members of a fishery region are the fishing right holders in the region and national fishery organizations. A fisheries region may make commitments and purchase property in its name or for its use. An important duty for fishery regions is to draft a plan for their use and management in their area. The draft plan describes the state of the fishing grounds and fish stocks and sets out guidelines for the management of fishery resources and sustainable fishing arrangements. This regional management plan is approved by the Centre for Economic Development, Transport and the Environment. The fishery region is also responsible for the implementation of the management plan and to collect monitoring data regarding fishing and the management actions. In addition, the duties defined by the fishing law (379/2015) include the organization of fishing supervision in the area, and to encourage the formation of joint permit areas for the needs of recreational and commercial fishing. The work of the fishery regions is financed primarily from the state fisheries management fees and it also distributes funds accrued from compensations relating to lure fishing on states license to the owners of the water area.

A regional fishery committee is established by the Centre for Economic Development, Transport and the Environment in its operating area to provide assistance in the management of fishery matters in that region, reconcile views and utilize research information (Fishing law 379/2015). The committee is set up for five years at a time and consists of representatives of the fishery regions, fishery and environmental organizations, research, administration, regional councils and, in the Sámi Homeland, representatives of the Sámi Parliament. Regional fishery committees assist the Centres for Economic Development, Transport and the Environment in dealing with fishery issues in the region. Regional fishery committees make proposals and take initiatives on the organization of fishing and management of fish stocks. The committee evaluates the plans for the management of fish resources and the management measures presented. It also makes proposals for reconciling measures presented in the management plans of different regions and in national fish resources management plans.

\subsection{INTERNATIONAL COOPERATION CASE STUDY: RIVER TORNIONJOKI SALMON FISHING - BORDER RIVER BETWEEN FINLAND AND SWEDEN}

River Tornionjoki is the largest unregulated river system in the Western Europe (Dysenius and Nilsson, 1994). It is located on the border between Finland and Sweden and flows to the Bothnian Bay in the Baltic Sea. The river's catchment is the northernmost point of the Baltic Sea catchments and it flows in a near natural state through a sparsely populated area. In Finland, it is the most important of the Baltic Sea salmon rivers. In fact, it is also one of the most important spawning grounds of 
Atlantic salmon in the world. More than one third of the salmon in the Baltic Sea are born in the River Tornionjoki system. The mean discharge is $400 \mathrm{~m}^{3} \mathrm{~s}^{-1}$ and during the spring flooding the discharge rate is typically $1000-2000 \mathrm{~m} 3 / \mathrm{s}$. The catchment area is $40010 \mathrm{~km}^{2}$ and $522 \mathrm{~km}$ in length which reaches to the subarctic zone 400 to 500 metres above sea level in the headwaters.

\subsubsection{Legal background}

The UNECE Convention - "The Convention on the Protection and Use of Transboundary Watercourses and International Lakes" (Water Convention) - is an international convention ratified by 40 countries and the European Union (http:// www.unece.org/env/water). The agreement aims to ensure the sustainable use of transboundary water resources by facilitating cooperation. The agreement requires the establishment of joint border water committees. The "Agreement between Finland and Sweden Concerning Transboundary Rivers" (91/2010) - complies with the principles of the UNECE Convention and forms the basis for the international management of the Tornionjoki River.

The main purpose of the Finnish-Swedish Agreement is to ensure equal opportunities for the two countries to use the river and to promote cross-border cooperation in fisheries and other water issues. Besides this, the Agreement contributes to efforts to prevent flood and environmental damages as it creates the conditions for the implementation of the Water Framework Directive and Floods Directive of the European Union in the Tornionjoki river basin. The Agreement provides the residents of the region with extensive rights to participate in the management of water permit issues on both sides of the border.

The Fishing Rule for the Tornionjoki River Fishing District is an integral part of the Agreement and establishes provisions concerning protected areas, fishing seasons and closed seasons, minimum sizes, and fishing gear and their use. The Fishing Rule with current fishing restrictions can be found here: http://www.fsgk.se/Fishingregulations-.html. The public authorities responsible for management are specified by the Finnish and Swedish Governments, and these authorities discuss any derogation from the Fishing Rule which may be needed on an annual basis. Such derogations are assessed on the basis of changes in the fish populations and they may concern, for example, timing of fishing seasons.

\subsubsection{Monitoring system}

The authorities specified by the Agreement between Finland and Sweden are at national level and are the Finnish Ministry of Agriculture and Forestry and the Swedish Agency for Marine and Water Management (previously Swedish Board of Fisheries). At regional level, the fisheries in the Tornionjoki fishing zone is managed and monitored by the Centre for Economic Development, Transport and the Environment for Lapland in Finland and the Provincial Government of Norrbotten in Sweden. Management of salmon fisheries based on the Agreement in the Tornionjoki River also includes the coastal area directly outside the river mouth (Figure 7). This agreement includes, for example, a specified time period within which the commercial coastal fishery in the river mouth is allowed to start. Deviations from the agreed fishing regulations are negotiated and decided upon on an annual basis by the Swedish Agency for Marine and Water Management (according to a Government commission from the Swedish Ministry of Enterprise and Innovation) and the Finnish Ministry of Agriculture and Forestry.

The Agreement between Finland and Sweden Concerning Transboundary Rivers sets up the Finnish-Swedish Transboundary River Commission as a cooperation body between the two states (http://fsgk.se/). The Commission is responsible for fishery issues and also other tasks specified in the Agreement, such as water management and protection and flood risk management. The Transboundary Commission works 
FIGURE 7

Above: Map of Tornionjoki River between Finland and Sweden and its main rivers. The yellow dot is the location of the smolt trap and the red dot is the location of the sonar monitoring the number of upstream migration adult salmon.

Below: The statistical fishing areas in the Bothnian Bay. The red line is the sea frontier between Finland and Sweden. The dotted blue line defines the area where coastal fisheries are regulated by the Agreement between Finland and Sweden Concerning Transboundary Rivers
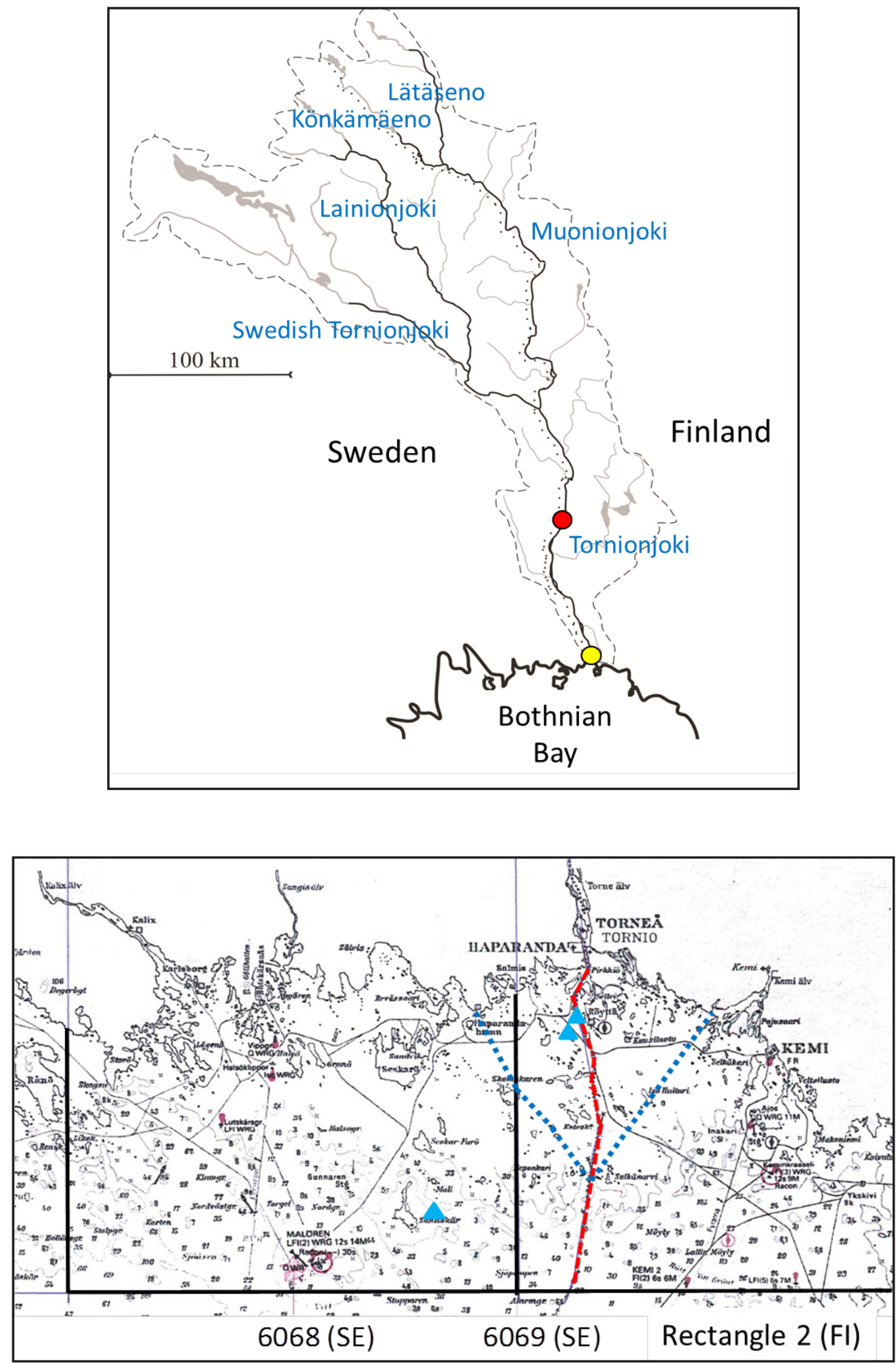
together with the municipalities, business entrepreneurs, public authorities and other actors in the region. The Commission monitors the application of the Agreement and draws attention to needs to amend the Agreement. The fishing rules are reviewed annually, and for this, experts from both countries - the Natural Resources Institute Finland and the Swedish University of Agricultural Sciences - produce a joint biological survey report on the state of stocks. This annual update report describes the development and status of salmon, brown trout and whitefish stocks. For salmon, the report also includes a summary of the development of the Baltic Sea salmon fishing and the salmon advice of the International Council for the Exploration of the Sea (ICES). ICES produces annual advice to the EU, based on several agreements, on the development of fish stocks and fisheries in the marine area.

Monitoring the Tornionjoki River migratory fish stocks, salmon and sea trout are also a part of data collection for the EU for the Common Fisheries Policy. The EU fisheries management relies on data collected, managed and supplied by EU countries under the Data Collection Framework, Regulation (EU) 2017/1004 on the establishment of a Union framework for the collection, management and use of data in the fisheries sector and support for scientific advice regarding the Common Fisheries Policy. Furthermore, the Commission Implementing Decision (EU) 2016/1701 lays down rules on the format for the submission of work plans for data collection in the fisheries and aquaculture sectors (notified under document C(2016)5304). The Baltic Salmon and Trout Assessment Working Group (WGBAST) of ICES reviews data from salmon spawning rivers, salmon fisheries, stocking statistics etc. These data are utilized by the full life history model in the ICES Baltic salmon stock assessment.

\subsubsection{Data collection}

In Tornionjoki, data collection is coordinated between Finland and Sweden. Numbers of adult salmon ascending the river are counted annually by multi-beam echo sounders. Parr densities are estimated annually by electrofishing. Smolt numbers are estimated by smolt trapping. Recreational fisheries are monitored, and their catches are estimated by postal surveys targeted to those who have purchased joint fishing permits for salmon fishing in the river. On the Swedish side, not all fishers use the joint fishing permit because it does not cover the whole river in the Swedish area. Also, fishers' organizations operating in the Swedish side of the river area are annually contacted to collect their catch data. Biological samples are taken from recreational catches on a yearly basis. The registered commercial coastal fishers fishing in the river mouth area report their catches directly to the authorities on both sides of the border.

\subsubsection{Fishing and catches}

Fishing of Tornio River salmon is regulated in the Baltic Sea by internationally agreed fishing quotas, and salmon fishing in the river is mutually managed by Finland and Sweden. The fishing and catch statistics presented here are based on the recent report from the Finnish-Swedish Transboundary River Commission's biological survey report (Palm et al., 2019).

Commercial coastal fishing near the river mouth of the Tornionjoki River is mainly fyke net fishing. Coastal catches have been stable compared to the big changes in the numbers of migrating adult salmon to the river (Table 3). This is obviously due to the fact that coastal salmon fisheries are strongly regulated by time constraints (starting date) and total allowable catches (TAC).

The recreational catch from the river has been increasing since 2012 (Table 4) together with the increasing numbers of adult fish ascending the river. The number of joint fishing permits sold has doubled in 15 years and between 2014-2018 about 10000 to 12000 permits were sold annually. Recreational fishing is mainly angling from the shore or trolling with a small boat with or without engine. There is also 
some traditional fishing with long handheld dip-nets, seine or floating nets. The total recreational salmon catch in the river is not regulated, but fishing restrictions, like the bag limit (one salmon per day per person), target the effort of recreational fishing.

TABLE 3

Catches of Baltic salmon in the coastal commercial fishing near the mouth of the Tornionjoki River 2005-2018 (Palm et al., 2019). Weight is given in tonnes

\begin{tabular}{|r|r|r|r|r|r|r|}
\hline & \multicolumn{2}{|c|}{ Sweden } & \multicolumn{2}{c|}{ Finland } & \multicolumn{2}{c|}{ Total catch } \\
\hline 2005 & Pcs & Weight & \multicolumn{1}{|c|}{ PcS } & Weight & Pcs & Weight \\
\hline 2006 & 19934 & 80.3 & 10126 & 47.2 & 30060 & 127.5 \\
\hline 2007 & 10777 & 59.1 & 6662 & 38.5 & 17439 & 97.6 \\
\hline 2008 & 7780 & 37.9 & 6135 & 27.0 & 13915 & 64.9 \\
\hline 2009 & 17806 & 71.8 & 10298 & 46.0 & 19665 & 97.9 \\
\hline 2010 & 8065 & 42.7 & 14211 & 66.9 & 32017 & 138.4 \\
\hline 2011 & 8479 & 50.3 & 12013 & 56.5 & 20492 & 106.8 \\
\hline 2012 & 9105 & 53.7 & 15686 & 83.1 & 24791 & 136.9 \\
\hline 2013 & 7887 & 50.7 & 12643 & 78.1 & 20530 & 128.8 \\
\hline 2014 & 12371 & 70.7 & 13376 & 75.4 & 25747 & 146.1 \\
\hline 2015 & 12312 & 82.7 & 11607 & 45.0 & 23919 & 127.7 \\
\hline 2016 & 13529 & 86.8 & 7574 & 37.4 & 21103 & 124.2 \\
\hline 2017 & 8179 & 48.5 & 7306 & 37.0 & 15485 & 85.5 \\
\hline $2018 *$ & 15646 & 105.5 & 5865 & 39.6 & 21511 & 145.1 \\
\hline
\end{tabular}

*Partially incomplete data.

TABLE 4

Catches of Baltic salmon in recreational fishing in the Tornionjoki River 1997-2018

(Palm et al., 2019). Weight is given in tonnes

\begin{tabular}{|c|c|c|c|c|c|c|}
\hline \multirow[t]{2}{*}{ Year } & \multicolumn{2}{|l|}{ Sweden } & \multicolumn{2}{|l|}{ Finland } & \multicolumn{2}{|l|}{ Total } \\
\hline & PCS & Weight & PCS & Weight & PCS & Weight \\
\hline 1997 & - & 10.3 & 7839 & 64.0 & - & 74.3 \\
\hline 1998 & 1225 & 10.5 & 3805 & 39.0 & 5030 & 49.5 \\
\hline 1999 & 1063 & 7.8 & 1672 & 16.2 & 2735 & 24.0 \\
\hline 2000 & 1173 & 7.3 & 4475 & 24.7 & 5648 & 32.0 \\
\hline 2001 & 983 & 5.8 & 3860 & 21.3 & 4843 & 27.1 \\
\hline 2002 & 775 & 4.7 & 2667 & 15.0 & 3442 & 19.8 \\
\hline 2003 & 520 & 3.4 & 1668 & 11.5 & 2188 & 14.9 \\
\hline 2004 & 798 & 4.1 & 2942 & 19.7 & 3740 & 23.8 \\
\hline 2005 & 1530 & 12.8 & 3190 & 25.6 & 4720 & 38.4 \\
\hline 2006 & 645 & 4.3 & 1470 & 11.6 & 2115 & 16.0 \\
\hline 2007 & 1515 & 13.0 & 2651 & 22.0 & 4166 & 35.0 \\
\hline 2008 & 2705 & 18.0 & 8762 & 57.0 & 11467 & 75.0 \\
\hline 2009 & 1036 & 7.1 & 4675 & 30.1 & 5711 & 37.2 \\
\hline 2010 & 958 & 7.6 & 3144 & 23.7 & 4102 & 31.3 \\
\hline 2011 & 1770 & 15.6 & 3481 & 27.9 & 5251 & 43.5 \\
\hline 2012 & 4376 & 37.2 & 10725 & 84.7 & 15101 & 122.0 \\
\hline 2013 & 1789 & 14.3 & 8405 & 58.0 & 10194 & 72.3 \\
\hline 2014 & 2828 & 22.7 & 15125 & 124.0 & 17953 & 146.7 \\
\hline 2015 & 3973 & 29.2 & 12709 & 101.6 & 16682 & 130.8 \\
\hline 2016 & 5068 & 35.0 & 17202 & 131.9 & 22270 & 166.9 \\
\hline 2017 & 3080 & 21.1 & 10533 & 71.3 & 13613 & 92.5 \\
\hline $2018^{*}$ & 2440 & 15.9 & 11288 & 74.9 & 13728 & 90.8 \\
\hline
\end{tabular}

*Partially incomplete data. 


\subsubsection{Catch statistics and scientific advice}

Catch statistics and monitoring results (electrofishing for juvenile densities, smolt trapping for the numbers of migratory juveniles and sonar counting for ascending adults) are also used by the Tornionjoki River transboundary commission experts, Natural Resources Institute Finland and Swedish University of Agricultural Sciences, which produce biological survey reports focusing more on the management of the Tornionjoki River.

The development of the Tornionjoki River salmon stock has been positive during the last two decades. The main reasons for this are due to more strict management activities to regulate the salmon fishery in the sea and coastal area. These include stricter political decisions about Total Allowable Catches (TAC) for different countries in the Baltic Sea which rely on scientific advice. In addition, stricter technical regulations for coastal salmon fisheries and the ban of driftnets have diminished the fishing effort in the sea area. The amount of salmon smolts migrating from the river to the Baltic Sea has been 1-2 million annually since 2008 (Figure 8). Nowadays it is the most productive salmon-river in the Baltic Sea area.

Monitoring of adult salmon numbers ascending the river during their spawning run was started in 2009. A horizontal sonar (DIDSON/ARIS) was used to calculate fish numbers. The observed number of upstream migrating salmon has varied between 17200 - 100200 annually (Figure 9). The lowest numbers were observed in the beginning of the monitoring period 2009-2011, and the largest, around 100000 salmon, in 2014 and 2016 (Figure 9).

On long runs, the salmon juvenile densities in the river seem to follow the amount of adult salmon ascending to the river (Palm et al., 2019). However, on a shorter scale, other factors than the number of adult salmon interact with the juvenile production. Densities have been on a relatively steady rise until the record year 2015, and since then there has been short downturn in juvenile densities (Figure 10).

ICES estimates that the positive development in the Tornionjoki River salmon stock has led to its MSY (Maximum Sustainable Yield) target (ICES, 2018a). According to

FIGURE 8

The estimated amount of salmon smolts migrating from Tornionjoki River to the Baltic Sea 1996-2018 (estimate and 90 percent probability intervals)

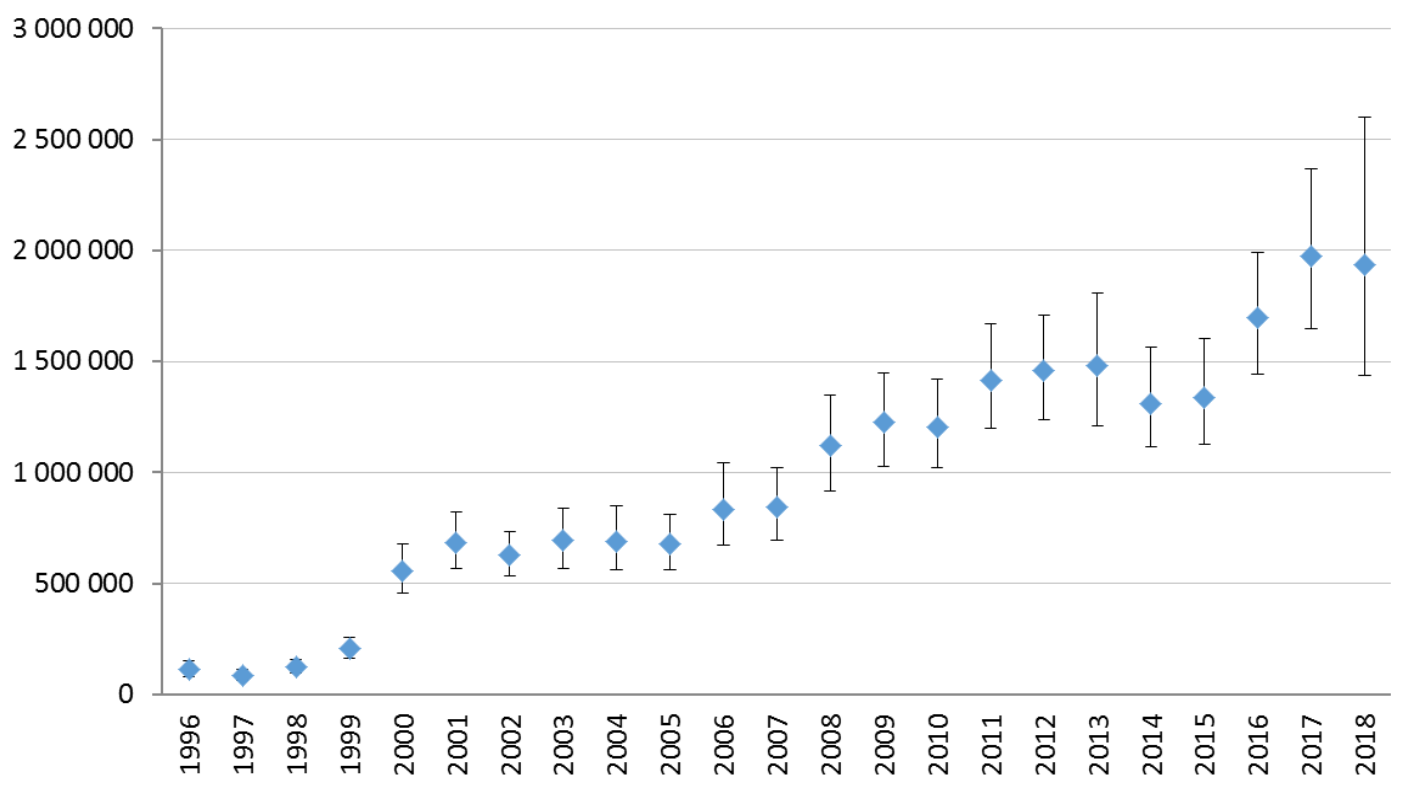


ICES, reaching the level of 75 percent of the maximal smolt production capacity of the river is a proxy for MSY status. In the Tornionjoki case, MSY means a production of about 1.6 million smolts. An empirical stock-recruitment relationship is used to calculate how many salmon eggs are needed to produce this amount of smolts.

FIGURE 9

The annual numbers of upstream migrating adult salmon in Tornionjok River 2009-2018

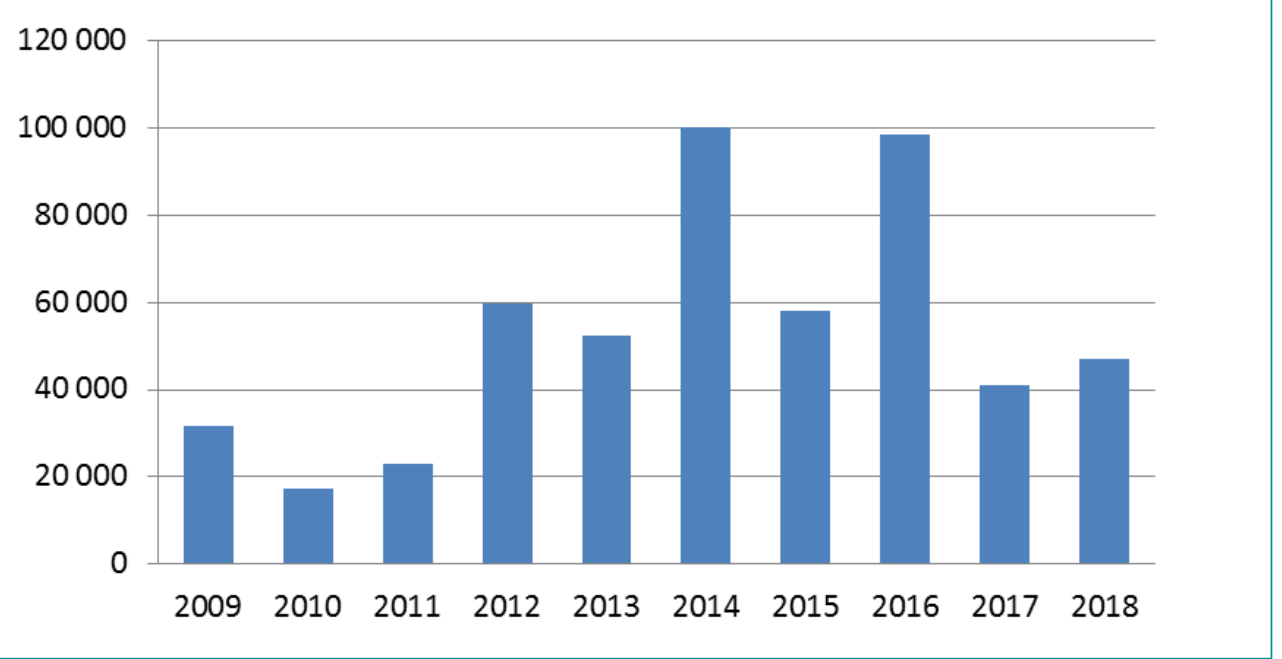

Source: Palm et al., 2019.

FIGURE 10

The salmon juvenile densities (all age groups combined, mean for three years) in different parts of the Tornionjoki River from 1986 to 2018

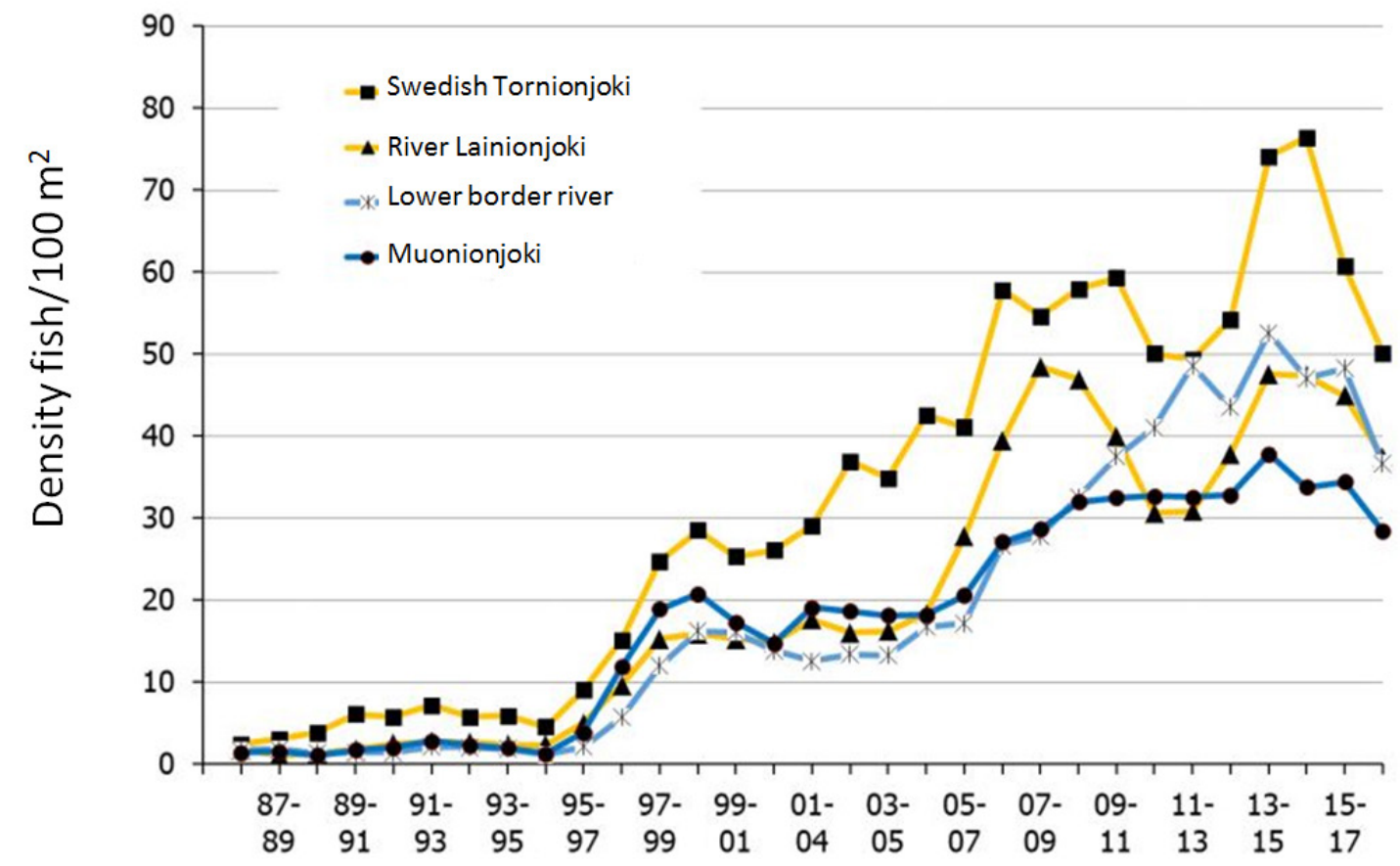


Further, in their annual reporting, the Tornionjoki River researchers use more detailed data from the river, e.g., they calculate how many females are needed to produce this amount of eggs (Palm et al., 2019). They ended up with an amount of 52000 yearly ascending salmon to reach the MSY (Palm et al., 2019). These calculations include a large amount of uncertainty and the results also depend on the selected risk level. The researchers conclude that although MSY is reached with high certainty in years of abundant smolt runs, this is not the case in all years (Palm et al., 2019).

The recovery of salmon from the brink of extinction in the 1980s is an excellent example of the benefits of abstaining from overfishing. The revived salmon stock of the Tornio River produces a catch of between 50000 and 80000 fish per year, the majority of which are still caught by sea fisheries and between 10000 and 20000 are caught in the river itself. 


\section{Country examples: Croatia ${ }^{3}$}

\subsection{DATA COLLECTION FOR STATISTICS}

There are several different data collection systems according to the Freshwater Fisheries Act and its bylaws. The Ministry of Agriculture, Fisheries Directorate (Ministry) keeps registers of all the data collected on freshwater fisheries.

The Ministry collects data and keeps a register about all the owners of fishing rights (the right of a person or legal person allocated by the state to organize sports fisheries, sell licenses to anglers and manage the fish stocks inside specified administrative borders), commercial fishers (owners of commercial fisheries licenses), borders of the fishing zones for commercial and sports fisheries, fish catch records in commercial and sports fisheries, management plans for six-year periods, yearly management plans sent by owners of fishing rights, and all the other relevant documents. From 2005, the Ministry has prescribed special uniform fish logbooks for anglers and for commercial fishers. Compiled fish logbooks are collected yearly, by post or e-mail, by the Croatian Sports Fisheries Association (HŠRS) http://ribolovni-savez.hr/ (web page available only on Croatian language). HŠRS aggregates this data and sends it to the Ministry. The new Freshwater Fisheries Act was released in 2019, and will be fully implemented in the coming years. The data collection will be managed digitally by owners of the fishing rights or commercial fishers. They will have access to certain levels of the fisheries database. At present, the data collected is not realistic and does not reflect the real catch.

\subsubsection{Recreational fishing}

Recreational and sport fishing in Croatia's inland waters is not distinguished - sport fishing is a common term, because according to the Sports Act, sport is a part of recreation and vice-versa. Sport fishing is permitted in running or standing waters under the concession of a fishing rights owner. Concessions are free, i.e. one does not have to pay the state in advance to own a fishing right, but 10 percent of every fishing license payment goes to the state budget. All surface and ground water is owned by the Republic of Croatia and there is no private ownership of any water body, thus fishing rights for using and managing surface waters need to be obtained. These rights can be obtained through concession by the Ministry of Agriculture for a maximum 20-year period, by public tender. Owners of fishing rights (owners) should have a valid management plan (every 6 years management plans should be revised), made by authorized institutions. Owners of fishing rights must possess records of the quantity of sold sport fishing licenses. Every year, the state prints a certain amount of licenses in an official approved printer and these licenses are then distributed via HRŠS to the owners of fishing rights. At the end of year, the said owners are obliged to return licenses that are not sold to HRŠS as well as the number of sold licenses. Anglers can purchase licenses from fishing rights owners to conduct recreational (sport) fishing in a particular fishing water body or zone.

\subsubsection{Data collection}

Data is collected once a year. Fishing rights owners update a list of all the fishing waters (lakes and rivers) inside their fishing zone, mark any changes and send them to the Ministry. According to the new Freshwater Fisheries Act, the register will be digitally managed in the future.

3 This section refers to numerous laws, regulations and official decisions published in the Official Gazette of the Republic of Croatia https://www.nn.hr. 
Anglers enter their catch data (only for fish which are not released) into the logbook prescribed by national legislation. It is forbidden for recreational anglers to sell the fish. The fish caught and kept by anglers should be marked by cutting the lower part of caudal fin. Logbooks are available from the owners of fishing rights (owners). Anglers should also report the yearly catch data with the logbooks which must be delivered to the owners by the end of January. Owners collate all catch statistics and send them to the Croatian Sports Fisheries Association (HŠRS) by the end of March. HŠRS sends the aggregated data to the Ministry of Agriculture by the end of May. This system is very slow, but according to the New Freshwater Fisheries Act, the catch data collection and sharing will be digital in the near future. The statistics also include fishing by foreign visitors or by Croats living abroad, but this data is not separated from Croatian citizens' data. Owners collect catch data, anglers' personal data (name and address), serial number of licenses, and weight and number of 20 selected fish species (Table 5). Recording of other species is not obligatory.

The catch data is used in fishing effort management at particular water bodies. It guides the planning of restocking selected fish species. The Ministry of Agriculture reports to the European Commission, according to Art. 16 of Council Directive 92/43/ EEC of 21 May 1992, on the conservation of natural habitats and of wild fauna and flora. The list of reported species marked by * in Table 5 including starlet (Acipenser ruthenus) denotes fish data caught by commercial fishers.

TABLE 5

Fish species set by Ministry of Agriculture for data collection (weight and numbers caught) by owners of fishing rights and the origin of fish species ( $\mathrm{N}$-native, A-non-native, *reported to the European Commission)

\begin{tabular}{|c|c|c|}
\hline English name & Scientific name & Origin \\
\hline Common carp & Cyprinus carpio & $\mathrm{N}$ \\
\hline Grass carp & Chtenopharingodon idella & A \\
\hline Bighead carp & Hypophthalmichthys nobilis & A \\
\hline Silver carp & Hypophthalmichthys molitrix & A \\
\hline European catfish & Silurus glanis & $\mathrm{N}$ \\
\hline Zander & Sander lucioperca & $\mathrm{N}$ \\
\hline Northern pike & Esox Lucius & $\mathrm{N}$ \\
\hline Tench & Tinca tinca & $\mathrm{N}$ \\
\hline Common bream & Abramis brama & $\mathrm{N}$ \\
\hline Ide & Leuciscus idus & $\mathrm{N}$ \\
\hline Asp & Aspius aspius & $\mathrm{N}$ \\
\hline Gibel carp & Carassius gibelio & A \\
\hline Grayling* & Thymallus thymallus & $\mathrm{N}$ \\
\hline Huchen* & Hucho hucho & $\mathrm{N}$ \\
\hline Barbel* & Barbus barbus & $\mathrm{N}$ \\
\hline Danube barbel* & Barbus balcanicus & $\mathrm{N}$ \\
\hline Italian barbel* & Barbus plebejus & $\mathrm{N}$ \\
\hline Sichel* & Pelecus cultratus & $\mathrm{N}$ \\
\hline Danube roach* & Rutilus pigus & $\mathrm{N}$ \\
\hline Twait shad* & Alosa fallax & $\mathrm{N}$ \\
\hline
\end{tabular}




\subsubsection{Compiling statistics}

Recreational fisheries licenses are established by the national legislation act and can be sold as daily licenses or as licenses for the whole year. The funds paid for the license constitute income for fishing rights owners (owners) ( 80 percent), HŠRS (10 percent) and the State Budget of the Republic of Croatia (10 percent). Owners can limit anglers' fishing effort for native fish species to protect fish stocks. Catch quotas cannot be set for non-native fish species.

In 2017, the number of registered owners in Croatian inland waters was 130 private or legal persons. For the most part, these are legal persons, such as sports anglers units, associations or higher forms of regional sports fishing alliances (for instance, some counties have only one owner, and some have 20 or so owners). The total number of anglers was 38515 with a catch of $456316 \mathrm{~kg}$ of fish (source: HRŠS, 2018). Raw data are stored by the Ministry and no special statistical analyses are performed.

There are several problems with the use of catch data collected with the described system. Perhaps the main problem is that owners of fishing rights only send aggregated data. From such a data it is not possible to make an analysis for each water body or for the trophic levels of different fish species (i.e. limnophyle vs reophyle). Also, catch data collected for large rivers (Sava or Danube) are not separated, thus comparison with catch data collected from commercial fishers (see Chapter 4.1.2) is not possible. Furthermore, data from catch and release fishing is not collected.

\subsubsection{Data availability}

Collected data are available to fishing rights owners, HŠRS and the Ministry however monitoring studies are publicly available, on demand. The establishment of new freshwater fisheries digital database will make fisheries statistics publicly available. The new database will consist of several layers of approach, so that every fisheries topic will have its own database. The information which is now available to the public consists of basic fishing regulations and it is available on the Ministry website https://ribarstvo.mps.hr/default.aspx?id=2802

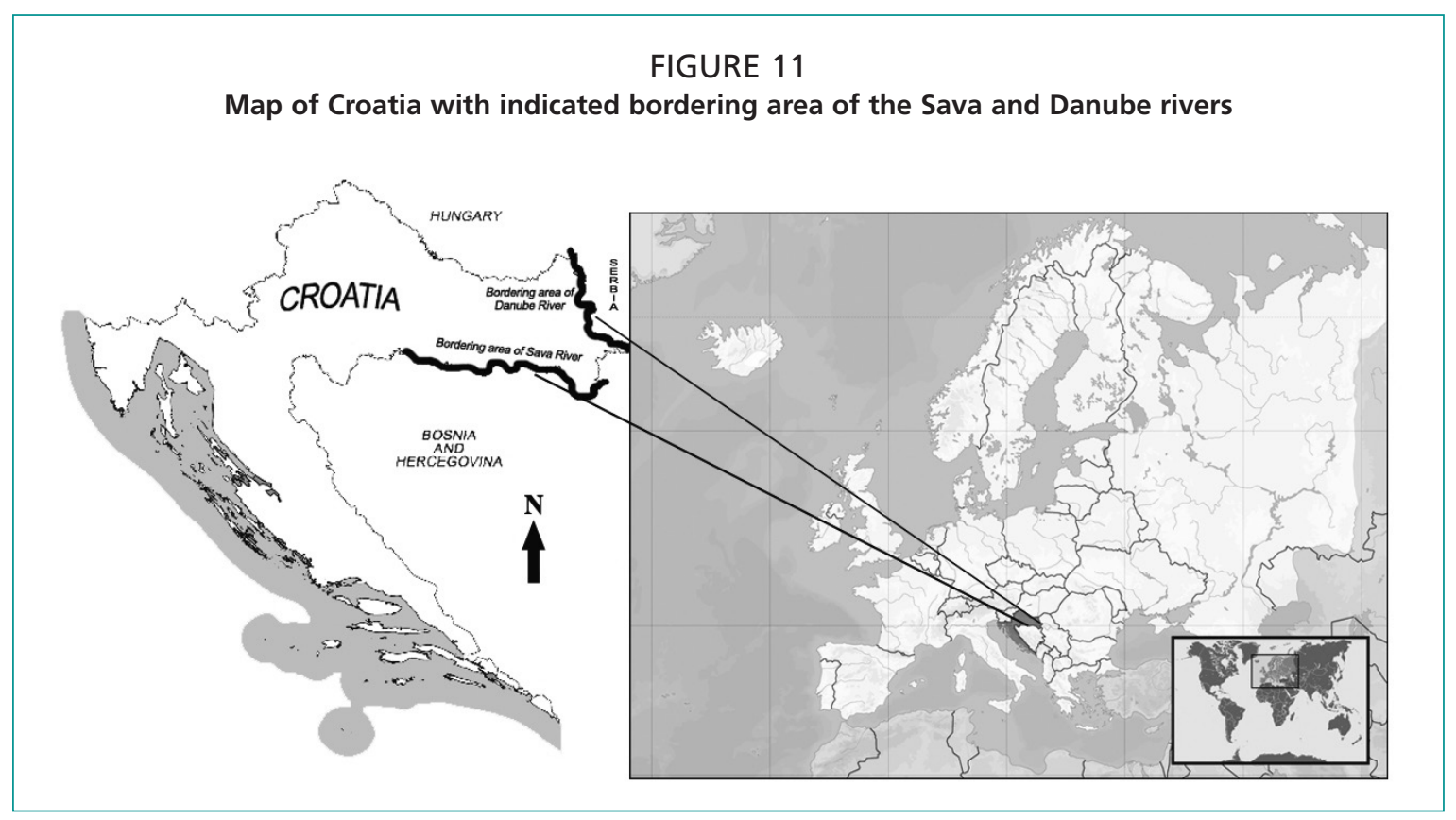

Source: Palm et al., 2019. 


\subsubsection{Commercial inland fishing}

Commercial fishing is only allowed in fishing areas in the Sava River and the Danube River according to the Freshwater Fisheries Act and its sub-act. Licenses for commercial fishers are issued by the Ministry of Agriculture which also establishes the types and quantities of fishing gear allowed, and the annual catch quota.

\subsubsection{Data collection}

Commercial fishers (owners of commercial fishing licenses) must keep records of fish catch on a weekly, monthly and yearly basis. The Ministry of Agriculture provides logbooks with the licenses. Completed logbooks are returned to the Ministry by post or e-mail every month (by the $10^{\text {th }}$ day of each month). A completed annual logbook is sent to the Ministry by January $31^{\text {st }}$. According to the New Freshwater Fisheries Act, catch data collection and sharing will be digital through a special mobile application, so it should be also more easily monitored by fisheries inspectors. Commercial fishers report the total weight and number of selected fish species caught (Table 6).

Data is used by the authorized institutions to calculate catch fishing quotas for commercial fishers. According to the Act of Nature Protection, besides reporting to the Ministry of Agriculture, commercial inland fishers must send reports of non-native fish catch to the Ministry of Environmental Protection and Energy before selling fish on the market.

\section{TABLE 6}

Fish species set by Ministry of Agriculture for data collection (weight and numbers caught) for commercial fishers to report

\begin{tabular}{|l|c|l|}
\hline Fish species & Weight $\mathbf{( k g )}$ & No. specimens \\
\hline Common carp (Cyprinus carpio) & + & + \\
\hline European catfish (Silurus glanis) & + & + \\
\hline Zander (Sander lucioperca) & + & + \\
\hline Northern pike (Esox lucius) & + & + \\
\hline Sterlet (Acipenser ruthenus) & + & + \\
\hline Common bream (Abramis brama) & + & + \\
\hline Asp (Leuciscus aspius) & + & Not prescribed \\
\hline Ide (Leuciscus idus) & + & Not prescribed \\
\hline Other indigenous species* & + & Not prescribed \\
\hline Other non-native species & + & Not prescribed \\
\hline
\end{tabular}

\subsubsection{Compiling statistics}

A limited number of licenses can be issued annually: (1) for the Sava River a total of 20 licenses; (2) for the Danube River a total of 50 licenses. Annual catch quotas of commercially-important fish species are regulated and limited at each fishing zone (see Chapter 4.6). Catch of non-native fish species is not limited. So far, prescribed catch quotas have never been exceeded, according to commercial fishing statistics.

The Ministry only keeps raw data and no particular statistical analyses are performed. Not all commercial inland fishers report their fishing data as required by legislation. Most of them do not record the whole fish catch and some do not send any report, so they are penalized.

There are several problems with the current data collecting system also due to incomplete reporting. The catch from different fishing gear cannot be distinguished. Commercial fishers and anglers are obliged to report the catch of different fish species, which makes the comparison of collected data difficult. It seems that the catch quotas set for some fish species are not reasonable. For example, tench is characteristic in 
backwaters (Simonović et al., 2017) and not in main courses of large rivers, thus commercial fishers will never catch the given quota. A second example is starlet: starlet quotas should be lower because this species is under national protection and is on the verge of extinction. The highest catch of commercial fishers is recorded for Danube bream but there is no catch quota prescribed for this species.

\subsubsection{Data availability}

Data from commercial inland fisheries is not available online. The commercial fisheries statistics are available only upon request to the Ministry of Agriculture for the monitoring studies.

\subsection{CASE STUDY: THE SAVA RIVER FISHING AREA WITH COMMERCIAL AND RECREATIONAL FISHING}

The Sava River Basin is a major drainage basin of Southeastern Europe and one of the most significant sub-basins of the Danube River Basin. Its total area equals $97713 \mathrm{~km}^{2}$, which represents 12 percent of the total Danube Basin area. The moderate climate of the northern hemisphere prevails in the basin. The average annual air temperature for the whole basin is $9.5^{\circ} \mathrm{C}$. The mean monthly temperature in January falls to about $1.5^{\circ} \mathrm{C}$, while in July it can reach almost $20^{\circ} \mathrm{C}$. The Sava River is formed by two mountainous streams - Sava Dolinka and Sava Bohinjka. From their confluence at Radovljica (Slovenia) to its mouth to the Danube, the Sava River is $945 \mathrm{~km}$ long, being the third longest tributary of the Danube. Together with its longer headwater, the Sava Dolinka River measures $990 \mathrm{~km}$. The Sava River represents the richest water in the Danube tributary. Having the long-term average discharge at the river mouth of about $1700 \mathrm{~m}^{3} / \mathrm{s}$, it contributes almost 25 percent to the Danube's total discharge. The basin hosts the largest complex of alluvial wetlands in the Danube Basin and large lowland forest complexes. It is unique for some of the floodplains still being intact, thus supporting biodiversity and flood alleviation. There are 167 protected areas in total, including six Ramsar sites, eight national parks, as well as numerous important bird and plant areas, protected areas at the national level, and Natura 2000 sites (Komatina and Grošelj, 2015). Fish and lamprey fauna of the River Sava catchment consists of 74 species, 5 of which are considered alien species (Simonović et al., 2015).

The historic importance of the Sava River has been focused on commercial and recreational fishing as a basic source of good quality food for local inhabitants (Piria et al., 2019). Due to damming, water quality degradation and huge hydromorphological changes from the beginning of $20^{\text {th }}$ century, the structure of dominant species changed which affected commercial fisheries (Simonović et al., 2017; Piria et al., 2019). From the $19^{\text {th }}$ century, commercial fish records were occasionally recorded in national technical journals, but the first systematic data collection only began in 2006. Recreational fishing was very well developed in the $19^{\text {th }}$ and $20^{\text {th }}$ centuries in the Sava River as was the relevant national legislation, but data collection only started in 2006 - the same year as for commercial fishers.

\subsubsection{Data collection}

Data provided by the Ministry of Agriculture were collected from 2006 to 2017 for commercial fishers and for recreational fishing from 2008-2017. All restrictions and regulations for commercial and recreational fishers are under the unique legislation previously described. Catch per unit effort (CPUE) were calculated by total annual catch $(\mathrm{kg})$ per one commercial fisher. 
TABLE 7

Number of licences issued to commercial fishers for the Sava River fishing area from 2006 to 2017

\begin{tabular}{|c|c|}
\hline Year & Number of issued licences \\
\hline 2006 & 9 \\
\hline 2007 & 8 \\
\hline 2008 & 7 \\
\hline 2009 & 6 \\
\hline 2010 & 9 \\
\hline 2011 & 7 \\
\hline 2012 & 9 \\
\hline 2013 & 9 \\
\hline 2014 & 15 \\
\hline 2015 & 16 \\
\hline 2016 & 17 \\
\hline 2017 & 17 \\
\hline
\end{tabular}

\subsubsection{Catch by commercial fishers}

The number of licences issued to commercial fishers each year by the Ministry of Agriculture was under the maximum permitted number (Table 7). The number of prescribed licenses is indicated in Chapter 4.6.

Data collected in logbooks sent by the license owners was under the total catch quota (Table 8). The data shows that for the 2015 and 2016 fishing seasons, the average total annual catch was $8530 \mathrm{~kg}$. However, in 2017 the total annual catch was $5459.50 \mathrm{~kg}$, $3070.50 \mathrm{~kg}$ lower than the average catches two years before. Also, the percentage of total permitted catch quota from 2007-2017 is between 9.38 and 27.57 percent. It is likely that fishers do not register and do not report the real annual catch.

TABLE 8

Total annual catch and percentage of total permitted catch quota of commercial fishers on the Sava River from 2007-2017

\begin{tabular}{|c|c|c|}
\hline Year & Catch/kg & \% of total permitted catch quota \\
\hline 2007 & 6113.10 & 14.28 \\
\hline 2008 & 11804.70 & 27.57 \\
\hline 2009 & 4015.90 & 9.38 \\
\hline 2010 & 8218.95 & 19.20 \\
\hline 2011 & 3832.70 & 8.95 \\
\hline 2012 & 9861.60 & 23.03 \\
\hline 2014 & 11015.50 & 25.73 \\
\hline 2015 & 8668.77 & 20.25 \\
\hline 2016 & 8392.00 & 19.60 \\
\hline 2017 & 5459.50 & 12.75 \\
\hline
\end{tabular}

Data analysis of licenses issued in 2017 show that 17 licenses were issued by the Ministry but only 11 licensees sent their completed logbooks (Table 9). Also, total catch data is not realistic. This data confirms that commercial fishers do not report real catch or do not report any catch.

TABLE 9

Number of commercial fishers and total catch by fishing zones in $\mathbf{2 0 1 7}$ for the Sava River

\begin{tabular}{|l|c|c|c|c|c|c|c|c|}
\hline ZONE & S1 & S2 & S3 & S4 & S1/S2* & S2/S3* & S3/S4* & Total \\
\hline No. license & 5 & 1 & 6 & 2 & 1 & 1 & 1 & 17 \\
\hline Total catch $(\mathrm{kg})$ & 2180.5 & 5.0 & 1579.0 & 865.0 & 266.0 & 119.0 & 445.0 & 5459.5 \\
\hline $\begin{array}{l}\text { No. completed } \\
\text { logbooks sent }\end{array}$ & 4 & 1 & 1 & 1 & 1 & 1 & 1 & 11 \\
\hline
\end{tabular}

*beneficiary possesses license for two fishing zones.

Table 10 shows the total annual catch, catch per important fish species $(\mathrm{kg})$, catch per unit effort (CPUE) and number of commercial fishers for Sava River for the period 2005-2017. Also, carp catch for the period 2005 to 2017 and catch of other species from 2010 to 2017 is presented. According to this data, it is clear that CPUE in general is decreasing. Common carp and bream are the most important species for commercial fishers in this region. Catch of both species are decreasing, e.g. catch of common carp was $199.60 \mathrm{~kg}$ which means that each fisher caught only $11 \mathrm{~kg}$ of this 


\begin{tabular}{|c|c|c|c|c|c|c|c|c|c|c|c|c|c|c|}
\hline & 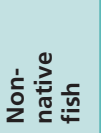 & & & & & & $\begin{array}{l}\text { ¿े } \\
\dot{m}\end{array}$ & 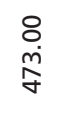 & $\begin{array}{l}\text { 吕 } \\
\text { 员 }\end{array}$ & ' & $\begin{array}{l}\stackrel{0}{0} \\
\stackrel{+}{0}\end{array}$ & 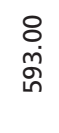 & $\begin{array}{l}\stackrel{\leftrightarrow}{0} \\
\dot{\sim} \\
\tilde{N}\end{array}$ & $\begin{array}{l}\stackrel{8}{\text { D }} \\
\stackrel{1}{=}\end{array}$ \\
\hline & 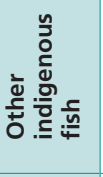 & & & & & & \begin{tabular}{l}
$\stackrel{8}{+}$ \\
$\stackrel{+}{N}$ \\
\multirow{N}{*}{}
\end{tabular} & 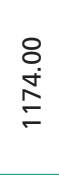 & $\begin{array}{l}\stackrel{\circ}{0} \\
\dot{0} \\
\stackrel{\infty}{+}\end{array}$ & ' & 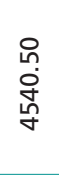 & $\begin{array}{l}\stackrel{\circ}{0} \\
\dot{n} \\
\stackrel{m}{m}\end{array}$ & 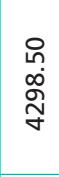 & $\begin{array}{l}\stackrel{8}{\dot{0}} \\
\dot{0} \\
i\end{array}$ \\
\hline 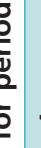 & $\frac{\circ}{4}$ & & & & & & $\begin{array}{l}\stackrel{8}{0} \\
\stackrel{8}{\circ}\end{array}$ & $\frac{\stackrel{0}{h}}{\dot{q}}$ & $\begin{array}{l}8 \\
\dot{f}\end{array}$ & ' & 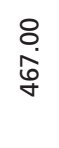 & 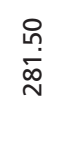 & 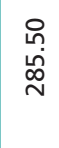 & $\begin{array}{l}\stackrel{\leftrightarrow}{\sim} \\
\stackrel{\sim}{0}\end{array}$ \\
\hline 5 & $\stackrel{\Xi}{\underline{0}}$ & & & & & & 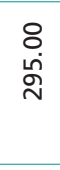 & $\begin{array}{l}\stackrel{\circ}{\infty} \\
\stackrel{\infty}{\sim}\end{array}$ & 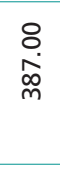 & ' & $\begin{array}{l}\stackrel{\circ}{0} \\
\text { p. }\end{array}$ & $\begin{array}{l}\text { 员 } \\
\text { 吕 }\end{array}$ & \begin{tabular}{l} 
ก̊. \\
\multirow{n}{n}{}
\end{tabular} & $\begin{array}{l}\stackrel{8}{+} \\
\text { 㟧 }\end{array}$ \\
\hline $\begin{array}{l}0 \\
\underline{y} \\
\underline{y} \\
z\end{array}$ & 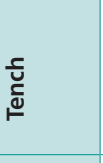 & & & & & & $\stackrel{8}{0}$ & : & $\stackrel{8}{0}$ & ' & $\stackrel{8}{i}$ & : & $\stackrel{8}{\circ}$ & : \\
\hline & 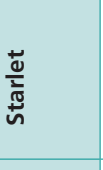 & & & & & & $\stackrel{8}{0}$ & $\begin{array}{l}\stackrel{8}{+} \\
+\end{array}$ & $\stackrel{8}{-}$ & ' & 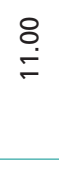 & $\begin{array}{l}0 \\
\text { م. } \\
\infty \\
0\end{array}$ & $\begin{array}{l}\stackrel{0}{0} \\
\stackrel{0}{ }\end{array}$ & $\stackrel{\leftrightarrow}{\stackrel{+}{*}}$ \\
\hline & 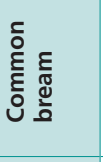 & & & & & & $\begin{array}{l}\stackrel{+}{+} \\
\stackrel{y}{y}\end{array}$ & $\underset{\infty}{\stackrel{8}{+}}$ & 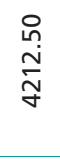 & ' & $\begin{array}{l}0 \\
\hat{n} \\
\stackrel{\circ}{\circ} \\
\stackrel{N}{N}\end{array}$ & $\begin{array}{l}0 \\
\stackrel{n}{ } \\
\infty \\
\stackrel{m}{N}\end{array}$ & 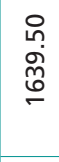 & $\begin{array}{l}\stackrel{\circ}{0} \\
\stackrel{M}{n} \\
=\end{array}$ \\
\hline & 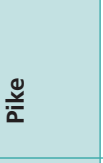 & & & & & & 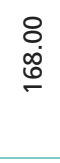 & 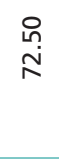 & 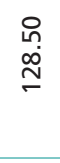 & ' & 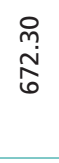 & 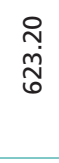 & $\begin{array}{l}\stackrel{8}{\dot{⿰}} \\
\dot{d}\end{array}$ & $\begin{array}{l}8 \\
\dot{+} \\
\grave{m}\end{array}$ \\
\hline 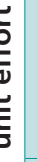 & 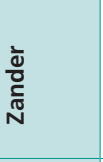 & & & & & & $\begin{array}{l}: \\
\stackrel{0}{0} \\
\text { N. }\end{array}$ & $\begin{array}{l}\stackrel{P}{0} \\
\stackrel{\dot{\alpha}}{N}\end{array}$ & $\begin{array}{l}\stackrel{0}{0} \\
\text { } \\
\circ\end{array}$ & ' & 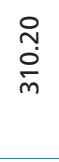 & 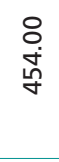 & $\begin{array}{l}8 \\
\text { d } \\
\text { N }\end{array}$ & $\begin{array}{l}\stackrel{\circ}{\circ} \\
\stackrel{\circ}{\rightleftharpoons}\end{array}$ \\
\hline & 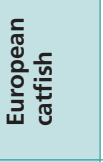 & & & & & & $\begin{array}{l}\stackrel{P}{0} \\
\text { ơ }\end{array}$ & $\begin{array}{l}\stackrel{8}{0} \\
\infty \\
\infty \\
m\end{array}$ & \begin{tabular}{l}
0 \\
$\stackrel{0}{0}$ \\
\multirow{0}{0}{}
\end{tabular} & ' & $\begin{array}{l}\text { ஃ } \\
\text { ه্ं }\end{array}$ & $\begin{array}{l}\stackrel{\bigcirc}{\dot{J}} \\
\text { }\end{array}$ & 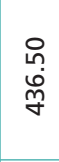 & 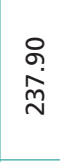 \\
\hline n & 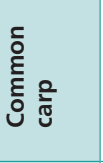 & \begin{tabular}{l}
$\tilde{m}$ \\
\multirow{g}{*}{}
\end{tabular} & $\begin{array}{l}\bar{o} \\
\text { ஸ̉ }\end{array}$ & 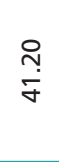 & $\begin{array}{l}\text { o } \\
\text { gे }\end{array}$ & 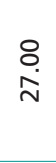 & 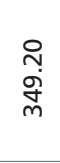 & 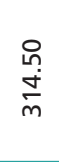 & $\begin{array}{l}\text { ৪ } \\
\infty \\
\circ\end{array}$ & ' & 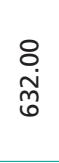 & $\begin{array}{l}\stackrel{0}{h} \\
\stackrel{n}{N} \\
\stackrel{n}{n}\end{array}$ & $\begin{array}{l}\stackrel{8}{ن} \\
\stackrel{v}{\sigma}\end{array}$ & $\begin{array}{l}\circ \\
\stackrel{\circ}{\circ} \\
\stackrel{1}{\circ}\end{array}$ \\
\hline & پ્ّ & $\underset{\substack{m \\
m}}{m}$ & \begin{tabular}{l}
\multirow{J}{0}{} \\
$\stackrel{0}{0}$ \\
0
\end{tabular} & $\begin{array}{l}\frac{\sigma}{d} \\
\stackrel{d}{f}\end{array}$ & 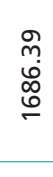 & $\begin{array}{l}\tilde{N} \\
\text { Oे } \\
\text {. }\end{array}$ & $\begin{array}{l}\infty \\
\infty \\
\stackrel{0}{0} \\
\stackrel{\alpha}{0}\end{array}$ & $\begin{array}{l}\stackrel{n}{n} \\
\stackrel{\leftrightarrow}{N}\end{array}$ & $\begin{array}{l}\bar{o} \\
\dot{\phi} \\
\stackrel{\sigma}{\sigma}\end{array}$ & ' & $\begin{array}{l}\hat{m} \\
\hat{j} \\
\end{array}$ & $\begin{array}{l}\stackrel{\infty}{\infty} \\
\stackrel{+}{+} \\
\stackrel{n}{n}\end{array}$ & $\begin{array}{l}\hat{b} \\
\dot{j} \\
\dot{g}\end{array}$ & $\stackrel{\stackrel{n}{\dot{\Gamma}}}{\stackrel{\tilde{m}}{m}}$ \\
\hline 2 & 密 & $\begin{array}{l}q \\
\dot{0} \\
\stackrel{0}{0} \\
\infty \\
i n\end{array}$ & 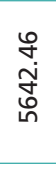 & $\frac{\stackrel{n}{r}}{\frac{m}{\sigma}}$ & $\begin{array}{l}\text { 苞 } \\
\stackrel{\infty}{=}\end{array}$ & $\begin{array}{l}\frac{8}{2} \\
\stackrel{n}{\sigma} \\
\dot{q}\end{array}$ & $\begin{array}{l}\stackrel{\omega}{\alpha} \\
\infty \\
\infty \\
\infty\end{array}$ & 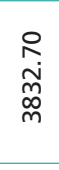 & $\begin{array}{l}\circ \\
\stackrel{0}{\dot{f}} \\
\dot{f}\end{array}$ & ' & 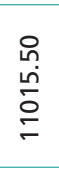 & $\begin{array}{l}\text { N } \\
\infty \\
0 \\
0 \\
\infty\end{array}$ & $\begin{array}{l}8 \\
\text { i } \\
\tilde{N} \\
\infty\end{array}$ & 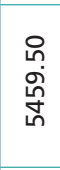 \\
\hline $\bar{\Xi}$ & 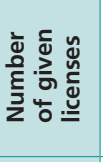 & $\infty$ & $a$ & $\infty$ & $r$ & 6 & $a$ & $r$ & $\sigma$ & $\sigma$ & $\stackrel{n}{\sim}$ & 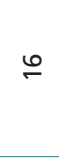 & $\approx$ & $\approx$ \\
\hline & 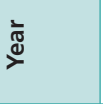 & 占 & ๕ั & ڤેे & $\stackrel{\text { ¿ }}{\circ}$ & ठ্ণ & $\stackrel{\circ}{\circ}$ & $\bar{i}$ & $\tilde{\sim}$ & $\stackrel{m}{i}$ & $\stackrel{+}{\stackrel{+}{2}}$ & $\stackrel{\operatorname{Ln}}{\stackrel{n}{n}}$ & $\stackrel{0}{i}$ & $\hat{i}$ \\
\hline
\end{tabular}


species (5 specimens). Tench, species characteristic for backwaters, was not recorded in commercial fishers' catch. Increased catch of starlet was recorded. However, anglers from Slovenia in 2015 accidentally released alien Siberian sturgeon (Piria et al., 2018), and this could be a possible reason why this catch increased. Commercial fishers can barely distinguish between these two sturgeon species.

\subsubsection{Catch by recreational fishers}

In 2017, at the Sava River fishing area, 51 owners of fishing rights were recorded. Data about the number of anglers and logbooks was returned by only 44 owners. In total, 11590 anglers with a total catch of $206252.85 \mathrm{~kg}$ was recorded in the Ministry of Agriculture and Croatian angling association for 2017. The number of recorded anglers in the same fishing area from 2008 to 2017 decreased by more than 2000 anglers (Figure 12).

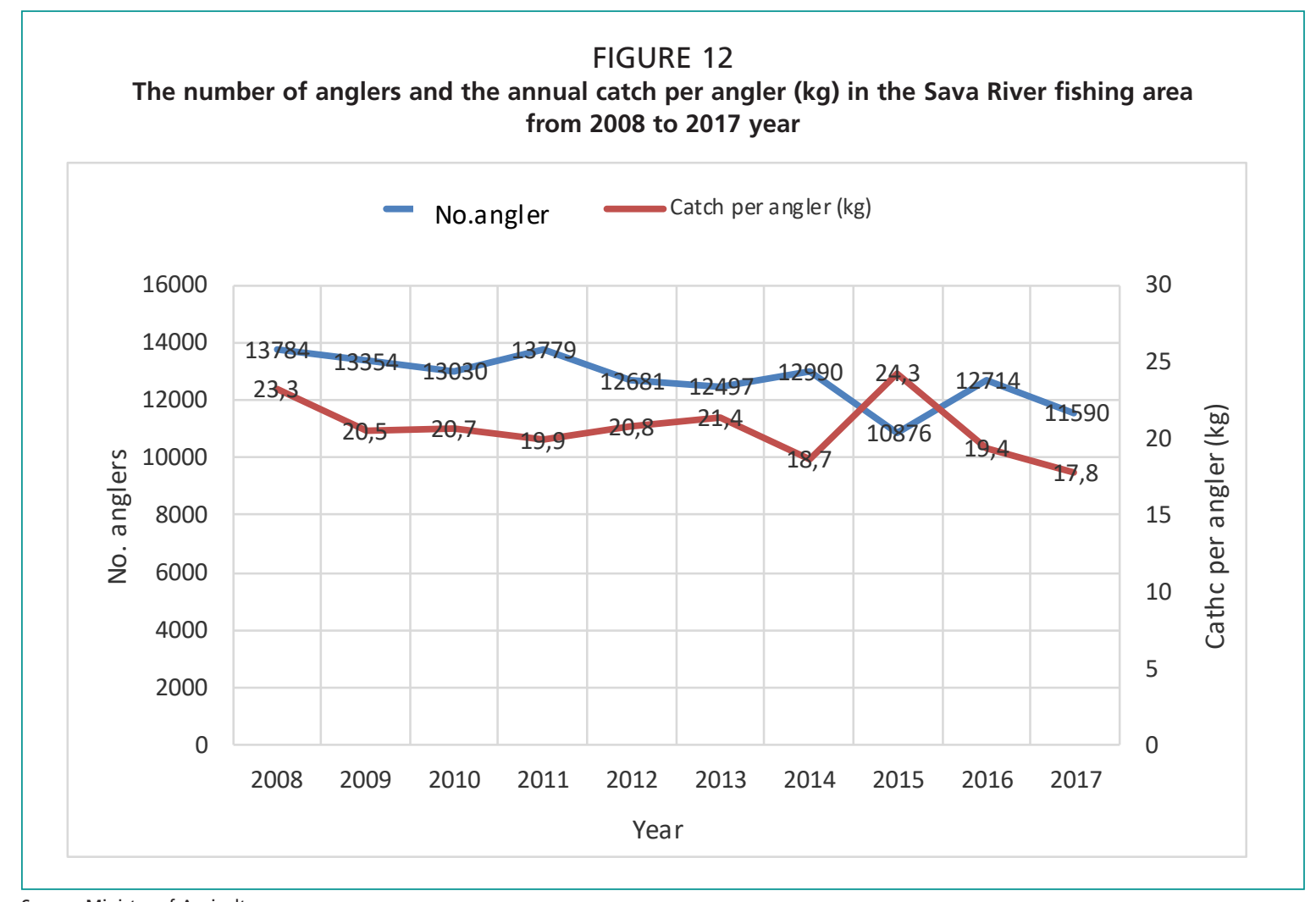

Source: Ministry of Agriculture.

The catch for recreational fishers from 2008-2017 indicates common carp and gibel carp as the main caught species (Figure 13).

\subsubsection{The co-existence of recreational and commercial fisheries}

Data collected about Croatian inland fisheries are not very reliable but some important trends can be noted. For example, anglers in the Sava River deliberately catch a higher percentage of common carp, northern pike, and non-native species (grass carp and gibel carp), than commercial fishers (Figure 14). Commercial fishers mostly catch common bream (Treer and Kubatov, 2017).

Treer and Kubatov (2017) concluded that fishing with nets, artisanal fishers differ from anglers in two major ways: they are less selective and they catch bigger specimens. According to official data, the existing ratio between recreational and artisanal fishers in the Sava river sections does not negatively affect each other's or overall fishing. 


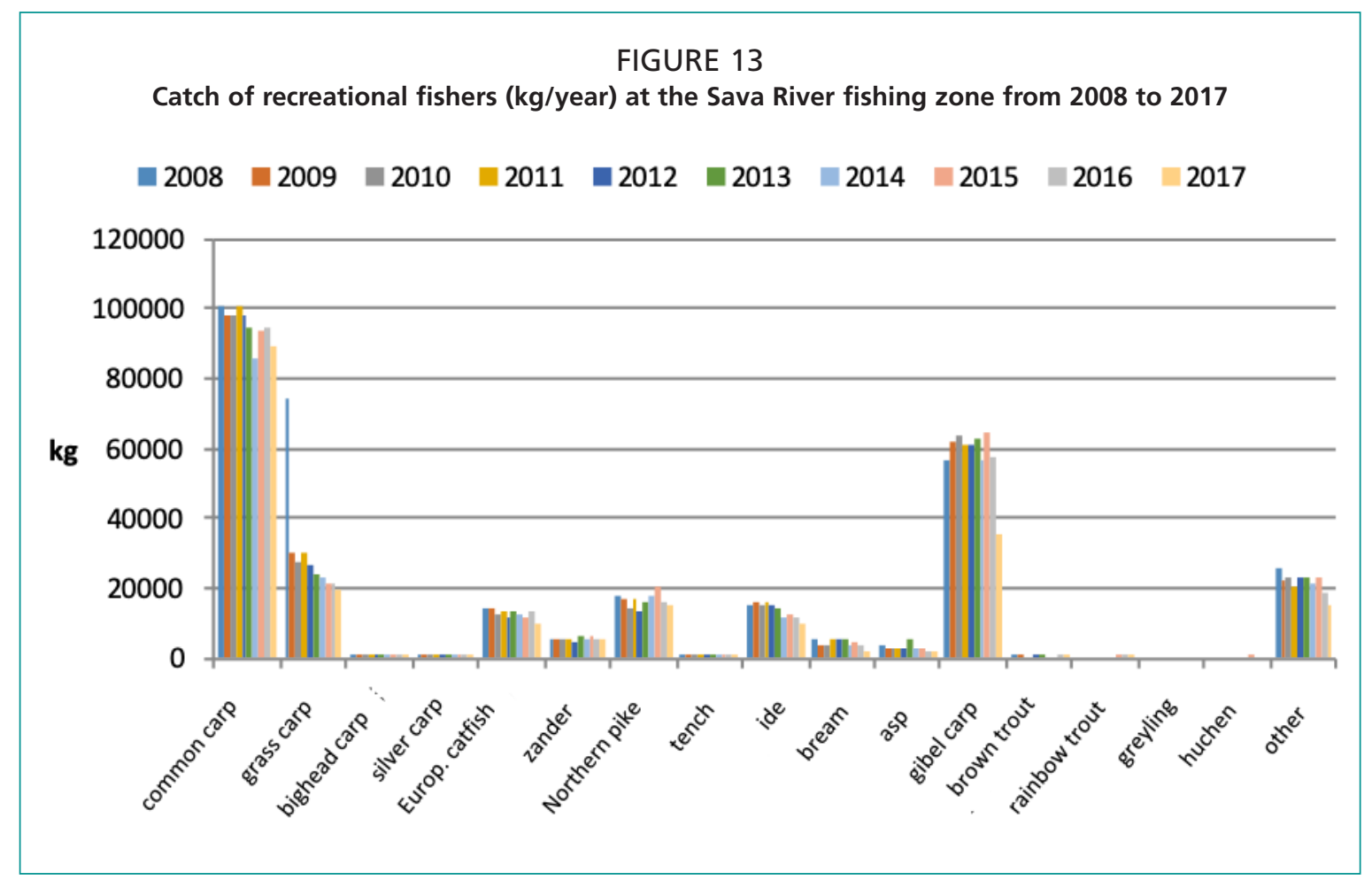

Source: Ministry of Agriculture.

FIGURE 14

Average annual share of species in total catch $(\% \mathrm{~kg})$ by recreational and commercial (artisanal) fishers in the Sava River (analysed data from 2004-2011)

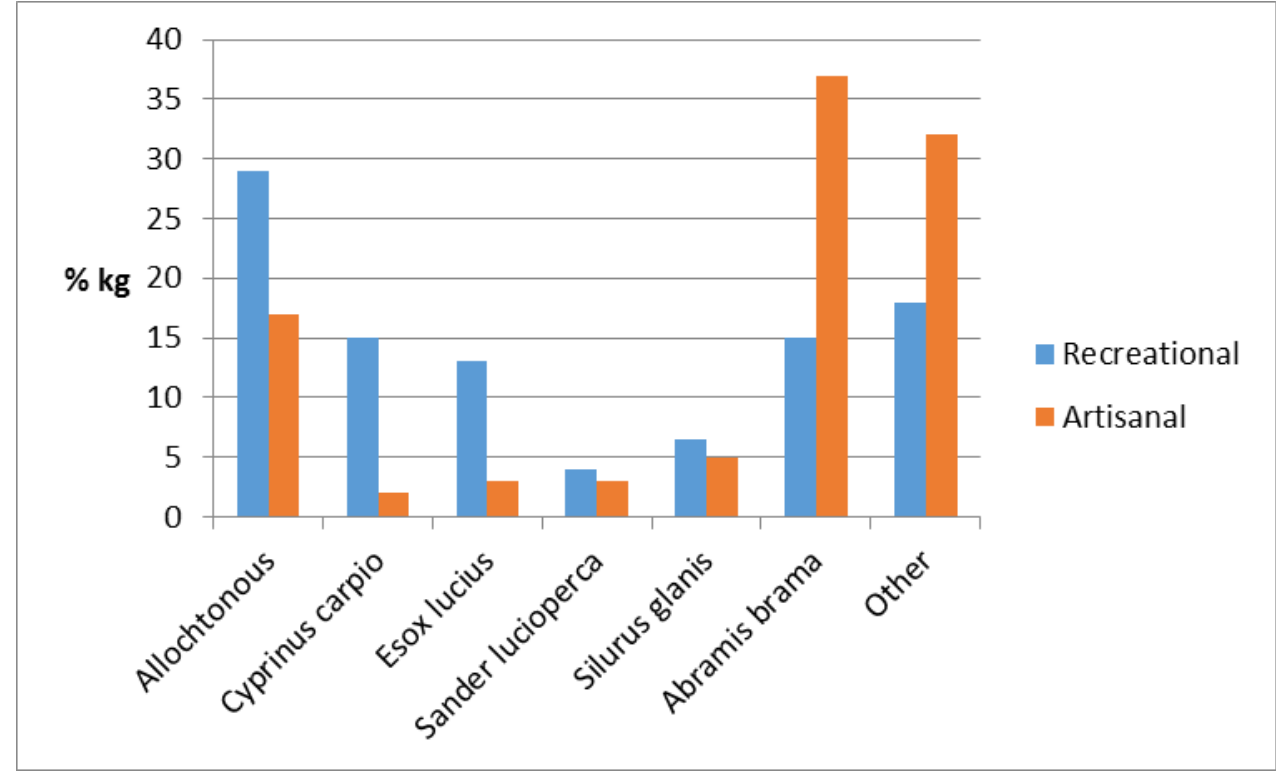

Source: Treer and Kubatov, 2017.

\subsection{CASE STUDY: SOCIO-ECONOMIC VALUATION OF RECREATIONAL AND}

\section{COMMERCIAL FISHERS}

A comprehensive pilot study was done on socio-economic valuation of recreational and commercial fisheries under the multilateral project funded by the Croatian Ministry of Agriculture, Forestry and Water Management and Norwegian partner Akvaplan-Niva (Mrakovčić et al., 2006) but only the results on recreational fisheries were published 
(Matulić et al., 2010). Since then, no similar study has been carried out. The survey results presented in this chapter focuses on anglers residing along the bordering rivers the Sava and Danube River - and commercial fishers in the same region (Chapter 4.3.2). The data shown was taken from an unpublished study by Mrakovčić et al. (2006) and published paper by Matulić et al. (2010).

\subsubsection{Recreational fisheries}

The survey was conducted in 2005 on 383 recreational anglers with recreational fishing licenses, using a questionnaire consisting of 48 questions. The results of the analysis of the questionnaire on recreational fisheries in the Croatian areas of the Sava and Danube rivers show that majority of anglers were males (94 percent) and were over 40 years of age. The majority of recreational anglers were elderly and possess secondary school qualifications (more than 70 percent). Most anglers ( 97 percent) had passed the fishing examination required for angling, and only 3 percent had not. The anglers with a lower educational level (no primary education) were not familiar with the current legislation (Matulić et al., 2010).

Anglers have different motivations for going fishing. Evaluation of the significance of specific factors to fish (such as hobbies), revealed that fishers indicated that it is very important for them for relaxation and recreation (63 percent), socializing with friends (58 percent) and socializing with family (45 percent). Other very important motives for fishing included adventure, excitement, sport and competition. To catch a personal trophy or hone their fishing skills were only somewhat important or not important at all. However, more than 50 percent stated that it is important for them to catch fish for food (Mrakovčić et al., 2005).

Dependence on fishing location and structure of catch for recreational fishers were also analysed. Results show that most of the surveyed anglers fish only in rivers for catching pike-perch and catfish. Many anglers used a combination of fishing on rivers and lakes or a combination on rivers and commercial fishponds or combine fishing on all three types of water bodies. Hence, those who opt for angling on rivers and commercial fishponds usually catch northern pike, common carp and grass carp. Anglers with a fishing preference on rivers and lakes usually catch other various nontypical fish species. The anglers who fish on commercial ponds or lakes usually catch Prussian carp (Figure 15). Trout does not inhabit the investigated area of the Danube and Sava rivers therefore anglers probably travel to commercial lakes where it is possible to fish this species (Matulić et al., 2010).

During one calendar year, 32 percent of fishers surveyed spent 60-180 days fishing. 27 percent spent 30-60 days fishing, and 22 percent spent 10-30 days fishing. Only one percent of anglers spent more than 300 days fishing annually. The average angler spends 87 days fishing (Mrakovčić et al., 2005). Anglers, who fish at a distance of up to $3 \mathrm{~km}$, spend up to four hours fishing. Those who are 3-10 km away, spend from four up to 24 hours fishing. Those who are $10-50 \mathrm{~km}$ away, spend from eight hours to three days fishing. Fishing at longer distances $(>50 \mathrm{~km})$, spend from one to seven or more days (Matulić et al., 2010).

In one fishing day during a calendar year, 38 percent of anglers catch 1-2 $\mathrm{kg}$ of fish per day, 30 percent catch $2-5 \mathrm{~kg}$ of fish, and 11 percent catch over $5 \mathrm{~kg}$ of fish. Satisfaction analysis of the fishing results showed that the majority of anglers were satisfied with their fishing results.

Analysis of factors which influence catch, showed that anglers believe that identical weight should be given to the choice of bait, choice of fishing spot, fishing season, weather conditions, part of the day when they are caught as well as angling skills. Fishers' luck, fishing gear and fishing techniques were also important to them (Mrakovčić et al., 2005). 
FIGURE 15

Anglers dependency on fishing location and the catch content (RivLakes=Rivers and lakes, RivComp=Rivers and commercial ponds, RLC=River, lakes, commercial ponds, LakComp=Lakes and commercial ponds, Componds= commercial ponds, Rivers=Rivers, Lakes=lakes, PrusCarp=Prussian carp, Trouts=trout, Pikeperc=Pike perch, Catfish=catfish, CommCarp=Common carp, Pike=Pike, Largmbas=Largemouth bass, GrasCarp=Grass carp, Other=Other)

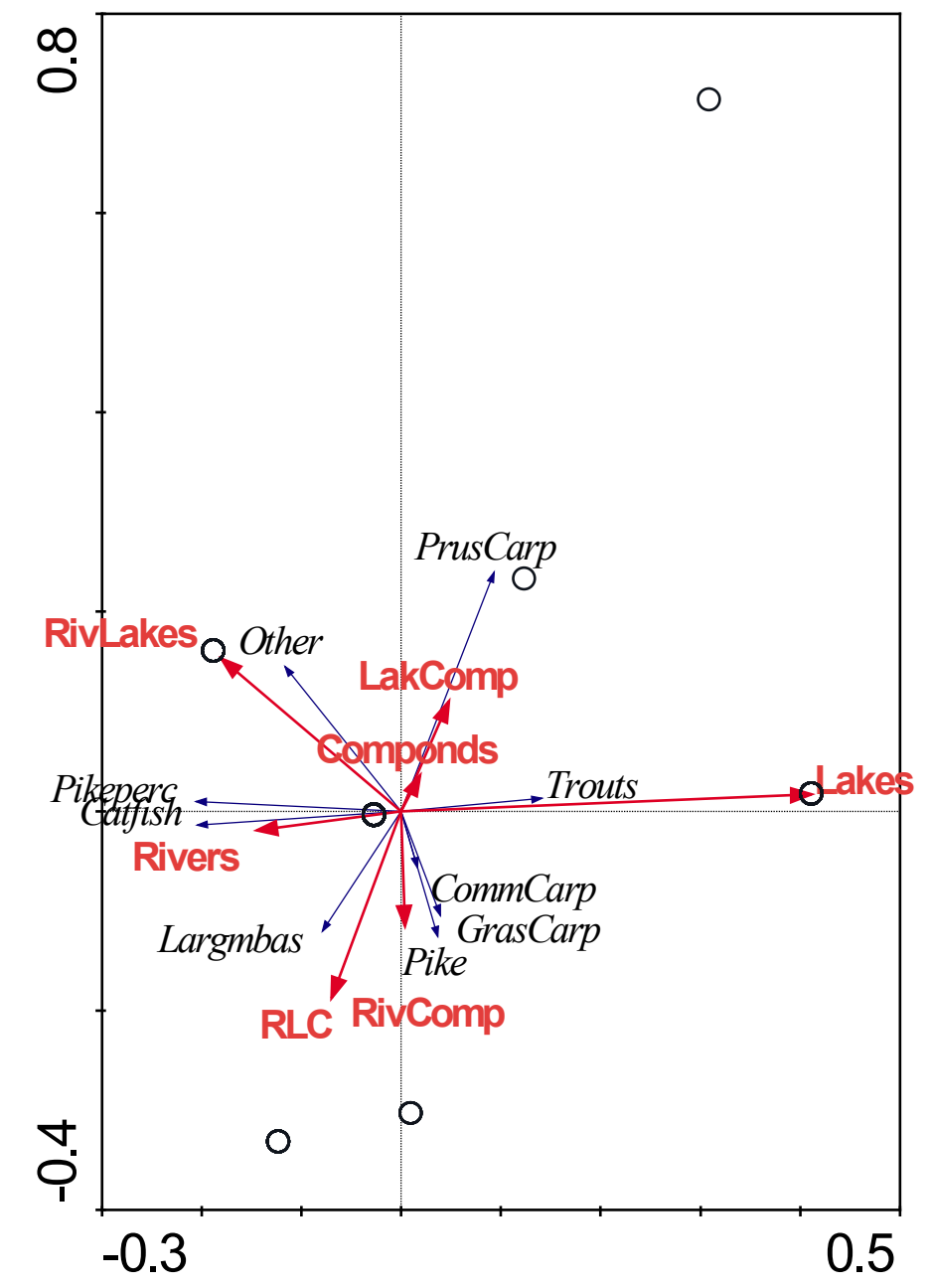

Source: Matulić et al., 2010.

\subsubsection{Commercial fishers}

The survey included 22 commercial fishers holding fishing licenses for the border waters of the Sava and Danube rivers. The questionnaire for the commercial fishers contained a total of 41 questions. The commercial fishers are 100 percent male, aged between 30 and 60. Their education levels are: 36 percent have finished high school, 27 percent have finished elementary school, and 18 percent have not completed elementary school.

In order to carry out their activity, commercial fishers must pass an examination. The majority of the fishers (91 percent) indicate fishing as their only source of income. Results of the survey show a high level of individuality in the operation of commercial fishing. Most of the fishers usually fish alone (82 percent), 27 percent of them fish with the help of someone from their family, and only 2 (9 percent) fish with a friend or another person. Payment made to persons helping with fishing activities can be by money ( 9 percent), part of the catch, and part money ( 9 percent), or by compensation, daily rates, payment for fish transportation (32 percent), and 
the remaining according to other agreements. Also, 77 percent of the fishers own one fishing vessel, 14 percent own two vessels, and 9 percent own more than two. The vessels are mainly $6 \mathrm{~m}$ long (95 percent) and are mostly constructed from wood (86 percent). None of the surveyed fishers possess an inner engine but use an outboard engine. 82 percent of the fishers use a motor power of $5 \mathrm{HP}, 14$ percent of 5 to $10 \mathrm{HP}, 32$ percent use 10 to $20 \mathrm{HP}$, and 9 percent use 20 to $40 \mathrm{HP}$. Most of the fishers (16) own only one engine; four have two engines of different powers, and two have three engines. The engine uses mainly a fuel mixture ( 86 percent), and 23 percent use gasoline. Those that have two or more motors use gasoline and a fuel mixture depending on the characteristics of each individual motor. The consumption of fuel also depends on the power of the motor engine, the fishing gear and frequency of fishing. On average, 64 percent of those surveyed use less than 101 of fuel per fishing trip, and the average monthly consumption ranges between 10 and $100 \mathrm{l}$. Annually, 23 percent of the fishers use less than 1001 of fuel, and 18 percent use over 8001 .

45 percent of commercial fishers fish within the distance of $5 \mathrm{~km}$ from the place of embarking. During one fishing day, most fishing activity lasts more than 4 hours (depending on fishing gear in use). Most fishers spent from 150 to 180 days fishing during one calendar year. The fishing gears used are fully owned by commercial fishers. The structure of the fishing gear owned by the fishers is shown in Table 11.

TABLE 11

Structure of authorized fishing gear registered by the owners in Rivers Sava and Danube, Croatia (Mrakovčić et al., 2005)

\begin{tabular}{|l|c|c|c|}
\hline Fishing gear registered by owners & Owned (\%) & Not owned (\%) & No response to question (\%) \\
\hline Surface gill and trammel nets & 91 & 5 & 4 \\
\hline Bottom gill and trammel nets & 91 & 5 & 4 \\
\hline Seine nets & 91 & 5 & 9 \\
\hline Cast net & 59 & 32 & 9 \\
\hline Net with hard rim & 68 & 23 & 4 \\
\hline Hoop net & 73 & 27 & 9 \\
\hline Trap net & 64 & 45 & 14 \\
\hline Buckalo* & 41 & 23 & 9 \\
\hline
\end{tabular}

"Buckalo: catfish attracting device with which one splashes on the water surface and using a fishing rod or fishing line with 1 hook on it.

The opinion of commercial fishers about legal regulations on commercial fishing is illustrated in Table 12. Each statement from the questionnaire had an equal number of positive and negative responses. Commercial fishers are not satisfied with the amount of allowable fishing gear, fish catch quota and think that annual payments are too high. Also, they complain that fishing logbooks are too complicated.

Commercial fishers receive from 75-100 percent of their total income from fishing, which amounts to an annual net ranging between 10000 and 50000 kuna (EUR 1333 -6 666). The total personal income from fishing is close to the total average income of fishing households (Figure 16).

The sale of fish is an important factor for commercial fishing. The majority of fishers sell fish on the market through their own market network (55 percent), and through existing fish markets (23 percent). In the distribution and sale of fish, the commercial fishers have a significant part (50 percent) in other/alternative selling chains. Seven of the fishers sell on the market, two to restaurants, one processes the fish while one catches fish for his own trading business. 
TABLE 12

How much do you agree with the mentioned statements (\%) (Mrakovčić et al., 2005)

\begin{tabular}{|c|c|c|c|c|}
\hline Statement & $\begin{array}{l}\text { Agree } \\
\text { completely }\end{array}$ & $\begin{array}{l}\text { Mainly } \\
\text { agree }\end{array}$ & $\begin{array}{l}\text { Mainly do } \\
\text { not agree }\end{array}$ & $\begin{array}{l}\text { Do not } \\
\text { agree at all }\end{array}$ \\
\hline Fishing examination is very important & 59 & 23 & 9 & 9 \\
\hline Price of the fishing examination is too high & 23 & 27 & 14 & 36 \\
\hline $\begin{array}{l}\text { The number of possible licenses for } \\
\text { commercial fishers is too high }\end{array}$ & 18 & 32 & 14 & 36 \\
\hline $\begin{array}{l}\text { The amount and fish species which is } \\
\text { permitted annually in commercial fishing is } \\
\text { too small }\end{array}$ & 55 & 23 & 18 & 5 \\
\hline $\begin{array}{l}\text { The amount of annual payment for } \\
\text { commercial fishing is too high }\end{array}$ & 14 & 23 & 23 & 41 \\
\hline $\begin{array}{l}\text { The border areas for commercial fishing are } \\
\text { too narrow }\end{array}$ & 41 & 18 & 18 & 23 \\
\hline $\begin{array}{l}\text { The type of fishing gear which is permitted } \\
\text { for one license is satisfactory }\end{array}$ & 41 & 23 & 18 & 18 \\
\hline $\begin{array}{l}\text { The amount of fishing gear which is } \\
\text { allowed to be registered for each fishing } \\
\text { license is too little }\end{array}$ & 27 & 36 & 5 & 32 \\
\hline $\begin{array}{l}\text { The purpose, type and amount of fishing } \\
\text { gear which is allowed to be registered for } \\
\text { one fishing license is not satisfactory }\end{array}$ & 27 & 45 & 0 & 27 \\
\hline $\begin{array}{l}\text { The type, content and conducting of } \\
\text { catching list in commercial fishing is } \\
\text { complicated }\end{array}$ & 55 & 14 & 5 & 27 \\
\hline
\end{tabular}

FIGURE 16

Part of the profit from fishing in total personal income and in household income

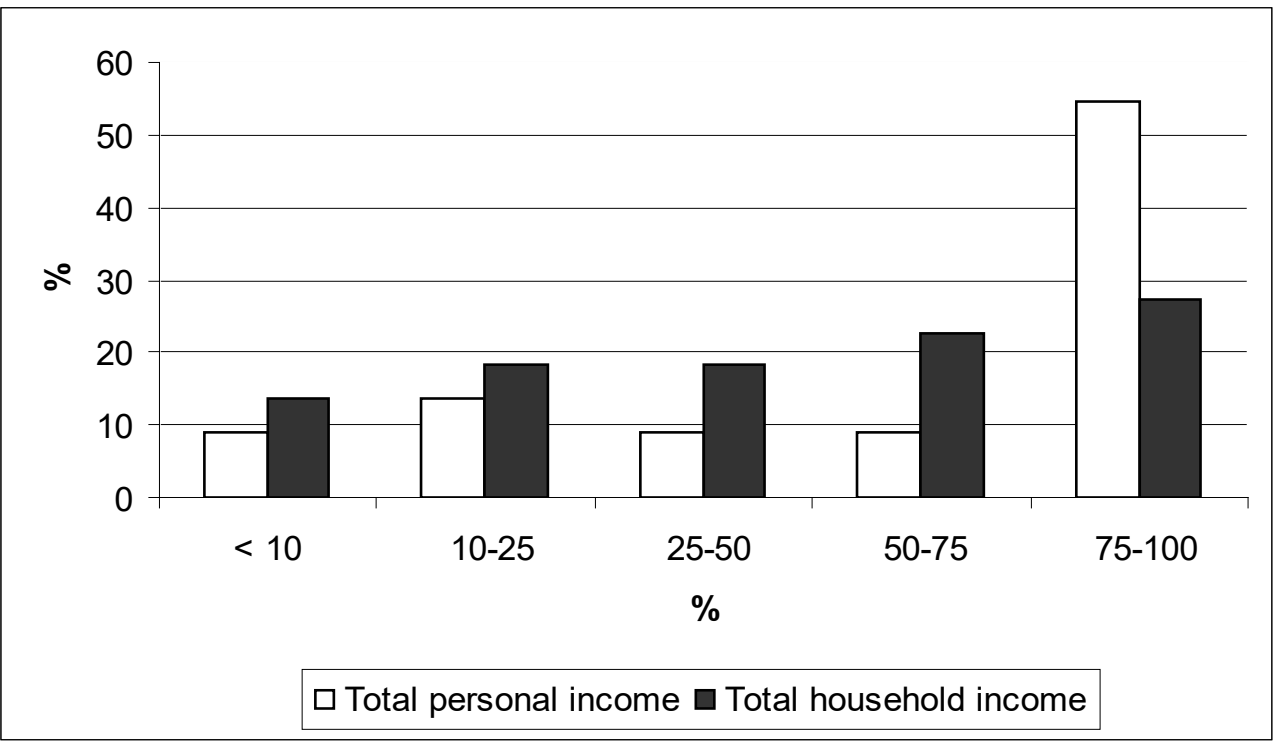

Source: Mrakovčić et al., 2005

\subsubsection{Integrated socio-economic status}

Freshwater fishing is represented by two major groups: recreational (sports) fishing and commercial fishing. Recreational fishing is much more widespread and is organized into fishing associations. Commercial fishers are organized through the Chamber of Commerce, but there are only a few fishers who are willing to represent their interests in public. Conflicts between these two groups exists. Even despite efforts by several 
workshops organized by the Ministry of Agriculture and scientific institutions to resolve this problem, all actions failed. Recreational fishing associations complain that commercial fishers with their fishing activities (sometimes illegal) devastate ichthyofaunal diversity and that they fish outside legal fishing zones. Commercial fishers claim the same for anglers. Indeed, the use of non-allowed and illegal fishing gears are widespread in both groups, but control of fishing activities is weak. However, currently, with increasing inspection control of commercial fishers, illegal gears and illegal activities are in better control. Nonetheless, illegal activities (poaching) still occur but mostly by the local inhabitants who do not have fishing licences.

Contrary to commercial fisheries, effective control of poaching in sport fishing still is not resolved. By law, each sport fishing association (owner of the fishing right) should organize volunteers to control fishing activities on fishing waters inside the fishing zone under their concession. If volunteers discover illegal activities, they do not possess any official power to suppress poaching, only to report it to the fisheries inspection, police and jurisdiction system; this system will be improved with the new Act. Illegal fishing activities include: 1) the improper and illegal use of fishing gears; 2) illegal quantity of fish caught; 3 ) fishing during protected periods such as spawning time; 4) keeping undersized fish caught; and 5) illegal selling of fish catch by anglers (allowed only for commercial fishers).

Results from the questionnaires can be summarized as follows: commercial and recreational fishing stakeholders have differing insights as to their economic considerations. Commercial fishers live from fishing activities and their income depends on fish catch. However, annual income from their fishing activity is very low, thus they have to secure other sources of income. Contrary to that, anglers mostly catch for pleasure, socialization and spend a considerable sum of money for their angling activity. Common to both groups, is that fishing activity is dominated by males, and they are not very familiar with relevant legislation. Also, both groups lack awareness that inland waters and resources represent natural wealth and biodiversity for all.

\subsection{LEGAL BACKGROUND}

In Croatia, according to the Water Act, waters are a common good and have special protection by the Republic of Croatia. The usage of surface waters and groundwater bodies cannot be the subject to property rights and any other rights. However, private possession is respected in that water bodies that exist on private property cannot be the subject of public tenders to grant fishing rights to persons or legal persons by the state (by the Ministry). "Private" waters are thus excluded from the Freshwater Fisheries Act.

Commercial and recreational freshwater fisheries are regulated according to the Freshwater Fisheries Act and special sub-acts regarding commercial freshwater fisheries. There are also sub-laws which deal with legal fish sizes, closed seasons and estimation of damages on fish stocks (poaching and fish mortalities). Regulations for commercial fisheries also including commercial fisher exams, fishing permits, fishing tools and gear, allowable annual catch quotas, catch data delivery and fisher logbooks.

Anglers' rights and responsibilities, according to the Freshwater Fisheries Act, are regulated in detail by the Freshwater Sports Fishing Ordinance. The Freshwater Sports Fishing Ordinance includes regulations for technical features, the number of fishing tools allowed, fishing gear, content of scientific studies and methodologies, all kinds of registers, the fishing exam programme, fishery managers' expertise exam programme, water bailiff exam programme, water bailiff instructions, the layout and content of fishing licenses and fishing restrictions.

Fish conservation measures are regulated through the Fish Conservation Ordinance. The recreational (sport) fishing management plan should be written according to 
Natural Protection Act, the ordinance of strictly protected species, and regulation on the ecological network.

\subsubsection{Fishing rights}

According to the Freshwater Fisheries Act, the Ministry of Agriculture grants fishing rights for free to legal persons, through public tenders, for all the fishing waters inside a fishing zone. The fishing right is free, and the owner does not have to pay to the state in advance (like in a classical concession) but the owner is obliged to pay 10 percent of every license fee to the state and 10 percent of the license fees to the HŠRS. The best bidder receives a 20 -year contract, but the bidding value isn't monetary, but is based on the quality of the management plan. Fishing zones are created according to the administrative territorial borders of counties, towns and municipalities, but applications for certain fishing waters as a particular fishing zone inside the borders of a larger fishing zone can also be made. After receiving the administrative decision act, the owner of the fishing rights signs a fishing right contract with the Minister of Agriculture for a period of 20 years. In this case, the Minister is the person who is authorized to sign the contract in the name of the state. This contract contains the terms of conducting fishing rights, obligations of the owner to organize recreational (sports) fisheries in the fishing zone, restocking, organizing water bailiff services, etc. There are currently 130 owners of fishing rights in Croatia although there are ca. 450 active sports fishing associations and most of them are associated with the 130 aforementioned owners. The majority are sports angling associations, from small sports clubs to large sports fishing associations with several thousand members in a particular county (e.g. Osječko-baranjska county, Brodsko-posavska county etc.). There are only a few small companies and small private fish farms that own fishing rights. All of the sports fishing associations are non-profit associations and they are subject to several laws (Sports Act, Associations Act, etc.). Furthermore, there are several nature-protected areas that have fishing rights in their area (Risnjak National Park, Kopački Rit Nature Park and Vransko Jezero Nature park). Fishing waters inside the Lonjsko polje Nature Park are managed by the sports fishing association Sisak.

Regarding fishing rights, there are some problems identified, for example fishing rights on public owned water bodies which are used for exploitation of mineral resources (gravel, clay), or which share a border with private land. Some mineral resources exploitation companies tend to exploit the ground and/or waters for a long period of time, often not making soft slopes and approaches to the water bodies. Exploitation companies do not want anglers to witness their actions. But wherever there is a water body, there are fish, and wherever there are fish and no further restrictions, the state needs to organize recreational fisheries for the public. If a company obtains a concession for exploitation of mineral resources, that does not include the use of water, fish or forest. There have been many legal actions regarding granting fishing rights to one subject and rejecting another, etc. There is no major interest by companies and entrepreneurs in having fishing rights, because of many obligations required (organization of recreational fisheries, distribution and selling of fishing licenses, organization of water bailiff services, purchasing and restocking of fish, submitting logbooks), without any financial compensation. Freshwater recreational fishing in Croatia is still not recognized as beneficial and profitable and it's mainly for real enthusiasts and nature lovers. During the last decade, as the catch and release concept increased, there are few fishing rights owners who established necessary conditions to implement this new concept. There is a rapid increase in targeted fishing tourism in such water bodies (Lake Borovik near the Town Dakovo, Lake Šumbar near the Town Karlovac), due to excellent angling conditions and large, healthy fish. This kind of fishing tourism is an excellent promoter for the rural areas and brings fresh financial funds to local communities. 
Anglers buy licenses valid for a particular fishing zone from the owners of the fishing rights. These licenses can be valid for a larger area (fishing zones of other nearby owners) if the owners sign reciprocity contracts. Fishing licenses are owned by the state and issued by the Ministry of Agriculture through owners of the fishing rights, with validation periods of one day (daily license) or one year (yearly license).

Yearly license buyers must have a fishing exam certificate, and foreign citizens too must possess this certificate issued in their home country. If they don't have said certificate, foreign anglers have to pass the exam in Croatia. Daily licenses are sold without the need for a fishing exam certificate. In order to buy fishing licenses, and for all additional information, anglers should contact fishing rights owners directly. The complete list of fishing right owners, their fishing zones, and their contact information can be found on the Croatian Sports Fishing Association website: www.ribolovni-savez.hr.

The main aspect of fishing associations/owners of fishing rights is to organize sport fishing (angling) and all associated activities. First, the owner of the fishing right must have an expert to conduct all the activities (there is an expert exam to pass). One year after signing the contract with the Ministry, the owner must have detailed management plan in place. After approval of the plan by the Ministry, the owner is obliged submit an annual management plan. A management plan is a technical report prepared by one of the scientific institutions registered for research in freshwater fisheries and freshwater ecology. After approval of the management plan, it must be revised every six years and submitted to the Ministry for approval. Furthermore, owners have to organize a water bailiff service (people with water bailiff exam), purchase exact species and quantities of fish for restocking (according to the restocking plan). Restocking of fishing waters should be made exclusively with indigenous fish species in quantities defined in the management plan. Unfortunately, it is not easy to find sufficient species and quantities in Croatian aquaculture farms to meet the requirements defined in the management plans.

Additionally, fisheries management plans define the maximum amount (numbers $/ \mathrm{kg}$ ) of some interesting/protected fish species which can be kept by the anglers on a daily and yearly basis. Some of them also define the number of fishing days allowed, so that the fishing effort can be reduced to the level needed.

Owners aggregate all the fishing log catch data and send them to the HŠRS by the end of March for the previous year. They are responsible for nature protection according to the conditions set out in the management plan. Once a year, owners must submit data about fishing waters and changes which are made during the year. Regarding state fishing licenses, owners are obliged to sell them to anglers. 80 percent of the collected revenue finance owner requirements. They are obliged to deposit 10 percent of funds into the Ministry's account - State budget (to finance the monitoring programme) and a further 10 percent of funds into the HŠRS account. Additionally, owners of fishing rights are obliged to send a monthly calculation report of all the funds that have been deposited with the Ministry. Finally, owners organize freshwater fishery education, undertake environmental cleaning activities, organize various fishing sport competitions, and participate in various tourist activities.

\subsection{FISHING RESTRICTIONS}

There are some general regulations for angling. Sport fishing-angling is allowed with at most three (3) fishing rods with one hook, and exceptionally artificial bait which can have more than one hook, at most two. Sport fishing-angling on all the salmonid species is allowed with one fishing rod and one artificial fly or bait. Angling of European catfish from the boat is allowed with one catfish attractant (in Croatian: bućkalo), one fishing rod or fishing lure with one hook. Fishing rods and 
fishing gear must be under constant immediate attention of the angler. Artificial bait can have at most two hooks (single-hook, double-hook or three-hook) with or without contra-hook. The size of the artificial bait for huchen (Danube salmon) and marble trout should not be less than $18 \mathrm{~cm}$. Except for common fishing regulations, every fishing right owner has their own internal regulations (allowed daily catch in kilograms or pieces, night fishing, using of boats, etc.) based on verified fisheries management studies and yearly plans, as well as other internal financial regulations regarding membership.

Apart from the general fishing regulations, there are conservation measures regulated through the Fish Conservation Ordinance. General fishing restrictions, catch sizes, closed seasons and restrictions on size of fish and on fishing activity when spawning are set out in Table 13 and apply to the following species: brown trout, lake trout, soft-muzzled trout, rainbow trout, huchen, marble trout, grayling, tench, barbel, Northern pike, pike-perch, common carp, European catfish, sterlet, asp and ide (orfe). Fishing restrictions apply during spawning and restrictions of fish size apply for some fish species, especially those which are most popular and which are endemic and/or are under some level of protection.

In order to preserve natural ecosystems, it is forbidden to restock with non-native fish species. The only exception applies to closed water bodies which are not in contact with connected river systems of particular basins. Moreover, it is forbidden to use alien fish species as bait. A detailed list of alien species is provided by Piria et al. (2018).

TABLE 13

Closed season for particular fishing area and the smallest fishing size allowed

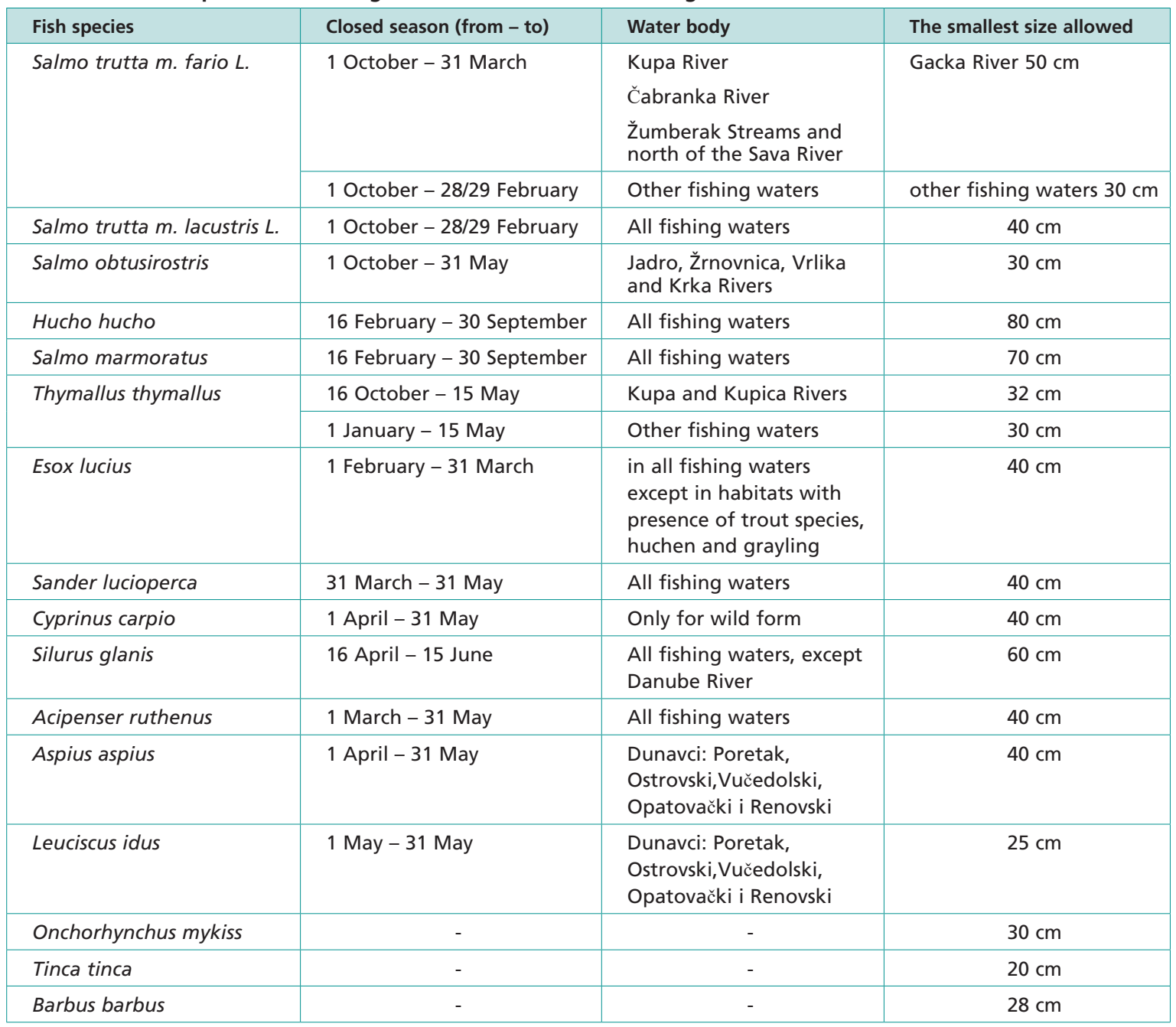


It is forbidden to use any kind of live bait (fish, worms or insect) in water bodies containing brown trout, huchen and grayling.

For sport fishing as well as for commercial fishing, no fishing activity is permitted from $1^{\text {st }}$ February to $31^{\text {st }}$ May in the following fishing zones on the Danube River (see Chapter 4.6.):

- D1 fishing zone - Šarkanjski, Zmajevački and Monjoroški Dunavac;

- D2 fishing zone - Porićki and Erdutski Dunavac

- D3 fishing zone - Iločki Dunavac

For sport fishing in these three zones, it is forbidden to take common carp, asp and ide and it is also forbidden to use live fish as bait.

Commercial fishers are forbidden to set up any permanent or temporary barrier to enclose fishing waters. Additionally, they cannot use artificial light at night for fishing.

If anglers catch fish species smaller than the allowed size or damage any fish stock, damage compensation is prescribed. The calculation is based on the total mass of each species caught and multiplied with a prescribed coefficient for each particular species.

According to the Natural Protection Act and the ordinance of strictly protected species, it is strictly forbidden to disturb the species listed in Table 14 in any way. Most of these species belong to the Adriatic Sea River Basin. Several fish species are protected only in some areas but in other areas, recreational fishing is still allowed (e.g. fishing on endemic Salmo obtusirostris is forbidden in rivers where it is native but allowed at a translocated site - Žrnovnica River).

\subsubsection{The new freshwater fisheries Act in Croatia}

As there is no EU common freshwater fisheries policy, every EU member country can stipulate its own fisheries policy according to its geomorphological, biological, ecological, ichthyological but also socio-economic circumstances and conditions. Croatia is in the process of creating the new Freshwater Fisheries Act, which is currently on the second reading in the Croatian Parliament. In the process, EU documents regarding the regulation of freshwater fish and fish products market in commercial fisheries are taken into account. These are specifically documents on the traceability of fish and fish products (Council Regulation (EC) No 1224/2009 of 20 November 2009 establishing a community control system to ensure compliance with the rules of the common fisheries policy and Regulation (EU) No 1379/2013 of the European Parliament and of the Council of 11 December 2013 on the common organization of fishery and aquaculture products markets).

Market regulations are of national importance to bring fish and fish products from inland waters effectively and safely to markets. Also, fish grey markets need to be brought under control and enable sufficient supply of freshwater fish and fish products to satisfy market needs. The traceability of the origin of fish is of upmost importance for consumers as well as for human health issues.

The laws in this Act that deal with the management plans of fish stocks are harmonized with nature protection and water management laws. In terms of recreational fisheries, the main goal is to transform fishing right owners from a "seller of the licenses" into a real manager who is responsible for fish stocks. Furthermore, the capability of developing recreational fisheries and overall tourist facilities is important.

The new Act reduces and cuts administrative obligations, procedures and expenses of all beneficiaries in freshwater fisheries, the Government Action plan for administrative relief (2018) will serve the subsistence and development of recreational and commercial fisheries in Croatia. Fishing right owners have the opportunity to introduce some closed free access water bodies into "pay lakes" or "fee fishing lakes", in order to expand sports fishing facilities and to enable the sport fishers to buy all the surplus catch they want. Under the current Freshwater Fisheries Act, it was not possible to buy fish that had been caught and anglers could only take a limited catch quantity 
established in the fishing right owner's management plan. This opens a new aspect on some voluntary fisheries locations and widens the facilities from strictly conservational catch and release to "pay lakes". There is also one important new issue regulating authentication of fishing licenses, which are now strictly connected to the fishing zones, assigned to each of the 130 owners of the fishing rights. The possibility that the Ministry of Agriculture can regulate fisheries licenses for particular fishing water zones, several nearby fishing zones or even big fishing zones is now being introduced. This could improve the management of connected zones and ease the purchasing and control of licenses. Fishing right owners can also establish contracts of reciprocity amongst themselves.

If a fishing rights owner wants to manage a new water body created after construction works, there is no need for a public tender, just a simple administrative procedure. Afterwards, a management plan for the water body must be provided to ensure it will be utilized in an ecological, biological and ichthyological manner.

Additionally, some minor decentralization of fisheries management is taking place as counties take on certain commercial fishery matters. County officials are appointed for immediate monitoring and control roles. There is some local interest to continue commercial fisheries with old, traditional fishing gear, equipment and methods, which were historically used by fishers. These have an important tourist value, as well as maintaining and conserving historical gear-making skills and for educational purposes. The Act allows fishers to use such historical gear and equipment only in the Sava and Danube rivers.

An electronic system will be created for purchasing electronic licenses, no-cash transactions, and allocation and distribution of financial funds. The purchasing of licenses will be eased. It is expected that the frequency and the number of anglers arriving as fishing tourists will increase benefiting the development of small rural communities. By introducing more flexible financing, the owners of the fishing rights can fulfil their financial obligations more easily according to the management plan (i.e. fish stocking and bailiffs). The financial value of the license is divided into two: one smaller, fixed part covering the financing of fisheries monitoring and public affairs of the Croatian Anglers' Association, as well as the 5-year accumulation of financial funds for financing management plan revision, and the bigger, variable part for owners of the fishing rights covering their management costs.

Authorized persons will be trained as inspectors as per the Offenses Act. A new category of fisheries is being introduced (fisheries for the purpose of public Aquaria), with trained personnel and updated norms in scientific-exploration institutions. Finally, the proposed Act highlights the responsible and sustainable use of fish stock as freshwater resources. The adjustments to the new law solutions will not represent any financial burden for the freshwater fisheries sector, as the state budget has funds for financing change, such as the electronic database as well as electronic applications for catch documentation and issuing of licenses.

\subsection{ENVIRONMENTAL ISSUES AND CONFLICTS WITH OTHER WATER USES}

Management plans prepared for sport fishing stakeholders must be in accordance with the Nature Protection and Water Acts (Ministry of Environmental Protection and Energy). The Ministry of Agriculture and the Ministry of Environmental Protection and Energy recently started to collaborate and their requests are incorporated into the Freshwater Fishery Act and sub-acts. Also, in management plans for recreational fishery, all restrictions and conservation measures prescribed in nature protection Acts and sub-acts must be included.

Particular conflict of interest exists between the inland fisheries in Croatia, the Croatian Waters company and energy production. Several hydropower plants (HPP) are currently under construction in Croatia, while the building of 124 more are 
TABLE 14

Fish species strictly protected by the Natural Protection Act

\begin{tabular}{|c|c|c|c|c|}
\hline Species & THREATENED CATEGORY & $\begin{array}{l}\text { International } \\
\text { agreement }\end{array}$ & ENDEM & Remark \\
\hline $\begin{array}{l}\text { Eudontomyzon vladykovi } \\
\text { (= Eudontomyzon danfordi) }\end{array}$ & precautionary principle & & & \\
\hline $\begin{array}{l}\text { Lampetra zanandreai } \\
\text { (= Lethenteron zanandreai) }\end{array}$ & EN & BE2 & & \\
\hline Petromyzon marinus & precautionary principle & & & \\
\hline Acipenser gueldenstaedtii & RE & & & \\
\hline Acipenser naccarii & CR (EN) & $\mathrm{BE} 2, \mathrm{DS} 4$ & & \\
\hline Acipenser nudiventris & RE & & & \\
\hline Acipenser stellatus & RE & & & \\
\hline Acipenser sturio * & RE & BE2 & & \\
\hline Huso huso & RE & BE2 & & \\
\hline Anguilla anguilla & CR (European Union) & & & $\begin{array}{l}\text { Populations from } \\
\text { Vransko lake and } \\
\text { from Krka River } \\
\text { (upstream of } \\
\text { Skradinski buk) }\end{array}$ \\
\hline Alosa fallax & EN & & & $\begin{array}{l}\text { Only from Natura } \\
2000 \text { HR5000031 } \\
\text { and Delta Neretva }\end{array}$ \\
\hline Alosa immaculata (= Alosa pontica) & DD, precautionary principle & & & \\
\hline $\begin{array}{l}\text { Alburnus arborella } \\
\text { (= Alburnus albidus) }\end{array}$ & VU & & & \\
\hline $\begin{array}{l}\text { Alburnus neretvae } \\
\text { (= Alburnus albidus) }\end{array}$ & precautionary principle & & & \\
\hline $\begin{array}{l}\text { Alburnus sarmaticus } \\
\text { (= Chalcalburnus chalcoides) }\end{array}$ & VU & & & \\
\hline Aulopyge huegelii & EN & & & \\
\hline Barbus plebejus & EN & & & $\begin{array}{l}\text { Krupa and Zrmanja } \\
\text { Rivers inside of } \\
\text { Velebit Nature Park }\end{array}$ \\
\hline Carassius carassius & VU & & & $\begin{array}{l}\text { Only in protected } \\
\text { areas Lonjsko polje, } \\
\text { Kopački rit and } \\
\text { Mura Drava Park }\end{array}$ \\
\hline Chondrostoma phoxinus & $\mathrm{CR}$ & & & \\
\hline $\begin{array}{l}\text { Delminichtys adspersus } \\
\text { (= Phoxinellus adspersus) }\end{array}$ & VU & & & \\
\hline $\begin{array}{l}\text { Delminichtys ghetaldii } \\
\text { (= Phoxinellus ghetaldii) }\end{array}$ & EN & & & \\
\hline $\begin{array}{l}\text { Delminichtys jadovensis } \\
\text { (= Phoxinellus jadovensis) }\end{array}$ & CR & & DA & \\
\hline $\begin{array}{l}\text { Delminichtys krbavensis (= } \\
\text { Phoxinellus krbavensis) }\end{array}$ & CR & & DA & \\
\hline Leucaspius delineatus & VU & & & \\
\hline Phoxinellus alepidotus & DD, precautionary principle & & & \\
\hline Phoxinellus dalmaticus & VU & & DA & \\
\hline Romanogobio benacensis & precautionary principle & & & \\
\hline $\begin{array}{l}\text { Romanogobio kesslerii } \\
\text { (= Gobio kesslerii) }\end{array}$ & precautionary principle & & & \\
\hline $\begin{array}{l}\text { Romanogobio uranoscopus } \\
\text { (= Gobio uranoscopus) }\end{array}$ & precautionary principle & & & \\
\hline $\begin{array}{l}\text { Romanogobio vladykovi } \\
\text { (= Gobio albipinnatus) }\end{array}$ & DD, precautionary principle & & & \\
\hline Rutilus aula & NT & & & \\
\hline
\end{tabular}




\begin{tabular}{|c|c|c|c|c|}
\hline Species & THREATENED CATEGORY & $\begin{array}{l}\text { International } \\
\text { agreement }\end{array}$ & ENDEM & Remark \\
\hline Squalius microlepis & CR & & & \\
\hline Squalius zrmanjae & VU & & DA & $\begin{array}{l}\text { Krupa and Zrmanja } \\
\text { Rivers inside of } \\
\text { Velebit Nature Park }\end{array}$ \\
\hline Telestes ukliva & CR & & DA & \\
\hline $\begin{array}{l}\text { Telestes croaticus } \\
\text { (= Phoxinellus croaticus) }\end{array}$ & EN & & DA & \\
\hline $\begin{array}{l}\text { Telestes fontinalis } \\
\text { (= Phoxinellus fontinalis) }\end{array}$ & EN & & DA & \\
\hline Telestes karsticus & & & DA & \\
\hline $\begin{array}{l}\text { Telestes metohiensis } \\
\text { (= Phoxinellus metohiensis) }\end{array}$ & RE & & & \\
\hline Telestes polylepis & CR & & DA & \\
\hline Telestes souffia (= Leuciscus souffia) & VU & & & \\
\hline Telestes turskyi & CR & & DA & \\
\hline Cobitis bilineata (= Cobitis taenia) & načelo predostrožnosti & & & \\
\hline Cobitis dalmatina (= Cobitis taenia) & VU & & DA & \\
\hline Cobitis elongata & VU & & & \\
\hline Cobitis illyrica (= Cobitis taenia) & VU & & DA & \\
\hline Cobitis jadovensis (= Cobitis taenia) & & & DA & \\
\hline Cobitis narentana (= Cobitis taenia) & VU & & & \\
\hline Misgurnus fossilis & VU & & & \\
\hline $\begin{array}{l}\text { Sabanejewia balcanica } \\
\text { (= Sabanejewia aurata) }\end{array}$ & VU & & & \\
\hline Aphanius fasciatus & EN & BE2 & & \\
\hline Salaria fluviatilis & VU & & & \\
\hline Gymnocephalus baloni & VU & & & \\
\hline Gymnocephalus schraetzer & CR & & & \\
\hline Zingel streber & VU & & & \\
\hline Zingel zingel & VU & & & \\
\hline Knipowitschia croatica & CR & & DA & \\
\hline Knipowitschia mrakovcici & EN & & DA & \\
\hline Knipowitschia panizzae & precautionary principle & & & \\
\hline Knipowitschia radovici & DD & & DA & \\
\hline Padogobius bonelli & EN & & & \\
\hline Pomatoschistus canestrinii & EN & BE2 & & \\
\hline Salmo dentex & CR & & & \\
\hline Salmo farioides & EN & & & \\
\hline Salmo marmoratus & CR & & & \\
\hline Salmo visovacensis & EN & & DA & \\
\hline $\begin{array}{l}\text { Salmothymus obtusirostris } \\
\text { (= Salmo obtusirostris) }\end{array}$ & CR & & & $\begin{array}{l}\text { Krka, Jadro Vrljika } \\
\text { Rivers and Delta } \\
\text { Neretva }\end{array}$ \\
\hline Cottus gobio & VU & & & $\begin{array}{l}\text { Only from Zrmanja } \\
\text { River }\end{array}$ \\
\hline
\end{tabular}


planned soon https://www.balkanrivers.net/en/vmap. Recently, a paper on these topics was released and concluded that disturbances in the fish assemblage pattern in the Sava riverbed have coincided with the presence of multiple stressors of human origin (Piria et al., 2019). The authors cited the example of Bregana Stream, a typical salmonid stream with confluence to the Sava River and the only known spawning site for blageon (Telestes souffia) in Croatia. Several years ago, construction work by the Croatian Water Company began along the entire lower course of the Bregana stream to channelize and cement parts of the riverbed, which completely altered the mouth of the stream into the Sava. Plans are also in place to construct a small hydroelectric plant at Bregana, which will laterally block the river course and alter the flow regime (http://zagrebnasavi.hr/item/mhe-brdovec/). These activities will directly alter the flow regime of this stream, affect salmonid recreational fishery and further threaten the blageon population.

Moreover, several campaigns against HPP construction have taken place. One was for the protection of the biggest salmonid in Europe - hutchen (Hucho bucho). The study by Freyhof et al. (2015) concluded that the only threat for hutchen are dams and barriers. If all HPP construction plans are realized, Europe could lose one very attractive sport fishing fish species from the wild. Furthermore, a few migratory sturgeon species from the Danube River basin have already been lost from the wild because of the same reason (Danube Iron Gate dam) (Mrakovčić et al., 2006). Even though Water Acts establish that for all intervention to riverbeds or for each water body, an ichthyological technical study should be done, this is not enough to stop the plans for hydropower construction to go ahead. What is more, fish passes should be constructed for each new HPP barrier, but in practice, there are only a few functional fish passes.

Fisheries also have conflict of interests with actions to protect from flooding, industrial and community wastewater, and agriculture pollution. Sand digging from large rivers are prohibited in Croatia but are not prohibited in bordering countries (Bosnia and Herzegovina). There is no valid international regulation between Croatia and other bordering countries to address this problem.

\subsection{COMMERCIAL FISHING IN INLAND WATERS}

Commercial fishing is permitted only at the Sava River and Danube River fishing areas according to the Freshwater Fisheries Act and sub-act. The Sava River fishing area is divided into four fishing zones (Figure 17) and the Danube River into three sections.

Licenses for commercial fishing are issued by the Ministry of Agriculture which prescribes the type and quantity of permitted fishing gear and equipment, and the annual catch quotas. The licenses can be granted to a person or company. A limited number of licenses can be issued annually: (1) a total of 20 licenses at the Sava River and (2) a total of 50 licenses at the Danube River. Annual catch quotas of commerciallyimportant fish species are regulated and limited for each fishing area (Table 15). Catch of non-native fish species is not limited but should be reported to the Ministry of Environmental Protection and Energy by licensees.

Statistical data from commercial fishers exists from 2005 but data collection includes only the most common fish species in commercial fishers' catch. In total, 28 licenses for the Danube and 17 for the Sava River were granted for commercial fishers in 2017. The most common fish species caught by commercial fishers is bream in both the Danube and Sava rivers. Common carp and European catfish are more significant for the Danube than for the Sava River (Figures 18 and 19). The biggest proportion of the catch in the Sava River belongs to other indigenous fish species. It is expected that with the implementation new Freshwater fisheries act and data collection will improve and include these in catch reports. 


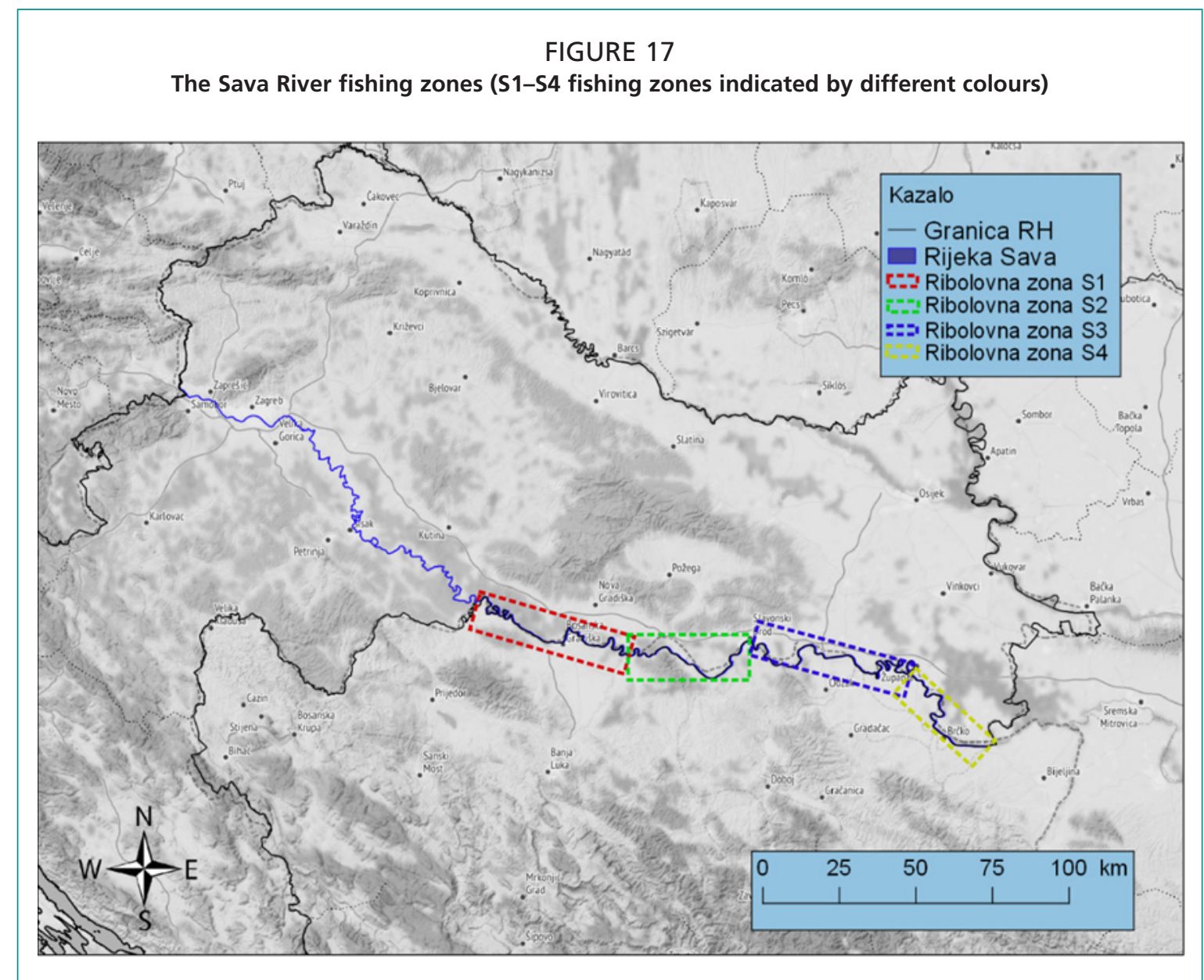

TABLE 15

Permitted annual catch quota $(\mathrm{kg})$ of commercially-important fish species for the Sava and Danube River fishing areas

\begin{tabular}{|l|c|c|}
\hline \multirow{2}{*}{ Fish species } & \multicolumn{2}{|c|}{ Catch quota (kg) } \\
\cline { 2 - 3 } & Sava & 5400 \\
\hline Common carp (Cyprinus carpio) & 1160 \\
\hline European catfish (Silurus glanis) & 2320 & 12000 \\
\hline Zander (Sander lucioperca) & 1388 & 3700 \\
\hline Northern pike (Esox lucius) & 990 & 4200 \\
\hline Sterlet (Acipenser ruthenus) & 123 & 800 \\
\hline Other indigenous species* & 33797 & 104400 \\
\hline TOTAL & 42814 & 130500 \\
\hline
\end{tabular}

*Asp (Leuciscus aspius), freshwater bream (Abramis brama), white bream (Blicca bjoerkna), ide (Leuciscus idus), barbel (Barbus barbus), common nase (Chondrostoma nasus) and other indigenous species inhabiting Croatian fishing zones.

Consumption of fish is very low in Croatia (6 kg per capita) and this is mostly marine fish species. Freshwater fish is traditionally consumed only in some parts of Croatia (Slavonija and Baranja County). It is not easy to find freshwater fish caught by commercial fishers in markets, with Croats preferring to buy wild fish. Hopefully, with the new Freshwater Fisheries Act, wild fish will be recognized and available on the market. 

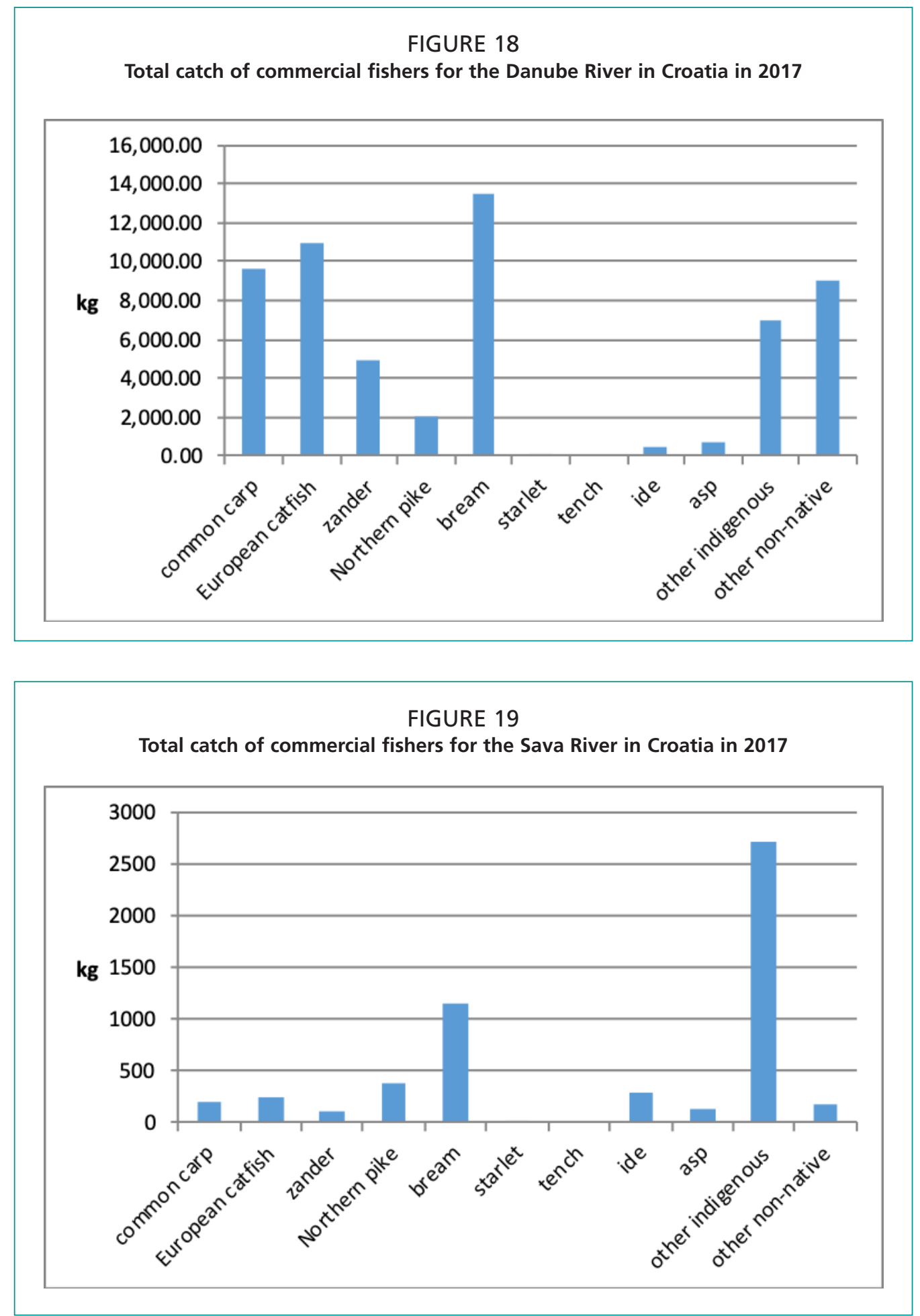

\subsection{RECREATIONAL FISHING IN INLAND WATERS}

Recreational fisheries data exist from 1997, but data collection with current methods (described in the data collection chapter) started from 2004. The number of recreational fishers in Croatian inland waters in 2018 was 36471 with a catch of $459349 \mathrm{~kg}$ of fish. During last few years, the total number of fishers and total catch has slightly decreased (Figure 20). 


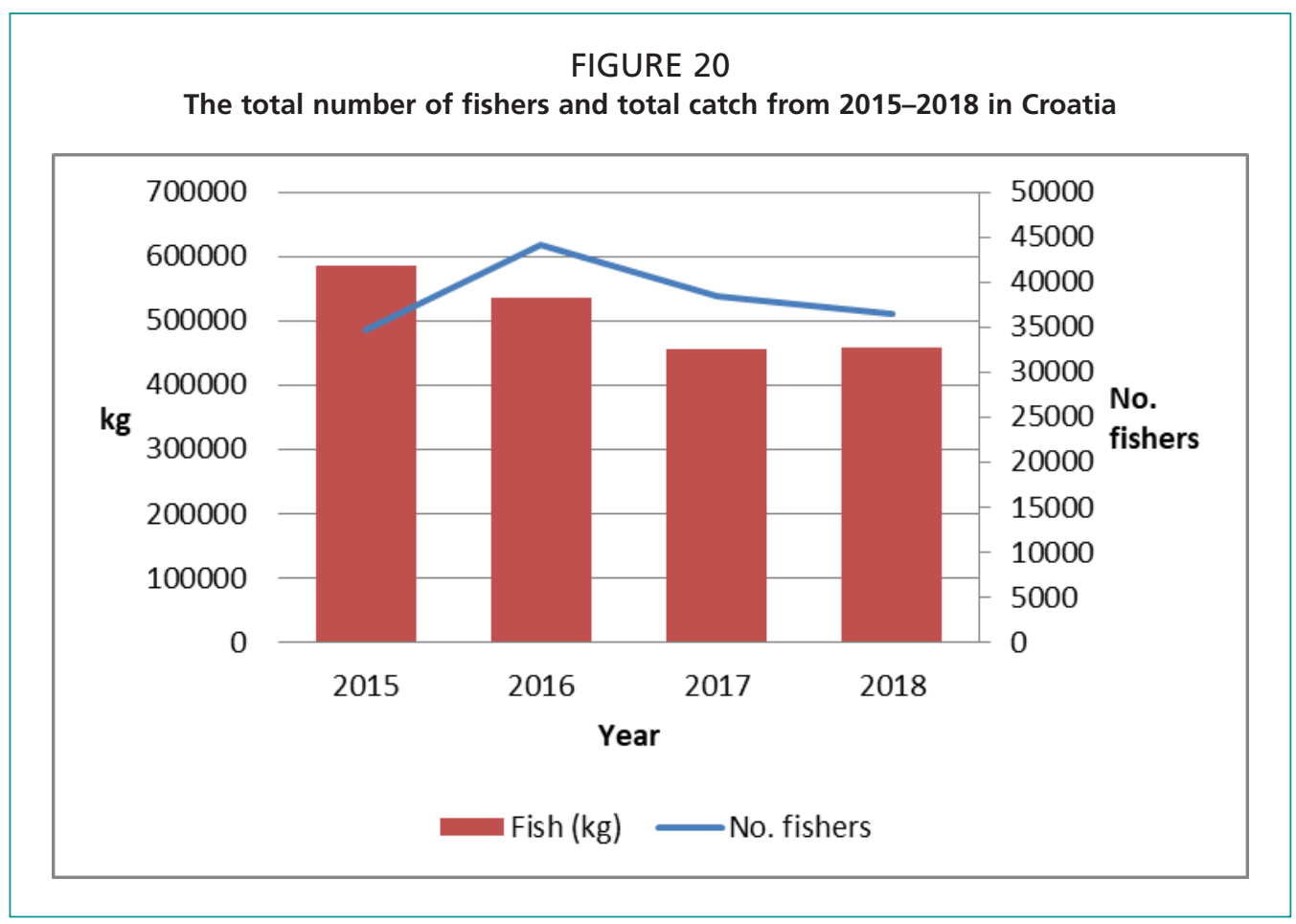

The most common fish species caught by recreational fishers are cyprinids: common carp, grass carp, European catfish, gibel carp, zander, Northern pike and bream (Figure 21). The total weight of each species caught exceeded $20000 \mathrm{~kg}$.

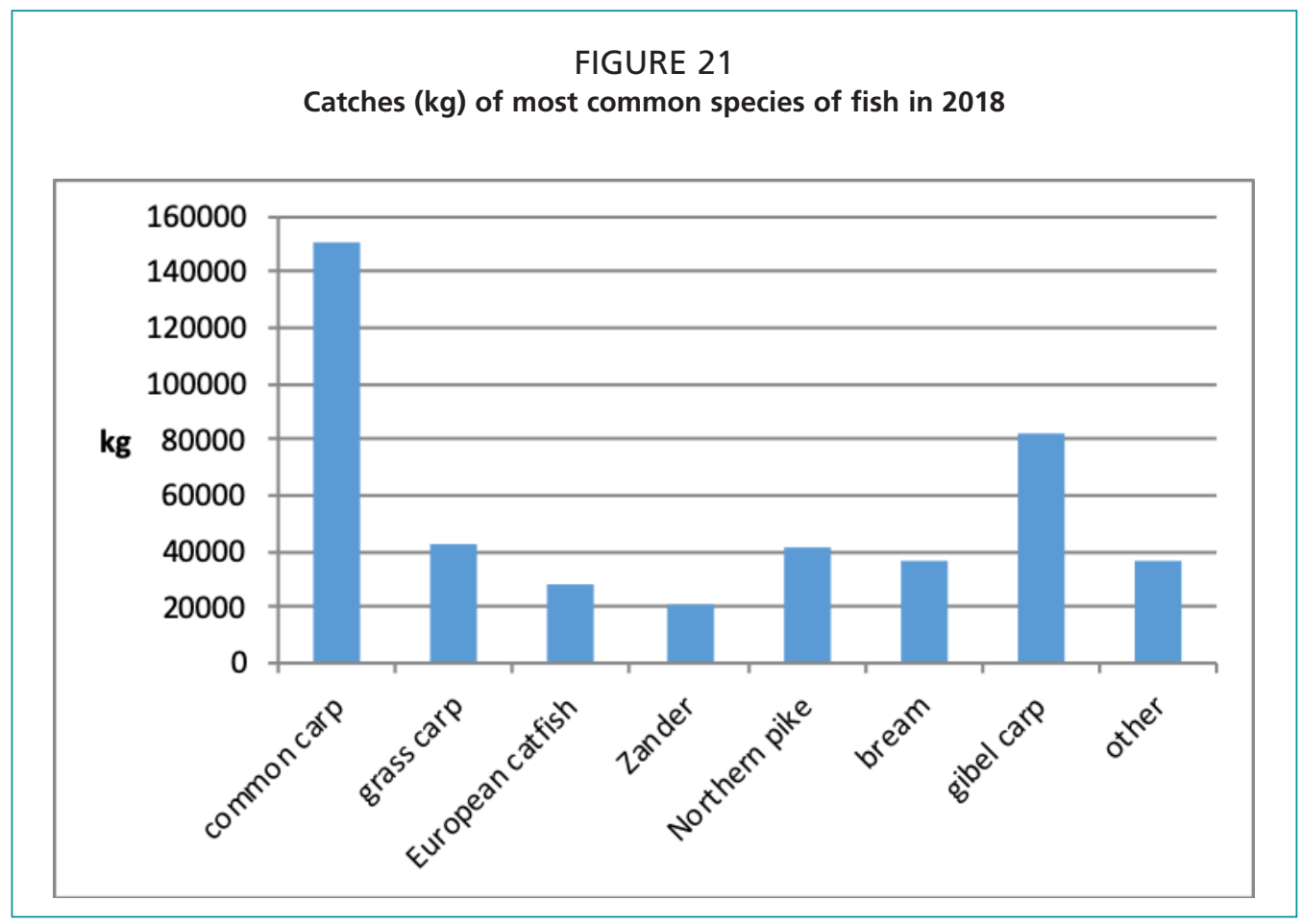

There are other attractive fish species caught by anglers but the weight of each species is lower than $8000 \mathrm{~kg}$ per year. Fly fishing tourism is popular particularly for the regions of Lika and Gorski Kotar, (e.g. Gacka and Kupa Rivers) but does not have a major role in comparison with other species in the catch (Figure 22). 
FIGURE 22

Catches $(\mathrm{kg})$ of other fish species which should be reported in fish logbooks for 2018

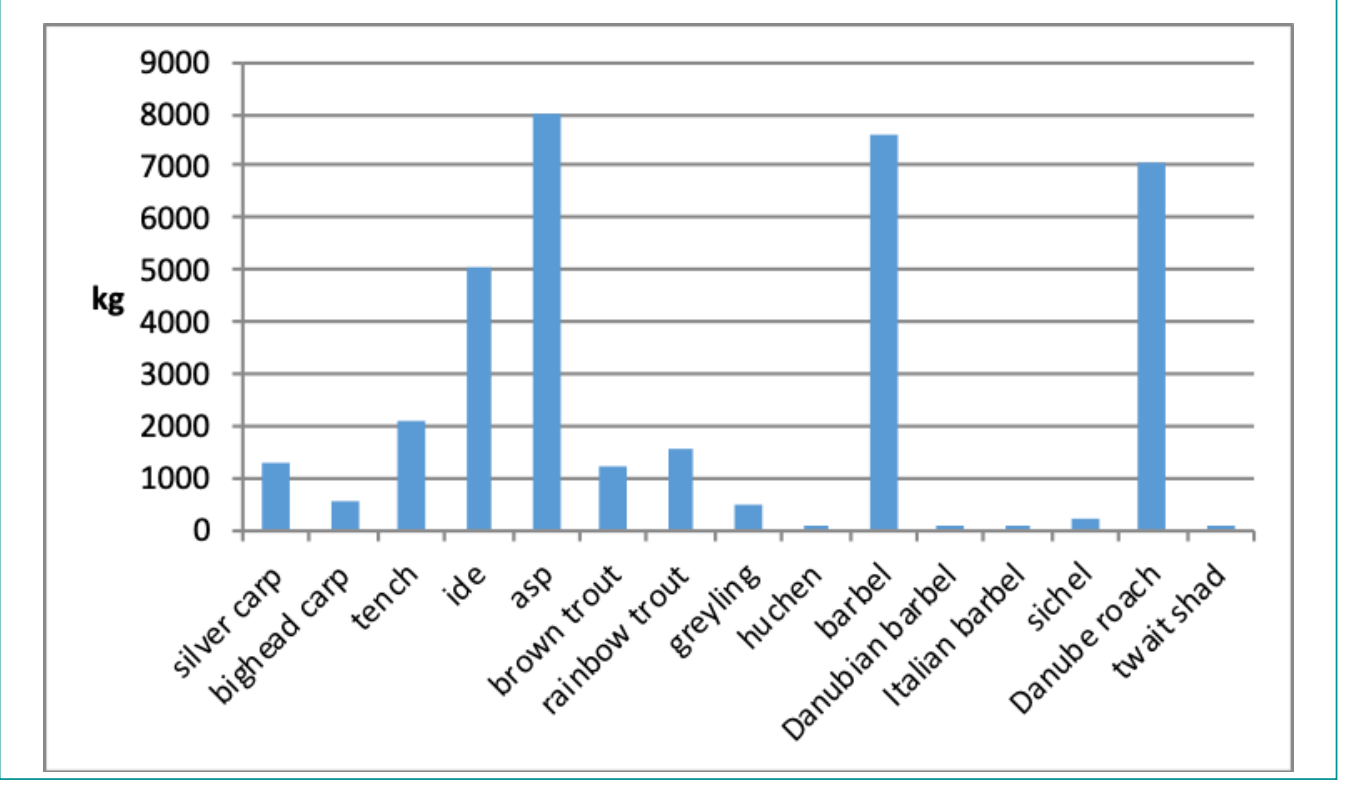

Fishing tourism in Croatia was devastated during the transitional time (1991-1995). The particularly popular destination was Gacka River with its known big salmonid fishes. Until today, fishing tourism has not recovered in Croatia, even if there are many places with untouched landscape and diverse ichthyofauna. This form of tourism in rural areas possesses huge potential and should be developed.

\subsection{MANAGEMENT AND MONITORING OF INLAND WATERS}

In the Republic of Croatia, fish and water quality monitoring are formally divided, due to different legal frameworks (the Freshwater Fisheries Act and the Water ctc). Water is monitored by the Ministry of Environment Protection and Energy, through the state-owned company "Hrvatske vode" with various other institutions, like the Public Health Institute. The programme for monitoring freshwater fisheries status has been conducted by the Ministry of Agriculture, Fisheries Directorate since 2002 (Articles 7 and 64 of the Croatian Freshwater fisheries Act). There are five main fishing areas in the Republic of Croatia, which are defined through main river basins:

1. Drava-Danube fishing zone

2. Sava fishing zone

3. Kupa fishing zone

4. Lika fishing zone

5. Jadran Fishing zone

The monitoring programme consists of:

- quantitative and qualitative structure of the ichthyofauna (organized by Order, Family and Genus) with a part of particular species in Families and Genuses, and the bulk of particular species in overall ichtyomass;

- estimate of yearly gain/increase of economically-important species for sports and commercial fisheries, in $\mathrm{kg} / \mathrm{ha}$;

- approximation of hygienic/sanitary conditions and evaluation of ichthyofauna health conditions;

- measures for conservation and maintenance of fish stock and the method of conducting those measures, which include organization of a fish warden service, monitoring of incident water pollution, diseases and fish mortalities, planning and translocation of fish after floods, planning of selective fishing of species that 
endanger other species;

- the daily and yearly allowable amount of catch by species in sports fisheries for every fishing zone, including overall amount of allowable catch based on yearly increase for every fishing water body of the owner of the fishing right;

- overall amount of allowable catch in commercial fisheries for every license issued and for every fishing zone.

The results obtained by the monitoring programme are used to inform the management plans for the owners of the fishing rights, and revisions of those management plans every 6 years, which represents the scientific basis for the management of fish stocks on fishing areas and zones (Article 7. of the Sports fisheries Sub-law). The monitoring programme is financed by 10 percent of every fishing license fee (Article 64. of the Freshwater Fisheries Act). With the new Freshwater Fisheries Act, electronic fishing licenses will be issued and the funds will be transmitted directly to the accounts of the owners of the fishing rights, Croatian Anglers' Association and the Ministry of Agriculture. The institutions will sign yearly contracts with the Ministry.

Monitoring is performed on a yearly basis throughout the year and the results (whole studies in paper and digital form) have to be submitted to the Ministry of Agriculture by the $15^{\text {th }}$ December for each year. As soon as the digital database is operational, all the studies from 2002-2019 will be uploaded into the database.

Diagrams of abundance and biomass are made in order to determine the population status (stable or unstable) according to Warwick (1986). Another very important method is Catch Per Unit Effort (CPUE), for it signals disturbances in population structure. CPUE is a relation which is normally used to remove the time and regional trends in fish stock abundance. The catch can be expressed as a number, or as mass of total catch, or as some regions or as some species. Another commonly used method is NPUE (Number of Catch Per Unit), which indicates whether the number of fish in the population is reduced by fishing. When the NPUE is used with fishing nets, data is needed for time in water (hours), the length and the height of the net $(\mathrm{m})$, mesh size $(\mathrm{cm})$ and the number of caught specimens.

Yearly growth of ichthyofauna is calculated through the determination of primary production, which is in direct linear connection to higher production, which in turn is related to ichtyomass. To determine ichtyoproduction, the most commonly used models are those which correlate some of the features of the fish communities with environmental factors. Ichtyoproduction means part of the population (growth) that can be taken out of nature without causing imbalance in the overall biomass.

It is important to mention that Republic of Croatia lost its Institute for Freshwater Fisheries, due to the transitional war (1991-1995), and the post-war privatization processes. This scientific research institution covered the whole of ex-Yugoslavia with scientific studies, and also monitored all of the aquaculture farms. There was a great need to provide new monitoring, so the legal foundations were made in the Freshwater Fisheries Act to ensure that existing scientific, research and educational institutions could provide it in the future.

The good praxis regarding fish stock monitoring from 2002-2019 is in fact that most of the results were used by the Ministry to create useful and rational sub-laws for national-level decisions. Also, the results were used at local level; fishing rights holders could improve their management plans and improve restocking, fishing regime and quotas. The shortfalls lie in the fact that the existing financing model could not ensure stable funds to finance monitoring.

\subsection{INTERNATIONAL COOPERATION}

The border rivers Dragonja, Kupa, Drava, Danube and Sava mark most of Croatia's land borders in addition to its sea borders, so fishery is an important factor present in nearly all of Croatia's political and other relations with its neighbours. There is just one 
international Fishery Agreement (with the Republic of Slovenia) as a model for fishing arrangements with neighbouring countries required for overall co-operation and joint administration of shared waters. For various political reasons, as well as the absence of real need for international co-operation in the past, such agreements were not made. Besides, as already mentioned, this was primarily due to reduced fishing efforts which made some strong protection mechanisms unnecessary. While there was no need for international commitments, there were many agreements concerning the rights and possibilities of fishing by specified zones and species. Such agreements, in addition to encouraging technological improvements, were often landmarks in the development of the Croatian fisheries.

The general public, fisheries experts in neighbouring countries, as well as the EU consultants who visited Croatia during the process of the country joining the EU, evaluated the Freshwater Fisheries Act (2001) as "strict and protection-oriented". These facts, as well as Croatia's general option for protection and sustainable management of natural water resources, resulted in Croatia being one of the countries to adhere to the FAO Code of Conduct for Responsible Fisheries. This Act formed a model for neighbouring countries because of its structure and content.

The main prerogative for creating international agreements in the field of freshwater fisheries is to have a clear border, so it is understandable that there is no mutual political will to make such agreements prior to solving border issues. 


\section{Coutry examples: Czechia}

In Czechia, commercial fishery from open waters (not counting aquaculture) is negligible (landing less than 50 metric tonnes). Recreational fishery catches are seventy times higher. All of the 315000 recreational anglers are obliged to report every single fish caught and kept. The information is then integrated into the fishing ground specific yearly summary catch of each angler. Yearly logbooks are collected by users of fishing grounds and these data are summarized for individual fishing grounds. Summaries are forwarded to the Ministry of Agriculture who issues the nationwide fishery statistics.

\subsection{DATA COLLECTION FOR STATISTICS}

Fish catch data in Czechia comes from users of fishing grounds and from aquaculture producers. Figure 23 describes the data flow for international reporting.

With very limited commercial catches from Czech waters, the main challenge is to assess the information about recreational fishery catches. Every retained fish from every fishing ground is recorded, thus it is relatively easy to obtain the main outputs: summary statistics for particular fishing grounds (see Table 16 as an example) and summary statistics for the particular regions (the Czech Republic is divided into 8 regions). Summary records are traditionally divided between salmonid and nonsalmonid fishing grounds (different licenses apply). Best practices and the main problems are discussed in later chapters.

Recreational fishing statistics are used mainly by fishery managers and regional authorities for further decisions on fishing ground management. This data is also needed to evaluate the social significance of recreational fishing.

The method of inland fisheries data collection in Czechia is very thorough and highly developed. Indeed, Czechia has one of the most sophisticated methods of data collection for fish harvest and fishing effort worldwide. The main strength is that data are available for each fishing ground and for each year. Anglers are legally bound to report fish catches. This is ensured in the field by angling guards. The data are comparable between individual fishing grounds, between regions, and also over time. Since fish catches are reported by regular anglers (and not by scientists), the error in reported fish catches is likely a bit higher when compared to scientific studies.

FIGURE 23

Schematic presentation of the international fisheries data collection in the Czech Republic

Information charts of reporting Czech fishery (and aquaculture)

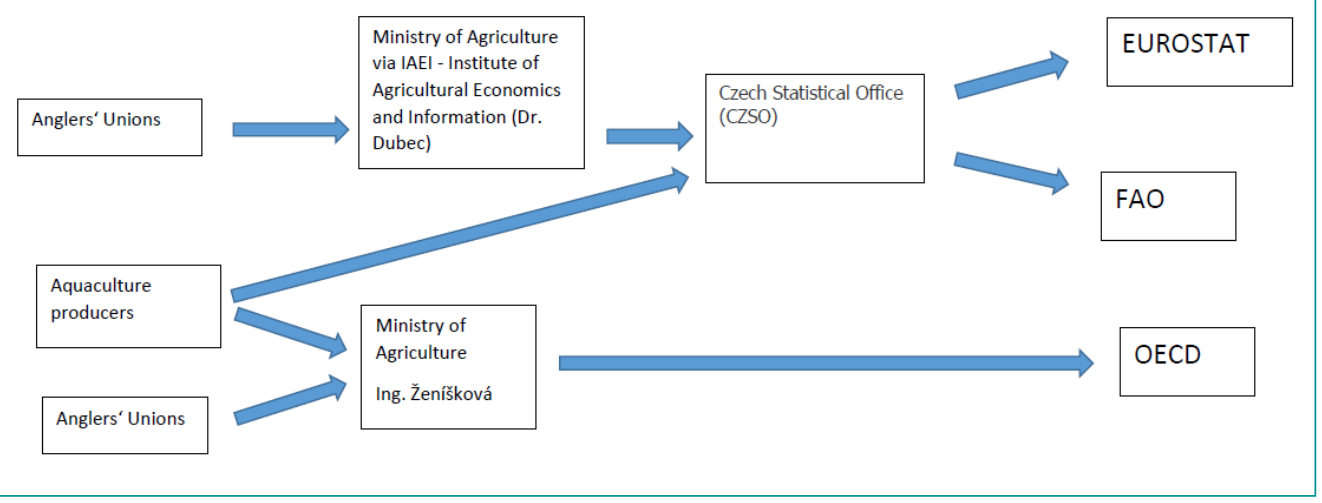


TABLE 16

An example of annotated yearly fishing ground summary sheet in Czech Republic (Lipno Reservoir 2018).

Fisheries management analysis 2018 - part A

Czech Fishermen's Association, South Bohemian Territorial Union

11186 anglers visted the ground (of those, 6976 retained a fish) total No. of daily visits: 122174 .

Return

rate.

2016-18

\begin{tabular}{|c|c|c|c|c|c|c|c|c|c|c|}
\hline \multirow[t]{2}{*}{ Species } & \multicolumn{3}{|c|}{ Stocked fish } & \multicolumn{3}{|c|}{ Catches } & \multirow{2}{*}{$\begin{array}{c}\begin{array}{c}\text { Average } \\
\text { weight. } \\
\text { (kg/ind) }\end{array} \\
\%\end{array}$} & \multicolumn{3}{|c|}{$\begin{array}{l}\text { Targeting species (how many } \\
\text { anglers retained given species) }\end{array}$} \\
\hline & Inds. & $\mathrm{kg}$ & 1,44 & Inds. & $\mathrm{kg}$ & $\begin{array}{l}\text { Average } \\
\text { weight. } \\
\text { (kg/ind) }\end{array}$ & & $\begin{array}{l}\text { No. of } \\
\text { successful } \\
\text { anglers }\end{array}$ & $\begin{array}{l}\text { Fish/ } \\
\text { successful } \\
\text { angler }\end{array}$ & $\begin{array}{l}\text { Overall } \\
\text { success } \\
\text { rate } \mathrm{f} / \\
\text { angler }\end{array}$ \\
\hline carp & 82689 & 119298 & 0,12 & 31928 & 76583,27 & 2,40 & 40,01 & 5510 & 5,8 & 2,9 \\
\hline tench & 2500 & 300 & & 96 & 54,62 & 0,57 & 9,85 & 58 & 1,7 & 0,0 \\
\hline bream & & & & 7064 & 3034,88 & 0,43 & & 829 & 8,5 & 0,6 \\
\hline chub & & & 0,10 & 53 & 103,85 & 1,96 & & 9 & 5,9 & 0,0 \\
\hline perch & 2500 & 255 & & 3211 & 1209,38 & 0,38 & 43,16 & 680 & 4,7 & 0,3 \\
\hline \multicolumn{11}{|l|}{ barbel } \\
\hline \multicolumn{11}{|l|}{ Chondrostoma } \\
\hline Vimba & & & & 1 & 0,97 & 0,97 & & 1 & 1,0 & 0,0 \\
\hline pike & 53760 & & & 3063 & 6140,74 & 2,00 & 4,66 & 1469 & 2,1 & 0,3 \\
\hline pikeperch & 23730 & & & 8210 & 14127,07 & 1,72 & 10,99 & 1855 & 4,4 & 0,7 \\
\hline Wels catfish & & & & 138 & 1543,32 & 11,18 & & 105 & 1,3 & 0,0 \\
\hline eel & & & & 142 & 138,63 & 0,98 & & 107 & 1,3 & 0,0 \\
\hline brown trout & & & & 9 & 5,84 & 0,65 & & 3 & 3,0 & 0,0 \\
\hline rainbow trout. & & & & 9 & 4,45 & 0,49 & 10,42 & 8 & 1,1 & 0,0 \\
\hline \multicolumn{11}{|l|}{ grayling } \\
\hline brook trout & & & & 1 & 0,25 & 0,25 & & 1 & 1,0 & 0,0 \\
\hline asp & & & & 87 & 247,44 & 2,84 & & 80 & 1,1 & 0,0 \\
\hline \multicolumn{11}{|l|}{ Coregonus. } \\
\hline \multicolumn{11}{|l|}{ Hucho } \\
\hline grass carp & & & & 54 & 233,70 & 4,33 & & 43 & 1,3 & 0,0 \\
\hline \multicolumn{11}{|l|}{ bighead } \\
\hline Carassius & & & & 68 & 13,19 & 0,19 & & 14 & 4,9 & 0,0 \\
\hline burbot & 1000000 & & & & & & & & & \\
\hline ide & & & 0,10 & 1 & 0,30 & 0,30 & & 1 & 1,0 & 0,0 \\
\hline Other species & 1300 & 130 & & 5339 & 570,64 & 0,11 & 54,00 & 431 & 12,4 & 0,5 \\
\hline total & 1166479 & 119983 & & 59474 & 104012,54 & 1,75 & & 6976 & 8,5 & 5,3 \\
\hline
\end{tabular}

\subsubsection{Scientific advice}

Several scientific studies on recreational fishing have been carried out in Czechia. Those studies used data from fishing logbooks and harvest summaries to draw conclusions on spatio-temporal changes in recreational fishing. Some of them were published in Czech journals and describe fish harvest rates (Lusk, 1996, Lusk et al., 1996, Vostradovský and Tichý, 1999, Baruš and Prokeš, 2000, Baruš et al., 2000, Pivnička a Rybáŕ, 2001, Lusk et al., 2003, Draštík et al., 2004, Pivnička et al., 2005). Other studies describing socio-ecological trends in recreational fisheries were published in international journals (Humpl et al., 2009, Jankovský et al., 2011, Boukal et al., 2012, Lyach and Čech 2017a, 
2017b, Lyach et al., 2018, Lyach and Remr 2019a, 2018b). Three studies assessed opinions and behaviour of anglers using online questionnaires (CAWI - computer assisted web interviews). Those studies were carried out by Spurný et al (2009, 2013, and 2017).

The users of fishing grounds and scientists often work closely together. They conduct regular ichthyological surveys, and the results are used for proper fisheries management. The research of recreational fisheries in fishing grounds (management, ichthyology, behaviour of anglers, the quality of fish meat, etc.) is conducted at Czech scientific institutions. The main scientific institutions are:

- University of South Bohemia in České Budějovice, the Faculty of Fisheries and Water Protection.

- Mendel University in Brno, specifically the Department of Fisheries and Hydrobiology.

- Czech University of Life Sciences in Prague, the Department of Zoology and Fisheries.

- Czech Academy of Sciences in Brno and in České Budějovice.

- T. G. Masaryk water research institute in Prague.

There are many books and articles published by Czech scientists (Lusk 1996, Lusk et al., 1996, Vostradovský and Tichý, 1999, Baruš and Prokeš, 2000, Baruš et al., 2000, Pivnička a Rybáŕ, 2001, Lusk et al., 2003, Draštík et al., 2004, Pivnička et al., 2005, Humpl et al., 2009, Jankovský et al., 2011, Boukal et al., 2012, Lyach and Čech, 2017a, 2017b, 2018a, 2018b, Lyach et al., 2018, Lyach and Remr 2019a, 2019b). Three studies assessed opinions and behaviour of anglers using online questionnaires (CAWI - computer assisted web interviews). Those studies were carried out by Spurný et al., (2009, 2013, 2017).

\subsection{LEGAL BACKGROUND}

Recreational fisheries are under the supervision of the Ministry of Agriculture and are enacted by Fisheries Act No. 99/2004 on fish farming, fishing rights, fishing inspections, protection of marine fishing resources and act amendments and by Decree No. 197/2004 of the Fishery Act.

This Act regulates the following:

- breeding, protection of fish and fishing, farming and fishing of aquatic organisms and protection of their life and environment;

- fish farming, performance of fishing rights, proclamation, amendments and repeal of fishing grounds and their protection;

- state administration performance in fishery, at proclamation, amendment and repeal of fishing grounds and at performance of fishing rights;

- register of management, management results gained, of angling and register of fishing permits issued in fish farming and at performance of fishing right;

- appointment, termination, powers and responsibility of fishing inspections;

- monitoring compliance of the act and decisions issued and sanctions for not meeting the obligations determined or for their violation,

- share of the state on remittance of costs of measures accepted in public interest,

- protection of marine fishing resources.

Recreational fisheries are permitted on the basis of fishing rights in the Czech Republic. Fishing rights are defined as an activity in a fishing ground granted to a legal or physical person by the relevant state administrative fisheries authority (authority), based on systematic culture, protection, fishing and control of aquatic organisms on fish, as well as on the use of riparian land. Fishing grounds are defined as part of a water body with an area of at least $500 \mathrm{~m}^{2}$ of continuous water, enabling the endurance of fish stocks and of other aquatic organisms, as proclaimed by decision of the relevant authority. The Czech Republic enables fishing rights in fishing grounds to legal or physical persons who may subsequently allow fishing to physical persons (fishers). 
Recreational fishing can only occur in fishing grounds where fishing rights are allowed. Recreational fishing is prohibited where there are no established fishing grounds and fishing rights are not permitted (except aquaculture). Authorities in the state fisheries administrative sector are primarily the Ministry of Agriculture, counties with designated competence and local authorities.

A fishing ground is established on a watercourse, a pond or on a closed water body by the relevant authority (Ministry of Agriculture or county with designated competence); and is authorized to establish fishing grounds only in its area of territorial jurisdiction. Owners of water bodies may apply for fishing grounds; landowners - where a closed water body is located - may apply for fishing grounds; or they may be granted upon the initiative of the relevant fishery authority on a watercourse (watercourses are assigned by the Czech Republic). Each fishing ground has a registration number and a designation. Fishing grounds are usually separated by significant barriers in the river or by a landmark (e.g. river dam, small power plant, bridge, weir, pond or other water structure). The fish living in fishing grounds are "res nullius" and are considered as a national asset. In the Czech Republic, there are approximately 2000 fishing grounds (area $42000 \mathrm{ha}$ ), of which the area of salmonid fishing grounds is 3700 ha and non-salmonid fishing grounds is $38000 \mathrm{ha}$ ). Salmonid fishing grounds are usually defined as smaller streams $(<10 \mathrm{~m}$ wide) that provide good environmental conditions for salmonid populations (feeding, growth, spawning). Non-salmonid fishing grounds are streams, rivers and other water bodies that do not meet the strict conditions of salmonid streams. Fishing rules differ between salmonid and non-salmonid fishing grounds in that salmonid fishing grounds have stricter rules for fishing, mainly regarding stricter fishing methods and bag limits as well as lower fishing effort.

\subsection{FISHING RIGHTS}

As soon as the fishing ground is established, the relevant fishery authority grants fishing rights for a period of 10 years to a legal person possessing the legal requirements for fishing rights, as determined by the Fishery Act. Fishing rights owners in fishing grounds are selected on the basis of open competition.

Fishing rights in fishing grounds are permitted by relevant fishery authorities on the basis of permission by owners. Fishing rights on closed water bodies is permitted on the basis of permission by its owner.

The relevant fishery authority determines the following characteristics when granting permission of fishing rights for every fishing ground:

- fish manager and his/her deputy;

- the method of management, including maintenance and development of the original fish stock;

- the procedure of fish stocking according to species, number and age categories of the fish stocked; and

- the maximum number of fishing permits to be issued.

The physical or legal person who has been granted fishing rights is called fishing ground user (user). Users are responsible for breeding and fishing, appropriately growing and fishing of aquatic organisms, and ensuring it is performed in accordance with the fishery code and its implementing legal directives. Users must manage them according to the methodology determined by the relevant fishery authority and in accordance with conditions and farming indicators stipulated in the fishing right. The user must ensure annual stocking of fish as stated in the right; the main goal of stocking is to ensure stable and viable fish populations in fishing grounds. The data on fish stocking are available for each individual fishing ground and for each year. 
Fishing ground users must arrange fishing inspections. Fishing inspections are specified upon the proposal of user of the fishing ground rights or of another authorized subject by the local authority. An individual, who is over 21 years of age and is qualified to undertake legal transactions, has proven knowledge of rights and duties of fishing inspections and knowledge of related legal directives can be appointed as a fishing inspector. Each user must keep and submit fishing records no later than $30^{\text {th }}$ April of the following calendar year. The implementing legal directive determines the details of register management and of the results gained from management in the fishing ground. The user must provide the following information:

- What kinds of fish and how many fish were stocked in the fishing ground?

- What kinds of fish and how many fish were caught by fishers?

The data on stocked fish and caught fish have been collected using the same method over time. Therefore, data collected between regions and periods are easily comparable. This statistical data are used to optimize fisheries management. Recently, data on fish harvest and fishing effort have been used for scientific purposes as well (Humpl et al., 2009, Jankovský et al., 2011, Boukal et al., 2012, Lyach and Čech 2017a, 2017b, 2018a, 2018b, Lyach and Remr, 2019a, 2019b). The main strength is that data are available for each fishing ground and for each year. Anglers are legally bound to report fish catches - which are also inspected.

Fishing licenses are issued to Czech citizens by the local authorities where the citizen resides, or to foreigners who are staying in the fishing district. Fishing permits for specific fishing grounds are issued by the users of the fishing grounds usually upon payment. The user names the holder of the fishing license in the fishing permit and determines further conditions for the fishing right. Fishers are obliged to state the date of fishing, fishing ground, number, species, total length and weight of the fish retained. Fish that are released back to water are not recorded.

\subsection{FISHING RESTRICTIONS}

Anglers must follow the rules stated in the Fishery Act and Decree No. 197/2004. Furthermore, anglers must follow the rules stated in the further conditions indicated on the fishing right. These rules are set by the user of the fishing ground. The most important legal rules for fishers include minimum size limits of selected fish species; daily allowed fishing times in a calendar year; permitted fishing methods, permitted technical means for fishing and the style of their use (allowed fishing techniques/lures/ baits, fishing gear) and periods of fish protection for selected fish species. Users may tighten up the law in terms of respect for environmental, ecological conditions and scientific reasons and in order to ensure proper fish management. Salmonid fishing grounds have stricter rules for fishing.

Fish species with high commercial and angling value have a minimum legal angling size. The same is true for species with interest to nature conservationists. Closed seasons are set for some fish species (piscivores, salmonids, migratory species, and endangered species) during the spawning period. Anglers are allowed to harvest only a limited amount of fish of each species in one day. This number is often relatively low ( 2 or 3 fish). Anglers are allowed to fish only for restricted days in a week (especially in salmonid fishing grounds). Daily hours of fishing are also limited based on season of the year. During winter, daily fishing hours are more restricted. Usage of fishing gear is strictly limited: only one fishing rod per angler on salmonid fishing grounds, maximum of two fishing rods per angler on non-salmonid fishing grounds. No-fishing zones are set on smaller streams and rivers that are dedicated to natural fish spawning. The list of fishing restrictions for individual fish species is shown in Table 17. Fish that do not reach minimum angling size or exceed maximum angling size, fish that are caught within closed season, fish that are caught using banned fishing techniques, and fish that are protected by other Acts and Directives must be returned back into the water. 


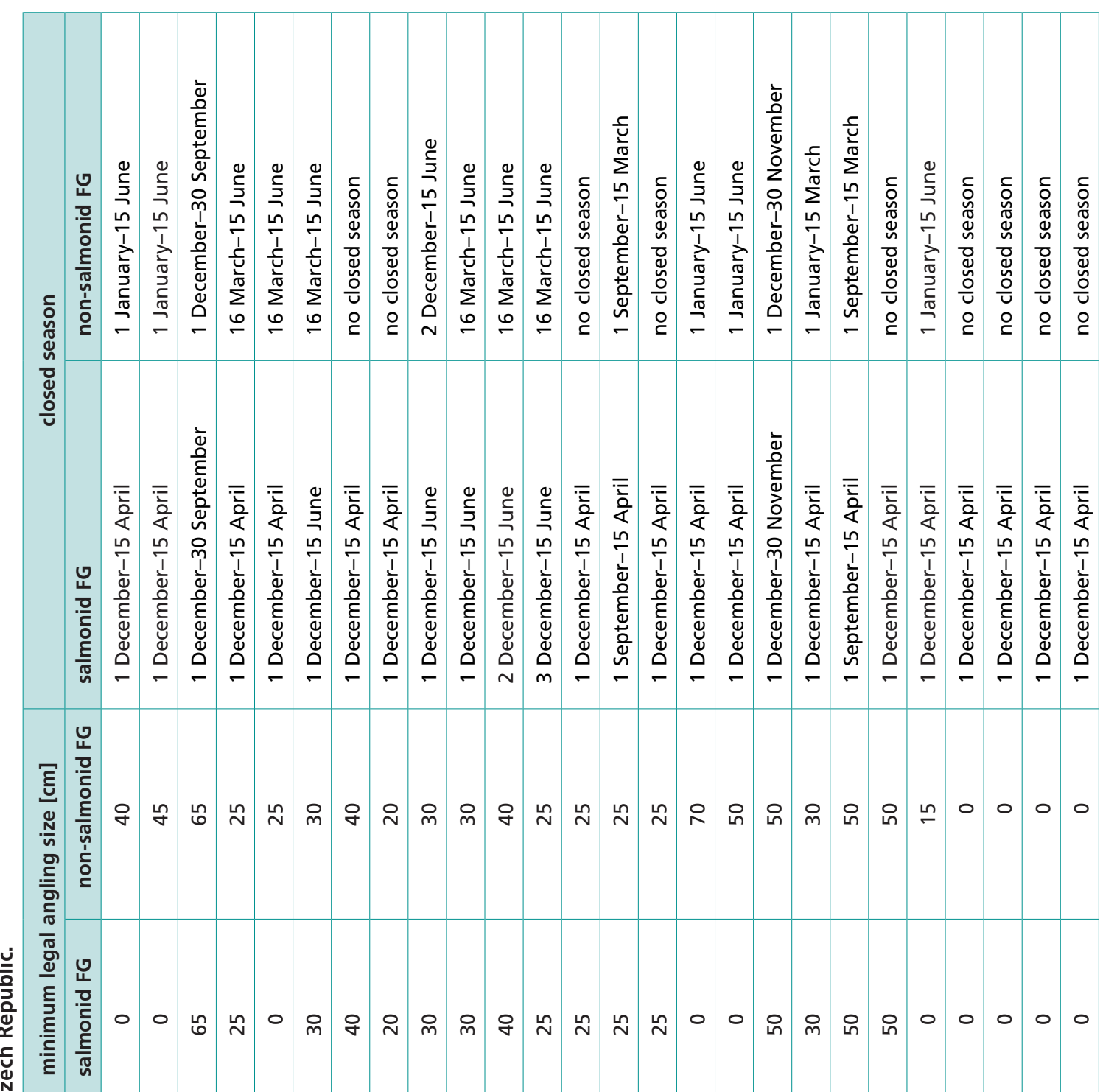

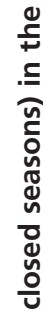

은

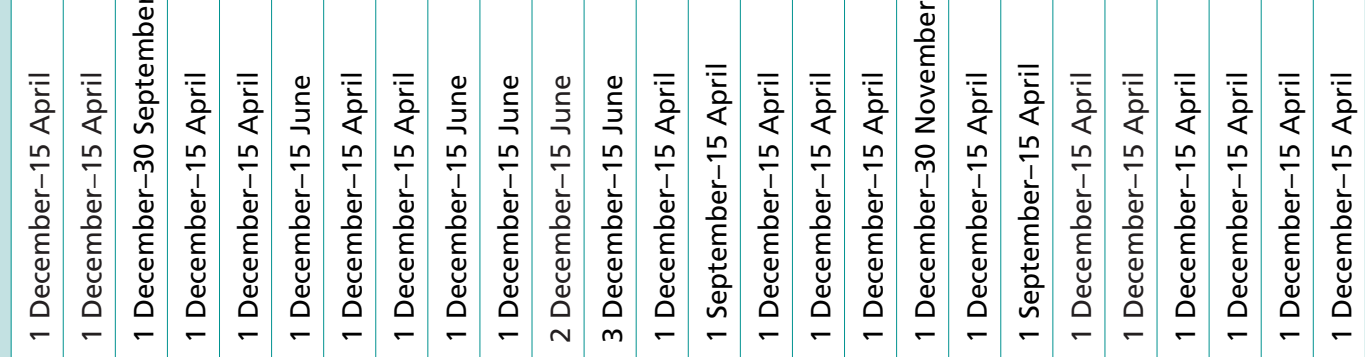

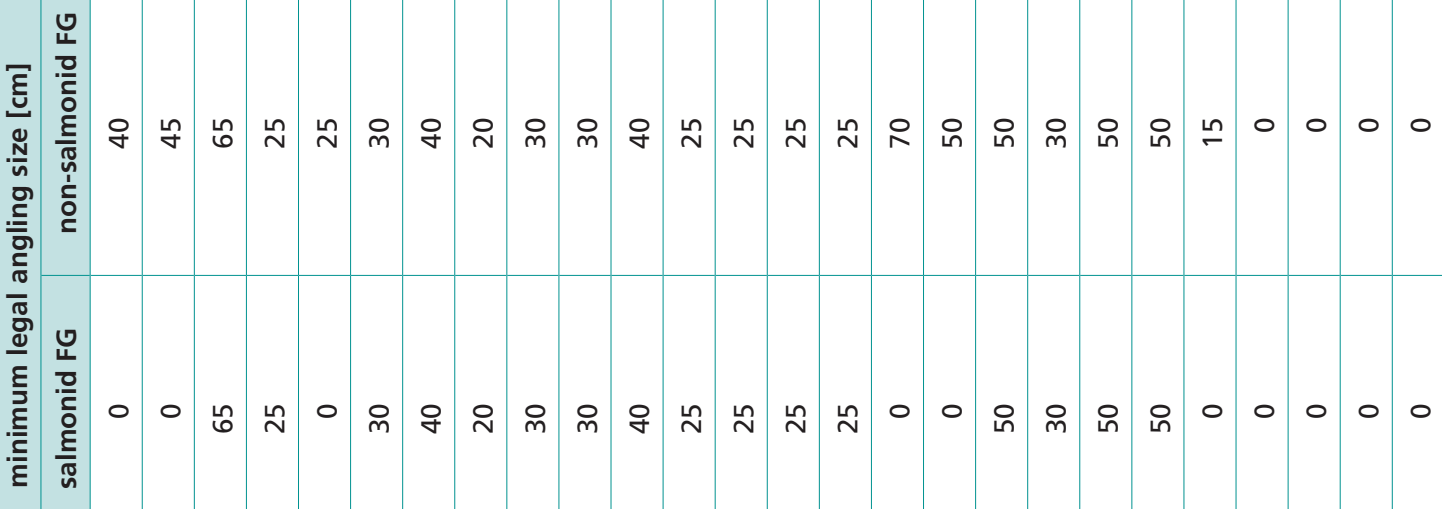
. 
In non-salmonid fishing grounds, the following fishing techniques are permitted:

- bottom fishing, fly fishing and float fishing;

- spinning fishing, trolling and small hand-net fishing only from $16^{\text {th }}$ of May until $31^{\text {st }}$ of December.

Each angler can only take $7 \mathrm{~kg}$ of fish per day even if angler fishes on more than one fishing ground. If a catch exceeds $7 \mathrm{~kg}$ in weight, the angler has to stop fishing for that day. Anglers can take only two of the following species per day: common carp, northern pike, zander, asp, European catfish, or combinations of listed species. Only three individual salmonid fish species (brown trout, rainbow trout, brook trout, European grayling) can be taken per day even if the angler fishes on more fishing grounds.

In salmonid fishing grounds the following fishing techniques are allowed:

- spinning fishing from $16^{\text {th }}$ of April until $31^{\text {st }}$ of August;

- fly fishing from $16^{\text {th }}$ of April until $30^{\text {th }}$ of November;

- bottom fishing and float fishing only for fish other than salmonid species and using only plant-based bait.

Predatory fish species (pike, European chub, European perch, European catfish, asp, zander) have to be removed when caught (no returns back into the water). Each angler can only take $7 \mathrm{~kg}$ of fish per day even if he/she fishes on more fishing grounds. If a catch exceeds $7 \mathrm{~kg}$ in weight, the angler has to stop fishing for that day. Only three individual salmonid fish (brown trout, brook trout, rainbow trout, European grayling) can be taken per day even if fished on more fishing grounds. Listed restrictions are cumulated across all salmonid fishing grounds (e.g. anglers can take a combined total of $7 \mathrm{~kg}$ of fish from all salmonid fishing grounds).

In addition, anglers are not allowed to fish using explosives, poison, narcotics, harpoons (or any sharp objects), bows and crossbows, firearms, larger nets, bare hands, and electric currents. Boat fishing and ice fishing is generally prohibited but exceptions can be made locally. Fishing from bridges, river dams, and fish passes (e.g. fish passes built around river dams) is also prohibited. Fishing during droughts and other extreme events (pollution events, floods) when fish accumulate in one spot is also not allowed.

Each angler is obliged to obtain two key documents before she/he can start fishing: a fishing permit and fishing licence. Each angler has to carry the documents with her/ him during the fishing trip. Adherence to fishing rules is monitored in the field by angling guards.

\subsection{RECREATIONAL FISHING}

The Ministry of Agriculture is the central authority for state fishery administration. The Ministry keeps a register of all decisions on proclamation, amendments and repeal of fishing grounds, and decisions on fishing right permissions. The Ministry also keeps central records of fishing rights in fishing grounds, and records on the management of 2000 fishing grounds. The Ministry of Agriculture produces annual reports about inland fisheries prospects.

\subsubsection{Users of fishing grounds - Czech and Moravian Anglers' Union}

The Czech Anglers' Union and the Moravian Anglers' Union are the biggest users of fishing grounds. The two unions manage the vast majority of fishing grounds in the Czech Republic. Approximately 315000 fishers were registered in Czech and Moravian fishing unions as of $31^{\text {st }}$ December 2016. The Czech Anglers' Union is one of the largest interest associations in the Czech Republic. This union is divided into seven regional boards and 483 local organizations.

The Czech and Moravian Anglers' Unions have had a centralized system to collect statistics for over 60 years. In general, every fish caught in a particular fishing ground must be recorded (date, species, length and weight). From 2005, every angling presence in a fishing ground must be recorded on the fishing permit, irrespective of retained 
catch (proxy of fishing effort, no information about the method of fishing is retained, only the date of the visit - this obligation is not stated in national legislation). Data are summarized on a yearly basis. The total catch from recreational fishing in 2017 is given in Table 18.

There are many types of anglers in Czechia. Generalists usually do not differentiate between harvested fish. Specialists usually focus on one or more individual fish species - mainly common carp, but also piscivores or salmonids. Specialized anglers often use different types of fishing gear and different fishing strategies.

TABLE 18

The annual total catch in $\mathbf{2 0 1 7}$ from the recreational inland fisheries in the Czech Republic, according to the Ministry of Agriculture

\begin{tabular}{|c|c|c|c|c|c|c|c|c|c|}
\hline species & $\begin{array}{l}\text { Cyprinus } \\
\text { carpio }\end{array}$ & $\begin{array}{l}\text { Tinca } \\
\text { tinca }\end{array}$ & $\begin{array}{l}\text { Esox } \\
\text { lucius }\end{array}$ & \multicolumn{2}{|c|}{$\begin{array}{l}\text { Sander } \\
\text { lucioperca }\end{array}$} & $\begin{array}{l}\text { Salmo } \\
\text { trutta }\end{array}$ & \multicolumn{2}{|c|}{$\begin{array}{l}\text { Oncorhynchus } \\
\text { mykiss }\end{array}$} & \\
\hline tonnes & 2750 & 24 & 121 & \multicolumn{2}{|l|}{100} & 15 & \multicolumn{2}{|r|}{67} & \\
\hline species & $\begin{array}{l}\text { Abramis } \\
\text { brama }\end{array}$ & $\begin{array}{l}\text { Silurus } \\
\text { glanis }\end{array}$ & $\begin{array}{l}\text { Anguilla } \\
\text { anguilla }\end{array}$ & \multicolumn{2}{|c|}{$\begin{array}{l}\text { Thymallus } \\
\text { thymallus }\end{array}$} & \multicolumn{2}{|c|}{$\begin{array}{l}\text { Leuciscus } \\
\text { aspius }\end{array}$} & \multicolumn{2}{|c|}{ Hypothalmichthys sp. } \\
\hline tonnes & 145 & 113 & 13 & \multicolumn{2}{|c|}{1} & \multicolumn{2}{|r|}{13} & \multicolumn{2}{|c|}{8} \\
\hline species & $\begin{array}{l}\text { Salvelinus } \\
\text { fontinalis }\end{array}$ & $\begin{array}{l}\text { Squalius } \\
\text { cephalus }\end{array}$ & \multicolumn{2}{|c|}{$\begin{array}{l}\text { Ctenopharyngodon } \\
\text { idella }\end{array}$} & \multicolumn{2}{|c|}{$\begin{array}{l}\text { Carassius } \\
\text { gibelio }\end{array}$} & $\begin{array}{l}\text { Perca } \\
\text { fluviatilis }\end{array}$ & Other & Total \\
\hline tonnes & 7 & 12 & \multicolumn{2}{|c|}{94} & \multicolumn{2}{|c|}{23} & 13 & 38 & 3557 \\
\hline
\end{tabular}

\subsubsection{Special groups and fishing}

The Czech Republic financially supports users to educate children in fishing clubs. Many local angling organizations (Czech and Moravian Anglers' Union) run fishing clubs that are dedicated to children (under 15 years old). The goal of these clubs is to educate children on fishing rules and conservation of fish species. Each fishing club is usually run by one or more lecturers who are also anglers.

Local angling organizations accommodate many handicapped anglers and many individual fishing grounds are accessible to handicapped anglers. Those fishing grounds are listed and marked in a special handbook that describes individual fishing grounds. One local angling organization (LAO Kladruby) accommodates around 700 handicapped anglers.

The Czech Anglers' Union sponsors competitions at national and international level. Czech competitors have successfully represented the nation for many years in the following disciplines: fishing technique; fly fishing, float fishing, spinning fishing and feeder.

\subsection{COMMERCIAL FISHING}

Historically, commercial river fisheries were important on the main rivers (Elbe, Vltava, Ohre and Morava). The construction of river channels combined with pollution caused by rapidly increasing industrial activities during the 19/20th centuries, resulted in the disappearance of the commercial fisheries (usually at family level). In fact, no commercial capture fisheries exist in the Czech Republic nowadays. There is only one small fishing group of the Pohořelice Fisheries Co. ( 2 boats, 4 part-time employees) that is authorized for fishery exploitation of a non-aquaculture water body, located at the Věstonice reservoir, which is a nature reserve. However, its contribution to the total Czech fisheries production figures is negligible.

The Věstonice reservoir (official name VD Nové Mlýny II) - 1033 ha in South Moravia - is the only area available for commercial capture fisheries with an average annual catch of around 40 metric tonnes in 2016-18. Electrofishing gear is exclusively used here. Catch is used partly for restocking angling fishing grounds (bream, roach and other coarse fish species, and trophy specimens of common carp, grass carp, 
European catfish, etc.) and partly for the market (common carp, predatory species - pike, zander, European catfish, herbivorous fish). Besides commercial fishing, angling is also performed on the reservoir on a limited stretch of bank. Catch of both commercial and recreation fishing is recorded on a yearly basis.

The reservoir's fish stock consists mainly of naturally spawning fish like bream, roach, perch and other coarse fish species, however regular stocking of carp, tench and predatory species is regularly provided by the managing company. There is a closed season between 1 January and 16 June, which is set for the protection of spawning fish. Also, closed areas cover the majority of the reservoir as the site is a natural reserve.

From a production point of view, the importance of inland fisheries in the Czech Republic is negligible, as it represents only about 0.2 percent of total fish production. Besides, only 4 part-time jobs are linked to this activity.

\subsection{MANAGEMENT AND MONITORING}

The monitoring of fishing grounds may only be carried out by the user or other institutions who have his/her consent. Monitoring activities look for the use of prohibited fishing methods (electrofishing), and for this, the user must request the competent fisheries authority for an exemption from the prohibited fishing methods. Monitoring also often includes the influence of fish-eating predators on the fish population.

The main water monitoring system in Czechia is run by the Czech Hydrometeorological Institute http://portal.chmi.cz/?l=en, which manages the central database - Arrow http://hydro.chmi.cz/isarrow/index.php?lng=eng, and which contains both chemical and biological data from thousands of profiles. River catchment authorities managed by the Ministry of Agriculture (five state enterprises for the catchment of Elbe, Morava, Oder, Ohře and Vltava) ensure the provision of most data. Water quality data is mostly collected in four-week intervals during the vegetation season.

There are different systems for fish monitoring in running and standing waters. In running waters monitoring includes only sampling of young-of-the-year fish inshore communities as a proxy for fish reproduction potential (Jurajda et al., 2006) https://www.mzp.cz/C1257458002F0DC7/cz/prehled_akceptovanych_metodik_ tekoucich_vod/\$FILE/OOV-RYBY_tekouci\%20vody-20130129.pdf. Young-of-theyear fish communities are sampled every 3-5 years in all running water bodies. Data including other chemical and biological parameters are being used to evaluate ecological quality or ecological potential from the perspective of the EU Water Framework Directive. Young-of-the-year fish data can be used to indicate natural reproduction of individual species. However, most decisions on fishery management is done by experts, with long-term fishery experience in particular water bodies and according to demands of fishers. In many cases, the main target species have no or limited natural reproduction and have to be stocked artificially. This is done mostly with older individuals than young-of-the-year fish and therefore the importance of stocked and fished fish cannot be judged from the monitoring results.

In standing water, monitoring includes analysis of all year classes by CEN multimesh gillnets, hydroacoustics and electrofishing according to Kubečka and Prchalová (2006). http://www.forumochranyprirody.cz/sites/default/files/29.pdf. Regular monitoring of all water bodies has not been established, however about 150 annual standard reservoir surveys are available in the databases of the Institute of Hydrobiology, Biology Centre Czech Academy of Sciences. https://www.hbu.cas.cz/en/. The population dynamics data in three-dimensional sampling are generally more comprehensive than just young-ofthe-year fish inshore communities. They are being used to guide the management of fish in water supply reservoirs and large post mining lakes. In recreational fishing grounds, the utilization of standard fish monitoring data is still in an early stage, however, there 
is potential for management utilization as the data contains the proportions and relative abundance of all species of different ages (see the Lipno case study later in this chapter).

Fish monitoring in fishing grounds may be carried out only by the fishing ground users or other institutions who have the user's consent. If monitoring involves the use of fishing methods other than angling (i.e. electrofishing), the user must request an exemption for prohibited fishing methods from the competent fisheries authority. Monitoring is often carried out to assess the influence of fish-eating predators on the fish population.

\subsection{ENVIRONMENTAL ISSUES AND CONFLICT WITH OTHER WATER USES}

Cooperation between fisheries managers and other users of water bodies is often complicated. Building of small hydro-power plants and anti-flood measurements is often perceived by fisheries managers as negative, mostly because it partially prevents migration of diadromous, rheophilic, and salmonid fish species. As a rule, local fisheries are involved in the process of approving new developments in the water industry, and at least the most important issues are taken into account.

Angling and fisheries managers claim that the fisheries sector is significantly threatened by increasing populations of fish-eating birds and mammals, especially the great cormorant Phalacrocorax carbo and the Eurasian otter Lutra lutra. Since otters are protected by environmental protection laws, commercial fisheries are being compensated for fish losses caused by otters. Fish losses caused by cormorants are only partially compensated. However, fish that are stocked in public rivers and streams are considered as "property of nobody" by law. Therefore, no compensation is provided for fish losses in recreational fisheries.

Nature conservation strongly criticizes intensive fish stocking, especially when non-native fish species are being stocked. The problem is that both common carp and rainbow trout - two of the most intensively stocked species - are not native to most of Czechia. Rainbow trout is not even native to Europe. Common carp could potentially compete for resources with native fish species. Carp also make the environment partially inhabitable to other species (fish, water birds, amphibians). Rainbow trout could potentially compete for food and shelter with native salmonids.

\subsection{DIADROMOUS SPECIES}

The importance of diadromous fish decreased sharply as a consequence of building dams in the first half of the $20^{\text {th }}$ century. Out of some ten diadromous species originally in Czech waters, only the eel, Anguilla anguilla has retained commercial importance.

\subsubsection{European eel}

Glass eels are mostly transported to Czechia and distributed in inland waters. The general preference is to avoid stocking into the catchment of large hydroelectric reservoirs, where adult eels can be killed by the turbines.

Eels can be angled in all fishing grounds. The legal size is $50 \mathrm{~cm}$ TL (total length). The closed period for eel fishing is 1 September - 30 November. As with fish, every captured eel in official fishing grounds is reported. For every fishing ground, there is information on numbers of stocked and harvested eel. General tendency of eel catch is clearly declining (Figure 24).

Eel management is controlled by national plans for the management in the rivers Elbe and Oder (eel management plan). National plans are being developed in the particular EU member states on the basis of Council Regulation (EC) No. 1100/2007.

\subsubsection{Atlantic salmon}

Atlantic salmon Salmo salar, used to be a highly commercial species. However, salmon populations perished in the 1950s after intensive building of water dams. 
FIGURE 24

The dynamics of yearly eel catches in fishing grounds of the Czech Anglers' Union (Official CAU statistics, blue thousands of individuals, red thousands of $\mathrm{kg}$ )

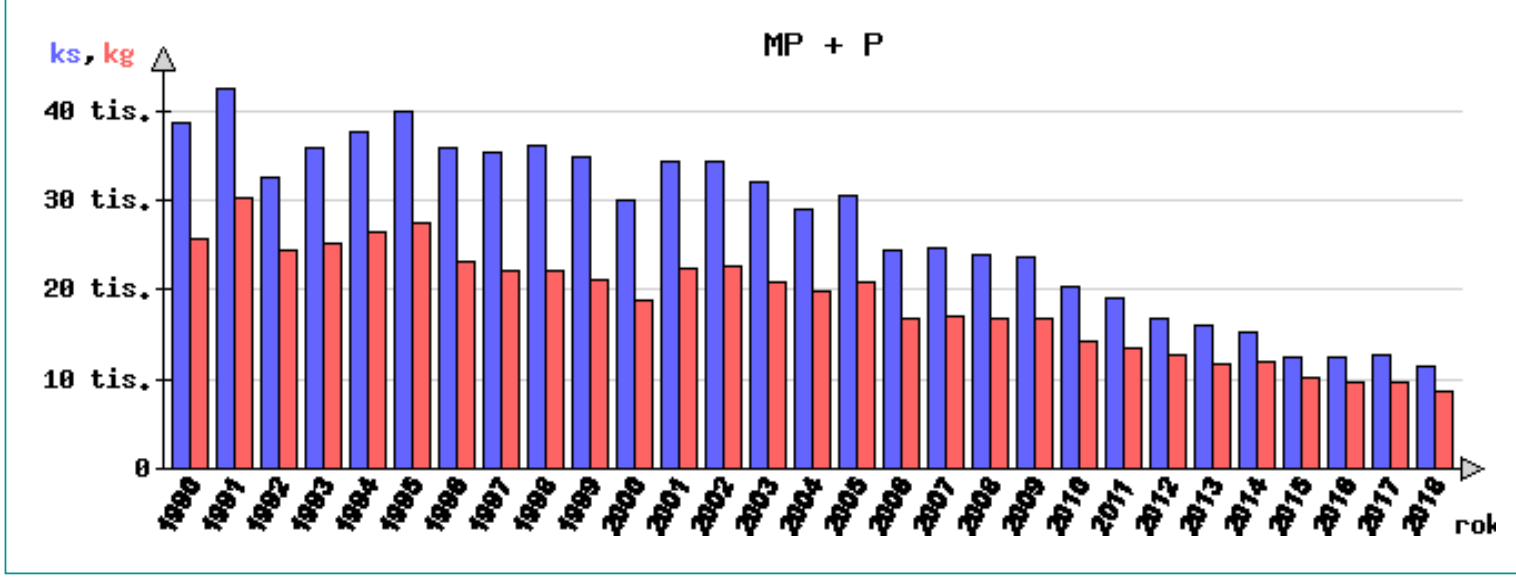

In 1998, a salmon reintroduction programme called "Salmon 2000" was launched. The goal of this programme was to use fish stocking to reintroduce salmon to rivers and streams in Czechia. So far, three streams have been chosen for salmon stocking (the Liboc stream, the Ještědský stream, and the Kamenice river). Salmon eggs are transported from western Sweden (River Götaälv and the River Ätran). Eggs are then incubated and hatched using two methods: (1) in aquaculture in east Germany (near Langburkersdorf); or (2) in incubators located in nursery streams. Results indicate around 10-30 adult salmon are observed to return to spawning grounds every year. Harvesting salmon is banned in Czechia - caught salmon have to be returned to the water. Caught salmon are not reported in angling catches, however, observed salmon are reported by the Czech Fishing Union, the Agency of nature and Landscape Protection, the National Park Bohemian Switzerland. Small salmon (fry, parr, and smolts) are monitored in the wild by scientists from the T. G. Masaryk Water Research Institute. A video salmon movement detector was installed in stocked streams to monitor fish movement. In addition, electrofishing surveys are conducted annually to estimate salmon density, growth, and survival. Scientists and fisheries sectors from Czechia and Germany cooperate on this project. Salmon stocking and monitoring is mostly financed under the EU Operational Programme "Environment". The biggest problem with salmon monitoring is that there are very few returning salmon in general. Adult mortality is very high, especially downstream from Czechia and in the Baltic and Northern seas. Return rates of salmon need to rapidly increase in order to make this reintroduction programme successful.

\subsection{CASE STUDY: LIPNO RESERVOIR - LARGE LAKE WITH EXTENSIVE RECREATIONAL FISHING}

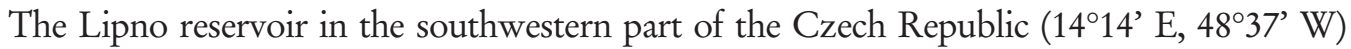
is the largest artificial lake in the country. Its surface area is $47 \mathrm{~km}^{2}$, mean depth 5.5 $\mathrm{m}$, mean water residence time $0.6 \mathrm{yr}$, and mean surface elevation $725 \mathrm{~m}$ above sea level. Its purposes include hydropower, flood protection, flow augmentation, and primarily recreation and fishing. The lake is dimictic, with an ice-free period from April to November, and summer surface water temperatures up to $25^{\circ} \mathrm{C}$. Its water has a slightly brownish colour $\left(20-30 \mathrm{mg} \mathrm{L}^{-1} \mathrm{Pt}\right)$ and the lake is moderately eutrophic with phosphorus as a limiting nutrient (total P 25-40 $\mu \mathrm{g} \mathrm{L}^{-1}$; mean/max. chlorophyll-a $15 / 40 \mu \mathrm{g} \mathrm{L}^{-1}$; water transparency about $2-2.5 \mathrm{~m}$ ). The usual water level cycle is as follows: the highest level in spring after snow melting in the catchment. During 
summer-autumn, the water level decreases and it is lowest at the start of winter so the reservoir is ready to catch snow water. Flooding of vegetation seems to have an effect on natural reproduction of many cyprinid fish species.

The Lipno Reservoir was filled in 1959. From a fishery point of view, it was exploited for both recreational and commercial fishing. Gradually, the proportion of commercial fishing decreased while the proportion of angling increased. The commercial fisheries were run by the state and it was oriented towards species that are less valued by the anglers (bream, white bream, roach, perch, whitefish). The bulk of catch was represented by less valued cyprinid fish and the State fishery experienced some problems with low market demand for these species. Sales problems and the adverse pressure from the anglers were the main reasons why commercial fishery was stopped in Lipno as in most other Czech reservoirs. Regular commercial fishing ceased in 1970 (Vostradovský and Tichý, 1999). The last attempt of commercial fishing was for harvesting of whitefish (Coregonus maraena and peled) during the NovemberDecember period at the turn of the centuries by the Angling Union. The catches were in the order of $1000 \mathrm{~kg} / \mathrm{season}$. Later, the stock of both whitefish species fell rapidly to full extinction (Kubečka, 2018) and harvesting ceased.

Fisheries management of the reservoir consists mainly in establishing the angling regulations and deciding on the stocking strategy. These measures are discussed by the "Management board", which meets three times a year. Their suggestions are then discussed and approved by the South Bohemian Board of the Anglers' Union.

\subsubsection{Data collecting}

Catch statistics from the Lipno Reservoir have been collected since 1958 on a yearly basis. As with all Czech fisheries, every fish taken from the fishing ground must be recorded. This database contains the numbers, total weight and average weight of every fished species (see Table 16). The actual length and weight of daily catch is recorded during angling visits but unfortunately this information is not routinely stored and is deleted after taking yearly catch summaries from every angler. The Biology Centre CAS and the University of South Bohemia retained all paper copies of anglers' logbooks from the region since 2010 and some of the daily results have been digitized (Boukal, personal communication, 2010, 2011, 2016). This information contains valuable information on angler behaviour, selectivity, seasonality and the size distribution of the catch of individual species. So far, there is insufficient support to prepare it for proper publication.

The fluctuation of angler catches throughout history motivated the South Bohemian Board of the Anglers' Union to initiate surveys of the lakes by ichthyological and stock assessment methods. These followed the early works of Vostradovský et al during 1960-1980. In the 1990s, surveys were done by traditional method of night shore seining (Říha et al., 2008) and by ichthyoplankton surveys, (Matěna et al., 1999). In 1993 and 1995, the first surveys by scientific echosounders were conducted. Since 2003, surveys are done in a more complex way, by a combination of scientific echosounders, CEN multimesh gillnets, fry trawling and beach seining. In 2009-12 adult fish pelagic trawling was also tested in the reservoir. The full list of surveys undertaken is provided by Kubečka et al. (2019); most results have not been published but are available in grey literature reports or in the databases of the Biology Centre CAS. Extensive samples of fish scales, otoliths and guts were collected. Limited questionnaire surveys of anglers were conducted in 2009 and 2016. During 1996-1997, the downstream passage of fish through the turbines of Lipno Reservoir and the damages were investigated (Hartvich et al., 1998,1999).

Annual stocking programmes during 1995-2015 included on average 74000 carp (91 $000 \mathrm{~kg}), 4300(580 \mathrm{~kg})$ one-two year old tench, $2800(470 \mathrm{~kg})$ bream, $2700(300 \mathrm{~kg})$ perch, 145000 yolk sac pike, 80000 pike yearlings, $600(300 \mathrm{~kg}) 1-3$ 
year old pike, 83000 yearlings of pike-perch, $1900(5 \mathrm{~kg}) 1-3$ year old pike-perch, $160(185 \mathrm{~kg})$ grass carp, $60(16 \mathrm{~kg})$ brown trout, $6500(2900 \mathrm{~kg})$ rainbow trout, 125 (33 kg) charr, Salvelinus fontinalis, 80000 larvae of burbot and $4200(335 \mathrm{~kg}$ ) of other fish (mainly cyprinid species). Of earlier stocked species, stocking of eel and wells catfish was stopped before 2000. Catfish influence upon other predatory species, especially pike-perch, has been considered undesirable. Eel has little chance to survive the passage through the turbines of Vltava river reservoir cascade and therefore stocking of this species in the whole catchment was stopped.

\subsubsection{Fishing restrictions}

General fishing rules for non-salmonid fishing grounds apply to the Lipno Reservoir (see Chapters 5.2 Legal background and 5.4 Fishing restrictions). Fishing from the boats and dragging the behind boats driven by rowing is permitted. Of all the possible animal lures, only the following are allowed: worms (Annelida) dipteran larvae (Chironmids), fly larvae and whole fish with total length (TL) larger than $15 \mathrm{~cm}$. The minimum legal size of all other fish species not mentioned in Table 17 is set at $15 \mathrm{~cm}$ TL. Non-stop daily fishing is allowed from 16 June until 31 August and anglers must use light at night so that their location is visible for fishing guards. Local limitations for angling activities apply at some areas on the reservoir.

In 2009, the minimum size of the bait fish was increased to $20 \mathrm{~cm}$ TL in order to protect the overfished pike-perch population. This rule practically excluded fishing of pike-perch with live bait. At the same time, several protected areas with a complete fishing ban were established. In 2016, the strict size limit for the bait fish was reduced to $15 \mathrm{~cm}$ TL and pike-perch catches increased (Figure 25).

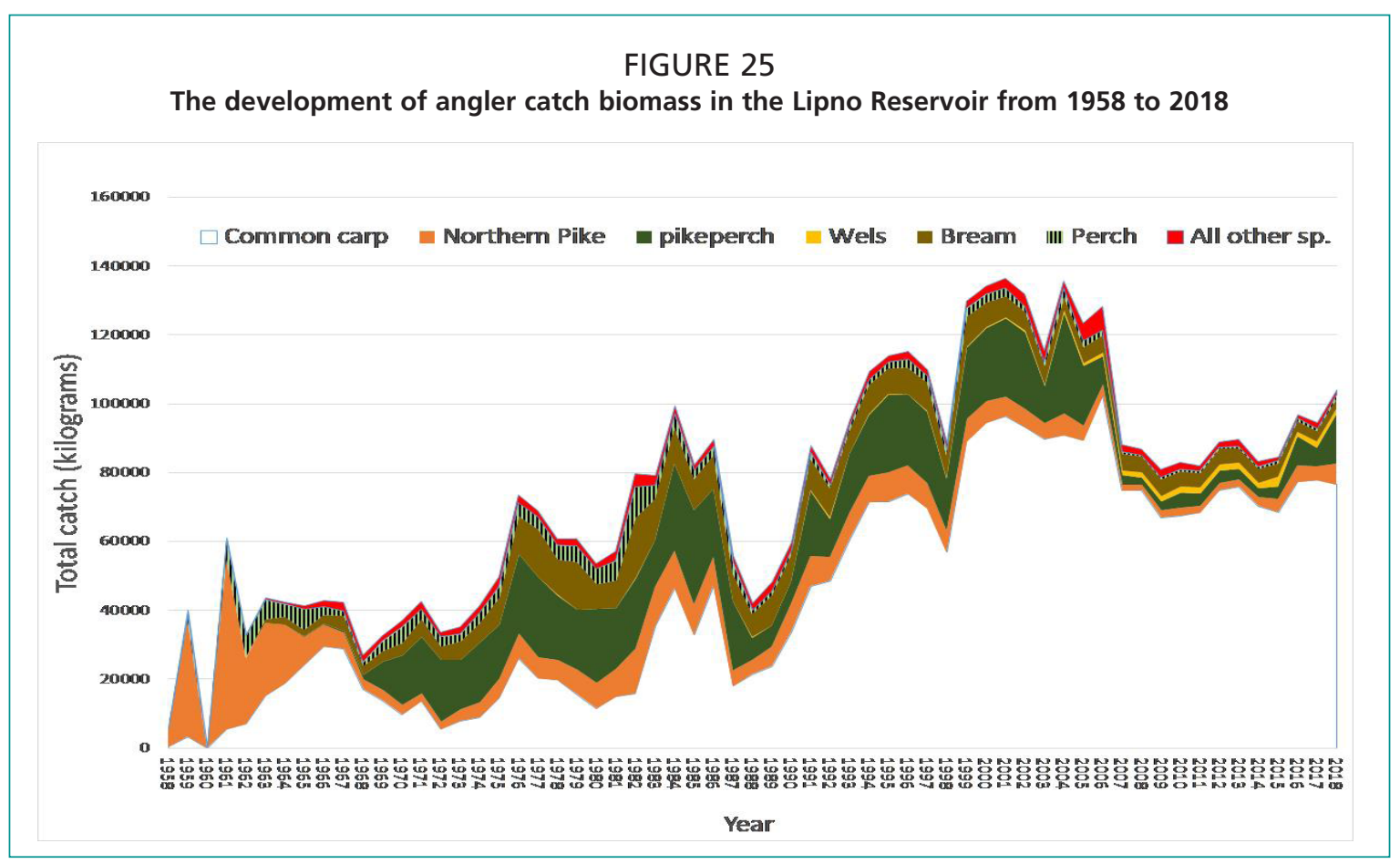

\subsubsection{Fishing and catches}

Figure 25 shows angler catches in the reservoir over time. It is possible to see a gradual increase in catches mainly due to an increase in carp angling. Carp is the main fish species. Natural reproduction in the reservoir is virtually inexistent and fully relies on artificial stocking (Boukal et al., 2012). Stocking has increased in both number and size over the years. This, together with an increasing number of anglers, led to significant 
increase in catches. One drop in catches was recorded between 1987 and 1990. Both biological and socio-economic reasons may have contributed to this drop. The second and more apparent drop in catches was recorded after 2005 with only a slight recovery in recent years (Figure 25). This factor has been studied in more detail and some clues offer an explanation. The Lipno Reservoir was well known for pike-perch (Sander lucioperca) catches. Normal harvest used to be in the order of 20 tons per season. At the turn of century, the growth rate and survival of pike-perch apparently declined and the population was not able to withstand strong angling pressure. Catches declined down to 2 tons per season. It was interesting to observe that several years after the pike-perch decline, some anglers lost interest in the lake and fishing visits declined by one third.

The Anglers' Union tried to maintain the attractiveness of the fishing ground by increased stocking of carp (Boukal et al., forthcoming) but this has not fully mitigated the decreased interest of anglers. In 2009, the Angling Union introduced protection measures to protect the pike-perch stock (see previous subchapter 5.8.2 - Fishing restrictions). At the same time, water level management was improved, so more fish were able to spawn in the flooded vegetation. More forage fish improved the food conditions for predatory fish and the growth rate of pike-perch improved after 2010. The year class success of the pike-perch seems to be strongly connected with the year class strength of perch. For example, a very strong year class of perch in 2017 gave rise to a very successful year class of pike-perch. The drivers of the perch and pike-perch year class success and their interactions should be studied further. Nevertheless, the pike-perch catches in Lipno and angler visits are showing signs of recovery.

Figure 25 also shows the peak of pike catches in the early years of the reservoir's existence and relatively low and relatively constant proportion of "other fish species" - bream and perch.

The Lipno fishery like all others from Czechia are extremely species and size selective. Figure 26 shows the biomass composition of multi-mesh gillnets (12 CEN sizes + 4 larger mesh sizes according to Šmejkal et al. (2015) in order to be size non-selective). The main biomass in benthic habitats is represented by roach (Rutilus rutilus) and white bream (Blica bjoerkna). The same species together with bleak (Alburnus alburnus) dominate open-water, pelagic habitats. None of these dominant species is important in terms of anglers' catches (Figure 23). Therefore, the production of the most abundant species is very little used. Carp represents some 10-15 percent of the present fish biomass in the lake but it accounts for some 80 percent of anglers' catch. The second most important game fish, pike-perch, represents on average 7 percent of biomass, but only part of this is of legal size (unlike carp where practically all individuals have legal size). This share in the community compared with high angler preference makes this species quite sensitive to overfishing. The same is true for other predatory fish. It would be definitely better if anglers used more natural production of common cyprinid fish like roach, white bream, bream and perch. The production of carp, which is stocked as 1.5-2 kg fish does not occur in Lipno Reservoir but is produced through aquaculture.

\subsubsection{Catch statistics and their scientific use}

Catch statistics are mostly used by the management board and the South Bohemian Board of the Anglers' Union. Earlier summaries were prepared by Vostradovský and Tichý (1999). Boukal et al. (2012) used fish statistics from Czech reservoirs, including Lipno, to model catch and survival of carp in the reservoirs. The largest Lipno reservoir showed the longest survival time of carp in the reservoir before anglers catch a significant part of the stocked fish. Recently, the catch data for carp and pike-perch were used to analyse the effectiveness of carp fishery (Boukal et al., forthcoming). 


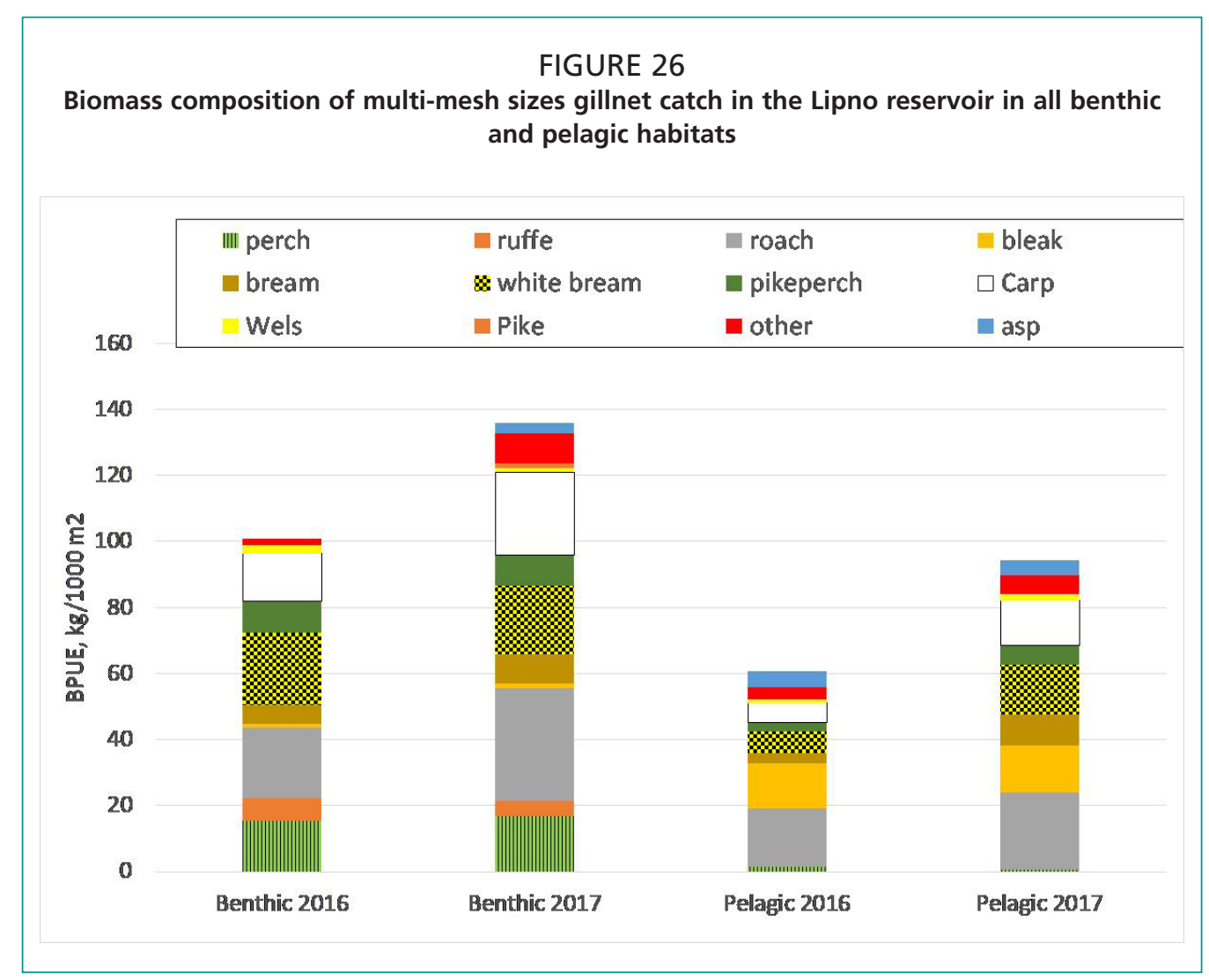

\subsubsection{Socio-economic valuation}

With some 15 thousand anglers, the Lipno recreational fishery merits socio-economical study. It clearly has a positive impact on the local tourist economy. It prolongs the tourist season to spring and autumn months. However, as far as we are aware, no such study has been done. Some partly processed information is available from earlier questionnaire searches. The team from Mendel University in Brno periodically prepares basic socio-economic studies of Czech fisheries. The last edition was published in 2017 (Spurný et al., 2017). https://www.rybsvaz.cz/download/rada/ CRS_socioekonomicka_studie_2017.pdf

\subsection{INTERNATIONAL COOPERATION: BORDER STREAMS AND FISHING GROUNDS}

The Ministry of Agriculture manages the fishing grounds in border streams as well as the fishing rights. International cooperation is not formalized between the countries. The state border passes through the middle of the border watercourses. The fishing ground users are permitted to fish only on half of the border fishing ground in the territory of the Czech Republic. 



\section{Country example: Denmark}

The foundation for Inland fisheries in Denmark is ca $30000 \mathrm{~km}$ of streams (15 $000 \mathrm{ha}$ ) and 45000 ha of lakes with an individual size up to 4056 ha. Most Danish freshwater lakes are small (98 percent $<1 \mathrm{ha}$ ) and shallow (50 percent $<1.6 \mathrm{~m}$ average depth). Common fish species in lakes are roach, Rutilus rutilus (L.), bream, Abramis brama (L.), perch, Perca fluviatilis L., pike, Esox lucius L., and eel, Anguilla anguilla (L.) (Møller et al., 2012). In streams, common species are brown trout (Salmo trutta), sticklebacks (i.e. Gasterosteus aculeatus and Pungitius pungitius) and eels (Larsen, 1955, Møller et al., 2012). Most streams are small and shallow with abundant macrophyte growth. Only two percent of streams are physically unaltered, the vast majority having been straightened and channelled (Brooks, 1984). In addition, drainage and lignite mining during and following the Second World War, have rendered many streams acidic, with a high iron content (Rasmussen and Geertz-Hansen, 2001). However, over the last 35 years many streams have been restored.

Inland fishing has a long tradition in Denmark. 300-400 years ago, fishing rights belonged to the Crown or noble landowners who exploited the resource primarily as a source of food for the household, including the royal court. Today, the basic rule is that the nearest landowner owns the fishing rights in lakes and streams with the exception that public bodies (the State or local city councils) can own fishing rights without being a landowner (Rasmussen and Geertz-Hansen, 2001). The commercial inland fisheries sector developed from the mid-late 1800s and the first angling clubs date back to ca. 1870 (Skov et al., 2019). Back then, angling was considered an unusual hobby, almost exclusively for the male upper class. With a general increase in prosperity and spare time for the population from around 1900, angling became more widespread as a hobby. Today, recreational anglers are by far the most dominant user of inland waters and the commercial fishing trade is close to being non-existent (Skov et al., 2019).

Below we focus on describing various fisheries data collected for statistics. This includes a description of who is responsible for any data collection, how and when data is collected and to whom the results are reported. Data collection from commercial fisheries and recreational fisheries is described separately.

\subsection{DATA COLLECTION FOR STATISTICS}

Below we focus on describing various fisheries data collected for statistics. This includes a description of who is responsible for any data collection, how and when data is collected and to whom the results are reported. Data collection from commercial fisheries and recreational fisheries is described separately.

\subsubsection{Commercial fishing}

Registration of catch from commercial fishery in inland waters was initiated in 1903 by the State. It was the responsibility for the individual commercial fishers to report their catch annually. No sanction was given to those who did not fulfil this obligation. Today, the duty to report landings follows the general EU Data Collection Framework requirements, and relevant data is reported to the EU. In addition, commercial catches in inland waters are reported annually to FAO by the Technical University of Denmark, National Institute of Aquatic Resources (DTU Aqua). 


\subsubsection{Recreational fishing}

With one exception - Atlantic salmon (Salmo salar) - there is no mandatory requirement for anglers, recreational standing gear fishers or landowners to report their catches. This is irrespective of gear type as long as the catches are for personal use (no trading of recreational catches is allowed). Hence, no official catch statistics for anglers and recreational standing gear fishers in inland waters are available, and thus data about harvest rates, effort, size, structure etc. of catch is scarce. A potential source of information about catches is provided by angling clubs, who run their own catch statistics. Some of these also collect information about fishing effort, which has provided a basis for CPUE estimates. Such CPUE estimates have been available for research (e.g. Jansen et al., 2013; Skov et al., 2017) and have provided information about historical trends in catch rates and size structure for a few lakes; and raw data is available to explore historical trends in even more lakes. However, historically there has been no official data transfer from the fishing clubs either to the State or to research institutions.

In rivers where there are native, partly self-reproductive populations of Atlantic salmon, which is on the Danish Red Data List, it is a legal requirement to ensure that anglers report any Atlantic salmon catches (both harvested and released). Hence, angling clubs renting the fishing rights in specific rivers have organized themselves into river-specific angling associations that collect the mandatory data and provide it to the Ministry, as well as to DTU Aqua who use the data to make river-specific management plans, including annual quotas (see also section Salmon case). DTU Aqua subsequently report to ICES and NASCO. Salmon catches are publicly available via designated homepages provided by the river-specific angling associations.

The obligations of EU data collection of marine fisheries (Council Regulation No. 2017/1004, Commission Regulation No. 665/2008) implies that Denmark shall collect data on recreational catches of certain marine fish species. Some of these species (i.e. brown trout, eel and Atlantic salmon) are diadromous and therefore relevant for inland fisheries. The method for data collection is a biannual recall survey, which is managed by DTU Aqua and run by Statistics Denmark. Specifically in the case of eel and trout, respondents are asked about temporal patterns (quarterly) of harvest in freshwater. The sampling frame are recreational fishers - who are Danish residents and hold a valid annual license, implying that no day or week license holders are included in the survey, nor are international tourists. The survey contains detailed questions on species harvested, numbers released and fishing effort over the last six months separated into two quarters. The information is collected separately for anglers and passive gear recreational fishers, and information is obtained specifically for the different ICES management areas as well as for freshwater in general, i.e. no separation between lakes and rivers (Sparrevohn et al., 2010, 2011; Sparrevohn and Storr-Paulsen, 2012; Olesen and Storr-Paulsen 2015). The collected data are reported in annual ICES working group reports and in some occasions as specific technical reports published by DTU Aqua (e.g. Olesen and Stohr-Paulsen, 2015). Respondents are randomly drawn from the sampling frame, and subsequently contacted by postal mail and asked to access an internet platform where the survey is presented in digital form. There is a suite of well-known bias issues related to recall surveys, such as recall bias, telescoping bias and non-respondent bias (Pollock et al., 1994). In addition, unknown bias specifically for catches in freshwater are introduced via the sampling frame, as certain groups of recreational fishers fall outside the sampling frame, i.e. landowners and certain anglers (older than 65 and younger than 18) who can fish legally without annual license (see below for a description of the licensing system). Based on recall survey, Sparrevohn et al. (2011) estimated that the annual catch of brown trout from recreational fishery (anglers and standing gear fishers) in freshwater in 2010, was 81 tonnes, of which anglers caught 75 tonnes and standing gear fishers caught 6 tonnes. 
In 2016, a citizen science approach was introduced for catch data collection as well as CPUE data from anglers. This approach is based on a digital platform where anglers can report their fishing trips. This includes information about fishing location, hours fished, target fish species as well as information about catches, i.e. species, length or weight, fate (released or harvested), and gear used as well as other information. Anglers are encouraged to report blank trips, which allows calculations of CPUE estimates. The digital platform (www.fangstjournalen.dtu.dk) is available for PCs and smartphones, and the latter is also available in German and English, enabling international fishing tourists to report. In order to motivate the anglers to report their fishing trips, the platform intends to provide a number of benefits for the individual angler. For example, it is possible to explore catch statistics for different fishing waters, compare own fishing statistics with that of other anglers, keep catches private or open for public statistics, opportunities to brag about own catches and share information and images from the platform via Facebook or Twitter. It is also possible to enter a monthly prize draw and finally, to get site-specific information about fisheries regulations. The development and continued maintenance of the platform is undertaken by DTU Aqua, who also store the data. Summary statistics for specific fishing waters are shared with the platform users, and examples of preliminary statistics calculated across fishing waters, is regularly published on a dedicated Facebook page. The main purpose of the Facebook page is to further motivate anglers to use the platform by showing how standardized angling data can inform about trends in catch rates and size structure of various fish species. By June 2019, around 10000 users had signed up on the platform. The use of citizen science approaches to collect standardized data about catch rates and fish size distributions, that can inform fisheries managers, is still in its infancy. Globally, the number of smartphones is growing. At the same time, the rapid development in smartphone technology, offers plenty of opportunities to inform and involve anglers in management (see review by Venturelli et al., 2017). This suggests that a citizen science approach, especially using smartphone technology, can have a future in data collection of fisheries data including inland waters. However, there is clearly a need for thorough evaluation of the quality of the data collected with this method.

\subsection{LEGAL BACKGROUND}

\subsubsection{Fishing rights}

Dating back to at least 1683 (stated in "The Act of the Danes", issued by King Christian $5^{\text {th }}$ ), the basic rule is that the nearest landowner owns the fishing rights in lakes and streams with the exception that public bodies (the State or local city councils) can own fishing rights without being a landowner (Rasmussen and Geertz-Hansen, 2001). In streams, fishing rights are usually privately owned, whereas in lakes it is more diverse. In fact, based on a survey from 2001, the fishing rights in about 25 percent (11 $250 \mathrm{ha}$ ) of the national lake area are owned by state or local municipalities, while about 75 percent (33 750 ha) are privately owned (Rasmussen and Geertz-Hansen, 2001). State-owned fishing rights in lakes are in most cases administered by the Ministry of Environment and Food and some by the Ministry of Defense (i.e. lakes in military zones). About 50 percent of these are available for recreational fishing, and 40 percent are hired out to commercial fisheries or angling associations. The remaining 10 percent of the state-owned lakes are not used for fishing. Of the privately owned lakes, $<50$ percent are available for recreational fishing, the remaining being unfished or used for commercial fisheries (Rasmussen and Geertz-Hansen, 2001). The Fisheries Act stipulates that both private owners and the state can lease the fishing rights to commercial and recreational fishers, but only for limited time periods, e.g. up to a maximum of 25 years (Jacobsen et al., 2004). In parts of the lakes owned by the State or municipalities, the public has open access to angling (e.g. in Lake Furesø (941 ha)). In streams and lakes, it is often angling clubs/associations who rent the 
fishing rights and distribute them between members. However, landowners as well as angling associations can also choose to rent out fishing rights on a daily basis. In lakes, it is assumed that less than 50 percent of privately-owned lakes are accessible to fisheries (Jacobsen et al., 2004).

\subsubsection{Fisheries management responsibility}

In Danish inland waters the only mandatory fisheries management that needs to be followed are the fisheries regulations issued by the State. These regulations can be national or local. In addition, the owner of the fishing rights can decide to include additional regulations as long as these are more restrictive than the mandatory ones, e.g. increase minimum size, expand closed season, etc. Apart from following the stipulated regulations, fishing right owners and/or lake/stream owners are not required to monitor or manage fishing intensity, landings, etc.

\subsubsection{Water quality monitoring responsibility}

Monitoring of water quality in lakes and rivers is a responsibility of the State (as part of fulfilling the requirements of the EU Water Framework Directive). This applies to all lakes, streams and rivers irrespective of ownership, i.e. of fishing rights and/or the land that adjoins the water body.

\subsubsection{Legal background for management of inland fisheries}

There are several legal acts that directly or indirectly can influence the management of inland fisheries in Denmark. This includes the Nature Protection Act, Environment Protection Act, Water Supply Act and most importantly the Fisheries Act. These four are described below.

\subsubsection{The Fisheries Act}

The first Fisheries Act in Denmark dates back to 1888 (Berg and Rasmussen, 2012). Today, the Act, together with associated regulations, specifies legal and illegal fishing gear, rights concerning the establishment of fish passages, minimum harvestable size, closed seasons, national and local advisory committees, catch inspection and administration procedures, and penalties (Pedersen et al., 2012).

The aim of the Fisheries Act is to secure a sustainable (biological as well as fiscal) foundation for commercial fisheries and the trades related to commercial fisheries as well as securing an opportunity for citizens to practice recreational fishing. This should be done by a management approach that protects and restores living resources in marine and inland water, as well as through an approach that focuses on the general protection of animals and plants. The Fisheries Act empowers the Ministry of Food and Environment to stipulate regulations governing inland and marine fisheries.

\section{Fisheries regulations}

The purpose of regulations under the Fisheries Act is to preserve and promote sustainable stocks of naturally occurring fish species, and to allow, among other reasons, the opportunity for the public to go fishing. This includes input regulations (e.g. closed areas, closed seasons, gear restrictions) and output regulations (e.g. minimum length limit, quotas), that can be used on a national and regional level (Box 1, Table 19). Among other things, the regulations aim to allow migratory fish to complete their life cycle, i.e. ensure free passage between spawning and feeding areas. Therefore, gillnet fishing is not allowed in streams. In lakes, fyke nets and gill nets are not allowed during the closed season of pike and pike-perch (Box 1, Table 19). In addition, fyke nets have to comply with certain mesh sizes and must include a device to prevent the trapping of otters (Lutra lutra), as well as to ensure that upstream-migrating adult 


\section{BOX 1 \\ Examples of fisheries regulations in inland water (general rules only)}

> Minimum size and closed season regulations for some species (see Table 19).

$>$ Closed season for specific waters and specific gears.

$>\quad 2 / 3$ of the width of streams and lakes must be kept free from fishing with fixed gears.

$>$ Minimum distance between fixed gears in streams and lakes is $100 \mathrm{~m}$.

$>$ Mesh size (bar length) in the cod end of fyke nets must be at least $15 \mathrm{~mm}$.

$>$ Dams or weirs without sufficient opportunity for fish passage, must have eel passes to facilitate upstream migration of elvers.

$>$ Landowners, commercial fishers and standing gear recreational fishers may use fixed gear.

$>$ In lakes larger than 10 ha, where streams with a width of at least $1 \mathrm{~m}$ pass through, fishing with standing gear is not allowed inside an area with a radius of $50 \mathrm{~m}$ both at in- and outlet of the stream.

$>$ In most places, fyke-nets must have a bar at the entrance to prevent otters (Lutra lutra) from entering the gear.

$>$ In lakes, the mesh size in gill-nets must be over $60 \mathrm{~mm}$ (knot-to-knot). During April and May, the use of gill-nets is banned (closed season for pike and pikeperch; see Table 19).

$>$ The use of fykenets for inland recreational fishing is not allowed from 16 October to 31 July.

$>$ Harvest fish from recreational fisheries is for personal use only and is not legally for sale.

$>$ Spearfishing, electrofishing and fishing with explosives and guns are not allowed in freshwater (with a permission, electrofishing can be used for scientific purposes).

salmonids are not caught. The regulations also specify protected zones at lake inlets/ outlets and at the mouths of streams entering the sea.

In addition to the general national regulations, there are numerous additional local or regional variations in these regulations, either set voluntarily by fishing right holders or mandatory by the Ministry. For example, mandatory quotas are used in the management of Atlantic salmon in some of the Danish rivers, and in some rivers, no recreational fishing is allowed from 16 November to 15 January. Moreover, in several river systems and lakes, local anglers have voluntarily set up daily bag limits for certain species.

Suggestions for new or revised regulations usually arise from the ministry itself (dictated by EU regulations), NGO's or in fewer cases, advice from experts, pointing out specific problems. The Ministry also has the possibility to appoint specific advisory boards including their members, for example to make sure that stakeholders are involved and potentially to get advice about social or commercial consequences of changes in regulations. Before changes to regulations are implemented, they go through a hearing process involving stakeholders and experts. One of the aims with this process is to have a transparent decision process and make as much information as possible available for the public. The hearing process and the involvement of related stakeholders is also considered essential in order to facilitate local commitment and 
TABLE 19

Minimum harvest size and closed seasons of some important species for inland fisheries. There are several other species occurring in Danish inland fisheries that are not mentioned. Fisheries for these are not regulated by minimum size or closed season. State-issued local rules can be different, e.g. a total ban (mid October - mid April) on Atlantic Salmon angling in the Western Jutland rivers (see Figure 31)

\begin{tabular}{|l|l|l|}
\hline Species & Minimum size & Closed season \\
\hline Pike Esox Lucius & $60 \mathrm{~cm}$ & 01 April-30 April \\
\hline Pike-perch, Sander lucioperca & $50 \mathrm{~cm}$ & 01 May-31 May \\
\hline Lake trout, Salmo trutta lacustris & $40 \mathrm{~cm}$ & 16 November-15 January \\
\hline Brown trout, Salmo trutta fario & $30 \mathrm{~cm}$ & 16 November-15 January \\
\hline Sea trout, Salmo trutta & $40 \mathrm{~cm}$ & 16 November-15 January \\
\hline Atlantic Salmon, Salmo salar & $40 \mathrm{~cm}$ & 16 November-15 January \\
\hline Perch, Perca flavioatilis & - & No closed season \\
\hline Whitefish, Coregonus lavaretus & $36 \mathrm{~cm}$ & 01 November-31 January \\
\hline Eel (Yellow), Anguilla Anguilla & $45 \mathrm{~cm}$ & No closed season, but gear restrictions** \\
\hline Noble crayfish, Astacus astacus & $9 \mathrm{~cm}$ & 01 October-31 July*** \\
\hline European flounder, Platichthys flesus & $25.5 \mathrm{~cm}$ & 15 February-14 May*** \\
\hline Grayling, Thymallus thymallus & - & 15 March-15 May \\
\hline Houting, Coregonus oxyrhynchus & - & 1 January - 31 December (No catch allowed) \\
\hline Vendace, Coregonus albula & - & 01 November-31 January \\
\hline
\end{tabular}

compliance to suggested regulations. In general, most regulations are revised regularly with 2-10 year intervals (Pedersen et al., 2012).

\section{The licensing system}

Since 1990, the Fisheries Act has stipulated that standing gear recreational fishers, i.e. fishers who use standing gear such as gill nets, fyke nets and hooks in inland and saltwater, require a standing gear State permit and, consequently, have to pay a license fee. The amount of fishing gear used is restricted - i.e. three gill nets (total length of $135 \mathrm{~m}$ ), fyke nets and hook lines for a total of six gears. All standing gear fishers older than 12 years (other than the adjoining landowners in freshwater) have to buy the State standing gear permit, which presently costs DKK 300 (EUR 40). This license is valid for the calendar year. In 2016, 31000 recreational standing gear fishers purchased an annual license.

The license system was expanded in 1993, to include angling and spearfishing. Hence, national and international anglers aged 18-65 have to pay a license fee (presently DKK 185 (EUR 25) annually) for an angling permit covering both inland and marine waters. The license is valid for 12 months from the date of issue. Exceptions to this are adjoining landowners, who can fish without license on their own land. Also, angling in designated "put and take" lakes, a popular type of recreational fisheries (Skov et al., 2019), requires no national license. In addition to the national license, recreational angling also requires permission from the owner of the fishing right (landowner or the State), which is sometimes facilitated through fishing club memberships (Rasmussen and Pedersen, 2018). In 2016, anglers (both marine and freshwater) purchased approximately 140000 annual licenses, 21000 weekly and 30000 daily licenses (Figure 24).

In 2017, the expected total revenue from recreational license fees was 41 million DKK (5.49 million Euros) which was used for: 1) Administration and inspection activities (12.7 percent of the revenue); 2) Management actions such as stocking (34.9 percent) and habitat restoration in streams and lakes (25.6 percent); and 3) Research and outreach aimed to support recreational fisheries management (26.8 percent).

More details about the use of the license fee money are presented later (Section 6.3.4). 


\section{Administration, advisory boards and case-based advisory}

The Fisheries Act and associated standing orders are administered by the Ministry of the Environment and Food (Ministry), which also carries out surveillance activities such as spot checks to ensure that anglers and fishers hold valid permits, use permitted gears, and do not harvest undersized fish or fish in closed areas/seasons.

The Fisheries Act also stipulates that an advisory board (board) should advise the Ministry about management of inland waters including regulations. The chair of this board is appointed by the Ministry, as are the stakeholder organizations that are represented on the board. In situations where there is a need for advice that falls outside the competences of the members of the board, the minister can appoint additional casespecific members. The board also evaluates and approves an action plan every third year, which includes descriptions of stocking plans, outreach and research that can improve recreational fisheries management. This set up implies that stakeholders have direct influence on the management of inland waters as well as on identifying research needs.

The Fisheries Act dictates that any changes in management practices that relate to inland waters conditions, and hence have a likelihood of affecting the fish populations, require specific evaluation by the Ministry. Hence, when the Ministry is notified about such cases, it states its opinion based on advice from research institutions. The decision on which the research institution is asked to advise the Ministry, is based on a case-bycase approach. However, historically and still today, DTU Aqua delivers a significant part of this advice. Until 2008, DTU Aqua was an applied research institute and a part of the Ministry (back then known as Danish Institute for Fisheries Research). Today DTU Aqua is an institute operating under the Technical University of Denmark.

\section{Rules about stocking}

Danish legislation stipulates that only biota (plants, animals, etc.) that are native to Denmark can be released into Danish nature without prior permission, according to Article 31 of the Nature Protection Act. Moreover, any stocking and/or transfer of inland and marine fish between habitats requires permission according to the Fisheries Act. Hence angling clubs, private owners, municipalities, etc. have to submit a stocking application to the Ministry before any stocking event, and stocking can only be commenced when the application has been evaluated. This evaluation will normally include a description of specific procedures that should be followed. For example, that fish should be stocked in numbers appropriate to the specific locality in question and that any stocking event should aim to minimize the disturbance of the genetic structure of native fish populations. In relation to this, the Ministry and DTU Aqua have drawn up guidelines (available at www.fiskepleje.dk) for catching and stripping wild fish for hatchery production of offspring for use in stocking. These are publicly available and distributed to those who breed fish for stocking purposes. Specifically, for salmonids these procedures are secured through the development of stream-specific stocking plans that specify the number, size/age and location of stocking for the individual fish species, which is conducted by DTU Aqua (Rasmussen and Geertz-Hansen, 1998; Rasmussen and Pedersen 2018). See Box 2 for further information.

\subsubsection{Nature Protection Act}

As mentioned above, the Nature Protection Act stipulates that only native plant and animal species may be released into Danish nature. In addition, release of plants and animals that is expected to change the environmental state of a habitat must only be done with a special permit according to Article 3 of the Act. For fish and crayfish, specifically, an order stipulates that the release of these animals is regulated by the Fisheries Act only, taking into account the purpose of the Nature Protection Act. 


\section{BOX 2}

\section{Brown trout stocking plans based on stream monitoring}

In addition to Water Framework Directive (WFD) monitoring (section 6.4.), every single river system in Denmark is monitored every seventh or eighth year. The main objective for this monitoring programme, initiated 72 years ago, is to establish the current state of brown trout production and subsequently any need for supplementary stocking of trout. However, since brown trout is an indicator species for water quality in streams and since other species are registered, the monitoring has a broader use potential.

The monitoring is done by visual inspections of habitat and water quality and in the majority of cases also by standardized electrofishing. In total, 876 individual river systems are monitored with a total of 7480 monitoring stations all over Denmark, of which electrofishing (two or three pass sampling on a $50 \mathrm{~m}$ long section and wading) takes place on about 4485 stations. In the remaining 2955 stations, only habitat conditions and water quality is registered (Rasmussen and Pedersen, 2018).

The electrofishing surveys is used to estimate the extent of wild spawning and wild fry density at the stations and evaluating the outcome of earlier releases of fry and parr. This implies that no stocking of trout fry takes place in the monitored rivers during spring before monitoring in the same year. All monitored stations are described (length of electrofishing site, depth, width, water velocity, colour of water, bottom structure (i.e. soft, sand, gravel and stone), hiding places for trout (bottom and stream banks), shade and vegetation cover.

The station is evaluated on a biotope scale from zero (not a trout locality) up to score five (highest quality) which feeds into the stocking plans for trout. Monitoring always takes place during the period between August to September. Note that only streams with widths up to about 7-8 $\mathrm{m}$ are monitored (by wading), and, in general, very little is known about fish populations in larger rivers in Denmark (Rasmussen and Pedersen, 2018).

The Technical University of Denmark, National Institute of Aquatic Resources (DTU Aqua) is responsible for the monitoring, which is published in a written report and made available to the public. Recently, a digital presentation was made available which includes a digital map of Denmark and its streams with links to all stocking reports as well as all reports set into a public map (https://www.fiskepleje.dk/Vandloeb/Oerredkort).

\subsubsection{Watercourse Act}

This Act governs the exploitation, management, maintenance and restoration of watercourses and lakes, in a manner that promotes good environmental quality of watercourses while ensuring adequate drainage of water. One of the provisions is the requirement for a $2 \mathrm{~m}$ uncultivated border zone alongside natural streams and lakes, as well as other streams and lakes designated as fish waters in the water management plans.

\subsubsection{Environmental Protection Act}

Among other things, this Act aims to prevent and control pollution of the aquatic environment. Regional councils are required to establish water quality objectives for fisheries as well as plans for achieving them.

\subsubsection{Water Supply Act}

Provisions of this Act require water abstraction to be undertaken in a manner that does not adversely affect inland waters. The Act ensures stable water levels in lakes, e.g. during pike spawning, and that freshwater fish farms operating in relation to streams 
and rivers cannot abstract more than a maximum of 50 percent of the median-minimum water flow in the watercourse, to ensure free passage for fauna.

These four Acts are administered either by the State directly (via State agencies) or in part by local municipalities or regional councils that are required to report to the relevant ministry.

\subsection{RECREATIONAL FISHING}

Various studies have estimated the numbers of anglers (both inland and marine) in Denmark from 425000 (Bohn and Roth, 1997), 442000 (Sparrevohn and Paulsen, 2012) and 616000 (Ministry of Food, Agriculture and Fisheries, 2010). The variation in numbers probably reflects variation in sampling methodology. Angling effort is somewhat equally distributed between marine and inland waters, i.e. the proportion of fishing trips for inland waters has been estimated by two independent studies to be 46 percent (Bohn and Roth 1997) and 44 percent respectively (Ministry of Food, Agriculture and Fisheries, 2010).

Between 2005 and 2018, the average number of angling licenses purchased each year was 150240 annual licenses, 18668 weekly licenses and 25263 daily licenses (Figure 24). Notably, the numbers of licenses sold is low in comparison with the estimates of numbers of anglers presented above. This suggests a substantial number of people fishing are without licenses either legally (e.g. under 18 or over 65 years old, are landowners, and anglers in $\mathrm{P}$ and $\mathrm{T}$ waters) or illegally. The average number of standing gear fishers in the period was 32722 people.

Over the last decade, there has been a decline in the sale of annual angling licenses but an increase in weekly and especially daily licenses (Figure 27). This implies a reduced number of anglers who fish frequently, which to some extent is compensated by an increase in anglers who fish more rarely. Standing gear licenses have also declined slightly, at least since 2008 (Figure 27).

Figure 27. Number of daily, weekly, and annual angler licenses (top) and and standing gear fisher licenses (bottom) sold between 2005 and 2018 (https://fiskeristyrelsen.dk/ media/10434/aarsstatistik.pdf). Note, licenses are valid for both inland and marine waters, and consequently do not necessarily reflect the number of recreational fishers in inland waters.

The first angling clubs date back to ca. 1870 and today numerous angling clubs exist. Some of these are organized through the Danish Anglers' Association, but the majority are not, and the Association has experienced a decline in members over the last years. There is no firm information about reasons for this, but it could be partly explained by the concurrent decline in anglers as indicated by a decrease in licenses sold (Figure 27).

The number of angling tourists can to some extent be evaluated from the number of sold licenses, but no information exists on whether these fish in marine or inland waters. The number of licenses sold to people who reside outside Denmark indicates an increase in international angling tourists over the last decade (Figure 28).

\subsubsection{Types of inland recreational fisheries and target species}

In freshwater, recreational fishing is almost exclusively carried out by angling, as spearfishing is not allowed and relatively few, primarily landowners, use stationary gear such as fykenet and gill nets.

The primary target species in lakes are pike, perch, pike-perch, carp and to a lesser extent eels and coarse fish species. In addition, PandT fisheries for primarily rainbow trout (Oncorbynchus mykiss) are popular, but species like brook trout (Salvelinus fontinalis), arctic char (Salvelinus alpinus) and hybrids between these, as well as sturgeon (Acipenser spp) and European catfish (Silurus glanis) are also available in these artificial fishing lakes. Depending on geographic region, species such as sea/ 
FIGURE 27

Number of daily, weekly, and annual angler licenses (top) and and standing gear fisher licenses (bottom) sold between 2005 and 2018 (https://fiskeristyrelsen.dk/media/10434/aarsstatistik.pdf)

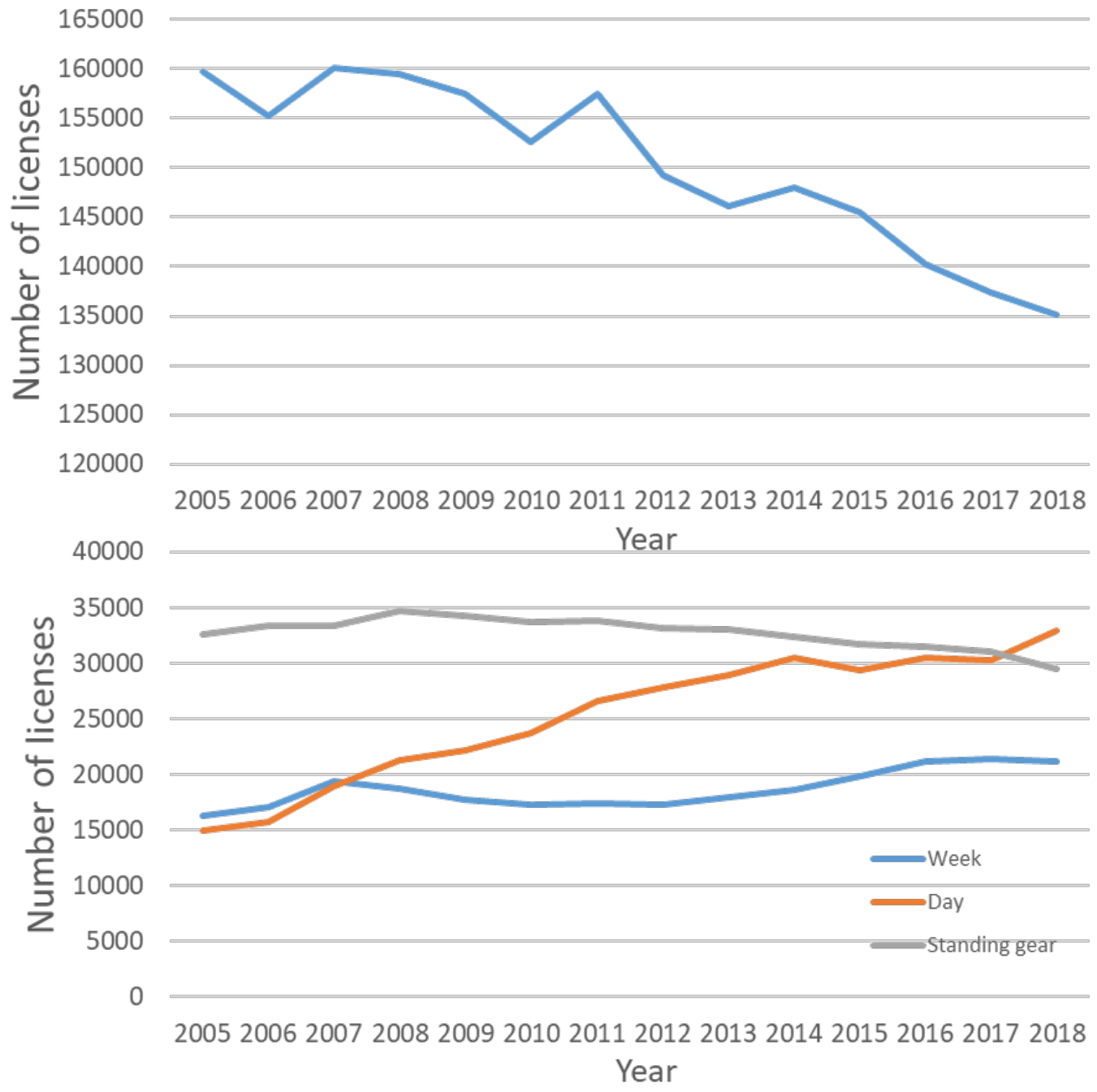

Note: licenses are valid for both inland and marine waters, and consequently do not necessarily reflect the number of recreational fishers in inland waters.

brown trout, Atlantic salmon, rainbow trout, pike and perch are primary target fish for fly-fishing, spin fishing and/or bait fishing anglers in streams (Skov et al., 2019). Noble crayfish (Astacus astacus) are fished throughout the country, mostly in small lakes and ponds. Unfortunately, other invasive crayfish species, i.e. Galician crayfish Astacus leptodactylus (Eschscholz), signal crayfish Pacifastacus leniusculus (Dana), have been released illegally in some areas of Denmark and especially signal crayfish is today widespread throughout Denmark, potentially jeopardizing the local existence of the native noble crayfish.

\subsubsection{Procedures for recreational fishing rights on publicly-owned water bodies}

There is no formal description of procedures to receive recreational fishing rights on publicly-owned water bodies. Fishing rights owned by the Ministry of Environment and Food will often be administrated by the Nature Agency which decides on the degree of public use of water bodies, mostly lakes based on the need for protection 
FIGURE 28

Number of annual, weekly and daily angler licenses sold to people who reside outside Denmark (https://fiskeristyrelsen.dk/media/10434/aarsstatistik.pdf)

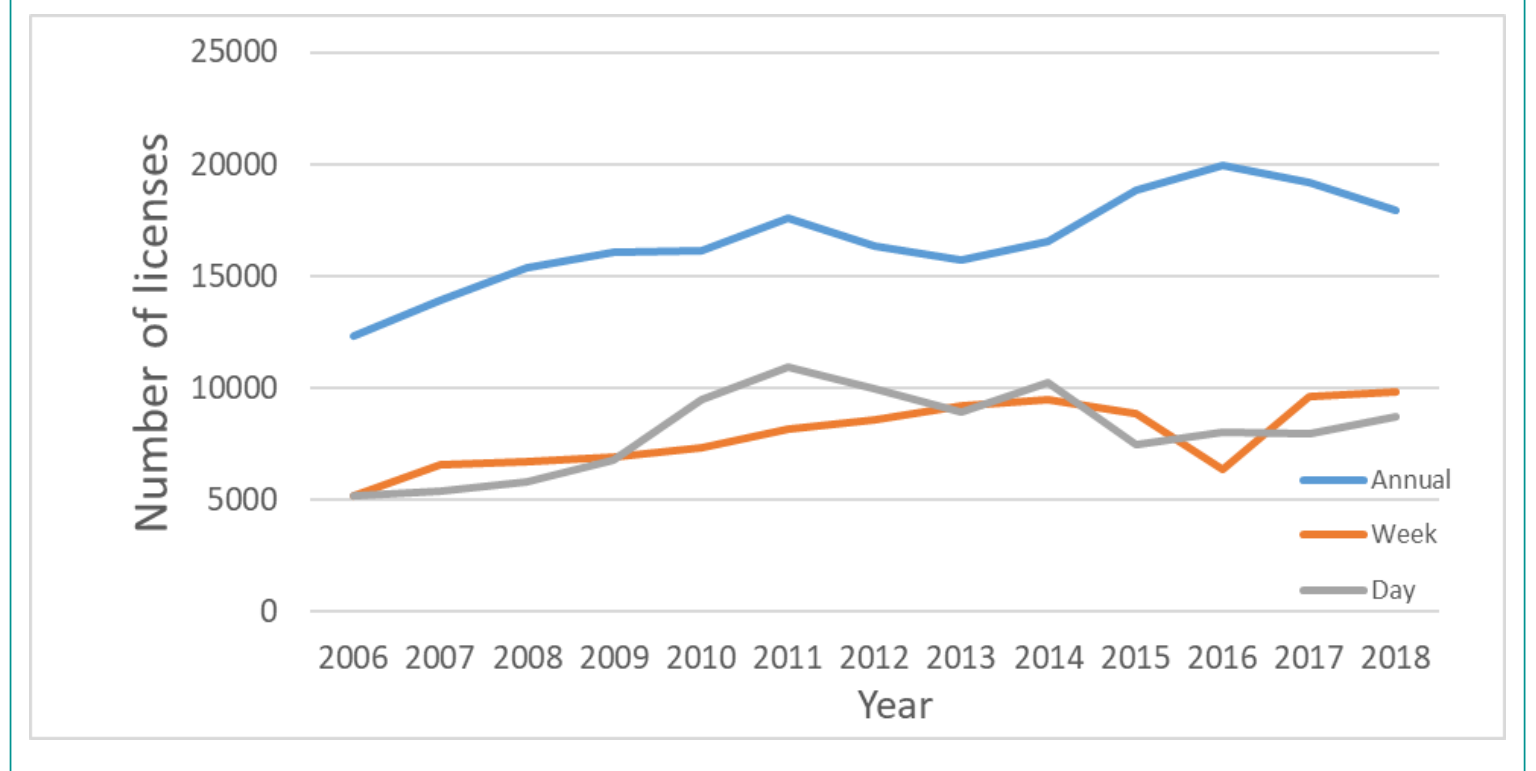

Note: for statistical purposes, this group also includes people who for various reasons bought a license without indicating their country of residence. It is assumed that this group only constitutes a minor part of the numbers reported

of wildlife etc. The Nature Agency develops specific management plans for local areas where they can decide if access to angling should be open to the public, or if fishing rights should be rented out on a daily basis. They can also choose to rent out fishing rights to local fishing clubs. Similarly, the Ministry of Defense produces local management plans for their military areas, which also include how fishing rights of any water body involved can be exploited. In water bodies owned by municipalities, local citizens often have free access to angling. However, the municipalities can also decide to rent out the fishing rights to local fishing clubs.

\subsubsection{Rights and responsibilities of recreational fishers and their organizations}

All recreational fishers must comply with mandatory national and regional regulations (Box 1 and Table 19) and, with a few exceptions outlined in section 6.2.4.1, have to buy a national angling or standing gear license. There are no specified responsibilities in relation to data collection or similar for recreational fishers fishing on public or private waters. The only exception regards catch registration of Atlantic salmon in eight rivers in western Jutland. Here, anglers have the responsibility to report catches on designated homepages before the end of the specific day where the catch took place.

\subsubsection{Management of recreational fisheries}

Management of inland recreational fisheries is an interactive process involving researchers, stakeholders and the Ministry. A cornerstone is that any advisory work provided to the Ministry should be research-based and thereby secure scientific, sound basis for management decisions. This research is based on peer-reviewed studies on relevant waters or fisheries, or by research generated from the license fees, normally conducted by DTU Aqua. In addition, a part of the license money is used for monitoring in order to evaluate the state of riverine fish populations, focusing on brown trout and Atlantic salmon in streams (Box 2). The management model used in Denmark is illustrated and conceptualized in Figure 29, where it shows how 


\section{FIGURE 29}

A flow chart of the management model for inland recreational fisheries in Denmark.

The overall goal is fish populations that can withstand exploitation from recreational (and commercial) fisheries. Three main management tools are used (arrow 1). The use of these is to some extent evaluated by monitoring (mostly streams (Box 2) and only remotely in lakes) (arrow 2) and research which is used to provide advice to the Ministry (horizontal arrow) which establishes the legislation (arrow 3). Science-based advice is also given to various stakeholders (e.g. fishing clubs and associations) (arrow 6). In return, groups of stakeholders are involved in research and monitoring in a number of ways, e.g., by supplying personnel to stream monitoring (Box 2), providing citizen science information (e.g. anglers reporting catches and effort) and as members in an advisory board that commissions the research (arrow 6). Stakeholders are also actively involved in stocking and habitat restoration (mostly in terms of providing personnel), e.g. by organizing and conducting electrofishing for mature fish (i.e. brown trout and Atlantic salmon) that are stripped in hatcheries and used in stocking programmes or by involvement in restoring spawning sites for salmonids (arrow 5). Stakeholders also provide input to legislation, e.g. through hearings or as members of an advisory board that can also give advice about legislation changes (arrow 4).

\section{Goal: Self-sustaining populations (which can be exploited)}

1

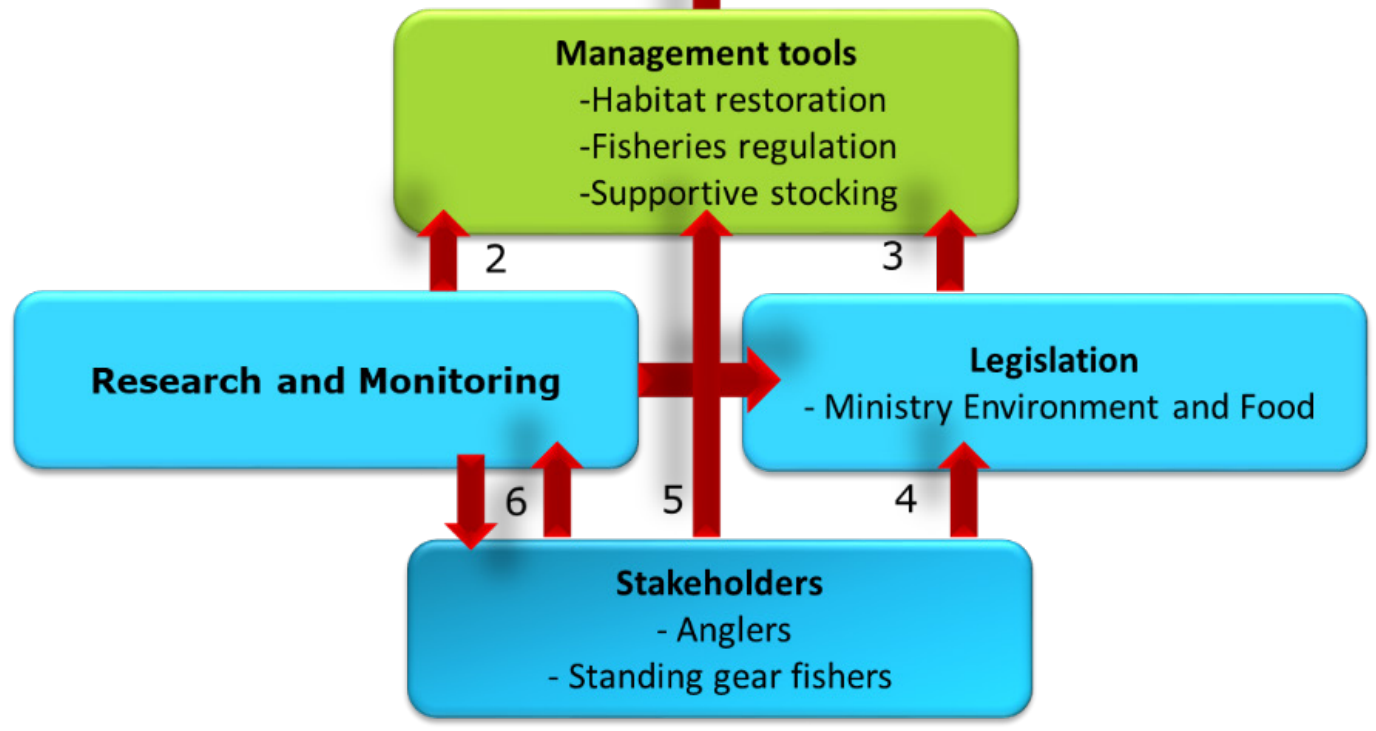

researches, managers and decision makers operate and interact, i.e. the close operation between the Ministry, research and stakeholders (Figure 29). Figure 29 also illustrates the three major tools in the Danish management toolbox, i.e. fisheries regulations, stocking activities and habitat restoration. We briefly describe how these tools are practiced in the following sections.

\subsubsection{Fisheries regulations}

The mandatory regulations stipulated by the Fisheries Act was mentioned earlier (Table 19, Box 2). In addition to these, there are a number of regional, site-specific regulations, either set as mandatory regulations by the Ministry or locally by fishing right holders or angling clubs. For the most part, these regulations are founded on principles about biological or social sustainability. In addition, voluntary individualbased regulations can be observed. An example is voluntary catch and release fishing, which has grown in popularity in recent years, not least among anglers fishing for 
pike, where release proportions can be up to 95 percent. These types of voluntary regulations are likely driven by individual and social norms.

\subsubsection{Stocking activities}

The "principle of authenticity" is a main guiding principle for stocking activities in Denmark and as such, a fish species may only be released in an area if it can be demonstrated that it is already present but in insufficient numbers, or that it has previously been present, but is now extinct (Berg and Møller, 1998). An exception to this has been made for non-native pike-perch, which has been released in approximately 100 Danish lakes since 1878 (Dahl, 1982). Today, permits to stock pike-perch are only granted in lakes where it has been stocked previously.

The importance of preserving the original/native and local fish stocks should also be considered when planning stocking activities. This implies that supplementary stocking should be based on offspring from local and wild fish. In cases where fish species have been eradicated by pollution and there is no immediate local genetic resource available, fish from nearby water systems may be used to produce stocking material. In very rare cases, and mostly related to brown trout, domesticated hatchery fish, i.e. fish stocks that have been kept at hatcheries for several generations, are used.

Stocking of fish into inland (and marine) waters can only be undertaken with the prior permission of the authorities. Observations from lakes and streams show that illegal stockings of native as well as non-native potentially invasive fish and crayfish are regularly occurring, but no data exists on the spatial or temporal extent of these introductions.

Stocking of eel for stock enhancement, i.e. supplementary stockings, has been carried out for several decades. Since 1987, all stocking activities have been administrated by the Ministry and have been funded mainly through resources generated from license fees. The advisory board determines the amount of money available for stocking of eels and the quantity that should be stocked in marine and inland waters. A tender is then circulated among Danish eel farmers to deliver 2-5 g eel for stocking purposes. Danish eel farmers usually purchase glass eels from France. Depending on the market price, the United Kingdom, Spain, Portugal and North Africa are other possible source countries. Those farmers offering the lowest price are offered a contract to deliver eels during the summer period of June-August anywhere in Denmark, according to a stocking plan prepared by DTU Aqua. The stocking plan provides details on quantity, place and time for the eels to be stocked. It also considers the suitability of the water with regard to natural food availability and hiding places for the stocked eel. The typical stocking densities for lakes is $100-600 \mathrm{eel} / \mathrm{ha}(2-5 \mathrm{~g})$ and for rivers, it is one eel $(2-5 \mathrm{~g})$ per seven $\mathrm{m}^{2}$. Before the eels are delivered for stocking, they are examined by the National Veterinary Institute for IPN, VHS, IHN viruses and Anguillicola crassus parasites. If the eels are detected positive for IPN virus or Anguillicola crassus, the eels will be excluded from the stocking programme. Two or three eel farmers are usually given a contract to supply eels for stocking. The total number of stocked eels vary between years (Figure 30). In 2017, close to 1.4 million 2-5 g eels were stocked in lakes and rivers. The eels are normally distributed throughout the country according to the stocking plan, which aims to cover all potential eel habitats within a 3-year period.

\section{Lake-specific stocking activities}

Stocking activities in lakes has taken place since the Middle Ages. The main purpose was to establish self-reproducing populations by stocking a relatively small number of large fish. Species involved were mainly tench, Tinca tinca (L.), crucian carp, Carassius carassius (L.), and later also carp, Cyprinus carpio L., and whitefish, Coregonus lavaretus (L.). Around 1860, the first hatcheries were established and stocking became more widespread and included more species. Moreover, it became possible to stock 
FIGURE 30

Restocking of young eels ( $2-5 \mathrm{~g})$ in lakes and rivers from 1987-2017, numbers in millions

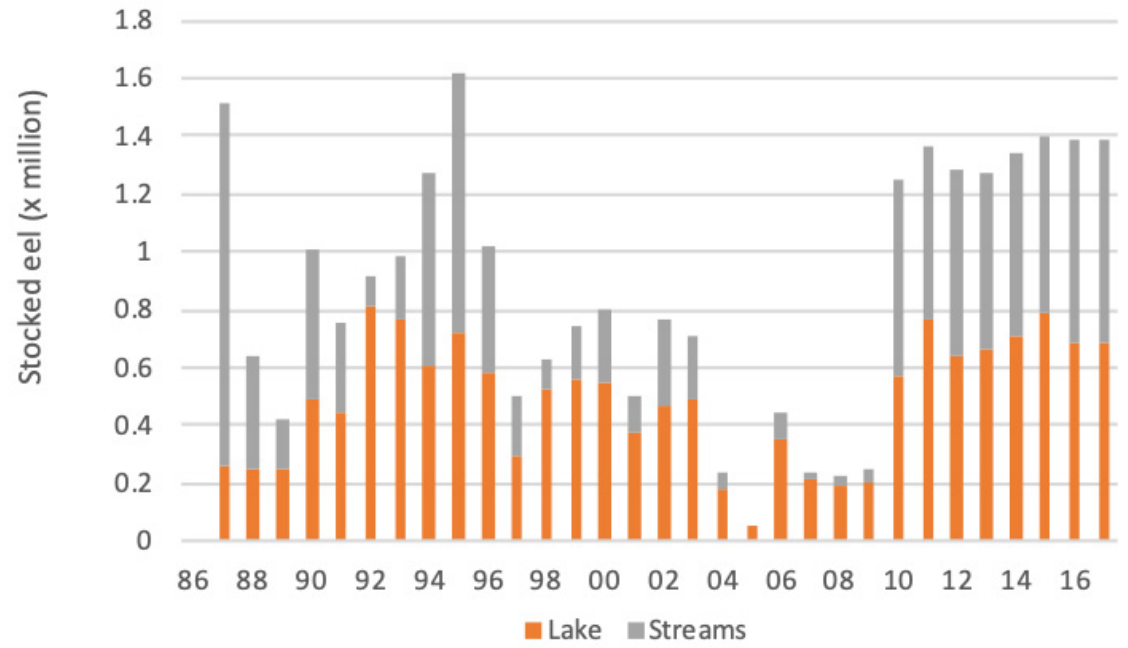

large quantities of fry or fingerlings. For about 100 years up to 1989, translocation of elvers from river mouths to inland lakes was a common activity aimed at increasing the value of commercial fisheries. Today, stocking in lakes is still being practiced, but is far less frequent than previously. See Jacobsen et al. (2004) for more information about temporal changes in species and stocking intensity in lakes.

\section{Stream-specific stocking activities}

Rasmussen and Pedersen (2018), summarize how brown trout today and over time has been by far the most frequently stocked fish in Danish streams. The authors report how the first years of stocking with brown trout fry (first stocking took place in 1858) could be characterized as more or less uncoordinated releases without regard to habitat quality, or fish requirements for depth and cover. In 1938, a so-called modern stocking plan was introduced with release of fry during spring (up to two fry per $\mathrm{m}^{2}$ ) distributed in small streams with stream depths up to $10 \mathrm{~cm}$. After introduction of electrofishing in Denmark in 1947, routine monitoring of a number of trout streams was initiated and fry were released based on the results from this monitoring (Rasmussen and Pedersen, 2018). Still today, stocking of brown trout is based on site-specific electrofishing monitoring programmes producing locality-specific stocking plans that stipulate the genetic origin, age and size of the stocking material (Box 2). This implies that trout should be stocked in numbers appropriate to the locality in question and that the specific stocking locality should take the genetic origin of native fish into account before stocking is undertaken. In relation to this, the Ministry and DTU Aqua have produced guidelines for catching and stripping wild fish for hatchery production of offspring for use in stocking. Moreover, these guidelines have been distributed to all local angling associations engaged in raising and stocking fish, and training and awareness courses, arranged by "fish care" consultants at DTU Aqua (see Section 3.3.6), have also been held on the subject. Despite these intentions, occasionally more domesticated fish stocks, i.e. fish stocks that have been kept at the hatcheries for several generations, are used. Additional detailed information of current stocking practices of brown trout and historical trends in stocking procedures of brown trout can be found in Rasmussen and Pedersen, (2018). 
In addition to brown trout, also eel, Atlantic salmon fry and juveniles are stocked in Danish streams.

\subsubsection{Habitat restoration}

In recent years, there has been a trend in the Danish management of recreational fisheries to focus more on habitat restoration and less on fish stocking as a management tool. In fact, in some cases, local anglers' clubs actually request that funds for stocking be converted into restoration projects. Likewise, the National Angler Association has published a vision that points to less and less stocking in coming years and more and more habitat restoration.

The need for habitat restoration in Danish streams is well documented. Practically all Danish streams have historically been subject to some kind of regulation (channelization, alignment and deepening to facilitate agriculture; damming for construction of water mills, hydropower stations or fish farms) (Brooks 1984). A few decades ago, many streams were also subjected to substantial organic pollution. In addition, drainage and lignite mining during and following the Second World War have made many streams acidic, with high iron and ochre content.

A central problem for migratory fish relates to the fact that many streams have been channelized and deepened over the years resulting in severe loss of rheophilic habitat (i.e. stream sections with fast flow and gravel substrate) ideal for spawning of trout and Atlantic salmon). In addition, weirs at water mills, fish farms, hydropower stations and weirs built for regulation of water level and energy production in the surrounding agriculture land have impaired migration and movement of diadromous and potadromous fish. This has prevented some freshwater species to complete their lifecycle because the barriers could not be overcome by the fish (in many cases because fish passes were inadequate or ill-suited to the particular species). Specifically for anadromous fish, it has also resulted in elevated mortality rates during downstream migration, when passing through reservoirs at weirs and dams. This has in some cases resulted in stock depletions and in some places complete extinction of the stocks (Birnie-Gauvin, K. et al., 2017a, 2017b, 2018, Rasmussen and Pedersen, 2018).

After the 1970s, water quality improved significantly in many streams, i.e. organic pollution became relatively rare and in recent years many of the migration barriers have been removed or fish passes have been improved. Local restoration work has, in many places, improved both accessibility and possibilities for spawning of brown trout and Atlantic salmon by the addition of spawning gravel in suitable places or restoration of natural habitats through removal. In a few places, larger projects have been carried out involving the hydrological system also in surrounding meadows.

It is mandatory to establish and operate eel passes at all dams and weirs without proper fish passage in the period $1^{\text {st }}$ April to $31^{\text {st }}$ October. The authorities can order owners to establish smolt sluices on all dams and weirs (at their own expense) and these must operate annually from $1^{\text {st }}$ March to $31^{\text {st }}$ May. At all freshwater fish farms, gratings have to be established at inlets $(6 \mathrm{~mm})$ and outlets $(10 \mathrm{~mm})$. Gratings are also required at the inlet $(10 \mathrm{~mm})$ and outlet $(20 \mathrm{~mm})$ of hydroelectric turbines, i.e. to prevent fish from entering. However, in some cases dispensation can be given, allowing $50 \mathrm{~mm}$ gratings at both inlet and outlet.

The initiative to commence restoration work in streams is often taken by local angling clubs or associations who actively promote projects to local/national politicians. Often it is also the anglers themselves, after participating in stream restoration courses for laymen at DTU Aqua (organized and driven by the fish care consultants (see Section 3.3.6)), who conduct the practical workload to restore streams, e.g. by putting out spawning gravel for salmonids. Often, money from the national license fee is used to pay for materials for these projects. License fee money can also be used in combination with the larger 
restoration projects e.g. in connection with restorations initiated by the need to fulfill the requirements of the EU Water Framework Directive (WFD).

Since the late 1980s, there have been several lake restoration projects directed towards mitigating eutrophication. After nutrient load reduction, a suite of different lake restoration approaches has been used, e.g. sediment dredging, aluminum treatments and biomanipulation. In relation to the latter, mass removal of cyprinid fishes has been most frequently practiced, sometimes in combination with stocking of fry from predatory fish, most often pike. These efforts can result in improved habitats for some predatory species (Jacobsen et al., 2004) and hence improved recreational fisheries targeting these species. This has also been the case in lakes where fry from predatory fish were stocked to predate on zoo planktivorous cyprinid fish. However, evaluations have shown that such supplementary stocking have rarely resulted in a density boost of fry (Skov, 2018). Consequently, it is likely that supplementary stocking, only to a minor extent, boosted the density of older pike, i.e. pike that are relevant in recreational fisheries (e.g., Guillerault et al., 2018). In a few cases, such as in reestablished lakes, stocking can be characterized as introduction, i.e. no pike were present before the stocking event. In these cases, the abundance of pike fry and subsequently older pike often increased (Skov, 2018).

Restoration projects specifically aimed at improving fish stocks, e.g. constructing spawning areas for pike are still quite rare in Danish lakes.

\subsubsection{Fish care consultants paid by license fees}

A part of the recreational fisheries management flow includes various interactions between researchers and stakeholders (Figure 26). In order to facilitate this, a part of the license money is used to employ two fish care consultants, who focus on recreational fisheries in inland waters. These are fisheries biologists positioned at DTU Aqua, with the specific responsibility to interact with stakeholders, e.g. fishing clubs, municipalities, landowners etc. This includes dissemination of management research results through meetings, conferences and/or a designated webpage. The fish care consultants also educate stakeholders in various topics such as:

- stream restoration and management for local authorities and local fishing associations;

- electrofishing for local communities and fishing associations;

- electrofishing for employees at the environmental authorities and consultants from companies that deal with environmental technology and management; and

- stock breeding for fish stocking purposes.

A website (www.Fiskepleje.dk, in Danish and partly in English) was set up in 2002 and financed by the license fees. The purpose of the website is to ensure that knowledge about fish and fisheries gained by research is available to a broad audience and in this way applied locally throughout Denmark. It also ensures that updated knowledge about fish stocks and ecosystems in water courses, lakes and coastal waters is available to the public in order to support the efforts of local authorities and fishing associations and thus support a sustainable recreational fishery in a diverse environment. The typical users of 'www.fiskepleje.dk' are employees in local or regional environmental authorities and in private consultancy companies, and not least recreational fishers. In addition, students, teachers and journalists as well as others with an interest in fish and fish care management use the website. The website provides information on research activities, publications, fish biology in rivers, lakes and coastal areas, as well as technical advice on restoration of streams. The prevailing stocking plans for trout (Box 2) as well as specific guidelines for stocking can also be found here. New results from research and other relevant issues are also published on the site. In addition, frequent newsletters are mailed to people who have signed up, currently $>5000$ people. 


\subsection{COMMERCIAL FISHING}

Commercial fishing in inland waters is not very widespread today as $<10$ fishers derive a substantial part of their income from commercial freshwater fisheries. This is in strong contrast to previous times. Skov et al. (2019) provide a summary of the history of Danish commercial inland fisheries and highlight how it used to be an important source of food and income some 300-400 years ago. Back then, all fishing rights belonged to the king or noble landowners who exploited the resource primarily as a source of food for the household, including the royal court. Fishing rights were highly valuable, and illegal fishing was severely punished. During this period, commercial fishing also took place, but to a minor extent. During the nineteenth century, many fishing rights were sold or given as privileges to civic citizens. The commercial use was increased and with the construction of railroads, export emerged as well, e.g. to the Hamburg fish market in Germany. Lakes were managed to generate the largest economic yield possible from fisheries and included management measures like stocking and introductions (Dahl, 1982).

In 1903, registration of commercial catch from inland waters was initiated by the State. These registrations show that most lakes were managed by one or a few fishers, often on a lease contract. Eels were the most important species, both economically and by weight, with an annual catch 1930-1980 at ca. $200 \mathrm{t}$ year-1, perch $40 \mathrm{t}$ year-1, pike $20 \mathrm{t}$ year-1 and pike-perch $50 \mathrm{t}$ year-1. The catch peaked in 1957 with a total of ca $1000 \mathrm{t}$ of fish caught. At its peak, several methods were used among commercial fishers, such as pound nets, trawling, gill netting, long lines and fyke nets.

Around 1980, a decrease in eel catches was observed, followed by decreasing catch of other species partly due to a decreasing number of active commercial fishers. In addition, environmental consciousness emerged in the 1980s, goals for lake fish management changed to target management of the aquatic environment as a whole, underlining the role of fish in the ecosystem (Jacobsen et al., 2004).

Increased eutrophication of Danish lakes during the last century has shifted the fish community composition towards dominance of coarse fish like roach and bream. Together with a decrease in eel stocks during the last 20-30 years (Moriarty and Dekker, 1997), this changed the basis for commercial lake fisheries, which in particular target eel, pike, pike-perch and perch. Jacobsen et al. (2004) give an overview of temporal changes in commercial catches between 1900 and 2000. As an example, in 1921 the fishery in the 343 ha Lake Hald had a yield equivalent to the yearly income of three labourers, while it was down to ca. 16 percent of one labourer in 1983 (Нøy et al., 2004). Today, commercial fisheries is a fading trade as the mean annual yield between 2009 and 2018 was, according to the official registration of landings, ca. $44 \mathrm{t}$, comprising 33 percent eel, 37 percent pike-perch, 11 percent pike and 9 percent perch. The decline in active commercial fishers is foreseen to continue and could result in the complete disappearance of this type of commercial fisheries in Denmark within a limited number of years. Despite commercial fisheries being limited to very few water bodies, conflicts between anglers and commercial fishers reoccur from time to time due to allocation issues.

\subsubsection{Rights and responsibilities of commercial fishers}

Commercial fishers have the responsibility to report their catches in specific waters and to follow current regulations.

\subsubsection{Management of commercial fisheries}

Management measures described in section 6.3.4 such as fish stocking and habitat restoration, benefit the populations of target fish, and if such fish is also targeted by commercial fisheries, then such management measures also benefit commercial fisheries. In terms of regulations, the Fisheries Act protects fish populations through 
the avoidance of overfishing. The rate of exploitation in commercial fisheries in inland fisheries is therefore regulated, mainly through restrictions on permitted gear, e.g. trawling is not allowed. Restrictions on mesh size in gillnets, closed season for gillnets, mesh size in fyke nets, distance between and size of gears (Box 1) prevents overfishing and catch of protected fish to a certain degree as well. The private ownership of fishing rights is expected to act as a self-regulating mechanism in preventing overfishing. In a lake with sole ownership of fishing rights, the owner will destroy future fishing opportunities for himself, if the fish population is overfished. Commercial fisheries in Danish inland waters (mostly in lakes) are not subject to quotas.

\subsection{MONITORING OF INLAND WATERS}

Below we summarize the various types of monitoring of Danish inland waters. In most cases, this monitoring is done to comply with the EU Water Framework Directive (WFD), which is under the responsibility of the Ministry of Environment and Food. Data are stored in a national online database (www.miljoeportal.dk) where research institutes and the public can gain access, and monitoring reports are frequently published in Danish with an English summary. Several universities have been and are still involved in WFD monitoring in various ways, but the University of Aarhus (Danish Center for Environment - DCE) is the most frequently involved and does most of the data handling (e.g. Johansson et al., 2019, Thodsen et al., 2019).

\subsubsection{Streams}

To fulfill the EU WFD obligations in Danish streams, two fish indices are used. One is the intercalibrated Lithuanian index (LZI), the other is an index based only on brown trout (Kristensen et al., 2014). The trout index is used in small rivers where only few fish species are found. This index has been shown to reflect water quality, connectivity and physical alterations. It is very simple, based on the density of young-of-the-year brown trout or salmon, requiring a density of 80 individuals $/ 100 \mathrm{~m}^{2}$ to achieve good ecological status.

WFD monitoring including index monitoring of brown trout, takes place in a number of streams throughout the country (Thodsen et al., 2019). This entails standardized electrofishing surveys in monitoring stations scattered in streams throughout the country (https://mst.dk/natur-vand/overvaagning-af-vand-og-natur/ vandloeb/) and includes:

- 800 stations covering all stream types in Denmark are monitored once every sixth year (not all are surveyed for fish);

- 35 climate-stations are monitored every year. These are used to describe year-toyear variations;

- 3800 additional stations are monitored over a six-year period. These stations are selected from stream sub-types not covered by the previous network (not all are surveyed for fish); and

- 7480 stations are covered by national plans for stocking/management (Box 2). Each station is visited every 7-8 years and of these, 4485 stations are electrofished to assess the density of trout/salmon (Box 2). Other species are also recorded. This is done by DTU Aqua, and data are made available for the Environmental Agency and the public (Box 2).

\subsubsection{Lakes}

The Ministry of Environment and Food monitors a number of lakes. The current monitoring programme for lakes (part of the National Monitoring Programme for Water and Nature - NOVANA) includes monitoring in relation to the EU WFD (European Union 2000) and the EU Habitats Directive (European Union 1992). According to the WFD, there are two main types of monitoring - control monitoring 
and operational monitoring (Johansson et al., 2019). According to the Habitats Directive, control monitoring and mapping of lake habitat types are required and a State programme exists for this purpose for lake habitat types in small lakes and ponds. This implies that one third of the Danish lakes $>5$ ha (198 lakes) are monitored regularly - normally every 6 years. This includes seasonal measurement of various chemical, physical and biological parameters and normally also includes standardized gillnetting for fish (Johansson et al., 2019). Of these 198 lakes, 18 are monitored more intensively, i.e. with higher within year and between year frequency. However, even in these years, standardized gillnetting for fish is restricted to every sixth year (Johansson et al., 2019). For water bodies smaller than 5 ha, a total number of 420 lakes/ponds are monitored with a six-year frequency ( 210 water bodies between 1-5 ha, 210 water bodies between $0.01-1 \mathrm{ha}$ ). Fish are usually not monitored in these water bodies (Johansson et al., 2019).

In addition to the regular monitoring described above, the Ministry of Environment and Food can include additional lakes in their monitoring programme. This could be lakes that have not previously been monitored or lakes that are already monitored every sixth year, but where there are good reasons to intensify monitoring. On average, 95 lakes are monitored annually in relation to this programme, and fish are monitored in 11 of them (Johansson et al., 2019).

Results from this lake monitoring are made publicly available through annual reports and a dedicated webpage (e.g. http://miljoegis.mim.dk/cbkort?profile=novana2017-21).

In some cases, local municipalities monitor lakes with strong local interest. Lakes can also be monitored as part of research projects. The full extent of this is unknown to us.

It should be noted that the majority of fish monitoring in the programmes described above, are based on standardized gill netting, which not always gives a solid indication of target fish in recreational fisheries, e.g. some predator fish (like pike) or large trophy fish in general (e.g. large bream and carp). Hence, the monitoring gives indications of trophic conditions, but not necessarily the status of the target fish in recreational fisheries.

\subsection{MANAGEMENT CASE: STATUS AND MANAGEMENT OF ATLANTIC SALMON POPULATIONS IN DENMARK}

The status of Atlantic salmon over the last decades has been worrisome across its entire distribution area, with populations at an all-time low (ICES, 2018b), despite great efforts to mitigate their decline. Their precipitous decline is due to a wide range of interacting factors (Mills et al., 2013) and exacerbated by their anadromous nature which exposes them to anthropogenic threats in both freshwater and marine environments. Given their economic value within the food industry, the angling community, as well as culture, the status of Atlantic salmon is relevant at both a national and international level, and thus there is great incentive to manage and conserve the species.

Until the 1920s, Atlantic salmon populations existed in one eastern and eight western Jutland rivers (Figure 31). In all rivers, the populations decreased dramatically during the 20th century, primarily due to habitat destruction, the building of impassable barriers to migration, nutrient impact from agriculture, and pollution. The River Gudenå was the only eastern Jutland river with its own salmon stock, which subsequently disappeared as a result of the installation of a large hydropower dam in 1920 (Aarestrup et al., 1999; Jepsen et al., 1998; Koed et al., 2002, 2019). Since the 1950s, it was thought that the salmon populations were eradicated from all Jutland rivers, with the exception of River Skjern. In an effort to restore these populations, stocking of non-native salmon (Scottish, Irish and Swedish fish) took place until the end of the 1980s (a total of a few thousand). 
Until the 1920s, Atlantic salmon populations existed in one eastern and eight western Jutland rivers. In five rivers (black) the native salmon populations have become extinct, while four (green) are still inhabited by populations of native origin

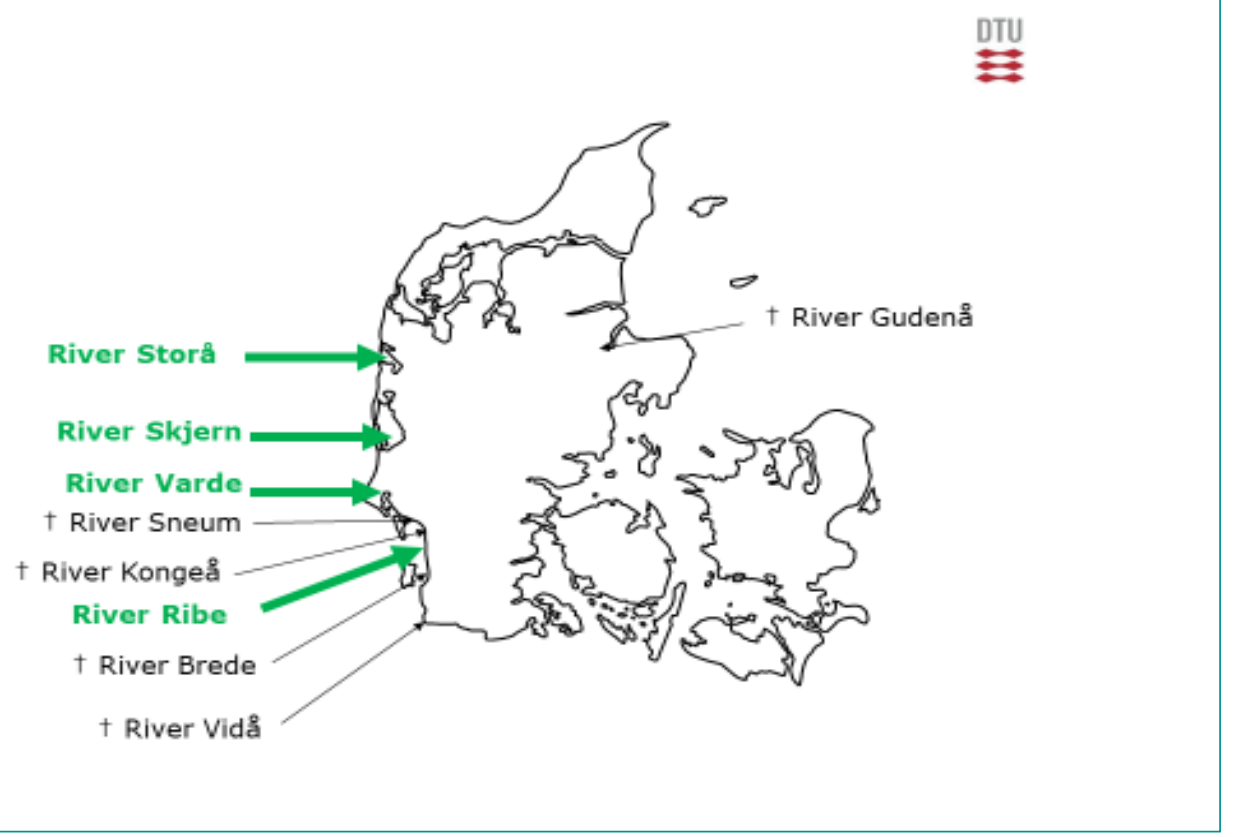

A review of the Atlantic salmon management efforts in Denmark in 1997 and a careful analysis of available stocking/capture data revealed that rivers Skjern, Ribe, Varde and Storå (Figure 28) likely had naturally-produced salmon. This was done by observing salmon production in years where no stocking occurred, and with a size distribution and morphology resembling the original salmon stocks (Koed et al., 1999). Together, these observations led to the suggestion that these rivers may still have native individuals within their populations. This suggestion was later confirmed through a genetic analysis which compared contemporary and archived salmon tissue samples (Nielsen et al., 1997, 2001).

\subsubsection{A new management plan}

The realization that native individuals were still present within the populations led to a change in the management strategy, with a renewed and stronger focus on changes in legislation and habitat restoration (removal of barriers and restoration of juvenile habitat) (Simonsen et al., 2004, Koed et al., 2019). Stocking practices were also altered so that only native individuals were stocked, and individuals from alien populations were removed (genetic screening). Furthermore, stocking became viewed as an approach to support natural reproduction in the streams where self-production from natural spawning was insufficient, rather than the prime method to restore salmon populations. Together, these management strategies have led to much healthier salmon populations in Denmark (Koed et al., 2019).

This multi-faceted management approach to manage Atlantic salmon in Denmark began in 1997. The focus has been on single populations/rivers and specifically on areas where individual counties can take action, meaning that most mitigation measures have been implemented in freshwater and coastal zones. While stocking of both halfyearlings and yearlings continued throughout the years, the numbers have decreased dramatically, reflecting an increase in natural production. For example, approximately 143000 young salmon were stocked in 2007; this number is now down to 65000 . Fishing seasons for angling were also shortened such that the season now lasts from 
April 16 to October 15, and fishing was banned in the fjords. Strict rules now apply to bait and hook type on lines to minimize damage sustained during fighting. These regulations apply to both rivers and coastal ecosystems. Lastly, and perhaps most importantly, significant changes were made to the river habitats where native salmon still existed. In the Stora river, 60 restoration projects and 15 barrier removals have taken place since 2004. During that same period, 98 sites were restored and 41 barriers were removed in the Skjern river, and 191 sites were restored and 17 barriers were removed in the Varde river. Habitat restoration included re-meandering of channelized river sections and addition of gravel for spawning.

Together, these measures have led to a significant increase in the Danish Atlantic salmon populations (Figure 32). In fact, stocking in the Stora river has been discontinued since 2017, as the population is far above the conservation limit of 1000 spawning adults yearly and can maintain this number with natural reproduction only. Catches of Atlantic salmon by anglers also reflect the overall positive impacts of successful management measures with a substantial increase in overall catches in each river (Figure 33).

\subsubsection{Implications}

Over the last 24 years, using recommendations from NASCO (North Atlantic Salmon Conservation Organization), stating that all populations should be maintained above their conservation limits (NASCO, 2009), and the EU Water Framework Directive, which has required member states to make significant changes in national water management plans, Denmark has successfully 'brought back' wild Atlantic salmon from the brink of extinction (Koed et al., 2019).

The new multi-faceted management plan applied in Denmark has been a vital element in successfully restoring local Atlantic salmon populations. The perspective, that most of the salmon-inhabited rivers have the potential for stocks to be significantly greater than what the conservation limit suggests (as seen by the current population estimates), has provided great incentive to set management objectives much higher. Management targets are currently significantly greater than the conservation limit of 1000 spawning fish in most rivers, enabling management to ensure a growing population. Despite this, angling quotas, i.e. number of Atlantic salmon that anglers can harvest per year, continue to represent $10-15$ percent of the population estimate that is they do not increase in proportion.

Denmark's success in restoring its salmon population is due mostly to the multifaceted management approach used - addressing major issues related to habitat quality and quantity, legislation and stocking. When populations are on the brink of extinction (as was the case in the early 1990s in Denmark), all possible strategies should be employed simultaneously to avoid wasting valuable time, because this is what practitioners often face in reality (Koed et al., 2019).

\subsection{INTERNATIONAL COOPERATION}

Denmark is involved in some international cooperation with Germany regarding a few streams (e.g. Vidå, Kruså, Meden $\AA$ ) located in the border area of the two countries. This cooperation - which is based on WFD requirements and aims to protect groundwater and surface water - is legally formulated (https://www.retsinformation.dk/Forms/ R0710.aspx?id=179677) and includes standardization of goals and shared monitoring. There is no formal cooperation regarding fisheries management in these streams.

\subsection{CHALLENGES FOR DANISH INLAND FISHERIES MANAGEMENT, CONFLICTS WITH OTHER WATER USES}

Pedersen et al. (2012) and Rasmussen and Pedersen (2018) summarize some of the future challenges for the state of Danish streams. In spite of a strong focus on stream restoration 
FIGURE 32

Estimated spawning population of Atlantic salmon in rivers Storå, Skjern and Varde over the years
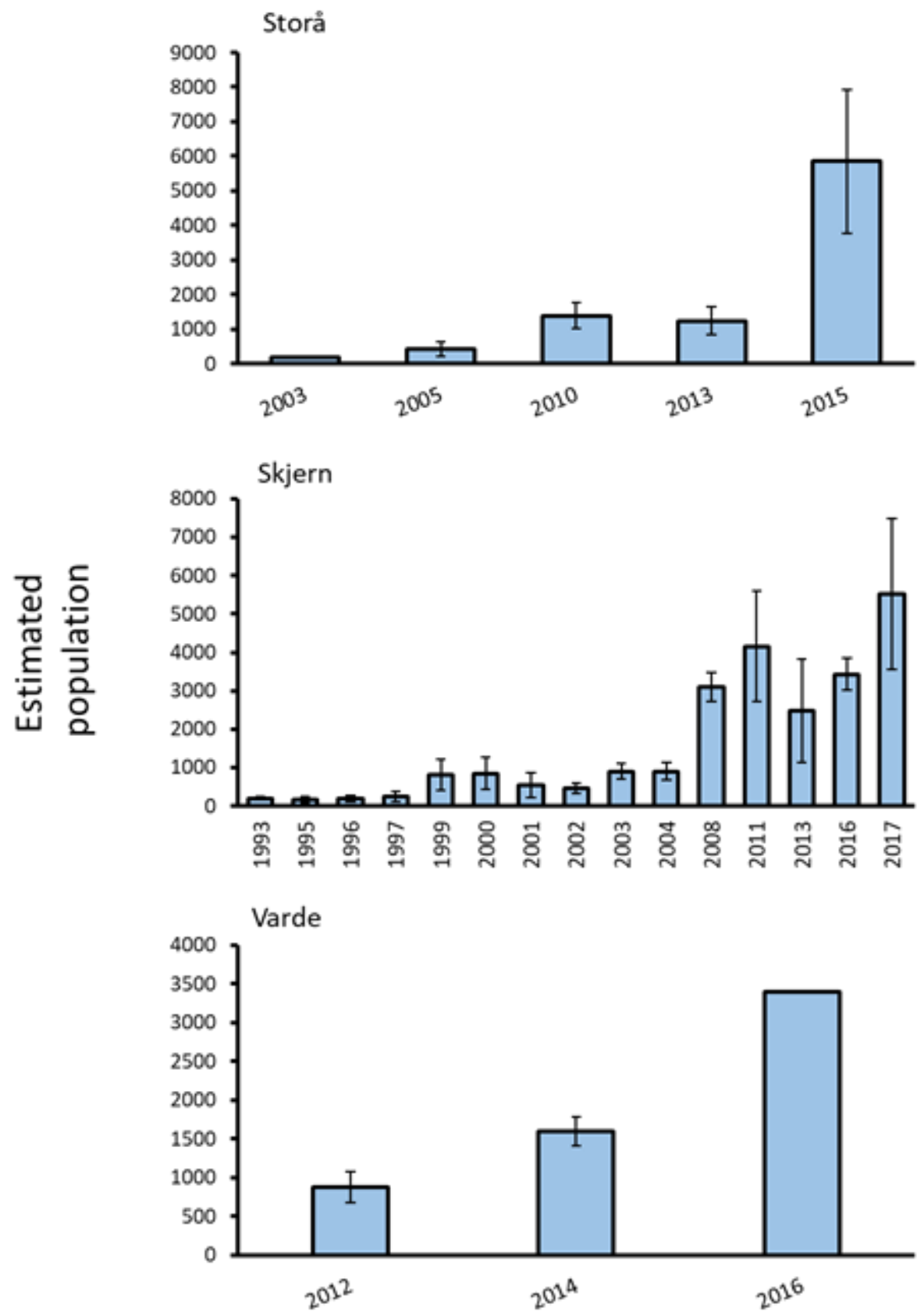

in recent years, conditions in many places are still far from optimal, with respect to all phases of the salmonid life cycle. Many barriers still exist and channelized streams often do not offer suitable habitats for the young trout. Recent status has indicated that approximately 26 percent of Danish streams (either small entire streams or parts of larger streams) produce less than 50 percent trout than could be expected based on stream capacity (HELCOM, 2011). The reason for this is, in most cases, due to poor habitat conditions (including heavy sand transport) or barriers (e.g. Birnie-Gauvin et al., 2017), including newly established artificial lakes in the lower parts of the streams. These lakes 


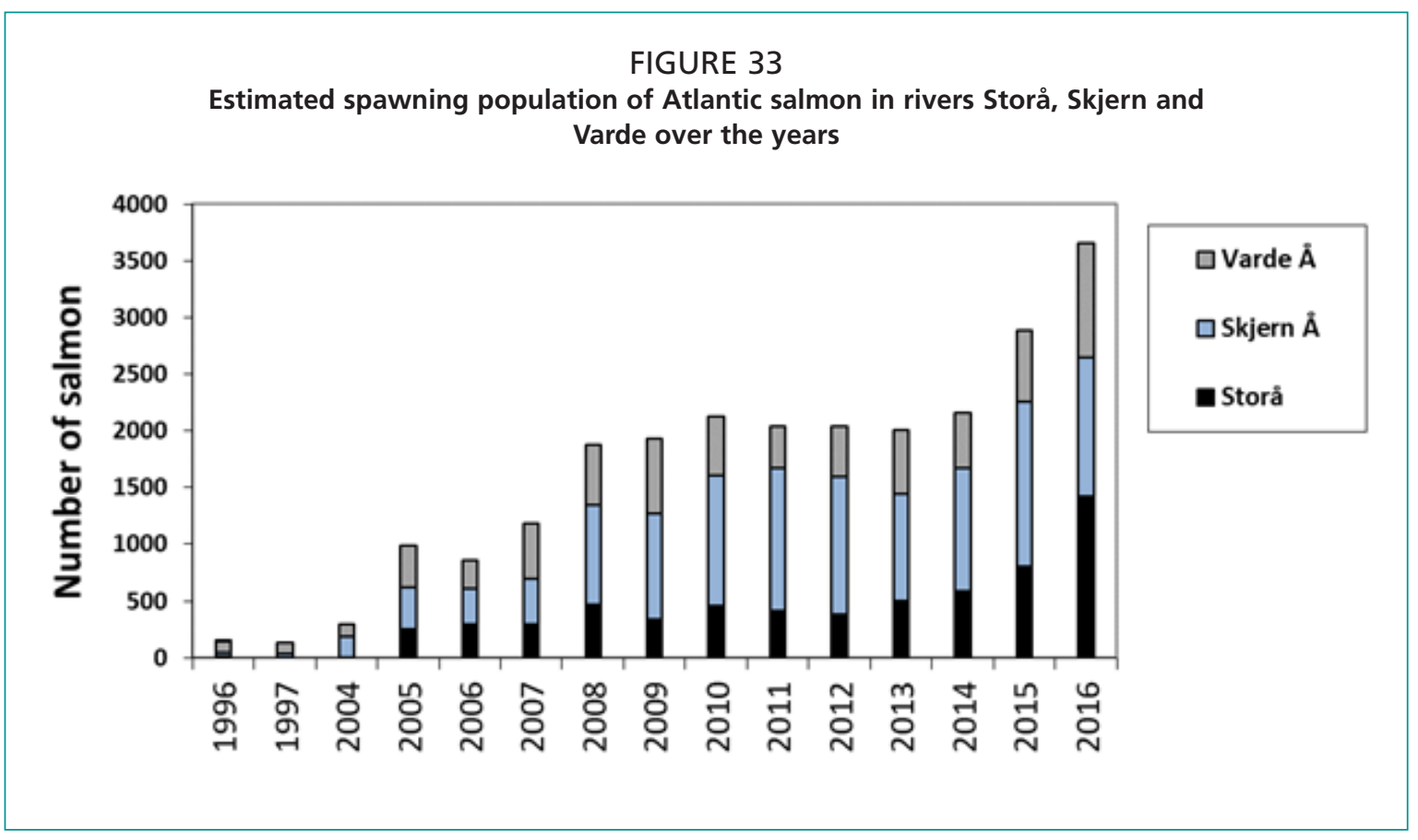

have been constructed as part of wetland projects established in order to reduce the level of nutrient emission (nitrogen) to coastal areas through denitrification. Such lakes have demonstrated to have a devastating effect on migratory salmonids, resulting in heavy smolt loss during seaward migration (Schwinn et al., 2019), and more projects involving this kind of lake are likely to be planned in future. One potential solution could be to construct artificial lakes with only partial water intake of the main flow (Pedersen et al., 2012). Another challenge is sand erosion, where sand from areas around the streams (fields, roads, urban areas, construction sites, etc.) and heavy sediment transport results in sand covering spawning gravel and reducing habitat availability. Covering of the spawning gravel results in loss of spawning possibilities - severely reduces egg survival and loss of habitats for young trout (Pedersen et al., 2012).

Predation from cormorants in particular, has been documented to be an important factor for many populations of stationary and migrating river fish and likely also plays a major role in the availability of fish for angling in lakes (Skov et al., 2014) and coastal areas (Jepsen et al., 2010). Since cormorants changed their foraging behaviour and started to visit even small streams, some fish populations have declined and the combination of a large otter and heron population with cormorant visits have had negative impacts on especially brown trout, grayling and salmon populations (Jepsen et al., 2014, 2018, 2019). Management/regulation of cormorants has become more active, with several hundred permissions for regulated control of cormorant populations issued annually, including intensive egg-oiling and hunting along rivers in winter, but so far without measurable effect on the level of predation. For more information consult the EIFAAC cormorant project.

Climate changes are likely to affect both streams and lakes and consequently inland fisheries (Harrod, 2015). Specifically in streams, more precipitation and in turn elevated discharge, is likely to increase maximum flow and hence increase erosion and sediment transport. More precipitation is expected during winter and locally in summer where heavy rainfall in connection with thunderstorms is expected to increase in frequency. Also, longer periods without precipitation are predicted, which can result in a reduction of productive area and consequently reduced production of brown trout and Atlantic salmon smolts. Already today, a number of streams are affected by water extraction for consumption, especially near larger cities and on some of the Danish 
islands, and in some places the subsequent reduced minimum flows is compensated by artificially adding water to the streams during critical periods (Pedersen et al., 2012). Climate changes are also likely to affect lakes in numerous ways, e.g. changes in size distribution of fish and a lower relative share of predator fish (Jeppesen et al., 2012).

Maintenance of streams, such as cutting stream macrophytes, removal of accumulated sediments and removal of woody debris, is regularly undertaken in most streams according to the Watercourse Act. This can have severe impact, particularly on salmonid populations as it can result in lack of shelter and changes in flow patterns. In recent years, there has been focus on introducing maintenance practices that are less harsh, but in many streams, maintenance is still unnecessarily heavy. In the coming water plans, reduced or more lenient maintenance is also proposed as a way to improve riverine habitat quality (Pedersen et al., 2012).

The majority of land in Denmark consists of drained agriculture fields and large areas with solid surface (roads, etc.). This results in rapid run-off through ditches and consequently large fluctuations in discharge, which has a negative impact on salmon and sea trout populations, especially in smaller catchments (Pedersen et al., 2012).

Point emissions from industries and sewage are no longer a general problem but are sometimes observed locally in the upper parts of streams. Accidents with sudden and heavy pollution with organic material from agricultural activity are observed from time to time, either when semi-liquid manure is spread on the fields as fertilizer or because of mishaps at the farms where tonnes of animal manure can end up in streams (Pedersen et al., 2012).

In the past, non-native, commercially-important fish species were often introduced into Danish waters. However today, the Nature Protection Act, stipulates that nonnative species must not be introduced and even for introduction of native fish species to a watercourse where they did not originally occur, requires special permission. It is known that invasive species can have negative impacts on indigenous species and their ecosystem, and that the zoogeographical diversity is worth preserving. Still, illegal introduction of non-native and native non-local fish and crayfish do occur frequently in lakes and streams (Skov et al., 2011).

Nutrient levels in lakes have been reduced over the last 30 years in many lakes due to reduced external input of nutrients such as via inflowing streams or drainage channels. However, in many of these lakes, internal loading, i.e. nutrients stored in the sediment, maintains high-nutrient loads. Moreover, heavy summer rainfall sometimes results in overflow at sewage plants and overflow waters with high-nutrient levels can end up in nearby, often urban, lakes. Therefore, eutrophication is still a problem in many Danish lakes (Johansson et al., 2019). Lake restoration attempts are, from time to time, initiated according to the EU WFD.

A few lakes and rivers still suffer from "ghost of the past" pollutions like heavy metals and organic compounds. An example stems from the Grindsted Products factory, which produced medicine and food additives in the 1960s, and resulted in leaching of heavy metals and organic compounds into a nearby lake and rivers. Still today, mercury contents in the flesh of pike in a nearby lake are so high that it is not fit for human consumption. Moreover, vinyl chlorides are still leaching from the area where the factory was located, causing concentrations 40 times higher than allowed in the nearby stream. 


\section{Country example: Ireland}

\subsection{DATA COLLECTION FOR STATISTICS}

\subsubsection{Recreational fishing}

Inland Fisheries Ireland (IFI) is the state agency responsible for collecting fisheries statistics in the Republic of Ireland, except in two catchment areas that straddle the border between the Republic of Ireland and Northern Ireland (Figure 34). The Loughs Agency is responsible for data collection in these two areas. This Agency was established as a cross-border body under the British Irish Agreement Act 1999 between the Government of the United Kingdom of Great Britain and Northern Ireland and the Government of the Republic of Ireland. Both agencies have a similar remit, i.e. responsibility for management, conservation, protection, promotion and development of inland fisheries.

Recreational fishing or angling in the Irish context refers to rod and line only (e.g. fly fishing, spinning, trolling) as all other methods, such as gill netting, traps, spear fishing, etc., are prohibited. There is no national rod licence in the Republic of Ireland for brown trout, Arctic char, pike and coarse fish species such as roach, perch, bream and tench, and therefore statistics for recreational angling are not available for these fish species. Many anglers pay a subscription to an angling club, but statistics are generally not collected in a formalised way for public state-owned fisheries (even

FIGURE 34

Map of Ireland showing the Republic of Ireland and Northern Ireland, the border (white line) between the two jurisdictions and the two Lough Agency areas

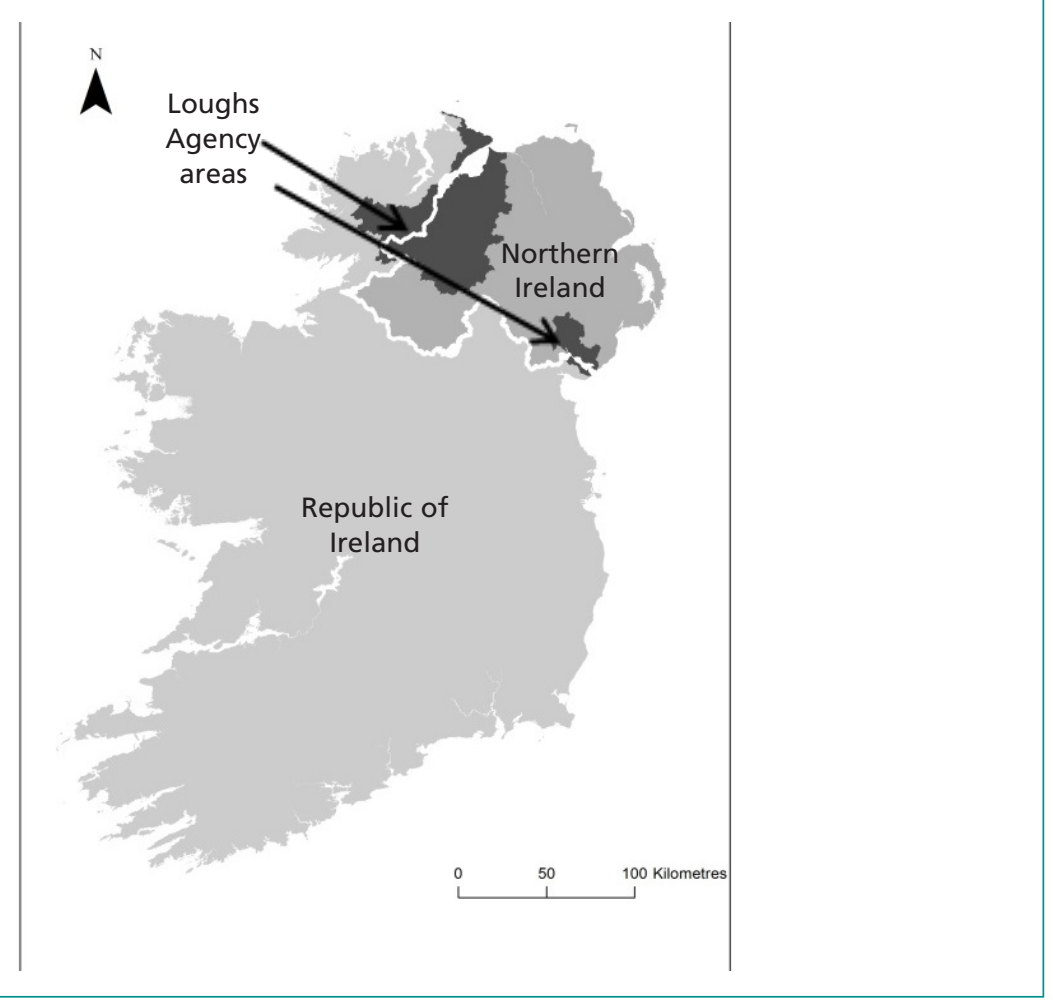


though it is a requirement of the lease - if a fishery is leased off the state by an angling club or association) - to report catches). However, there is a licencing system in place for salmon and sea trout angling as well as a system in place for collecting statistics for these species. This is described in detail below (case study Section 7.3). There are also some other data collection methods in place in Ireland; for example, the Irish Specimen Fish Committee (ISFC) is a voluntary scheme for verifying, recording and publicizing the capture of large (i.e. specimen) fish caught on rod and line by anglers in Irish waters, see case study (Section 7.4). Apart from official statistics reported by anglers for salmon and sea trout, IFI also carries out surveys (e.g. catchment-wide electric fishing for salmon - fry index), operates 32 fish counters and two upstream traps on two rivers to complement the catch data in closed and open fisheries to estimate total allowable catches for salmon.

\subsubsection{Data collection}

IFI is responsible for collecting recreational salmon and sea trout $(>40 \mathrm{~cm})$ fishing statistics on an annual basis except in the Loughs Agency area of the Republic of Ireland. Anglers record their catch of salmon and sea trout $>40 \mathrm{~cm}$ and return logbooks to IFI annually. Logbooks record both fish killed and those released. IFI also collects information of total sea trout rod catch (of all sizes) on a range of rivers nationally.

\subsubsection{Compiling statistics}

IFI collate all salmon and sea trout logbook returns from individual rivers into a database annually. The data are forwarded to the Technical Expert Group on Salmon (TEGOS), a group of expert scientists who report to the cross-border North South Standing Scientific Committee on Inland Fisheries, which provides annual management advice, based on available indices, on available salmon surplus by river for the following year. Fishery managers will use this scientific advice to inform fishery regulation. Additional details are provided below.

\subsubsection{Data availability}

Wild salmon and sea trout statistics are published annually on the IFI website (https://www.fisheriesireland.ie/Fisheries-management/salmon-management. html). Reports from the Technical Expert Group on Salmon (TEGOS) are also published annually on the same web page. IFI also publishes an "Irish angling update on a regular basis (daily and monthly) throughout the season which is used as a resource by anglers (https://fishinginireland.info/news/). Local fishery managers and anglers report catches in their fishery to IFI angling/development staff, but no official statistics are published (except for salmon and sea trout). The Irish Specimen Fish Committee publishes an annual report detailing all specimen and record fish caught (http://irish-trophy-fish.com/).

\subsubsection{Commercial inland fishing}

IFI is responsible for collecting any commercial licensed fishing statistics in inland waters. There is only one small commercial lake fishery in the Republic of Ireland, on Lough Ree in the Irish midlands and it is for brown trout catches only using draft nets. Fishers are required to apply for a fishing licence on an annual basis from IFI.

Large-scale commercial salmon fishing ceased in Ireland in 2006 with the introduction of a mixed-stock drift net ban by the State. Commercial fishing still exists in about 15 estuaries using traditional methods of draft and snap netting and the annual salmon commercial catch is about 8000 salmon. The Irish commercial eel fishery has been closed since 2009 . 


\subsubsection{Data collection}

There is no requirement to submit catch data on the one remaining commercial lake fishery in Ireland, but this is done on a voluntary basis by all licence holders. Total number of fish and total biomass figures are submitted annually to IFI, but no information on age class and size distribution is available.

\subsubsection{Compiling statistics}

Inland Fisheries Ireland maintains the database on catches.

\subsubsection{Data availability}

Statistics are not published for Lough Ree.

\subsection{CASE STUDY: ERRIFF RIVER - RECREATIONAL FISHING ONLY ${ }^{4}$}

The River Erriff system is a State-owned migratory salmonid fishery which is managed by IFI. An important salmonid fishery in the west of Ireland, it holds good stocks of Atlantic salmon, sea trout and brown trout. The system has been designated as the National Salmonid Index Catchment (NSIC) in the Republic of Ireland. The system is located in County Mayo in the west of Ireland, near the village of Leenane $\left(53^{\circ} 37^{\prime} 0.00^{\prime} \mathrm{N}: 9^{\circ} 40^{\prime} 17.10^{\prime} \mathrm{W}\right)$. The Erriff fishery is comprised of the River Erriff, its tributaries and a number of small lakes, including Tawnyard, Derrintin and Glenawough. Salmon angling is carried out along the lower $10 \mathrm{~km}$ of the River Erriff main channel, while Tawnyard Lough, the largest accessible lake, is the principal sea trout fishery (Figure 35). The Erriff has a catchment area of $166.3 \mathrm{~km}^{2}$, while Tawnyard Lough has a surface area of $\mathbf{5 6}$ ha. The catchment is sparsely populated, and the main agriculture practice is sheep farming. Some coniferous forestry is also present. The River Erriff flows into the sea at the head of Killary harbour (fjord), on the Atlantic coast in the west of Ireland. The River Erriff main channel has almost $13 \mathrm{~km}$ of prime recreational angling water divided into nine beats, which are owned by IFI. Only angling by rod is permitted on the Erriff River and on Tawnyard Lough, and fishers are further restricted to fly fishing from a boat.

\subsubsection{Data collection}

Rod catch statistics for salmon and sea trout on the Erriff River have been collected since 1975 on an annual basis (Figure 36). Catch statistics are compiled on a daily basis by the fishery manager and are published in a newsletter at the end of each year (https://www.fisheriesireland.ie/NSIC/related-publications.html). Since 2007, all statistics have been submitted via the salmon and sea trout log-book which is returned within seven days of the close of the season. Catch statistics are only collected for salmon and sea trout in the catchment.

\subsubsection{Catch statistics and its scientific use}

A dedicated research station with fish counting and trapping facilities is located at Aasleagh Falls by the mouth of this fishery which flows into Killary Harbour fjord. A downstream wolf-type trap has also been in operation on the Black River downstream of Tawnyard Lough since 1985. Both smolts and kelts are diverted into the trap annually from March to June. The research facility is managed by IFI and supports a wide range of scientific research and monitoring activities on the resident salmonid populations and their migratory component as undertaken by the State agency and its national and international partners. This work aims to contribute to the better understanding of the biology, life history and population dynamics of Atlantic salmon and sea trout and the effects of environmental and anthropogenic factors on their continued sustainability.

\footnotetext{
4 A bibliography for this case study is provided in the section on Other Sources of Information.
} 


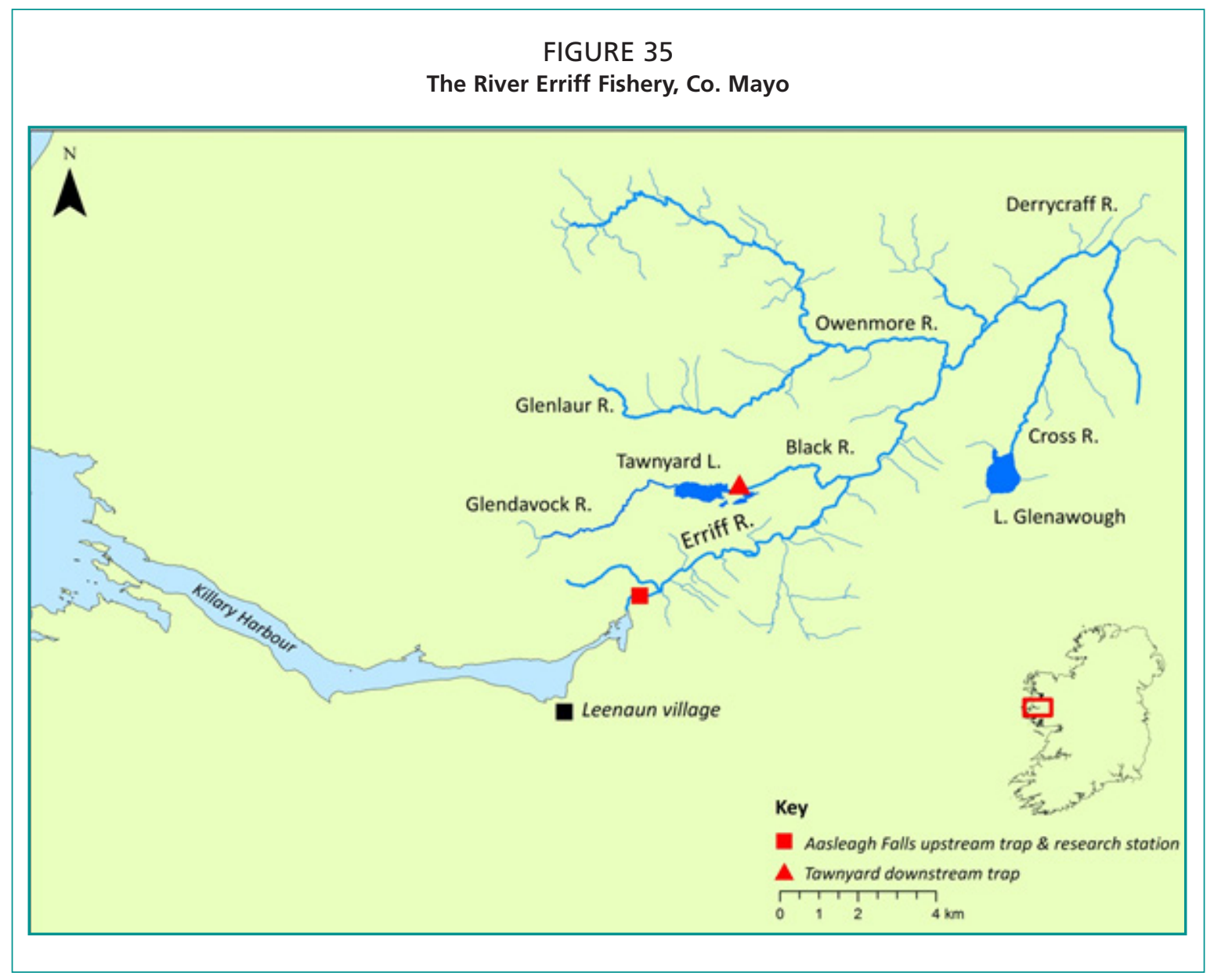

FIGURE 36

Summary of fishing catches in the Erriff Fishery 1975 to 2018

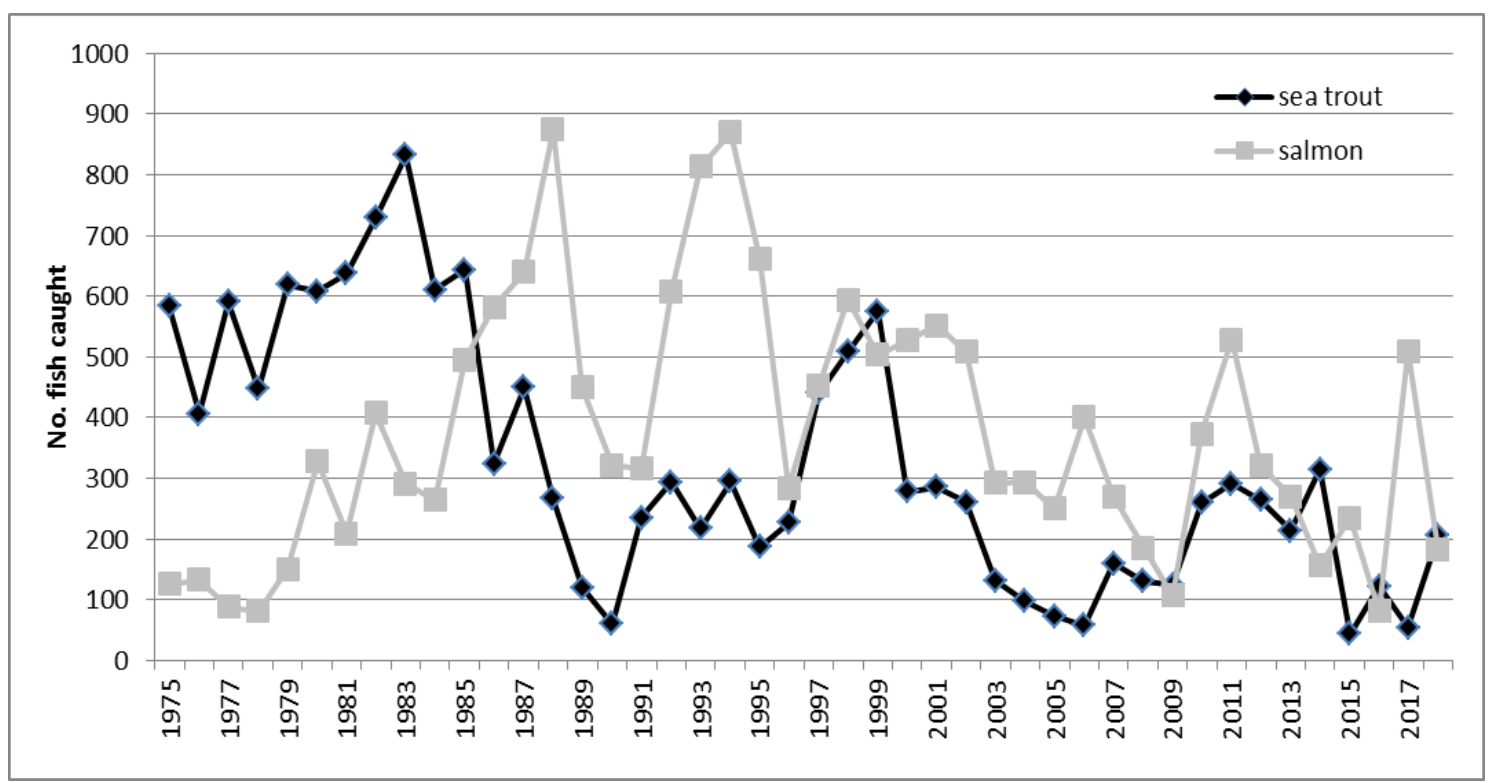


The output is applied to better inform the conservation and management of these socioeconomically important species within Ireland and further afield.

Several scientific papers have used the catch statistics and other data (upstream and downstream trap data) from the Erriff River and are listed in the bibliography.

\subsection{CASE STUDY: SALMON AND SEA TROUT RECREATIONAL ANGLING, DATA COLLECTION AND STATISTICS IN IRELAND}

Data on salmon rod catch and commercial salmon catch are available in Ireland since 1929. Detailed recreational (salmon and sea trout only) fishing statistics for the Irish Republic have been compiled by Inland Fisheries Ireland (previously the Central and Regional Fisheries Boards) since 2001. The Wild Salmon and Sea Trout Tagging Scheme commenced for both commercial and recreational salmon fishing licence holders on $1^{\text {st }}$ January 2001, having been provided for in the Fisheries (Amendment) Act, 1999 (No. 35 of 1999). This was followed by the introduction of Total Allowable Catches (TAC) for the commercial salmon fishing sector and bag limits for recreational anglers in 2002. Since 2007, following consultation with IFI and a Standing Scientific Committee in December every year, the Minister sets the total allowable salmon harvest on an annual basis for each of the rivers which exceed the Conservation Limit (CL). From 2010 onwards, the Wild Salmon and Sea Trout Tagging Scheme for both commercial and recreational salmon fishing licence holders has been provided for in Section 69 of the Inland Fisheries Act, 2010 (No. 10 of 2010). A similar tagging scheme to that in the Irish Republic is in force in the two cross-border catchments managed by the Loughs Agency.

The principal aims of the Wild Salmon and Sea Trout Tagging Scheme are to provide a means of collecting accurate nominal catch statistics and estimates of salmon stock exploitation, to develop best management strategies and to ensure salmon are exploited in a manner consistent with their long-term sustainability, on an individual river basis.

Salmon are managed on a river-by-river basis as opposed to a national or district basis. Rivers which have an identifiable surplus over the conservation limit are open for salmon and sea trout fishing. Rivers meeting in excess of 50 percent of the conservation limit are granted catch and release status subject to fisheries management approval. Rivers for which there is insufficient scientific information, or which historically have had a rod catch of less than 10 salmon per annum, remain closed. A scheme of rehabilitation of rivers was introduced with priority given to rivers which were below the conservation limit funded through the introduction of a salmon conservation component (Salmon Conservation Fund) which is equal to the cost of the licence, on all angling and commercial licence sales. This fund contributes towards a programme of projects related to the conservation of salmon and sea trout. Projects typically fund habitat rehabilitation projects relating to improving fish access, inputting spawning gravel, improving rearing habitat and removing excess shading, and fencing riverbanks. Funds are allocated annually.

The goal is to encourage the recovery of stocks in those rivers not yet meeting their conservation limits, to manage all rivers in compliance with the Habitats Directive, to conserve the resource and facilitate its exploitation on an equitable and sustainable basis.

\subsubsection{Data collection}

Under the Wild Salmon and Sea Trout Tagging Scheme regulations all fishers must attach a gill tag to each salmon (or sea trout $>40 \mathrm{~cm}$ ) they catch and retain. A logbook entry must then be made giving the details of the fish caught. All logbooks and unused tags must be returned to IFI within a period of 7 days after the last day of the relevant fishing season, or after the licence has been in force (one day and 21-day licences are available), as set out in the regulations. A system of brown gill tags is used 
in association with blue gill tags for the tagging of wild salmon and sea trout in certain listed rivers which have a low surplus for harvesting.

\subsubsection{Salmon and sea trout licence}

The state salmon and sea trout licence is available as a district or national licence. A national licence covers all fishery districts while a district licence only covers the fishery district in which the licence is purchased. The State licence does not entitle an angler to fish for salmon on a river or lake and a permit must be obtained from the fishery owner or angling club.

Anglers can purchase their salmon and sea trout angling licence from IFI or any rod licence distributor. There is also an online option. These vary from an annual ordinary licence, annual district licence or 21-day ordinary licence. On payment, the angler is issued with a licence, a logbook and three gill tags up to $11^{\text {th }}$ May, and a further seven gill tags from $12^{\text {th }}$ May to $30^{\text {th }}$ September, up to a maximum of ten gill tags provided they have completed their logbook appropriately. Only one gill tag is issued to those anglers who purchase a one-day ordinary licence. A business reply envelope (to return the logbook) and a plastic wallet for the logbook are issued with the licence to each angler.

\subsubsection{Open, closed and catch and release rivers}

Salmon fishing opens on January $1^{\text {st }}$ on a handful of rivers and after that the remaining rivers open on various dates in February, March, April and May. The majority close on $30^{\text {th }}$ September but some remain open until $12^{\text {th }}$ October for sea trout.

\subsubsection{Salmon and sea trout gill tags}

The gill tag used by salmon and sea trout anglers is a blue plastic self-locking device (an additional brown tag is also required for certain rivers) to ensure angling quotas are not exceeded (Figure 37). Each blue tag is embossed with a code identifying where the tag was issued, the year in which the tag can be used, a security code and a tag serial number. Each rod licence holder is issued with tags for his/her own use. The tags are not transferable and must not be re-used. One tag must be attached to each salmon (any size) and sea trout $(>40 \mathrm{~cm})$ caught and retained. Tags must be attached

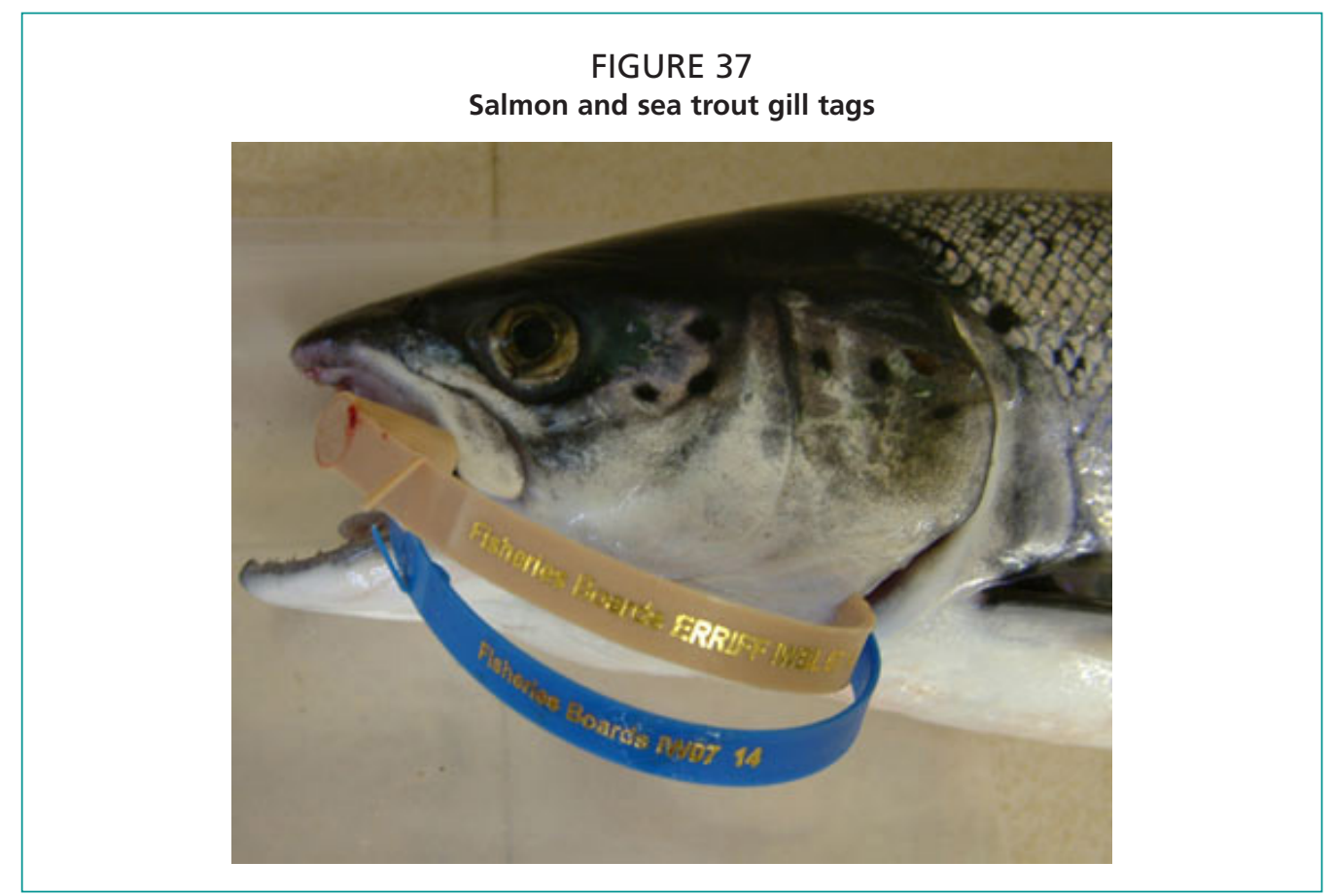


immediately on landing the fish and must be attached through the gill opening and mouth and securely double locked. Additional tags will be issued to the angler on request up to the maximum allowable of 10 tags annually.

\subsubsection{Salmon and sea trout angling logbook}

Anglers are issued with a logbook along with gill tags. Details of the issued gill tags are entered into the logbook by the issuing agent. Each angler must have the logbook in his/her possession while fishing for salmon or sea trout. All details of their catch must be recorded, even if the fish is released. Details of any lost or damaged gill tags should also be recorded and details of lost or damaged logbooks must also be reported to IFI. In accordance with the regulations, all completed logbooks, tags (even if there is no catch recorded), and all unused tags must be returned to the issuing office of IFI by the $19^{\text {th }}$ October annually. Anglers are required to obtain proof of postage and to retain such proof for 12 months.

\subsubsection{Prohibition of sale of rod-caught salmon and sea trout}

Anglers are prohibited from selling salmon (any size) or sea trout (any size) caught by rod and line.

\subsubsection{Calculation of River-Specific Conservation Limits (CLs)}

Following advice from the International Council for the Exploration of the Seas and North Atlantic Salmon Conservation Organization, Irish salmon stocks have been managed on a river-by-river basis since 2007 with biological reference points (BRPs) based on maximum sustainable yield (MSY). A method for estimating BRPs at the river scale and the associated variability arising from observed variability in population structures and fecundities is used. Angling logbooks provide river-specific weight data to give sea age and fecundity ranges. Estimates of river-wetted areas, to account for available nursery habitat for juveniles and river-specific carrying capacities, are used. To transport BRPs, Bayesian stock-recruitment analysis is used with a list of monitored rivers, salmon smolt ages and the proportion of one-sea-winter and multi-sea-winter salmon per river. The approach used is portable across stocks and has the potential to be implemented in other jurisdictions to improve the management of Atlantic salmon.

\subsubsection{Assessment methodology for salmon catch advice}

In-river or estuarine measures of salmon abundance are used, such as fish counter data and $\mathrm{rod} /$ net catch data, to provide a primary measure of spawning stocks and attainment of CLs. A summary of the approach is shown below in Figure 38.

With the operation of fisheries restricted to estuaries (commercial fisheries) and rivers from 2007, the assessment is now focused primarily on estimating individual river returns from catch data, counter data (if available) and ranges of rod catch exploitation rates derived from observed values in Irish rivers in recent years. Every effort is made to obtain relevant data and monitor the performance of stocks (attainment of CL) at the river level and consequently to assess the status of individual riverine stocks. Several sources of information are used in this process.

\subsubsection{Commercial catch data}

Despite the closure of the mixed-stock fisheries at sea, the catch statistics derived from the estuarine commercial fisheries (draft nets and snap nets) remain an important source of quantitative information if fished, particularly in determining the overall size of the returning stock and the attainment of river CLs. Following implementation of the wild salmon and sea trout tagging scheme, which commenced in 2001, catch data are derived from the logbook returns of commercial fishers with reporting rates at 100 percent. 


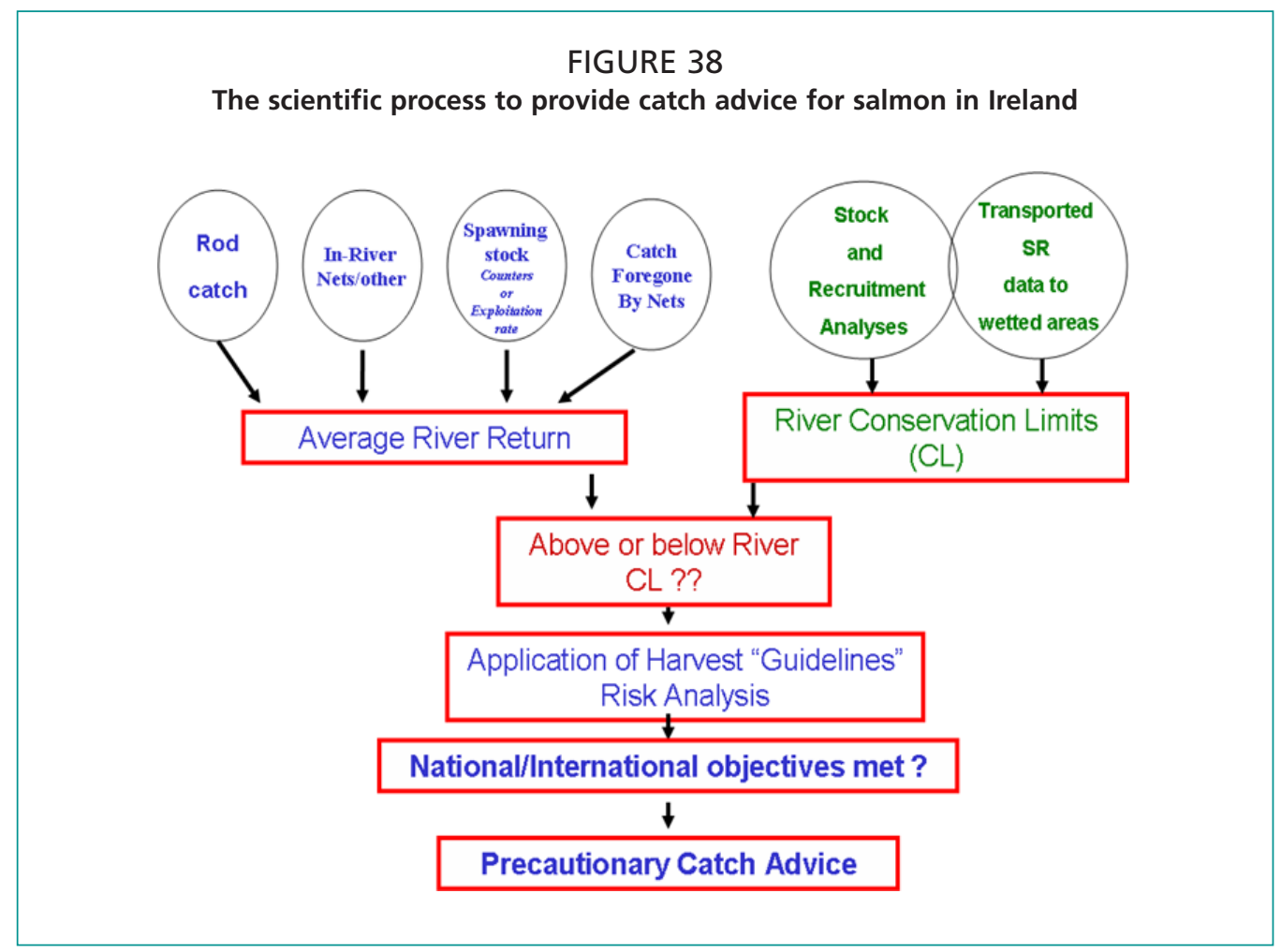

\subsubsection{Rod catch data}

The reported rod catch from the wild salmon and sea trout tagging scheme is adjusted to take into account the numbers of fish that have been caught by anglers who do not return their logbook. The adjustment follows the approach by Small (1991). Angling logbook returns have seen a steady return rate averaging around 70 percent in recent years.

\subsubsection{Total traps and counters}

Data are available from 30 fish counters and two salmon traps.

\subsubsection{Catchment-wide electrofishing}

Information on juvenile salmon abundance indices derived from catchment-wide electrofishing surveys carried out annually by IFI is examined to indicate stock status. Systems where catch data are limited (no counter or rod catch data) are targeted on a rolling programme basis. Currently, management advise that rivers achieving an average salmon fry abundance of 15 fry per 5-minute electrofishing survey can be open for catch and release angling. This information is used primarily where new information has not been available for rod catches - that is no counter data or the fishery is closed.

\subsubsection{Status of individual rivers relative to conservation limits}

In line with international advice on salmon stocks, the TEGOS advise that the best way to meet national and international objectives of conserving salmon stocks in all salmon rivers is to allow fisheries only in rivers or the estuary of that river, where there is a greater probability of targeting only the stocks originating from these rivers (i.e. single stock fisheries). They further advise that fisheries should take place only on stocks that are shown to be meeting their CL with the catch restricted to the estimated surplus above CL. This advice follows from international best practice, as advised by ICES and NASCO.

The main objective of the scientific advice is therefore to ensure that there are sufficient spawning salmon remaining after commercial and recreational fisheries to meet the required CL for that river. In order to do this, the number of salmon 
which will be available before the fishery takes place, must be "forecast" for each river annually, based on the average returns in recent years (usually the most recent 5 years provide sufficient information). The information required for this forecast is derived from commercial catch data, from extrapolation of rod catch information using exploitation rates or from estimates based on fish counter information.

\subsubsection{Estimating the total catch in each river}

As stated previously, the catch data for draft nets, other commercial engines (snap nets) and rods, derive from mandatory fishing logbooks or from vouched information supplied by IFI directly. The forecast model requires the inclusion of the fish taken by the commercial fisheries in the estuaries of each river, if present.

\subsubsection{Estimating the returns of adult salmon in each river using rod exploitation rates}

Rod exploitation rates derive from observed exploitation rate values from fish counters or traps on Irish rivers and are supported by information from the scientific literature and the National Coded-wire Tagging and Tag Recovery Programme. Exploitation by angling on grilse stocks varies but is generally between 10 percent and 30 percent of the total river stock available (Milner et al., 2001). These authors quote mean values of 19 percent for UK rivers, while values for specific Irish grilse (1SW salmon) fisheries have been estimated for the River Erriff at 19 percent between 1986 and 2000 (Gargan et al., 2001), and 15 percent for the Burrishoole between 1970 and 2000 (Whelan et al., 2001). Estimates of angling exploitation on multi-sea-winter stocks are generally higher than those reported for grilse (Solomon and Potter, 1992) and this has also been observed from Irish fish counter data. In 2008, the Standing Scientific Committee for salmon (SSCS) evaluated all existing information on individual rod fisheries made available by IFI, including field observations of fisheries which have known high or low intensity, to derive more precise estimates of the likely rod exploitation rate on a river-by-river basis. An extensive review of salmon exploitation rates in Irish rivers (Millane et al., 2017) using rod catch and fish counter data was published in 2017 but has not yet been incorporated into estimates of adult salmon return.

Provided the catch in a river is known, the total stock can be estimated by extrapolation using an appropriate exploitation rate in the fishery, as follows:

If the rod catch of salmon was 150 fish and the exploitation rate in the fishery was 10 percent, then the total stock of salmon available to generate this catch would be estimated as the catch raised by the exploitation rate:

Catch / Exploitation rate * 100

In this case $150 / 10 * 100=1500$ salmon.

For most rivers, the specific exploitation rates are not known and therefore a range of values is applied within which the true value is expected to be. Furthermore, as there is now specific rod exploitation data for Irish rivers with fish counters, it has been possible to allocate all rivers into specific groups representing heavily fished (higher exploitation rate) and medium fished to lightly fished rivers (low exploitation rate) based on field observations. This restricts the overall range of values being used to a more likely range rather than applying the entire range of values observed.

\subsubsection{Provision of harvest guidelines}

Once estimates of average number of spawners, average catch, and river-specific CLs have been derived, harvest options are provided with the associated probability of meeting CLs. Where estimates were available for both a counter or trap and a rod 
catch, the values for the counter or trap are used. Following the procedure used by ICES for the provision of catch advice for West Greenland, the harvest option that provides a 0.75 probability level (or 75 percent chance) of meeting the CL for a given stock is recommended. Where there is no harvest option which will provide a 75 percent chance of meeting the CL, there is no surplus of fish to support a harvest (commercial or rod). Given the uncertainty in the data and the use of a risk analysis method to allow for some of this uncertainty, a further limitation is applied to the recruit per spawner index of each river. A maximum recruit per spawner value is applied to the abundance outputs derived from the risk assessment of three, i.e. for every spawner three recruits may be produced. This is considered to better reflect the overall status of salmon stocks both nationally and internationally.

An objective of the catch advice is to ensure that harvest fisheries only take place on river stocks meeting and exceeding CLs. The means to achieve this objective is to allow only harvest fisheries which can specifically target single stocks that are meeting their CLs. Where a fishery comprises more than one stock, the risk analysis is based on the simultaneous attainment of CL for all contributing stocks.

In a number of rivers, the CL will be achieved by the contributions of both $1 \mathrm{SW}$ (grilse) and MSW (spring fish). There is conservation of biodiversity and fisheries development value in identifying and protecting both life history types. It is important for fisheries management to be able to determine how much of the CL is likely to be met by either MSW or 1SW fish and to regulate fisheries for both components separately. More information is required on the proportions of each component of the stock being exploited and the timing of their entry into estuaries and freshwater. Advice has been provided on 1 SW and MSW separately where a significant early run component has been identified and can be managed separately on the assumption that all fish counted or caught before $31^{\text {st }}$ May are considered to be MSW fish.

\subsubsection{Advantages}

It is possible to monitor the fishery at a relatively low cost and the data can be used to estimate CPUE or for assessing pressures on fish stocks. In Ireland, the data is used to set conservation limits and determine if individual river stocks are meeting or exceeding CL. The scientific committee publishes all the data used in this analysis annually.

\subsubsection{Disadvantages}

The main disadvantage is that each river has to be assessed annually and a new set of advice given. The scientific committee analyses rod catch, counter and commercial catch data each year and updates the five-year time-series. Multi-annual advice could be given regarding attainment of CL but this would not incorporate the most recent river-specific stock estimates.

\subsection{CASE STUDY: A LONG-TERM CROSS-BORDER ANGLING SPECIES DATA COLLECTION SCHEME}

The Irish Specimen Fish Committee (ISFC) was founded in 1955 and is an independent voluntary body representative of angling interests (Irish angling federations, Government Departments and official organizations with an interest in angling) on the island of Ireland (Republic of Ireland and Northern Ireland). It relies on grantaid funding and the majority of funding is provided by state agencies north and south of the border. Donations are also provided by anglers. IFI provides much of the administrative and other support and AFBI NI provides a specimen fish identification service for anglers in Northern Ireland.

ISFC's principal function is to verify, record and publicize the capture of large (i.e. specimen) fish caught on rod and line by anglers in Irish waters (all of the island), 
both in freshwater and marine waters. It coordinates and administers a specimen awards scheme which is designed to recognize any angler who catches a specimen fish and to publicize the angling venue. Successful anglers are awarded a certificate and a commemorative badge annually. Specially commissioned medals are presented to captors of record fish and special awards are also made to captors of multiple specimen fish (on a cumulative basis). Over 30000 claims have been received by the ISFC over the past 63 years. This dataset is one of the most valuable and long-running timeseries of its type. It has been used extensively to provide documented proof of the angling value of different waters countrywide. In addition to their value for promotion of angling tourism, the annual reports provide invaluable information for anglers when planning angling trips, particularly those seeking a 'specimen' fish. An awards ceremony is held every year and many anglers attend this. A list of specimen fish is published annually as well as an annual report, and more information is available online at www.irish-trophy-fish.com.

Only fish which can be fully vouched for (species, weight and or length) can be accepted and listed. Fish must be weighed on tested and certified weighing scales. Weights/lengths must also be witnessed. Many species are now eligible for lengthbased claims which is increasingly favoured by anglers. Genetic identification is used to verify speciation of shad species and cyprinid hybrids. Photographs including a measure of scale are also required to verify records. An atlas is currently being produced documenting 60 years of specimen fish catches, including where fish have been caught.

The ISFC service provides angling promotion and promotional material, highlights prime specimen fish locations, angling tourism support (Republic of Ireland and Northern Ireland), and an incentive for repeat visits to Ireland by tourists or to Irish venues by Irish anglers through the cumulative awards scheme. In addition, it is used to show the distribution of species at spatial and temporal levels.

\subsection{CASE STUDY: SOCIO-ECONOMIC STUDIES}

Numerous angler surveys have been carried out in Ireland over the last 30 years. Whelan and Marsh (1988), using an angling survey, estimated annual domestic angler expenditure in 1987 at IR£ 15.6 million, foreign tourist angler expenditure of at least IR\& 12 million, with both supporting 1900 full-time job equivalents with IR£ 15 million in tax revenue. Whereas in a more general marine leisure survey, the Marine Institute (1997) estimated that domestic game anglers, which include salmon anglers, spent IR£ 10 million per annum supporting almost 400 jobs.

One of the first published estimates of an angling demand function in Ireland was by O'Neill and Davis (1991) who estimated a demand function for coarse and game angling in Northern Ireland. At that time, they estimated a total user benefit of £9.1(sterling) million. In 2002, the impact of angling trips in Ireland was explored by using data from County Donegal in the northwest of Ireland (Curtis, 2002). Salmon angling quality, age and nationality were found to affect angling demand. Mean travel cost per day was estimated to be €86.34: accommodation and meals = $€ 40.63$ per day; fishing expenses $=€ 17.78$; and actual travel expenses $=€ 27.93$ per day. Using the travel cost count model, Curtis (2002) then estimated that the consumer surplus value of an angling trip in Ireland was $€ 175.22$ per day.

More recently, Inland Fisheries Ireland commissioned Tourism Development International (TDI) to undertake a socio-economic study (to assess the volume, value and economic impact) of recreational angling in Ireland as there was an absence of detailed information available for the sector (TDI, 2013). The aim of the report was to provide information which would underpin effective strategic planning and decision 
making in respect of angling product development and marketing and to estimate an economic value for recreational angling.

The project comprised a household survey (a representative sample of 2000 Irish adults (15+) at 60 locations across the country), survey of recreational anglers (1 060 domestic and visiting anglers were contacted and from these 903 interviews were undertaken), survey of angling stakeholders (interviews with 105 angling enterprises, including fishing guides and instructors, charter boat operators, fishing tackle shops, boat hire enterprises and accommodation establishments) and desk research (TDI, 2013).

The main findings of the study are as follows:

- Up to 406000 individuals participated in recreational angling in Ireland in 2012 and 252000 of these were Irish. 28 percent of recreational anglers were from overseas. More recently, this latter figure was revised upwards to 273600 Irish recreational anglers ( $\geq 15$ years) (NSAD, 2015a).

- The total direct expenditure on recreational angling in 2012 was estimated at $€ 555$ million (with additional spending worth an extra $€ 310$ million), but this was estimated to have risen to over $€ 600$ million in 2015 (NSAD, 2015b). Approximately 20 percent of this figure was generated by foreign anglers.

- Following adjustments for imports and displacements, the overall economic impact of recreational angling was estimated to be approximately $€ 755$ million (direct and indirect). Subsequent survey work and analysis in 2015 has seen this figure rising to $€ 836$ million (NSAD, 2015a).

- Total tourist angling expenditure can be estimated at approximately $€ 280$ million.

- Recreational angling was estimated to support approximately 10000 jobs in 2012 and this was revised to 11000 jobs in 2015. Most jobs were located in the most peripheral and rural parts of Ireland and along the coastline (NSAD, 2015b).

- The value that the public placed on avoiding deterioration in the quality of Ireland's natural fish stocks and angling experience (non-market value) was estimated to be $€ 58$ million per annum.

- Domestic anglers took an average of 13.6 day angling trips and one in four took an overnight fishing trip. Overseas anglers made an average of two angling trips to Ireland.

Further research, commissioned by IFI, indicated that expenditure by brown trout anglers contributed about $€ 148$ million (84 962 anglers) to the Irish economy annually in $2014 / 2015$, while salmon and sea trout anglers contributed approximately $€ 210$ million (128 988 anglers) (NSAD, 2015a). 12 percent of Irish anglers (approximately 32832 anglers) indicated pike angling as their preference. The combined net expenditure for pike angling in Ireland is thought to be approximately €102 million 2014/2015 (NSAD, 2015a).

Respondents in the Survey of Recreational Anglers identified outstanding scenery and friendliness/hospitality of the Irish people as the most appealing aspects of Ireland as a destination for recreational angling (TDI, 2013). A significant proportion of anglers also rated the Irish angling product highly in terms of its restful/relaxed ambience, the quality of accommodation and the reputation of the angling product. The improvement in water quality was cited as the most positive development in angling in Ireland in recent years (TDI, 2013). However, there is evidence of a decline in recreational angling participation levels in recent years. Quality of fishing, economic recession, poor weather, lack of fish, overfishing, illegal fishing, netting, commercial fishing, pollution and invasive species were each identified as factors which have contributed to the dissatisfaction with current fish stocks.

Angling in Ireland is a significant economic activity, but it also plays a central role in rural and peripheral communities, providing recreational opportunities for both 
young and old, and encouraging participation in healthy outdoor activity. In many cases, rural areas may be lacking in alternative tourist attractions and in their absence, angling provides the focus for an important and sustainable source of income for the catering and accommodation service providers in these communities.

Recreational angling also attracts anglers outside of the main traditional tourist seasons (shoulder periods March-May and mid-August-October) and extends the traditional tourist season for accommodation and service providers with the potential to provide increased employment and entrepreneurial opportunities within these communities.

The popularity and value of angling in Ireland relies significantly on non-catch related factors identified by TDI (2013), and the specific relative influence of factors that affected perceptions of reduced quality of fishing need to be identified, including the effect of water quality on fish stocks relative to other factors.

Since 2013, further socio-economic studies have been undertaken to estimate the value of different aspects of the Irish fishery resource; for example, modelling recreational anglers' decisions to voluntarily release their catch, to assess anglers' preferences in relation to pike stock management in brown trout fisheries (Deely et al., 2019; Grilli et al., 2019, Curtis, 2018). More information can be found on www.esri/ publications.

A recent ecosystem services research project, funded by the Irish Environmental Protection Agency, evaluated the economic benefits associated with enhancements to river ecosystem services with policy options targeted at meeting Ireland's Water Framework Directive commitments (Kelly-Quinn et al., 2019). Part of the project included an economic choice experiment to evaluate river user preferences for enhancements to five ecosystem services: water quality, water health, bankside vegetation, wildlife and angling. For angling, the choice experiment was represented by the density of "catchable" sized trout $(>25 \mathrm{~cm})$ and adult salmon. A survey questionnaire was developed and given to stakeholders in three catchments. A total of 469 people were interviewed for the study, of which 350 people were asked about their values for improvements to river services in the three catchments, and a further 119 people were asked about their values for improvements to river services across all Irish rivers. Generally, males were willing to pay more to attain improvements to rivers, with improved wildlife being most highly valued ( $€ 62$ for both), followed by improved water quality ( $€ 57$ for males and $€ 45$ for females). Generally, people living in rural areas had the highest values, followed by those living in cities and then towns, which is likely to reflect rural people's closer connections to the rivers.

Angling was highly valued in one of the three catchments in the east (River Dodder); anglers were willing to pay $€ 19.20$ for one extra trout per household per year. A separate study of only anglers was also carried out for the project to determine the value that they place on fish (salmon and trout) numbers and size and on water quality. A choice experiment was again carried out in the River Moy catchment (an important salmon fishing river in County Mayo, western Ireland). Questionnaires were posted to 200 anglers and 78 were returned (39 percent response rate) which included 10 percent anglers from Northern Ireland and overseas. The 'choice experiment' required anglers to choose between two sets of three fishing scenarios containing the four attributes of fish size (weight), fish number, water quality and trip price, each presented at one of three levels (Kelly-Quinn et al., 2019). Results showed that anglers place high value on core angling characteristics such as big fish size and catch number but also placed a high value on good water quality (Kelly-Quinn et al., 2019). 


\subsection{LEGAL BACKGROUND}

\subsubsection{Data collection and statistics}

In the Republic of Ireland, Inland Fisheries Ireland is responsible for collecting statistics on recreational and commercial fishing in inland waters (except in the Loughs Agency Area).

\subsubsection{Fishing restrictions, statutory instruments and bye-laws}

Fishing restrictions are complicated in Ireland as they are not standardized across the country and they also vary for species, but there are some general restrictions. The main legislation defining fishing rights in the Republic of Ireland is covered by the Fisheries Consolidation Act 1959, followed by the Fisheries Amendment Act 2010 and subsequent amendments. There are also a range of bye-laws covering many fishing restrictions (i.e. a bye-law is made by a body such as a local authority or a State fisheries agency, under an enabling power established by an act of government and which has been confirmed by the appropriate Departmental Minister). Many have been introduced for conservation purposes, some are related to method restrictions, some are general across multiple species and some are species specific.

\subsubsection{Licences/permits}

While no licence is required for trout, pike, coarse fishing and marine sport fish in the Republic of Ireland, a licence is required for salmon and sea trout. A licence is also required in waters under the remit of the Loughs Agency in the Republic of Ireland for all fish species. The Wild Salmon and Sea trout Tagging Scheme regulates salmon and sea trout fishing in Ireland and is administered by Inland Fisheries Ireland. In addition, anglers in the Shannon region (Irish midlands) must purchase a Midland Fisheries Group permit to fish in certain waters (Rivers Suck, Inny, Brosna, Little Brosna and Camlin). Many private recreational fisheries also still exist in Ireland today. Most private fisheries are for spring salmon, grilse, sea trout and large brown trout, and permits have to be purchased in additional to the state licence, and most fishing is done from boats or riverbank with rods only. Many river beats are rotated on a halfday basis (e.g. Erriff, Inagh, Moy fisheries). There are approximately 170 State-owned fisheries in the Republic of Ireland, and many of these are leased to angling clubs, associations etc. on an annual basis. Each fishery is required to fill out an end of year report detailing catches etc.

\subsubsection{Probibited fishing methods}

The use of nets for fish capture is prohibited in freshwater under Irish law (Fisheries Consolidation Act 1959, Section 95(1) - "It shall not be lawful for any person to use any net for the capture of fish in the freshwater portion of any river or in any freshwater lakes unless used in accordance with bye-laws, it's a landing net, used solely for the purpose of removing fish from traps in a weir, is constructed for the capture of eels"). The Minister can however make a bye-law to authorize their use, for any species of fish other than salmon, trout or eels, subject to conditions. For example, the Minister can permit the use of draft nets to capture trout in a specified lake ( $<30$ sq miles), where the applicant furnishes evidence of consent from all the fishery owners on the lake and satisfies the Minister that within 20 years of $1^{\text {st }}$ January 1948 nets were used as of right in the lake for the capture of trout by members of the public who depended on such netting as a means of livelihood.

Fixed engines (e.g. "stake nets, bag nets, fixed draft net, a head weir or any net, implement engine or device fixed to the soil or secured by one or more anchors or by any other means and used solely for the purpose of taking or facilitating the taking of fish") for the capture of salmon are also prohibited. Other capture methods are also prohibited such as a gaff or an eel spear. Penalties are also associated with taking 
salmon or trout in an eel weir, in a river by cross lines, damming a river for the purpose of taking salmon or trout, using light or fire for the purpose of taking fish. The use of deleterious matter for the capture, destruction or injury of fish is also prohibited.

\subsubsection{Penalties (on the spot fines)}

On the spot fines of $€ 150$ can be issued for a range of fisheries offences (Inland Fisheries (Fixed Charge Notice) Regulations S.I. No. 363 of 2014), e.g. fishing in a closed season, taking fish smaller than allowed, taking more fish than a bag limit allows, etc. Fishing gear can be seized, and vehicles can be searched (Fisheries Consolidation Act 1959).

\subsubsection{Examples of some general bye-laws}

The "Prohibition of Foul hooking Bye-Law No. 247 of 2008" prohibits the killing and possession of foul hooked fish (i.e. fish not hooked in the mouth) in any fishery district in any year.

Fly only bye-laws - On some waters fly only regulations or other method restrictions may be in place.

A new angling bye-law was passed in January 2019 (Angling Bye-Law No. 965, 2018) which prohibits the use of worms as bait or to use, or attempt to use any fish hooks, other than single or double barbless hooks in angling for any kind of fish in the waters of a river mentioned in the Bye-Law.

\subsubsection{Examples of some species-specific restrictions}

\section{Brown trout angling}

In general, a licence is not required to fish for brown trout in the Irish Republic, except in Loughs Agency waters (within the Republic of Ireland jurisdiction) in counties Donegal and Louth and anglers in the Shannon region (Irish midlands) must purchase a Midland Fisheries Group permit to fish certain waters (Rivers Suck, Inny, Brosna, Little Brosna and Camlin). The majority of waters are owned by the State or are privately owned. Many State-owned fisheries are leased to angling clubs or associations. A fishing permit issued by the lease gives the permit holder the right to fish for set periods. Many of the large western lakes offer free fishing for brown trout and do not require permits.

Some new Bye-Laws/Regulations have been introduced over the last two years to help conserve brown trout, for example, in the midland Shannon lakes, Bye-Law 949 (Conservation of trout - No. 8 or Limerick District) (Loughs Sheelin, Derravaragh, Owel, Ennell, Ree, and Derg, etc.). These regulations were introduced following consultation with anglers and are designed to improve conservation of wild trout stocks in the catchments.

Most brown trout fisheries open between February $15^{\text {th }}$ and March $1^{\text {st }}$. Most close on September 30th , with some exceptions which close on various dates between September $15^{\text {th }}$ and October $12^{\text {th }}$. Clubs may also have their own regulations on opening and closing dates. Almost every river and lake has defined size limits for brown trout, but anglers are advised to check with their local club or IFI office as these vary widely across the country. Many of these fisheries also have bag limits but many more don't, therefore anglers are advised to fish sustainably, and practice catch and release (Table 20).

\section{Salmon and sea trout angling}

New bye-laws are published annually covering open, catch and release waters and closed rivers for salmon and sea trout angling. Salmon fishing opens on January $1^{\text {st }}$ on a handful of rivers and after that the remaining rivers open on various dates in February, March, April and May. The majority close on $30^{\text {th }}$ September but some remain open until $12^{\text {th }}$ October for sea trout. 
TABLE 20

Examples of some of the fishing restrictions for brown trout in Ireland

\begin{tabular}{|c|c|c|c|c|c|c|c|c|}
\hline Fishery district & Waters & Opening day & Closing day & $\begin{array}{l}\text { Size } \\
\text { limit } \\
(\mathrm{cm})\end{array}$ & Bag limit & $\begin{array}{l}\text { No. } \\
\text { rods per } \\
\text { person }\end{array}$ & $\begin{array}{l}\text { No. rods } \\
\text { per boat }\end{array}$ & $\begin{array}{l}\text { Methods } \\
\text { restricted }\end{array}$ \\
\hline \multirow{3}{*}{$\begin{array}{l}\text { Limerick } \\
\text { fishery } \\
\text { district (Bye- } \\
\text { Law no. } 949 \\
\text { of } 2017 \text { - } \\
\text { Conservation } \\
\text { of trout) }\end{array}$} & $\begin{array}{l}\text { Lough } \\
\text { Derravaragh, } \\
\text { Lough Owel, } \\
\text { Lough Ennell }\end{array}$ & $1^{\text {st }}$ March & $12^{\text {th }}$ October & 36 & 2 & 2 & 4 & \\
\hline & Lough Ree & $1^{\text {st }}$ March & $30^{\text {th }}$ September & 36 & 2 & 2 & 4 & \\
\hline & Lough Derg & $15^{\text {th }}$ March & $30^{\text {th }}$ September & 36 & 2 & 2 & 4 & \\
\hline \multirow[t]{2}{*}{$\begin{array}{l}\text { Ballyshannon } \\
\text { District }\end{array}$} & $\begin{array}{l}\text { River Erne, } \\
\text { including } \\
\text { Annalee, } \\
\text { Cavan, } \\
\text { Dromore, } \\
\text { Laragh, } \\
\text { Bunnow and } \\
\text { Knappagh } \\
\text { river } \\
\text { tributaries }\end{array}$ & $1^{\text {st }}$ March & $30^{\text {th }}$ September & 30 & 2 & & $\mathrm{~N} / \mathrm{A}$ & \\
\hline & $\begin{array}{l}\text { Lough } \\
\text { Gowna } \\
\text { (Northern } \\
\text { Fisheries } \\
\text { Region } \\
\text { (Lough } \\
\text { Gowna) } \\
\text { conservation } \\
\text { of trout Bye- } \\
\text { Law 869, } \\
2010 \text { ) }\end{array}$ & & & 30 & 4 & & & \\
\hline $\begin{array}{l}\text { Galway } \\
\text { District }\end{array}$ & $\begin{array}{l}\text { Lough Carra } \\
\text { Clare River }\end{array}$ & $1^{\text {st }}$ March & $30^{\text {th }}$ September & 33 & $\begin{array}{c}4 \\
\text { (only } 1 \\
>4.54 \mathrm{kgs} \text { ) }\end{array}$ & & $\begin{array}{l}1 \text { or } 2 \text { rods } \\
\text { depending } \\
\text { on method }\end{array}$ & \\
\hline
\end{tabular}

\section{Bag and size limits}

There is an annual maximum angling bag limit of 10 salmon (any size) or sea trout $(>40 \mathrm{~cm})$ on "open" rivers (i.e. where you may catch and retain a salmon or sea trout). Bag limits are subject to any quota allocated to a river and its tributaries. All salmon (and sea trout) rod holders must also affix a gill tag to all retained salmon (any size) or sea trout $(>40 \mathrm{~cm})$.

Additional restrictions are as follows. An angler may take:

- A total of one salmon (any size) or sea trout $(>40 \mathrm{~cm})$ per day for the period beginning January $1^{\text {st }}$ to May $11^{\text {th }}$ ( 3 fish in total may be retained for this period).

- Daily bag limit: 3 salmon (any size) or sea trout $\left(>40 \mathrm{~cm}\right.$ ) per day from May $12^{\text {th }}$ to August $31^{\text {st }}$ (except where a salmon rod (one-day) ordinary licence is held, 1 fish).

- Daily bag limit: One salmon (any size) or sea trout $9>40 \mathrm{~cm}$ ) per day from $1^{\text {st }}$ September to the close of the season.

- There is an angling bag limit of 3 sea trout $(<40 \mathrm{~cm})$ per angler per day.

Fishing for sea trout is further restricted in certain areas. It is an offence to kill any sea trout in certain parts of the west of Ireland (Galway, Connemara or Ballinakill fisheries districts).

After the daily bag limit has been taken, anglers are permitted to fish catch and release (candr), using single or double, barbless hooks and anglers may not use worms. 
The killing and possession of foul hooked fish is also prohibited. On rivers where candr is permitted anglers may not use worms, anglers must use single or double, barbless hooks, the fish must be handled carefully and should not be removed from the water prior to release.

On all other rivers (not listed in the annual Wild Salmon and Sea Trout Tagging Scheme (Amendment) Regulations e.g. S.I. 636 of 2016), angling for salmon (any size) and sea trout $(>40 \mathrm{~cm})$ is prohibited. There are also some additional regulations for some specific case study rivers where there are identifiable problems. For example:

- The Regulations on the Avoca river (a river in the east of Ireland that is subject to mining effluent) prohibit the taking of any sea trout as well as prohibiting the use of worms as bait and any fish hooks other than single barbless hooks in angling for sea trout $(<40 \mathrm{~cm})$ (Bye-Law No. 890, 2011).

- The River Tor and its tributaries are closed for angling for all species of fish (ByeLaw No. 311, 2011).

- The regulations on the River Suir provide for candr in angling for salmon (any size) and sea trout (over $40 \mathrm{~cm}$ ) in the main channel (and include the waters of the Rivers Clodiagh, Lingaun and Blackwater). They also prohibit the use of worms, prawn, shrimp or any other crustacean or artificial forms thereof as bait and any fish hooks other than single or double barbless hooks during the period 17 March to 30 September (Conservation of Salmon and Sea Trout (River Suir) Bye-Law No 968, 2018).

- Regulations on the River Slaney provide for candr in angling for salmon (any size) and sea trout (over $40 \mathrm{~cm}$ ) in the River Slaney only, during the period 1 April to 31 August. The Bye-Law also provides for the use of artificial fly only using single or double barbless hooks upstream of the Railway Bridge, Enniscorthy, Co. Wexfod and provides for the use of single barbless hooks and a ban on worms as bait downstream of the Railway Bridge, Enniscorthy, Co. Wexford when angling for salmon or sea trout (any size). (Conservation of Salmon and Sea Trout (River Slaney) Bye-Law No. 970, 2018.

\section{Coarse fish and pike angling}

There are a number of restrictions covered by bye-laws for coarse fish species and pike angling in Ireland.

- Conservation of and prohibition of sale of coarse fish (Bye-Law No. 806, 2006) provides a number of conservation measures for these species e.g. no more than 4 coarse fish shall be taken and killed by any means on any one day.

- The only legal method to catch pike and coarse fish in Ireland is by rod and line (Control of Fishing for Coarse fish in freshwater Bye-Law No. 595, 1977).

- A person may fish with not more than two rods at any time (Control of Fishing for Coarse Fish in Fresh Water Bye-Law No. 595, 1977).

- It is illegal to have or to use live fish as bait (Use of Live Fish as Bait in Fresh Water Bye-Law No. 592, 1977).

- It is illegal to transfer live roach from one water body to any other water body (Transfer of Live Roach, Bye-Law No. 561, 1973).

- Angling Bye-Law No. 955 of 2017 prohibits the use of any fishhooks, other than single barbless hooks, and also prohibits the use of worms as bait in angling for all species of fish in the waters specified in the Bye-Law.

\section{Pike}

The Conservation of Pike Bye-Law No. 809, 2006 provides for the following conservation measures: 
- It is prohibited to kill more than 1 pike in any one day and it is prohibited to kill any pike greater than $50 \mathrm{~cm}$ in length.

- It is prohibited for any person to have in their possession more than 1 whole pike less than $50 \mathrm{~cm}$ or more than $0.75 \mathrm{kgs}$ of pike flesh.

- It is prohibited for a person to have in his or her possession more than 12 coarse fish for use as bait in fishing for pike

- Where a person has more than 4 coarse fish in his or her possession for use as bait in fishing for pike, the person, in respect of fish in excess of that number and subject to the paragraph (i) above must have:

a) Obtained the fish from a fish tackle dealer or fish bait supplier registered with Inland Fisheries Ireland; and

b) Obtained and retained a receipt of their purchase.

\section{Eel fishing}

Recreational and commercial eel fishery is closed in the Republic of Ireland. The Conservation of Eel Fishing Bye-Law, No. C.S. 319, 2015 prohibits the taking, attempting to take, fishing for or attempting to fish for, aiding or assisting the taking of, or fishing for eel in any fishery district in the State. It also prohibits being in possession of, selling or offering for sale or reward, or purchasing eel caught or taken by any means in any fishery district in the State. Additionally, the Conservation of Eel Fishing (Prohibition on Issue of Licences) Bye-Law No. 858, 2009 prohibits the issuing of eel licences for fishing of eels by any fishing method in any fishery district.

\subsubsection{Fishing rights - Republic of Ireland}

In the Republic of Ireland, anywhere a fishery exists in freshwater there is a right to fish or a fishing right. This right is owned by either a private individual or a group such as an angling club or the State. The owner of the fishing rights can choose to make fishing available for public use, either for the payment of a fee or free of charge of permit; this is sometimes referred to as 'free fishing' nonetheless it is still essentially 'private property'.

The title to fisheries / fishing rights in Ireland derives from the appropriation of lands by Britain (the island of Ireland was ruled by Britain up to 1921, after that Ireland was partitioned under British law, which created Northern Ireland), under the Acts of Confiscation of the $17^{\text {th }}$ century and the subsequent granting of estates by Britain to its favoured subjects. The boundaries of these estates tend to correspond to townland boundaries and so the associated fishing rights are also mostly defined by townland boundaries. Townland boundaries and hence fishing rights generally extend to the half-way mark of a river and to the centre point of a lake out from the adjoining land. However, for townlands adjoining a river below its tidal reaches (due to the public right on sea fisheries) the boundary is at the water's edge rather than the centreline.

The Irish Land Commission was created in 1881 and from 1885 it was the body responsible for re-distributing farmland in Ireland. The Commission assisted in the agreed transfer of freehold farmland from landlord to tenant. The Commission transferred 13.5 million acres $\left(55000 \mathrm{~km}^{2}\right)$ by 1920. In 1992, the Irish Land Commission was dissolved, and the system of land purchase/transfer ceased. Under section 5 of the Irish Land Commission (Dissolution) Act, fishing rights previously under the ownership of the Land Commission were transferred to the Central Fisheries Board (now Inland Fisheries Ireland).

Fishing rights may be held by individuals or bodies in the same way as land may be held. In Ireland, there are no laws dictating that the ownership of fishing rights may not be severed from that of the bed and soil or the adjoining land, meaning that one person can own the bed and soil and another the fishing rights. Consequently, lands and fishing rights have changed hands sometimes together and sometimes separately. 
Quite often fishing rights are passed on from generation to generation in a family and consequently can be shared between multiple descendants spread across the globe. It is not uncommon for the owner of a fishing right be unaware that they even own the right. For this reason, it can often be quite confusing to track down the current owner of a fishing right.

In the mid 1990s, a significant amount of money was invested in Ireland's angling infrastructure under the Tourism Angling Measure (T.A.M.), the aim of which was to improve the domestic and tourism angling product. One of the conditions of receiving aid under this measure was that title to a fishery had to be established. During this period, a significant amount of work was done on establishing the title and ownership of a large number of fisheries including a number of State fisheries. By the late 1990s, work had been completed on approximately 170 State fisheries. Many of these fisheries are now under licence to various angling clubs.

IFI does not have a complete database of all fishing rights in Ireland, but only holds information on those they own. IFI owns approximately 170 State fisheries. The ethos of the State fisheries is to make angling accessible to as many as possible. Part of the licence agreement for the fishery (normally 5 years) stipulates that tickets must be made readily available by the licencing club or organization to visiting anglers. These should be made available in local tackle shops, through accommodation providers and directly through a club committee member. Contact details and locations for buying tickets should also be advertised on a signpost erected by the club on the fishery itself. Many of the 170 State-owned fisheries are leased to angling clubs etc. on an annual basis. Each fishery is required to fill out an end of year report detailing catches etc.

\subsection{ENVIRONMENTAL ISSUES AND CONFLICTS WITH OTHER WATER USERS}

The interests of inland fisheries in Ireland are supported at State level by the Minister of Communications, Climate Action and Environment. The Minister has overall responsibility for the regulatory framework to ensure the conservation, protection and management of the inland fisheries resource. Two agencies are responsible for developing and advising the Minister on policy and national strategies relating to inland fisheries, including sea angling (i.e. Inland Fisheries Ireland and the Loughs Agency (for two cross-border areas)). IFI is responsible for the day-to-day management of the resource including setting conservation limits, issuing fishing licences and acting on reports of pollution and poaching. IFI enforces the Inland Fisheries Acts (1959 to 2010) and implements the policies agreed by the Minister regarding conservation, protection, management, marketing, development and improvement of the resource. In addition to enforcing the Fisheries Acts, IFI is also empowered to enforce the Water Pollution Acts 1977 and 1990 when discharges to fisheries-sensitive locations impact on water, leading to deterioration in water quality and possible fish kills. IFI also has a research function that provides the scientific knowledge and advice to the Minister. Further, IFI is committed to ensuring that angling in Ireland continues to be recognized as a valuable asset, promotes angling as a leisure pursuit and provides a number of education and outreach programmes at local and national level.

While the quality of Irish water is among the best in Europe, there are many water users (e.g. water abstraction for drinking water purposes, hydropower, wastewater discharges, industrial discharges or abstraction, food production/agriculture, other recreational users etc.) conflicting with the interests of freshwater inland fisheries in Ireland. IFI has a team of environmental officers who enforce fisheries legislation and the Water Pollution Acts. They carry out thousands of environmental inspections in conjunction with their protection colleagues every year (e.g. in 2017, 26726 environmental inspections were carried out - these covered a range of topics from forestry, agriculture, industrial, habitat and wastewater and water treatment plants) and 
they can also initiate prosecution cases for environmental offences. IFI also comments on any relevant planning applications, statutory or public consultations.

The EU Water Framework Directive (WFD) is now the primary water policy driver in Ireland and its objectives incorporate a multi-sectoral achievement of good ecological quality (including good fish status). The Water Policy Regulations (S.I. No. 722 of 2003), Surface Waters Regulations (S.I. No. 272 of 2009) and Groundwater Regulations (S.I. No. 9 of 2010) regulate the shape of the WFD characterization, monitoring and status assessment programmes in terms of assigning responsibilities for the monitoring of different water categories, determining the quality elements and undertaking the characterization and classification assessments. The Surface Waters Regulations introduce a wide-ranging set of environmental standards for Irish surface waters.

The River Basin Management Plan for Ireland 2018-2021 outlines Ireland's approach as it works to protect its rivers, lakes and other water bodies up to 2021. The Plan has placed an emphasis on establishing the right governance and delivery structures for an effective catchment-based approach to protecting/restoring water quality with the aim of having all stakeholders working together to deliver positive outcomes.

The Environmental Protection Agency is responsible for environmental regulation of water-related activities and water quality in Ireland. The Agency also has responsibility for coordination and oversight of the Irish WFD programme including national coordination of all of its technical aspects. The Department of Housing, Planning and Local Government (DEHPLG) is responsible for economic and policy aspects of the WFD. These tasks were extended during the second cycle to include drafting environmental objectives, undertaking catchment characterization, preparing template river basin management plans and compiling a common programme of measures for further development and input by local authorities and finalization and approval by the Minister for the Environment.

A new Local Authority Waters Programme (LAWPRO) was created in 2016 to develop and implement the River Basin Management Plan as required by the WFD. The 31 local authorities are working side by side to achieve common goals. LAWPRO includes a catchment assessment team, five catchment managers and 30 catchment scientists, a community office and 12 community officers. The catchment scientists are carrying out scientific assessments and aiming to drive the implementation of mitigation measures at local level while the communities office is providing opportunities to raise awareness, discover the local causes of water pollution, activate engagement of local communities and identify measures in consultation with landowners, industry and other stakeholders that can reduce pollution inputs to local rivers. In addition to this, an Agricultural Sustainability Support and Advisory Programme (ASSAP), funded by the Department of Housing, Planning and Local Government (DHPLG), the Department of Agriculture, Food and the Marine (DAFM) and the dairy co-ops, has been implemented and includes 30 agricultural advisors. These are working under Teagasc and some dairy co-ops on a one-to-one basis with farmers to bring about behavioural change through improved agricultural practices in areas which have identified pressures on water bodies.

Applications for most planning developments in Ireland are submitted to the planning section of the local authority in the county where the development is proposed. The 26 local authorities are responsible for determining the majority of planning applications and for enforcement. The Environmental Protection Agency has responsibility for preventing and controlling environmental emissions from certain activities with potential for significant impact on the environment through the operation of a system of integrated pollution control licensing (IPC). The objective of the system is to ensure that relevant activities operate to a standard which provides a high level of protection for the environment. The system is based on the application of BATNEEC (best 
available technology not entailing excessive costs) in order to prevent or eliminate, or where that is not practicable, to limit, abate or reduce emissions from activities. Planning permission and an IPC licence is required for certain development activities. In certain cases (e.g. large-scale developments including agriculture, food industry, chemical industry, infrastructure and urban developments), an Environmental Impact statement (EIS) must also be prepared and submitted with the planning application and the IPC licence application. In some instances, an EIS is mandatory irrespective of the size of the project (developments as listed in Schedule 5 of the Irish Planning and Development Regulations, 2001 to 2002). The National Parks and Wildlife Service, as part of the Department of Culture, Heritage and the Gaeltacht, also has a role in relation to development proposals where nature conservation issues may arise. The role is primarily an advisory one, in the context of statutory consultations from various consent authorities or pre-application consultations. Appropriate assessment has been a legal requirement in Ireland since 1997 and is required for any plan or project that is not directly connected with or necessary to the management of a Natura 2000 site (special areas of conservation or special protection areas) concerned and should only be authorized if it will not adversely affect the integrity of the site. Planning refusals can be appealed through An Bord Pleanala (The Planning Board), an independent national planning appeals board.

\subsubsection{Legislation relating to water in Ireland}

Some of the main Irish legislation and EU Directives relating to water are listed in Table 21. The control of water pollution in Ireland is undertaken through the Local Government Water Pollution Acts 1977-1990 and the Water Services Act 2007-2013 ("A person shall not cause or permit the entry of pollution matter to enter waters"). Fishing waters are also protected from poisoning and pollution under the Fisheries Consolidation Act 1959 (i.e. "any person who (a) steeps flax or hemp in any waters or throws, empties, permits or causes to fall into any waters any deleterious matter shall be guilty of an offence" (171 (1) (172 (2)), subsequent amendments (Fisheries amendment Acts 1962-2000) and the Inland Fisheries Act 2010. Spawning beds, spawn, fry and smolts of salmon, trout or eels are also protected under the same Act (173 91).

\subsubsection{Conflicts between recreational and cultural services}

Freshwater ecosystems provide multiple services and multiple goods and benefits to society (Feeley et al., 2017). Freshwater rivers and lakes in Ireland have historically been places for recreation in addition to trade, water supply and providing food, but many different groups are now competing for the recreational use (e.g. anglers, canoeists, rowers, swimmers, adventure parks, water skiers, jet skiers, etc.) in certain areas. The management of ecosystems can change the type, magnitude, and relative mix of services provided by an ecosystem and in some instances there may be an explicit choice in the management of an ecosystem. For example, jet-skiing, speed boating and water skiing are partially or completely banned on Loughs Ramor, Sheelin, Oughter, Gowna, Annagh and Brackley in the north midlands of Ireland due to the popularity of these lakes for angling and swimming. The management of these lakes by the local county council limits the type of recreational cultural service that can legally occur. Other conflicts may occur: such as the introduction and spread of non-native coarse fish may improve coarse fish angling in the affected areas but will impact upon the native trout and salmon populations and the associated angling service (Feeley et al., 2017).

\subsection{MONITORING FISH}

The responsibility for monitoring fish for the Water Framework Directive in the Irish Republic has been assigned to IFI. The monitoring programme covers over 
TABLE 21

Main Irish legislation and EU Directives relating to water

\begin{tabular}{|c|c|}
\hline Irish Legislation & EU legislation \\
\hline $\begin{array}{l}\text { European Communities (Water Policy) Regulations, } \\
2003 \text { S.I. No } 722 \text { of } 2003\end{array}$ & $\begin{array}{l}\text { Birds Directive (79/409/EEC); } \\
\text { Drinking Water Directive (80/778/EEC) as amended }\end{array}$ \\
\hline $\begin{array}{l}\text { European Communities (Drinking Water) (No. 2) } \\
\text { Regulations, } 2007 \text { (S.I. No. } 278 \text { of 2007) }\end{array}$ & $\begin{array}{l}\text { by Directive (98/83/EC); } \\
\text { Major Accidents (Seveso) Directive (96/82/EC); }\end{array}$ \\
\hline $\begin{array}{l}\text { European Communities Environmental Objectives } \\
\text { (Surface waters) Regulations, } 2009 \text { (S.I. No. } 272 \text { of } \\
\text { 2009) }\end{array}$ & $\begin{array}{l}\text { Environmental Impact Assessment Directive } \\
\text { (85/337/EEC); }\end{array}$ \\
\hline $\begin{array}{l}\text { European Communities Environmental Objectives } \\
\text { (Groundwater) Regulations, } 2010 \text { (S.I. No. } 9 \text { of } \\
\text { 2010) }\end{array}$ & $\begin{array}{l}\text { Sewage Sludge Directive (86/278/EEC); } \\
\text { Urban Waste-water Treatment Directive (91/271/ } \\
\text { EEC); }\end{array}$ \\
\hline $\begin{array}{l}\text { European Communities (Good Agricultural Practice } \\
\text { for Protection of Waters) Regulations, } 2010 \text { (S.I. } \\
\text { No. } 610 \text { of 2010) }\end{array}$ & $\begin{array}{l}\text { Plant Protection Products Directive (91/414/EEC); } \\
\text { Nitrates Directive (91/676/EEC); }\end{array}$ \\
\hline $\begin{array}{l}\text { European Communities (Technical Specifications } \\
\text { for the Chemical Analysis and Monitoring of } \\
\text { Water Status) Regulations, } 2011 \text { (S.I. No. } 489 \text { of } \\
\text { 2011) }\end{array}$ & $\begin{array}{l}\text { Habitats Directive (92/43/EEC); } \\
\text { Integrated Pollution Prevention Control Directive } \\
\text { (96/61/EC); }\end{array}$ \\
\hline $\begin{array}{l}\text { Fisheries Consolidation Act } 1959 \text { (and all } \\
\text { subsequent amendments) }\end{array}$ & $\begin{array}{l}\text { Water Framework Directive (2000/60/EC); } \\
\text { Bathing Water Directive (2006/7/EC) (repeals } \\
\text { 76/160/EEC); }\end{array}$ \\
\hline Inland Fisheries Act 2010 (and any amendments) & Groundwater Directive (2006/118/EC); \\
\hline $\begin{array}{l}\text { Water Pollution Acts } 1977 \text { and } 1990 \\
\text { European Union (Water Policy) (Abstractions } \\
\text { Registration) Regulations } 2018 \text { (S.I. No. } 261 \text { of } \\
\text { 2018)) (this covers abstractions >25m3/day and } \\
\text { requires the creation of a water abstraction } \\
\text { register). }\end{array}$ & $\begin{array}{l}\text { Floods Directive (2007/56/EC); } \\
\text { Marine Strategy Framework Directive (2008/56/EC). }\end{array}$ \\
\hline
\end{tabular}

300 sites in rivers, lakes and transitional waters (more information is available on www.wfdfish.ie). In addition, the Irish implementing legislation for the Habitats Directive identifies the Minister for Communications, Climate Action and Environment as having a role in carrying out monitoring status of the relevant fish species (salmon, three species of lamprey, three species of shad and pollan). As such, IFI has an ongoing monitoring programme to fulfil this Ministerial obligation. This programme is complemented by including those additional fish species listed in the current Irish Red Data Book as endangered or at risk in the monitoring programme (e.g. Arctic char, smelt) (www.fisheriesireland.ie). IFI also carries out research and routine fish stock monitoring surveys to assess the status of other fish stocks in many water bodies (rivers and lakes) across the country. The survey objectives are varied and cover many programmes e.g. eel management programme, salmon catchment-wide electrofishing programme, national brown trout research programme, national coarse fish research programme etc. Many of the programmes have synergies with each other to ensure optimal use of resources. The aim of most of the programmes is to develop a knowledge base on various fish species to assess their current status and to identify issues and requirements needed to sustain the various species. Fish stock surveys are conducted using a variety of methods including electrofishing, various forms of netting and hydroacoustics. IFI are also leading a programme to collect and collate data to support the development of a national inventory of barriers that may be impacting on a range of migratory fish species, including species protected under the Birds and Habitats Directive.

\subsection{COMMERCIAL FISHING IN INLAND WATERS}

There is only one small commercial lake fishery in the Republic of Ireland, and this is situated on Lough Ree in the midlands. Lough Ree is the third largest lake in the Republic of Ireland with an area of 10500 ha, a mean depth of $6.2 \mathrm{~m}$ and a maximum depth of $36 \mathrm{~m}$. Water levels in the lake are regulated by the Electricity Supply Board 
(ESB) and Waterways Ireland (WI). The ESB controls water levels for the purpose of electricity generation and WI controls levels for navigation purposes. The lake has also been designated as a Special Area of Conservation and a Special Protection Area for multiple habitats and species. Lough Ree is also home to the endangered fish species pollan (Coregonus autumnalis) listed on Annex V of the Habitats Directive and in the Irish Red Data Book as endangered (King et al., 2011).

Commercial catches on the lake are for brown trout only. Fishers are required to apply for a fishing licence on an annual basis from IFI. Fishing rights date back to at least the 1940s but could date to an earlier period. Up to 12 licences can be issued annually and the season extends from $15^{\text {th }}$ of February to the $31^{\text {st }} \mathrm{July}$ and is based around the islands on the lake. The method used is draft nets and no other method is permitted. There is no catch or size limit applied, but the size limit should be comparable to the current recreational angling limit of $36 \mathrm{~cm}$ (Mooney, IFI, personal communication). There is no requirement to report catches, but this is done on a voluntary basis by many of the licence holders; however, there is no data available for some years or some figures are underestimates as only number or biomass were reported. Total number of fish and total biomass figures are submitted, but no information on age, class and size distribution is available. IFI maintains the database on catches, but the statistics are not published. Currently the lake is also included in Inland Fisheries Ireland's fish stock monitoring programme for the WFD, brown trout and coarse fish research programmes (www.wfdfish.ie).

\subsection{RECREATIONAL FISHING IN INLAND WATERS}

IFI commissioned Tourism Development International (TDI) to undertake a socioeconomic study to assess the volume, value and economic impact of recreational angling in Ireland. This report also included some information on the age profile of recreational anglers (TDI, 2013). Information on market profile, length of stay, country of residence, angling category, age, occupation, party composition, party size, types of accommodation used, transport used and angling club membership, etc., was also collected during the survey.

Only rod and line angling (e.g. fly fishing, spinning, trolling) is permitted in Ireland, all other types such as gill netting, traps, etc., are prohibited.

\subsubsection{Age profile of recreational anglers in Ireland}

Of the estimated 406000 individuals who took part in recreational angling, 252000 were Irish anglers (62 percent). Northern Irish anglers represented ten percent of anglers and overseas visitors accounted for 28 percent; however, this number can fluctuate (TDI, 2013).

Almost half (49 percent) of all anglers fishing in Ireland were in the 35-54 age group. Only 14 percent were aged 18-34. The age profile of anglers from the UK was an older one, with more than half (52 percent) falling into the $55+$ age group while only 40 percent of European anglers were in the same age category. The age profile of domestic anglers was younger than overseas anglers.

Sea angling had the highest proportion of anglers in the 18-34 age category (23 percent); while bass and coarse angling had the highest proportion of anglers who were middle aged, 56 percent were between 35 and 54 years of age. Game angling had the oldest age profile with almost half of salmon/sea trout/brown trout anglers falling in the 55+ age cohort (TDI, 2013). The profile of pike anglers was the youngest with almost 18 percent under the age of 35 .

\subsubsection{Occupation of anglers}

Approximately 62 percent of anglers in Ireland were determined to be from the ABC1 socio-economic background (i.e. middle class) and the remaining 38 percent were 
from C2DE backgrounds (i.e. working class, including skilled workers). A higher proportion of overseas anglers were from the ABC background (TDI, 2013). It was also determined that those participating in salmon and sea trout angling were even more likely to be social class $\mathrm{ABC} 1$, while coarse anglers had a much higher proportion in the C2DE category (TDI, 2013).

\subsubsection{Angling clubs}

There are an estimated 367 angling clubs in Ireland and more than half (54 percent) of respondents had purchased a membership. Domestic anglers had an estimated 69 percent membership while overseas anglers had 23 percent (TDI, 2013).

\subsubsection{Angling category participation}

Sea angling, salmon, brown trout followed by pike angling are the most popular categories for domestic anglers in Ireland (NSAD, 2015a). High proportions of domestic anglers engage in fishing for more than one species. Salmon, sea bass and sea angling are the most popular with overseas anglers. A large proportion of anglers fishing for salmon (52 percent) and sea bass (63 percent) were from out of state. Sea trout, coarse and sea angling also attracted a large proportion of out of state anglers. Brown trout and pike anglers are predominantly from the domestic market (TDI, 2013).

The profile of angling activity varies across the country; the southeast (88 percent), Shannon (76 percent) and western (65 percent) areas rely heavily on anglers from the domestic market, while the eastern and north-western areas attracted domestic and overseas anglers in almost equal proportions. In contrast, large proportions (69 percent) of anglers in the southwest were from out of state (TDI, 2013).

\subsubsection{Number of angling trips}

It was estimated that domestic anglers took an average of 13.6-day angling trips and approximately 22 percent of domestic anglers took an overnight trip (mean $=5.25$ trips). Overseas anglers had made approximately two angling trips to Ireland in the previous 12 months, while European anglers in particular took a higher than average number of trips (2.35). Many anglers, particularly overseas anglers were found to be loyal to specific fisheries in Ireland (TDI, 2013).

\subsection{INTERNATIONAL COOPERATION}

There are a number of cross-border catchments which transect the Irish border between the Republic of Ireland and Northern Ireland. Two that discharge to the sea in the Irish Republic, are managed for sea trout and salmon (i.e. Drowes River/Lough Melvin and the River Fane). The normal bag limits which apply to Irish rivers also apply to the Drowes and Fane systems.

\subsubsection{Case study: Drowes - Melvin catchment}

The Drowes/Melvin catchment transects the border between the Republic of Ireland and Northern Ireland. The Drowes fishery (located entirely within the Republic of Ireland) is one of Ireland's premier spring salmon and grilse fisheries. The first salmon of the season is often caught on the Drowes fishery as it is one of a few rivers open on the $1^{\text {st }}$ of January. There is a run of spring salmon from January to April/May and the main grilse run starts at the end of May, peaking in June/July.

- The salmon season is from $1^{\text {st }}$ January to $30^{\text {th }}$ September inclusive.

- The brown trout season is from $15^{\text {th }}$ February to $30^{\text {th }}$ September inclusive.

- Permits - A permit is required to fish the Drowes river (day or weekly ticket).

- Licence - A Republic of Ireland salmon and sea trout licence is required if fishing for those species. 


\section{Lough Melvin fishery}

Lough Melvin is one of the most important salmonid fisheries in the northwest of Ireland. There are four distinct species of trout present in the lake (gillaroo, sonaghan, ferox and brown trout). Arctic char, perch tench and rudd are also present.

The lake straddles the border between the Republic of Ireland and Northern Ireland and therefore the fishing regulations are slightly different depending on where the angler is fishing. The North East corner of the lake lies in Northern Ireland and as such requires a Northern Ireland fishing licence and a Garrison Angler's permit to fish (see map, Figure 39). The remaining area lies in the Irish Republic, therefore, a licence for brown trout (or other species such as perch and rudd) fishing is not required in approximately two thirds of it, but a licence for salmon or sea trout is required. The Rossinver fishery Syndicate controls the remaining one third of fishing (see map) in the Republic of Ireland. A permit is also required for the Rossinver fishery.

- Angling season - The salmon season is from $1^{\text {st }}$ February to $30^{\text {th }}$ September inclusive. The brown trout season is from $15^{\text {th }}$ February to $30^{\text {th }}$ September (inclusive of the Rossinver Fishery).

- Permits - Separate permits are required for the Rossinver and Garrison Fisheries.

- Licence - a RoI state salmon and sea trout licence is required when fishing in the Republic of Ireland part of the lake and a Northern Ireland licence is required in the Garrison part of the lake if angling for any species of fish (Figure 39).

- Lough Melvin Garrison salmon tags are issued on a Garrison Permit. Anglers are allowed to kill two salmon per year on the Garrison Waters of Lough Melvin. Two tags per angler are issued annually. On the Irish Republic side of the fishery, the normal salmon bag limits apply i.e. only three salmon can be killed between the $1^{\text {st }}$ February and the $12^{\text {th }}$ May. A total of ten salmon can be taken annually.

- Methods: All legitimate angling methods are allowed.

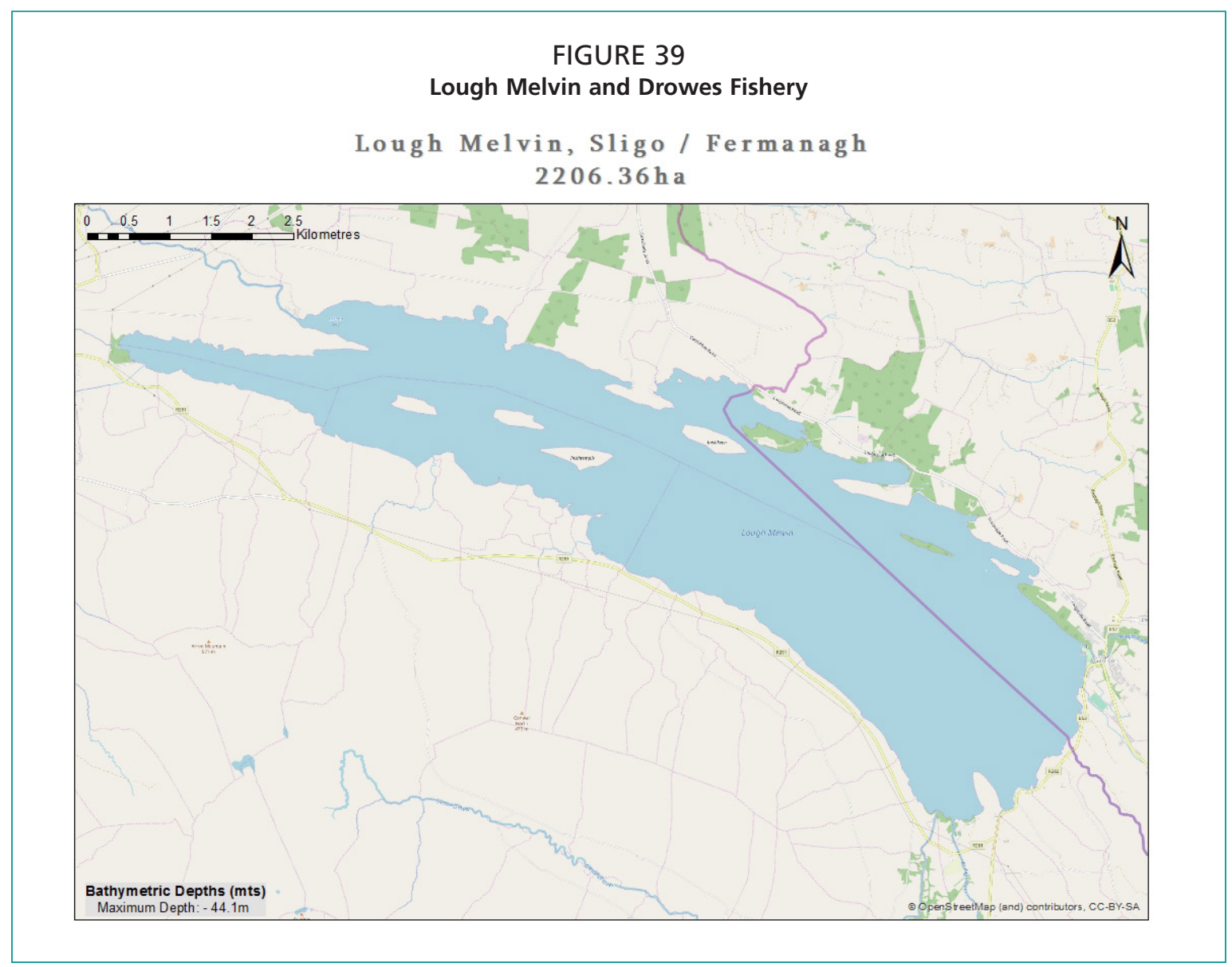





\section{Methodologies suitable for data collection in inland fisheries}

A suite of different types of information from fisheries is required to secure a firm foundation for the future management of inland fisheries. Hence, several types of data should potentially be collected from all European Inland waters. This includes information about target species and the catch (in absolute numbers or as catch rates (CPUE)), ideally also including the size or age of fish in the catch, fishing pressure (effort), and fate of the fish (harvested or released). It is equally important to acquire information on socio-economic aspects of inland fisheries (e.g. expenditure at local and national level), and the perceived quality of fishing and angler/fisher heterogeneity to gain important insights about the characteristics of the fishing population, as well as the prevalence of certain attitudes, preferences and behaviours among those working in the sector. In addition, fisheries-independent methods should be used e.g. to obtain biological data about the fish stock or fish density to allow trend analysis and application of data-poor assessment methods common in marine fisheries (Arlinghaus et al., 2019).

As part of this report we made a short review of the inland fisheries data collection in Europe (see Chapter 2). Data was collected from literature and the Internet. An inquiry was sent to inland fisheries researchers in April-June 2019 in European countries. The researchers were asked for input about the methods they used to collect data about commercial and recreational fisheries in their country (Box 3). Suitable methodologies to collect socioeconomic data in fisheries are not reviewed here as they are already reviewed elsewhere (e.g. Parkilla et al., 2010) and examples are given in the text (Chapter 3.3).

In this section we provide some general insights about relevant methodologies that can be used to collect data. This includes fisheriesindependent data and fisheries-dependent data i.e. data provided by fishers through some kind of survey. In the latter, focus is on collecting data from the recreational fisheries. Next, we give an overview of different methodologies that were used to collect data about inland fisheries in Europe and highlight their strengths and weakness. Finally, we conclude and suggest a way forward to improve data collection in inland waters i.e. by enhanced corporation with working groups from the marine fisheries sector.

\section{BOX 3}

The email query that was sent to the European countries

Dear,

I am contacting you because EIFAAC is preparing a report to FAO about the methods used to collect inland fisheries data (recreational and commercial) in Europe. There are five detailed country examples (Finland, Denmark, Ireland, Croatia and Czech Republic) and a short review from other countries in Europe.

Could you help me with the case of your country? Is inland recreational fisheries data collected? If yes, which ministry and/or institute is responsible? Which method(s) is/ are used (i.e. postal questionnaire surveys, national or only from certain water bodies, are salmon rivers monitored differently)? And what about the inland commercial fisheries: Do they exist, is data collected, are commercial fishers registered, and how are catch statistics collected? 


\subsection{DIFFERENT METHODS USED TO COLLECT DATA FROM INLAND FISHERIES}

\subsubsection{Fisheries-independent methods}

While fishery-dependent data include obligatory data on catches and fishing effort, fishery-independent data are collected using scientific methods (including probabilistic sampling) for example to estimate fish abundance, community or size composition or other attributes of the targeted fish populations. Typically, these attributes cannot be easily derived from fishery-dependent data. Examples of such fishery-independent methods in this report are, for example, biological sampling for age, growth and maturity information (see Chapter 3.2), monitoring the number of upstream migrating adult salmon with horizontal sonar and smolt trapping to estimate the numbers of downstream migrating smolts in Finland (see Chapter 3.9.5). The use of hydroacoustics to estimate fish numbers, standardized electrofishing in sampling of young-of-the-year age classes in rivers and CEN-standard gill-net fishing in lakes in Czech Republic (see Chapter 5.7), and habitat inspections together with standardized electrofishing in Danish streams (Box 2), are all examples of fishery-independent data collection that can inform fisheries management. Fisheryindependent surveys also include angler surveys with probabilistic sampling to assess the expenditure of anglers or other key attributes of the fishery.

It is essential that sampling is undertaken in a standardized way. An example of this in Europe is sampling of fish communities for the Water Framework Directive, where standardized methods are used, and the results intercalibrated among the EU countries, to reveal the ecological status of rivers and lakes. The fisheryindependent methods in inland fisheries are reviewed by Lorenzen et al. (2016). Importantly, what is currently underutilized is the use of data-poor assessment methods common in marine fisheries to use fishery-dependent data (e.g. on size structure) to assess fisheries reference points; there is therefore large potential for further use of these methods (Fitzgerald et al., 2018). Another rapidly developing method worth mentioning here is the use of eDNA to detect the fish species present and their relative abundances (Pont et al., forthcoming).

\subsubsection{Fishery-dependent methods}

\subsubsection{Commercial inland fisheries}

\section{Registration}

In almost all European countries, where commercial inland fisheries existed, the commercial fishers and companies were registered by the authorities (see Chapter 2). Registration is important because commercial fishers are in many cases justified to use specific fishing gear allowed only for professional purposes. Registration therefore also ensures compliance with fishery regulations. Registering also helps to keep track about the need of renewal of fishing licenses and can help in the design and implementation of fishing effort. Inland fisheries in Europe are typically small scale, but in larger inland fisheries it is important to register also the size and type of the vessels.

\section{Logbooks}

For the most part, registered commercial fishers were obliged to report their catches. The reporting was done for daily, weekly, monthly (or several months) or annual catches (see Chapter 2). More often than recall catch reports, fishers were required to record their catch and effort data on a specially designed logbook. Logbooks produce more accurate data than recall reports and are also easier to monitor. Sometimes the information from the logbooks was further clarified by personal contacts like telephone calls (Finland). Filling in a logbook is, however, an additional task for the fishers and only essential information should be collected.

In some countries (Chapter 2 and country examples), concerns were raised about the reliability of self-reporting especially when there are catch quotas for commercial 
fishing. Validation of the accuracy of the reports is required from time to time by inspectors. In large-scale inland fisheries, fishers were required to report their catches to inspectors or by electronic record before they entered the landing site (Estonia). It is also possible to follow the movements of vessels through GPS-systems.

Many European countries (Finland, Sweden, Estonia, England and Wales, Montenegro) are using or are preparing to use (e.g. France, Croatia) reporting of commercial catches by web-based applications records. Mobile solutions are also more likely and common in the future. As this is not possible in all places, especially on-site, the possibility to use the traditional paper version should continue to be available.

\section{Questionnaires}

Commercial catches can be estimated through questionnaire surveys. Questionnaires refer to forms filled in by respondents themselves. Questionnaires can be handed, posted or emailed to all commercial license holders. The data collected can be refined through phone call contacts for example, and non-response errors should be conducted if the sample is to be extrapolated to the population. However, recall surveys have potentially a greater number of error sources than logbooks.

\section{Interviews}

Collection of fisheries data through interviews can be either structured interviews with specific survey forms, or open interviews such as note taking when talking with fishers. Interviews can be individual interviews, or panel interviews of a small number of representatives. Interviews or panels can be part of the questionnaire survey clarifying some important issues.

\section{Direct observations}

Observers can make direct measurements at landing sites of the commercial fishing or the fishing vessels. Observers can also conduct interviews and surveys using questionnaires. Inland commercial fisheries are typically small scale and landing sites scattered and observers were better suited for large-scale inland fisheries with predictable landing sites and times. The observers should not carry out other activities, such as inspections or licensing.

\section{Scientific research}

Research methods should be undertaken to measure variables related to fish populations under fishing pressure. The objective is to obtain observations especially on biological (e.g. stock abundance, fish size, growth and maturity) variables. For stock assessment this requires, in addition to catch and effort data, biological sampling (size and age) from commercial catches. The information obtained from the socio-economic research will help to plan and manage the fisheries to achieve their different objectives (Pinello et al., 2017). This requires data, for example, from sales, costs and ownerships.

\section{New technologies}

In the marine commercial fisheries sector, technological and digital advances are expected to allow innovative monitoring equipment to better manage fish stocks (Girard and Du Payrat, 2017). These technologies, including navigation systems, internet of things (IoT), sensors, robotics, data storage and transmission are expected to become more compact and cheaper (Girard and Du Payrat, 2017). These can be used by fishers or companies as well as governments to monitor the fisheries sector. Inland commercial fisheries should also identify existing technologies and their potential for use in the whole value chain. Implementation of new technologies requires new 
investment, and in small- scale inland fisheries this would be difficult without outside support.

\subsubsection{Recreational fisheries}

There are numerous methodologies available to collect fisheries-dependent data from recreational fisheries, often with a strong focus on angling. These are described in a number of solid reviews (e.g. Pollock et al., 1994; Lyle et al., 2002; NRC, 2006, Jones and Pollock, 2013, and Lorentzen et al., 2016) and will form the basis for the following section. Often it can be a challenge to collect accurate and precise data from recreational fisheries. This is due to several reasons such as often there can be a huge temporal and spatial variation in participation, and it can be a challenge to sample this variation in an unbiased manner. In many cases, address frames from which to draw random samples are missing, which creates costly endeavours to create a sample. Moreover, there will often be country and/or region-specific conditions that impair a "one-fits-all" sampling strategy.

An important first step in deciding for the optimal method to collect data from recreational fisheries, is to be very precise about the expected use of the collected data. Next, once the method has been chosen, it is crucial to define a sampling frame i.e. the population of fishers from which data should be collected e.g. based on fisher typology, target species or spatial patterns, and subsequently collect information from a random sample of fishers from this sampling frame. One approach to establish a sampling frame is screening surveys, where a random sample of people are contacted and asked if they qualify to be included in the given sampling frame (e.g. if they undertook recreational inland fishing within the last year). Another approach is list frame surveys, which is possible in countries where a fishing license register is available. However, this approach implies that the sampling frame is solely the members on the list, which may or may not be ideal. For example, fishers who for some reason are not included in the fishing license register (e.g. illegal fishers, tourists) will not be included in this method. Historically, screening and list frame surveys have most often been done by telephone or by mail, but recently online surveys are more common.

In surveys that are conducted off site, i.e. anglers are contacted outside their fishing locations (e.g. at home), it is a common feature that participants are asked to recall catches and efforts that date several months back e.g. "How many perch have you caught over the last six months." It is well documented that such recall surveys often lead to inaccurate data i.e. overestimated catches and effort (Connelly and Brown, 1995; Connelly et al., 2000). By contrast, attitudes and other characteristics of anglers can be reliably measured in off-site surveys. In terms of catches, if similar procedures are used from year to year, recall surveys may still be useful in determining relativities and can therefore be useful in tracking trends over time (Jones and Pollock, 2013). Another challenge with off-site surveys is that it can be difficult to achieve high response rates, because not all fishers that are contacted actually respond. This can introduce so called "non-response bias" if those who refuse or fail to respond to surveys are overrepresented on specific fishing behaviours or characteristics (Pollock et al., 1994). In order to minimize non-response bias, it is common to send several reminders and encouraging non responds to respond. Non-response bias can sometimes be corrected by reaching out to those who did not respond e.g. via telephone, and thus collect a separate estimate of fishing patterns from this group. Further, there are a number of additional reporting biases that can also affect data quality when people are contacted off site and asked to recall catches, including prestige, telescoping, rounding or digit biases, and deliberate deception (Pollock et al., 1994). Recall surveys are reported to be used to collect data about recreational fisheries in inland waters, in some of the European countries such as in Finland.

An alternative way to minimize recall bias is to ask participants to keep a logbook/ diary. In some surveys, logbooks have become a central part as fishers are recruited 
for a so-called rotating logbook panel. Here members of the sampling frame are contacted and asked to keep a logbook of their fishing trips and catches for a limited period e.g. 12 months. During the period of commitment, regular follow-ups of participants to remind and encourage ongoing participation are conducted. Such a rotating panel design for an off-site diary or logbook survey approach may be relative costly, but it may also provide greater accuracy in the resulting catch estimates. This approach is successfully used to collect catch data from marine and inland waters in Holland (Van der Hammen, 2016).

Another way to reach the members of the sampling frame is on-site surveys. In this method, fishers are contacted and interviewed on the fishing site (creel survey). In the present survey of European sampling methods, only Sweden indicated that this method is occasionally used. On-site methods are costly but, especially when it comes to catches, more accurate as people only need to recall the catch of the day. In addition, the non-response bias is normally much lower than in off-site surveys, because people are more likely to share information when confronted face to face (Jones and Pollock, 2013) Further, the interviewer can inspect the catch and get accurate information about the harvested catch, e.g. length and weight, and, if relevant, get biological samples from harvested fish. If designed properly, on-site surveys can also provide information about fishing effort i.e. number of fishers in the study area. However, estimates of effort can also be obtained from separate methods such as aerial counts (used in Holland, see also Jones and Pollock, 2013). On-site surveys are not suitable for nationwide surveys due to the high costs related to the survey e.g. to educate and hire interviewers.

Another alternative are self-reporting programmes i.e. where fishers report their catches on an annual, monthly or daily basis. Some authors suggest a cautious approach when using this method, as they may result in large measurement errors. Some of these are known from other surveys mentioned above (intentional deception, recall bias, prestige bias or lack of knowledge (e.g. species misidentification) (Jones and Pollock, 2013). As an example, Jones and Pollock (2013) underpin that fishers may perceive incentives to lie about the location and extent of their fishing efforts and catches in heavily regulated or restricted fisheries that can be characterized by adverse relationships among agencies and fishers. Hence, if this method it to be used, measures must be taken to avoid these biases. Our survey indicates that self-reporting, either mandatory or voluntary is commonly used among European countries. However, since we did not ask for examples of measures to avoid biases, we cannot estimate this aspect. However, several countries (Croatia, Serbia, Republic of North Macedonia) indicate that their self-reporting system is unreliable. See below for a more thorough discussion of self-reporting methods.

It can often be advantageous to combine methods, especially if information of effort is needed. For example, in the United States of America, the marine recreational information programme combines a mail survey (to get information about fishing effort such as number of fishing trips) with an on-site survey to estimate the mean catch per fishing trip. By combining the estimates from the two surveys, estimates of total marine recreational catch of finfish by species are obtained (The National Academies of Sciences, Engineering, and Medicine, 2017).

\subsubsection{Synthesis of the collected data}

A huge variation in data collection strategies (Table 22) can be seen across all countries that kindly submitted information about data collection for inland fisheries. This is most evident for data collection of recreational fisheries, as in most countries, it seems mandatory for commercial fishers to report their catches on a daily, monthly or annual basis (see "commercial fisheries" previously in this chapter).

With regards to recreational fisheries, several points are clear from our data collection: 1) in general, there is strong focus on data collection of salmonid species; 
2) few countries collect data for all waters and all species; 3 ) mandatory self-reporting is frequently used but participation/compliance is rarely evaluated and data quality is therefore unknown; 4) mandatory self-reporting can focus on single species (e.g. Atlantic salmon in Denmark) or multiple/all species (e.g. Czech Republic, Hungary, Serbia, and Montenegro).

The case studies provided detailed information for selected countries and from these we can highlight some good practices and interesting cases.

\section{Nationwide recall survey approach (Finland)}

The data is collected by postal questionnaire where the frame sample is the Population Register Centre Finland. The statistical unit is the household-dwelling. The main aims in inland waters are to monitor the trends in recreational fishing and results are needed to evaluate the social significance of recreational fishing. One part of the presented catch estimates includes the obligations of EU data collection of fisheries and the statistical programme of FAO.

The criteria for the survey are determined by the Advisory Board of the Official Statistics of Finland to keep the bias typical to recall surveys (see table above) as low as possible. The continuous repeatability of work under same criteria makes it possible to analyse trends in recreational fishing (effort, gears used) and also in catches of common fish species. Results can be upgraded to national level also to estimate the importance of recreational fishing in the society (e.g. age structure of fishers, men and women involved in recreational fishing). The results of the nationwide study can be used as a part of the calculations of the socio-economic importance of recreational fishing on a national level.

The large spatial scale of the national study makes it impossible to identify the catches of individual water bodies, lakes or rivers, from the data. Also, catches of rare species include a large error rate when data from few observations are expanded to national level.

\section{Mandatory self-reporting - different practices and different results}

With regards to recreational fisheries, we find it interesting that both Croatia and the Czech Republic use mandatory self-reporting as the main method of data collection but evaluate the quality of the collected data differently. In Croatia, fishers are obliged to enter catch data of harvested fish into a specific logbook prescribed by national legislation. These logbooks are administrated by the owner of the fishing rights in the given water body, as he/she collects the logbooks from the fishers once a year and sends them to the Croatian Sports Fisheries Association (HŠRS) in a collated form. In the country example, several problems with the use of these catch data are highlighted: owners of fishing rights send only aggregated data which makes it impossible to make an analysis per each water body or for different fish species trophic levels (i.e. limnophyle vs reophyle). Also, catch data collected for large rivers (Sava or Danube) are not separated, thus comparison with catch data collected from commercial fishers (see Chapter 4.1.2) is not possible. Further data from released fish is not collected which can be a challenge e.g. if voluntary catch and release fishing changes temporally (e.g. as has been observed in Denmark (Jansen et al., 2013)). The Croatian example does not provide evaluations of how the fishers comply to the system e.g. the proportion that reports, and if there are sanctions if fishers neglect reporting.

In the Czech Republic, anglers are obliged to write down and report every fish (date, species, length and weight) retained (implying that released fish are not recorded) during fishing including the fishing site. Yearly logbooks are collected from the fishers by local anglers' unions and are summarized for individual fishing grounds. Also, recording of the number of angling visits, irrespective of the catch, as 
a proxy of fishing efforts is compulsory. Catch and visits trends are being evaluated in order to maintain or increase the attractiveness and economical success of a fishing ground, which to our knowledge is a unique approach in the European context.

In the Czech Republic, fishers are sanctioned if they do not comply and return their annual logbook. Specifically, every fisher is strictly requested to carry the logbook with the fishing licence, where every visit (before starting the fishing day) and catch (after deciding to retain particular fish) must be recorded. Fishing rules are relatively strict and catching gear diversity is low (only rod and line or a lift net $1 \mathrm{x} 1 \mathrm{~m}$ is allowed). At the end of the year, the angler is strictly requested to fill in the summary (total number and weight of every taken species and number of visits at every fishing ground) and to hand this summary (opposite side of the logbook) to his/her local Anglers' Union. Czech anglers who fail to hand in the summary to the Anglers' Union cannot apply for the angling license for the next year. This results in a very high rate of logbook returns (close to 100 percent) for Czech anglers, whereas logbook returns are lower (about 40 percent) from foreign anglers using short-term fishing permits. However, these represent only small proportion of the catches. Further compliance is secured through control as part-time and full-time bailiffs frequently checking the licenses and the logbooks of the anglers. If records are wrong or absent from the logbook, the fishing license is retained. These regular checks are considered to be the main mechanism disciplining anglers in recording their catches. Hence, in the Czech Republic it is generally assumed that logbook records give a very realistic picture of fish removed from the water body, and that unreported illegal fishing could have been a problem in early days but has been rectified by the concentrated controlling effort. As in the case for Croatia, mandatory reporting about released fish could be relevant to include.

Contrary to the case in Croatia, the logbook approach in the Czech Republic benefits from collecting detailed information about catches and effort at high-spatial resolution. A major difference in methodology between the two countries is that fishers in the Czech Republic are strongly sanctioned if they do not submit in their annual logbooks, and more importantly, fishers and their logbooks are controlled at the fishing spots, potentially preventing some of the bias that relates to the selfreporting method.

The country examples from Denmark and Ireland also give examples of successful mandatory self-reporting of salmonid stocks (both harvested and released fish). In Denmark, catches have to be reported within a few days after the catch, whereas in Ireland annual logbooks are submitted. In Denmark the compliance of anglers is secured through control activities. In Ireland, all fishers must attach a gill tag to each salmon (or sea trout $>40 \mathrm{~cm}$ ) they catch and retain. A logbook entry must then be made giving details of the fish caught. All logbooks and unused tags must be returned to Inland Fisheries Ireland within a period of seven days after the last day of the relevant fishing season, or after the license has been in force (e.g. one day and 21-day licenses are available), as set out in the Regulations. A system of brown gill tags is used in association with blue gill tags for the tagging of wild salmon and sea trout in certain listed rivers which have a low surplus for harvesting.

\section{Electronic self-reporting in Denmark using a citizen science platform}

In Denmark, a system of voluntary self-reporting is used to collect data from recreational fisheries, specifically anglers. However, they have framed it as a citizen science project, implying that the anglers not only collect data, but also benefit in various ways from doing so. Currently, anglers provide information about fishing location, hours fished, target fish species as well as information about catches i.e. species, length or weight, fate (released or harvested), and gear used, as well as other information. Other information can be site-specific e.g. anglers 
are given the opportunity to report captures of tagged fish in waters where this is relevant. Anglers are encouraged to report blank trips, which allow calculations of CPUE estimates. Data is being collected via an electronic platform including a browser version and a smartphone app (for android and iPhone). This gives several advantages compared to traditional paper logbooks, as data can be collected swiftly and statistics can be compiled immediately and distributed to relevant stakeholders, such as the individual angler on the fishing site, fishing right owners, and fishing clubs (see Figure 40 for data flow).

Figure 40. A conceptual figure of the data flow from an angler app. The data that the individual angler provides from a fishing trip are uploaded to a server.

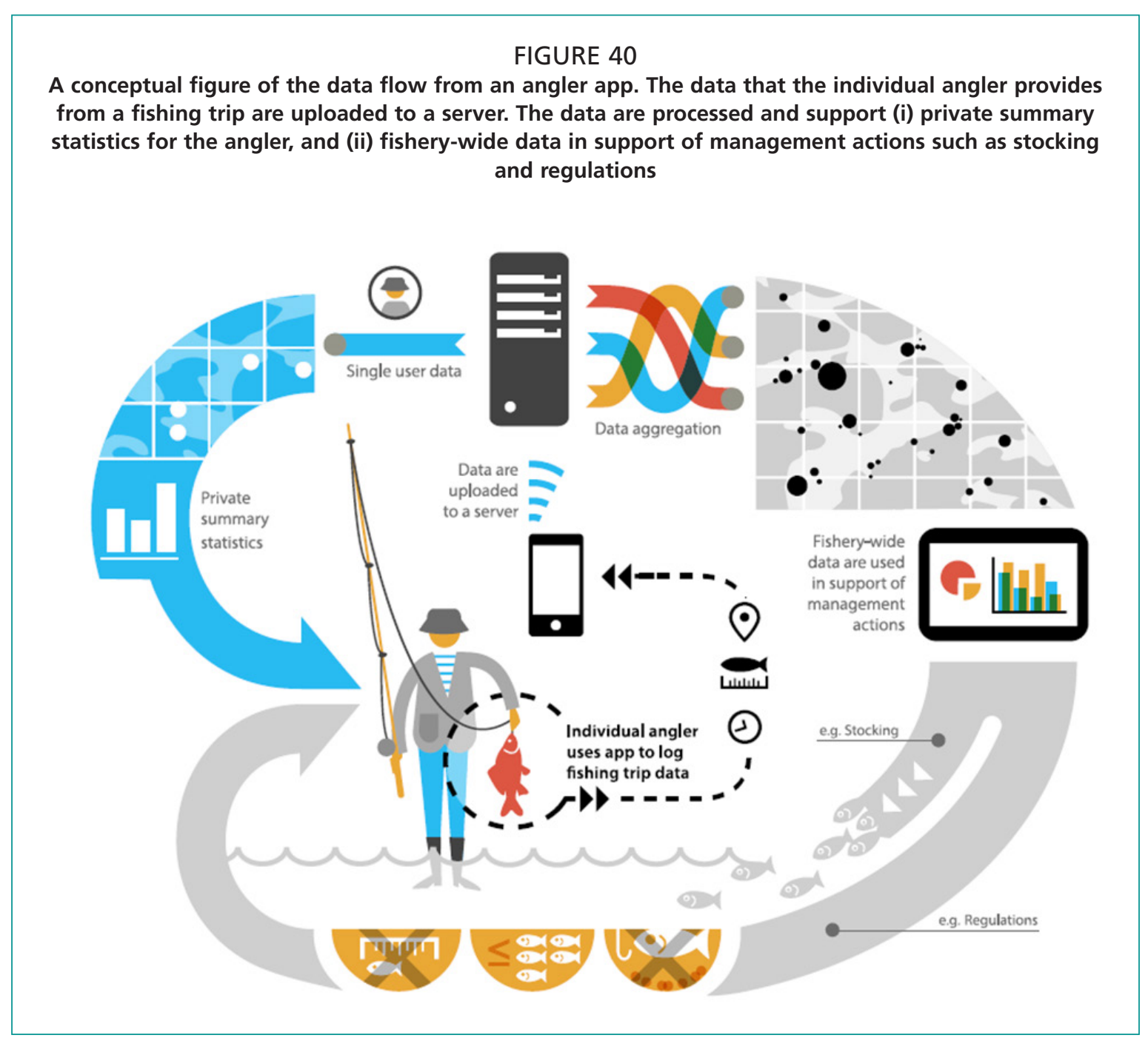

The data are processed and support (i) private summary statistics for the angler, and (ii) fishery-wide data in support of management actions such as stocking and regulations (Venturelli et al., 2017).

Apart from obtaining private summary statistics, the smartphone app approach provides other benefits e.g. anglers can swiftly receive site-specific information about current biological status of the fishing water or about regulations, which can prevent unintentional illegal fishing. It is also possible for anglers to keep catches private (i.e. only available for research) or open for public statistics, opportunities to brag about own catches and share information and images from the platform with Facebook or Twitter. It is also possible to enter a monthly prize draw. Citizen science projects 
often also include education and empowerment aspects (Garcia-Soto et al., 2017). This aspect is still under development, but so far a dedicated Facebook site gives examples of preliminary statistics calculated across fishing waters, and users are allowed to suggest specific additional analyses. Further, there are plans to expand the platform so anglers have easy access to laymen translations of scientific studies, chapters about fish biology, local and national regulations and more.

Generally, the smartphone technology is developing rapidly which provides many opportunities to collect data in a swift and user-friendly way. It has been argued that angler app data has potential to complement, supplement, and in some cases replace conventional data collection methods such as creels, paper logbooks, interviews and fisheries-independent surveys (Venturelli et al., 2017). There are already several commercial and some non-profit smartphone apps that have the potential to inform recreational fisheries in Europe. Many of these are restricted to specific waters or to specific species, which somewhat impair general use, and in many apps, essential data are lacking e.g. information about effort (Venturelli et al., 2017). The Danish platform is a unique example of a system developed by researchers for research and standardized data collection that covers all national fishing waters. The downside of this is that, the system asks the users for a substantial amount of information which can result in fatigue among the users. Preliminary results suggests that user retention on the platform after a year is around 25 percent, which is relatively high compared to other citizen science projects (Venturelli et al., 2017 and references herein), but still leaves plenty of room for improvement. Hence, the Danish researchers plan to direct even more focus towards encouraging and motivating the anglers to use the platform. Among other things, this includes a complete redesign of the user interface of the smartphone app, aiming to make reporting easier and the user benefits even stronger. In addition, it is being considered to expand the platform to also include recreational standing gear fishers. Nevertheless, as it is the case for other self-reporting methods, the Danish example potentially faces a lot of bias (Table 22) - most of them known from other methods. Future work should explore the extent of these biases and if and how they can be corrected for or alternatively strongly minimized e.g. by means suggested by Venturelli et al. (2017).

Finally, integrating an electronic reporting system such as the one used in Denmark, into Croatia's and the Czech Republic's mandatory self-reporting systems could be an interesting approach. In fact, both countries mention electronic reporting as a future measure in their data collection approach. In contrast, there are currently no plans of making catch and fishing trip reporting mandatory in Denmark. However, the combination of mandatory catch and effort reporting in recreational fisheries complemented by scientific surveys and assisted by novel technology, such as digital smartphone applications of logbooks and diaries to monitor catches and effort was recently recommended in an opinion paper on the future governance of recreational fisheries (Arlinghaus et al., 2019). Such an approach would have the dual benefits of providing data as well as sending a signal to anglers that monitoring is also their responsibility to improve stock assessments and avoid invisible collapses (Arlinghaus et al., 2019).

\section{Collecting important information about socio-economics and fisher heterogeneity}

The important role of fisher heterogeneity for understanding inland fisheries is well described (Parkkila et al., 2010, Cooke et al., 2015; Arlinghaus et al., 2019 ) to understand, for example, participation changes, motivation and satisfaction aspects, orientation towards voluntary catch and release and compliance with regulations. Also, knowing angler characteristics is important to produce better trend data for catch rates, as different anglers are differentially able to catch fish (skill effect). By 
TABLE 22

Overview of more or less frequently used methods used to sample recreational fisheries data from European inland waters and country examples. Some countries indicated the use of multiple methods for different purposes (e.g. estimating catches for the whole country with one method and monitoring salmon catch in a single river with another method). The list of methods used, and countries mentioned is not exclusive, as the level of details provided by the different countries varied

\begin{tabular}{|c|c|c|}
\hline Method & Benefits and advances & Problems and shortfalls \\
\hline $\begin{array}{l}\text { 1. Nation-wide surveys } \\
\text { (postal or web-based) } \\
\text { e.g. linking recreational } \\
\text { fishing to other outdoor } \\
\text { recreation activities and } \\
\text { nature-based tourism } \\
\text { on a national scale } \\
\text { based on samples from } \\
\text { the population and/ } \\
\text { or collecting specific } \\
\text { information about } \\
\text { catches, effort and other } \\
\text { relevant information (e.g. } \\
\text { Norway, Finland, Sweden) }\end{array}$ & $\begin{array}{l}\text { - Gives a national overview of the } \\
\text { proportion of the population that } \\
\text { engages in recreational fishing, how they } \\
\text { are fishing and what they are fishing for. } \\
\text { - It can also give information about total } \\
\text { catches and effort in inland fisheries } \\
\text { (if included in the survey), by scaling } \\
\text { collected data to the population. }\end{array}$ & $\begin{array}{l}\text { - Non- response bias: Only a fragment of people } \\
\text { respond, and the fishing behaviour (e.g. catches, } \\
\text { effort) of these people are different than for those } \\
\text { who did not respond. } \\
\text { - Spatial data less accurate } \\
\text { - If data about catches and effort are requested, the } \\
\text { collected data are prone to recall bias, especially } \\
\text { when recall bias exceeds a few months } \\
\text { - Often such surveys by default include numerous } \\
\text { questions which can make it difficult to include } \\
\text { additional fisheries specific questions. } \\
\text { - Examples of other biases related to off- site surveys } \\
\text { are prestige bias, rounding bias, lies, question } \\
\text { misinterpretation and species misidentification. }\end{array}$ \\
\hline $\begin{array}{l}\text { 3. Mandatory catch } \\
\text { reporting (in most } \\
\text { cases related only to } \\
\text { diadromous species } \\
\text { (Finland, Norway, } \\
\text { Sweden, Denmark, } \\
\text { Iceland, Estonia, Latvia, } \\
\text { France, Spain, Portugal, } \\
\text { England and Wales, } \\
\text { Scotland, Ireland, } \\
\text { Northern-Ireland, Czech } \\
\text { Republic, Hungary, } \\
\text { Serbia, Republic of North } \\
\text { Macedonia, Montenegro) }\end{array}$ & $\begin{array}{l}\text { - Can be cost-effective and provide } \\
\text { detailed data about catches. } \\
\text { - Can give a detailed overview of spatial } \\
\text { and temporal patterns in catches. }\end{array}$ & $\begin{array}{l}\text { - The quality of data depends on the set up, e.g. how } \\
\text { easy it is to report, how fishers are motivated to } \\
\text { contribute, how compliance is controlled including } \\
\text { which sanctions are made against those who do not } \\
\text { report. } \\
\text { - It may be difficult and costly to administer } \\
\text { if fishers are against the system, there is a risk of } \\
\text { erroneous data. } \\
\text { - In general, self- reported data runs the risk of being } \\
\text { biased by factors such as: intentional deception, } \\
\text { recall bias, prestige bias, or lack of knowledge (e.g. } \\
\text { species misidentifications). } \\
\text { - If not all fishers comply, there is a risk of non- } \\
\text { response bias. } \\
\text { - Often only collect information about catches and } \\
\text { not effort (e.g. no reports of fishing trips with no } \\
\text { catches). }\end{array}$ \\
\hline $\begin{array}{l}\text { 4. On-site surveys (e.g. } \\
\text { Sweden) }\end{array}$ & $\begin{array}{l}\text { - Collects good data, without many of } \\
\text { the biases that can be found in other } \\
\text { methods (e.g. recall). } \\
\text { - Can give information about effort and } \\
\text { trips with no catch. } \\
\text { - Data (e.g. length/weight) from harvested } \\
\text { fish can be controlled by the interviewer } \\
\text { and biological samples can be taken. }\end{array}$ & $\begin{array}{l}\text { - Only relevant at relatively small geographical scale, } \\
\text { as the labour involved in conducting such surveys, } \\
\text { makes it unrealistic to get nationwide results. } \\
\text { - Relative expensive. } \\
\text { - Risk of avidity bias i.e. avid fishers fish more often } \\
\text { and will be overrepresented in the sample. } \\
\text { - Information given at the interview about released } \\
\text { fish can suffer from prestige and rounding bias. }\end{array}$ \\
\hline $\begin{array}{l}\text { 5. Voluntary self-reporting } \\
\text { (e.g. Denmark, France, } \\
\text { Bulgaria) }\end{array}$ & The same as for \# 3 . & $\begin{array}{l}\text { - The quality depends on the set up e.g. how easy it } \\
\text { is to report, how fishers are motivated to contribute } \\
\text { and for how long they are retained once they have } \\
\text { started reporting. A potential solution is some kind } \\
\text { of reward system that the fisher finds beneficial. } \\
\text { - The sample frame is unknown due to self- } \\
\text { recruitment and the bias related to this is unknown. } \\
\text { - In addition, most of the challenges described for \#3 } \\
\text { also applies here. }\end{array}$ \\
\hline
\end{tabular}


knowing indicators of skill, the different "catching power" of different anglers can be controlled. Hence, we find it relevant to emphasize the work presented in the example from Croatia where attempts to explore the heterogeneity among recreational and commercial fishers are described. Many of the survey methods that are being used in European waters, can be expanded to include questions that relate to angler heterogeneity. Also, methods to explore socio-economic benefits is well described (Parkkilla et al., 2010), and some of these can be included in catch and effort surveys. Hence, if country budgets allow, it is relevant to consider if existing surveys should be expanded to include sampling of additional information about fisher heterogeneity and economic aspects. Biologists should seek out expertise from the human dimension studies in order to properly design studies. Given the large impact of angler type on catches, we strongly recommend to design future catch and effort studies always in parallel with assessing key characteristics of anglers (i.e. catch orientation, specialization level, involvement level) and to regularly study attitudes, preferences and constraints of the current angler population with detailed social science surveys. Moreover, we recommend that future studies address how such sampling could be standardized and therefore comparable between countries. This would allow for future cross-country comparisons, which undoubtedly would further our knowledge for instance, about how angler heterogeneity interacts with compliance to regulations.

\section{Future synergies}

In this report, we focus on inland fisheries. However, synergies could be obtained by a data collection approach that bridges freshwater and marine waters. This is especially the case when it comes to diadromous fish that are harvested both in freshwater and marine waters. Moreover, within the EU there is a focus on exploring and improving the methodology used to collect fisheries data from marine recreational fisheries. This is illustrated by the WGRFS working group under ICES (Working group of recreational fisheries surveys) which supplies recreational fishery data and estimates for ICES stock assessment and advisory processes, operating within its quality assurance framework and responding to the requirements of the EU Data Collection Framework (DCF) and other drivers (http://www.ices.dk/community/groups/Pages/WGRFS.aspx). In addition, the group is a forum for the planning and coordination of recreational fisheries data collection and analysis e.g. how to minimize potential sources of bias, such as under coverage of the recreational fishing population, non-response of individuals selected for sampling, and poor recall of fishing trips by respondents. Members of the WGRFS discuss and develop national marine surveys to obtain reliable, consistent and comparable catch and effort data. Finally, the group also focuses on the importance of data for evaluating the economic and social value of recreational sea fishing (http:// www.ices.dk/community/groups/Pages/WGRFS.aspx). Clearly, synergies could be achieved if the expertise from the WGFRS could be expanded to also include inland recreational fisheries. In general, within countries, potential synergies could develop if managers of inland fisheries and managers of marine fisheries interacted more. Today, management of recreational fisheries in inland and marine waters is often separated. 



\section{Acknowledgements}

We are grateful to the following people who have shared their knowledge with us. They are: Predrag Simonović, Danilo Mrdak, Vasil Kostov, Zbigniew Kaczkowski, Jacopo Cerri, Avdul Adrović, Doru Bănăduc, Apostolos Apostolou, Rigers Bakiu, Ali Serhan Tarkan, Carlos Alexandre, Teresa Ferreira, Øystein Aas, Colin Bean, Guðni Guðbergsson, Göran Sundblad, Jan Breine, Erik Degerman, Leonidas Vardakas, Javier Lobón-Cerviá, Uwe Brämick, Peter Lengyel, Marek Trella, Diego Dagani, Nicolas Stolzenberg, Franz Lahnsteiner, Jerome Guillouët, Thierry Demol, Indrek Ambos, Siret Kurvet, Kaspars Abersons, Maria Sfendilaki, Kaidi Kaljula, Gunnar Lambing, Henk Offringa, Herman Wanningen, Michaël Ovidio, Markus Vetemaa and many more. 



\section{References}

Aarestrup, K., Jepsen, N., Rasmussen, G. \& Okland, F. 1999. Movements of two strains of radio tagged Altlantic salmon, Salmo salar L., smolts through a reservoir. Fisheries Management and Ecology, 6: 97-107.

Arlinghaus, R., Mehner, T. \& Cowx, I.G. 2002. Reconciling traditional inland fisheries management and sustainability in industrialized countries, with emphasis on Europe. Fish and Fisheries, 3: 261-316.

Arlinghaus, R., Tillner, R. \& Bork, M. 2015. Explaining participation rates in recreational fishing across industrialised countries. Fisheries Management and Ecology, 22: 45-55.

Arlinghaus, R., Abbott, J.K., Fenichel, E.P., Carpenter, S.R., Hunt, L.M., Alós, J., Klefoth, T., Cooke, S.J., Hilborn, R., Jensen, O.P., Wilberg, M.J., Post, J.R. \& Manfredo, M.J. 2019. Opinion: Governing the recreational dimension of global fisheries. PNAS, 116 (12): 5209-5213 [online]. [Cited 2 March 2020]. https://doi.org/10.1073/ pnas. 1902796116

Bartley, D.M., De Graaf G.J., Valbo-Jørgensen, J. \& Marmulla, G. 2015. Inland capture fisheries: status and data issues. Fisheries Management and Ecology, 22: 71-77.

Baruš, V. \& Prokeš, M. 2000. What conclusions can be made on diversity of fish community in lower reaches of the Morava River from angler fishing yields. Biodiverzita ichtyofauny, III: 45-50.

Baruš, V., Prokeš, M. \& Penaz, M. 2000. Tendencies appearing in fishery yields by angling in the river Dyje downstream of the Nove Mlyny Reservoirs. In Mikešová, ed. The 4th conference on ichthyology: proceedings of the international conference, Vodňany, 10-12 (5): 198-201.

Beard, T.D., Arlinghaus, R., Cooke, S.J., McIntyre, P.B., De Silva, S., Bartley, D. \& Cowx, I.G. 2011. Ecosystem approach to inland fisheries: research needs and implementation strategies. Biology Letters, 7: 481-483.

Berg, S. \& Møller, M.M. 1998. Genetic and ecological guidelines for stocking fish in Denmark. Danish Institute of Fisheries Research. (in Danish)

Berg, S. \& Rasmussen, G.H. 2012. Freshwater in Denmark. In H. Carl \& P.R. Møller, eds. Atlas of Danish freshwater fish, pp. 37-48. Statens Naturhistoriske Museum. Københavns Universitet. (In Danish)

Birnie-Gauvin, K., Aarestrup, K., Riis, T. M. O., Jepsen, N. \& Koed, A. 2017a. Shining a light on the loss of rheophilic fish habitat in lowland rivers as a forgotten consequence of barriers and its implications for management. Aquatic Conservation: Marine and Freshwater Ecosystems, 27: 1345-1349 [online]. [Cited 2 March 2020]. https://doi. org/10.1002/aqc.2795

Birnie-Gauvin, K., Larsen, M. H., Nielsen, J. \& Aarestrup, K. 2017b. 30 years of data reveal a dramatic increase in abundance of brown trout following the removal of a small hydrodam. Journal of Environmental Management, 204: 467-471 [online]. [Cited 2 March 2020]. https://doi.org/10.1016/j.jenvman.2017.09.022

Birnie-Gauvin, K., Candee, M. M., Baktoft, H., Larsen, M. H., Koed, A. \& Aarestrup, K. 2018. River connectivity reestablished: effects and implications of six weir removals on brown trout smolt migration. River Research and Applications, 34: 548-554 [online]. [Cited 2 March 2020]. https://doi.org/10.1002/rra.3271

Bohn, J. \& Roth, E. 1997. Survey on angling in Denmark 1997 - Results and Comments. In A.L. Toivonen \& P. Tuumaimem, eds. Socio-Economics of Recreational Fishery. Copenhagen: Nordic Council of Ministers, Temanord, 604: 79-88. 
Brooks, A. 1984. Recommendations Bearing on the Sinuosity of Danish Stream Channels: Consequences of Realignment, Spatial Extent of Natural Channels. The Freshwater Laboratory, Environmental Protection Agency, Silkeborg.

Boukal, D.S., Jankovsky, M., Kubecka, J. \& Heino, M. 2012. Stock-catch analysis of carp recreational fisheries in Czech reservoirs: Insights into fish survival, water body productivity and impact of extreme events. Fisheries Research, 119: 23-32.

Boukal, D., Rahimi, A.M., Souza, A.T., Muška, M., Prchalová, M., Ř́ha, M., Tušer, M., Vašek, M. \& Kubečka, J. (forthcoming). Combining independent surveys with longterm catch and stocking data to inform recreational fishery managers: a common carp case study. Fisheries Research.

Coalition Clean Baltic. 2017. Recreational Fishing in the Baltic Sea Region [online]. Uppsala, Sweden. [Cited 2 March 2020]. https://ccb.se/wp-content/uploads/2018/02/ ccb_recreational_fishing.pdf

Colby, J. P. \& Lehtonen, H. 1994. Suggested causes for the collapse of zander, Stizostedion lucioperca (L.), populations in northern and central Finland through comparisons with North American walleye, Stizostedion vitreum (Mitchill). Aqua Fennica, 24: 9-20.

Connelly, N. A. \& Brown, T. L. 1995. Use of angler diaries to examine biases associated with 12-month recall on mail questionnaires. Transactions of the American Fisheries Society, 124: 413-422.

Connelly, N. A., Brown, T. L. \& Knuth, B. A. 2000. Assessing the relative importance of recall bias and nonresponse bias and adjusting for those biases in statewide angler surveys. Human Dimensions of Wildlife, 5: 19-29 [online]. [Cited 2 March 2020]. https:// doi.org/10.1080/10871200009359192

Cooke, S.J., Allison, E.H., Beard, D.T. Jr., Arlinghaus, R., Arthington, A.H., Bartley, D.M., Cowx, I.G., Fuentevilla, C., Leonard, N.J., Lorenzen, K., Lynch, A.J., Nguyen, V.M, Youn, S-J., Taylor, W.W. \& Welcomme, R.L. 2016. On the sustainability of inland fisheries: Finding a future for the forgotten. Ambio, 45: 753-764.

Cooke, S., Arlinghaus, R., Johnson, B.M. \& Cowx, I.G. 2015. Recreational fisheries in inland waters. In J.F. Craig, ed. Freshwater Fisheries Ecology, pp. 449-465.

Cowx, I.G. 2015. Characterisation of inland fisheries in Europe. Fisheries Management and Ecology, 22: 78-87.

Curtis, J.A. 2002. Estimating the Demand for Salmon Angling in Ireland. The Economic and Social Review, 33 (3): 319-332.

Curtis, J.A. 2018. Pike (Esox lucius) stock management in designated brown trout (salmo trutta) fisheries: anglers preferences. Fisheries Research, 207: 37-48.

Dahl, J. 1982. A century of pikeperch in Denmark. In: Documents presented at the symposium on stock enhancement in the management of freshwater fisheries, Budapest, 31 May - 2 June 1982. EIFAC Technical Paper [online]. Inland Fisheries Laboratory, Silkeborg, Denmark. [Cited 2 March 2020]. http://www.fao.org/tempref/FI/CDrom/ aquaculture/a0844t/docrep/009/AE997B/AE997B08.htm\#ch8

Deely, J., Hynes, S. \& Curtis, J. 2019. Combining actual and contingent behavior data to estimate the value of coarse fishing in Ireland. Fisheries Research, 215: 53-61.

Draštík, V., Kubečka, J., Šovčík, P. 2004. Hydrology and angler's catches in the Czech reservoirs. Ecobydrology and hydrobiology, 4: 429-439.

Dysenius, M. \& Nilsson, C. 1994. Fragmentation and flow regulation of river systems in the northern third of the world. Science, 266: 753-762.

Ernst \& Young. 2011. EU intervention in inland fisheries. EU wide report - final version. Framework contract $N^{\circ}$ FISH/2006/09 (Lot N³), Studies linked to the implementation of the European Fisheries Fund.

FAO. 2003. Fisheries Management. 2, The ecosystem approach to marine capture fisheries. FAO Technical Guidelines for Responsible Fisheries No. 4, Suppl. 2. Rome. 112 pp.

FAO. 2012. Technical guidelines for responsible fisheries: recreational fisheries. Rome. 192 pp. 
FAO. 2018. The State of World Fisheries and Aquaculture. Rome. 210 pp.

Feeley, H.B., Bruen, M., Bullock, C., Christie, M., Kelly, F. \& Kelly-Quinn, M. 2017. ESManage Project: Irish freshwater resources in the context of ecosystem services and assessment of ecosystem services provisions. EPA Research Report (2014-W-LS5) [online]. [Cited 2 March 2020]. http://www.epa.ie/pubs/reports/research/water/ EPA\%20RR\%20207\%20final\%20web-2.pdf

Fitzgerald, C.J., Delanty, K. \& Shephard, S. 2018. Inland fish stock assessment: Applying data-poor methods from marine systems. Fisheries Management and Ecology, 25: 240252.

Freyhof, J., Weiss, S., Adrović, A., Ćaleta, M., Duplić, A., Hrašovec, B., Kalamujić, B., Marčić, Z., Milošević, D., Mrakovčić, M., Mrdak, D., Piria, M., Simonović, P., Šljuka, S., Tomljanović, T. \& Zabric, D. 2015. The buchen Hucho bucho in the Balkan region: Distribution and future impacts by bydropower development [online]. Technical Report, RiverWatch \& EuroNatur. [Cited 2 March 2020]. DOI: 10.13140/RG.2.1.4916.9440

Funge-Smith, S.J. 2018. Review of the state of world fishery resources: inland fisheries. FAO Fisheries and Aquaculture Circular No. C942, Rev.3. Rome, FAO. 397 pp.

Garcia, S.M.,Zerbi, A., Aliaume, C., Do Chi, T. \& Lasserre, G. 2003. The ecosystem approach to fisheries. Issues, terminology, principles, institutional foundations, implementation and outlook. FAO Fisheries Technical Paper No. 443. Rome, FAO. 71 pp.

Garcia, S.M. \& Cochrane, K.L. 2005. Ecosystem approach to fisheries: a review of implementation guidelines. ICES Journal of Marine Science, 62: 311-318.

Garcia-Soto, C., van der Meeren, G.I, Busch, J., Delany, J., Domegan, C., Dubsky, K., Fauville, G., Gorsky, G., von Juterzenka, K., Malfatti, F., Mannaerts, G., Mchugh, P., Monestiez, P., Seys, J., Weslawski, J.M. \& Zielinski, O. 2017. Advancing Citizen Science for Coastal and Ocean Research. Position Paper 23 of the European Marine Board, Ostend, Belgium. [online]. [Cited 2 March 2020]. https://doi.org/10.5281/ zenodo.3338094

Gargan, P., Stafford, J. \& Ó’Maoiléidigh, N. 2001. The relationship between salmon rod catch, stock size, rod exploitation and rod effort on the Erriff Fishery, Western Ireland. In R. Shelton, ed. The Interpretation of Rod and Net Catch Data, pp. 68-75 [online]. The Atlantic Salmon Trust, Pitlochry. [Cited 2 March 2020]. http://www.environmentdata. org/download/file/ast:83/ast:83/1/0/OBJ/PDF/NA

Grilli, G., Curtis, J. \& Hynes, S. 2019. Modelling anglers' fish release choices using logbook data. Working paper no. 623. [online]. [Cited 2 March 2020]. http://aei.pitt. edu/102236/1/WP623.pdf

Guillerault, N., Hühn, D., Cucherousset, J., Arlinghaus, R. \& Skov, C. 2018. Stocking for pike population enhancement. In C. Skov \& P.A. Nilsson, eds. Biology and Ecology of Pike. CRC Press, pp. 215-248.

Harrod, C. 2015. Climate change and freshwater fisheries. In J.F. Craig, ed. Freshwater Fisheries Ecology, pp. 641-694. John Wiley \& Sons.

Hartvich, P. \& Kubecka, J. 1999. Fish losses due to their turbine passage in the Lipno Reservoir. Bulletin Fish. Res. Inst. Vodnany, 1/2: 85-90.

HELCOM. 2011. Salmon and sea trout populations and rivers in the Baltic Sea-HELCOM assessment of salmon (Salmo salar) and sea trout (Salmo trutta) populations and habitats in rivers flowing to the Baltic Sea. Baltic Sea Environment Proceedings No. 126A, 79 pp.

Høy, T., Markmann, P.N., Sivebæk, F. \& Berg, S. 2004. Denmarks lakes, the lakes in Northern Jutland and Viborg Counties. Strandbergs Forlag (in Danish). Huusko. A. and Hyvärinen, P. 2005. A high harvest rate induces a tendency to generation cycling in a freshwater fish population. Journal of Animal Ecology, 74: 525-531.

Humpl, M., Pivnicka, K. \& Jankovsky, M. 2009. Sport fishery statistics, water quality, and fish assemblages in the Berounka River in 1975-2005. Folia Zool, 58: 457-465.

Hyvärinen, P. \& Huusko, A. 2005. Long-term variation in brown trout, Salmo trutta L., stocking success in a large lake: interplay between availability of suitable prey and size at release. Ecology of Freshwater Fish, 14: 303-310. 
ICES. 2018a. Report of the Baltic Salmon and Trout Assessment Working Group (WGBAST), 20-28 March 2018, Turku, Finland. ICES CM 2018/ACOM:10. 369 pp.

ICES. 2018b. Report on the Working Group on North Atlantic Salmon (WGNAS). ICES CM 2018/ACOM: 21: 108-109. Woods Hole, Massachusetts, USA.

Jacobsen, L., Berg, S. \& Skov, C. 2004. Management of lake fish populations and lake fisheries in Denmark: History and current status. Fisheries Management and Ecology, 11: 219-224.

Jankovsky, M., Boukal, D.S., Pivnicka, K. \& Kubecka, J. 2011. Tracing possible drivers of synchronously fluctuating species catches in individual logbook data. Fisheries Management and Ecology, 18: 297-306.

Jansen, T., Arlinghaus, R., Als, T. \& Skov, C. 2013. Voluntary angler logbooks reveal long-term changes in a lentic pike, Esox lucius, population. Fisheries Management and Ecology, 20: 125-136.

Jeppesen, E., Mehner, T., Winfield, IJ., Kangur, K., Sarvala, J., Gerdeaux, D., Rask, M., Malmquist, HJ., Holmgren, K., Volta, P., Romo, S., Eckmann, R., Sandström, A., Blanco, S., Kangur, A., Stabo, HR., Tarvainen, M., Ventelä, AM., Søndergaard, M., Lau-ridsen, TL. \& Meerhoff, M. 2012. Impacts of climate warming on lake fish assemblages: evidence from 24 European long-term data series. Hydrobiologia, 694: 1-39.

Jepsen, N., Aarestrup, K., Økland, F. \& Rasmussen, G. 1998. Survival of radiotagged Atlantic salmon (Salmo salar L.)-and trout (Salmo trutta L.) smolts passing a reservoir during seaward migration. Hydrobiologia, 371: 347-353.

Jepsen, N., Sonnesen, P., Klenke, R. \& Bregnballe, T. 2010. The use of coded wire tags to estimate cormorant predation on fish stocks in an estuary. Marine and freshwater Biology, 61: 320-329.

Jepsen, N., Skov, C., Pedersen, S. \& Bregnballe, T. 2014. The role of predation on Danish freshwater fish populations with special focus on cormorants. DTU Aqua-report No. 283. (In Danish).

Jepsen, N., Ravn, H.D. \& Pedersen, S. 2018. Change of foraging behavior of cormorants and the effect on river fish. Hydrobiologia, 820: 189-199.

Jepsen, N., Flavio, H. \& Koed, A. 2019. The impact of Cormorant predation on Atlantic salmon and Sea trout smolt survival. Fisheries Management and Ecology, 26 (2): 183-186.

Johansson, L.S., Søndergaard, M. \& Landkildehus, F. 2019. Lakes 2017. NOVANA (In Danish). University of Aarhus, DCE, 42 s. Scientific report No. 307. [online]. [Cited 2 March 2020] http://dce2.au.dk/pub/SR307.pdf

Jones, M. \& Pollock, K.H. 2013. Recreational angler survey methods: estimation of effort, harvest, and released catch. In A.V. Zale, D.L. Parrish, and T.M. Sutton, eds. Fisheries Techniques, pp. 883-919. American Fisheries Society, Bethesda, MD.

Jurajda, P., Slavík, O. \& Adámek, Z. 2006. Methodology of sampling and processing of young-of-the-year fish communities of running waters. Official methodology of Czech Ministry of Environment, 10pp. [online]. [Cited 2 March 2020]. https://www.mzp. cz/C1257458002F0DC7/cz/prehled_akceptovanych_metodik_tekoucich_vod/\$FILE/ OOV-RYBY_tekouci\%20vody-20130129.pdf

Kaczkowski, Z. \& Grabowska, J. 2016. Problems and challenges of fish stock management in fresh waters of Poland. In J.F. Craig, ed. Freshwater Fisheries Ecology, pp. 208-215. John Wiley \& Sons.

Kelly-Quinn, M., Bruen, M., Christie, M., Bullock, C., Feeley, H., Hannigan, E., Hallouin, T., Kelly, F., Matson, R. \& Siwicka, E. 2019. Incorporation of Ecosystem Services values in the Integrated Management of Irish Freshwater Resources - ESManage (2014-W-LS-5). Final Report for the Environmental Protection Agency.

Keto, A. 2019. Water Framework Directive in Finland. Lecture slides at the Aalto University. [online]. Helsinki, Finland. [Cited 2 March 2020]. https://mycourses.aalto. fi/pluginfile.php/872753/mod_folder/content/0/0\%20-\%20Water\%20Framework\%20 Directive\%20-\%20SLIDES.pdf?forcedownload $=1$ 
King, J.L., Marnell, F., Kingston, N., Rosell, R., Boylan, P., Caffrey, J.M., FitzPatrick, Ú., Gargan, P.G., Kelly, F.L., O’Grady, M.F., Poole, R., Roche, W.K. \& Cassidy, D. 2011. Ireland Red List No. 5: Amphibians, Reptiles E Freshwater Fish. National Parks and Wildlife Service, Department of Arts, Heritage and the Gaeltacht, Dublin, Ireland.

Koed, A., Aarestrup, K., Nielsen, E.E. \& Heine Glüsing, H. 1999. Status of the salmon management plan [in Danish]. Silkeborg, Denmark: DFU-Rapport No. 66-99.

Koed, A., Jepsen, N., Aarestrup, K. \& Nielsen, C. 2002. Initial mortality of radio-tagged Atlantic salmon (Salmo salar L.) smolts following release downstream of a hydropower station. Hydrobiologia, 483: 31-37.

Koed, A., Birnie-Gauvin, K., Sivebæk, F. \& Aarestrup, K. 2019. From endangered to sustainable: Multi-faceted management in rivers and coasts improves Atlantic salmon (Salmo salar) populations in Denmark. Fisheries Management and Ecology. [online]. [Cited 2 March 2020]. https://doi.org/10.1111/fme.12385

Komatina, D. \& Grošelj, S. 2015. Transboundary Water Cooperation for Sustainable Development of the Sava River Basin. In R. Milačič et al., eds. The Sava River, The Handbook of Environmental Chemistry 31, pp. 1-25. Springer-Verlag Berlin Heidelberg.

Kristensen, E.A., Jepsen, N., Nielsen, J., Pedersen, S. \& Koed, A. 2014. Danish index for fish in streams (in Danish). University of Aarhus, Scientific report DCE No. 95.58 pp. [online]. [Cited 2 March 2020]. http://dce2.au.dk/pub/SR95.pdf

Kubečka, J. \& Prchalová, M. 2006. Methodology of catching and processing of fish samples in standing waters. Official methodology of Czech Ministry of Environment. 22 pp. [online]. [Cited 2 March 2020]. https://www.mzp.cz/C1257458002F0DC7/cz/prehled_ akceptovanych_metodik_vod/\$FILE/OOV-stojate_ryby-20061001.pdf

Kubeka J. 2017. Whitefish, catfish and artificial lakes. 58th Annual Report Institute of Hydrobiology, BC CAS: 8-10.

Kubečka, J., Souza A., Ř́iha, M., Muška, M., Vašek, M., Boukal, D., Prchalová, M., Jůza, T., Čech, M., Draštík, V., Frouzová, J., Hejzlar, J., Matěna, J., Moraes, K., Peterka, J., Randák, T., Šmejkal, M., Tušer, M., Blabolil, P. \& Vejř́ik, L. 2019. Pikeperch paradise? Qualitative reflections on quantitative surveys of the Lipno reservoir. Czech Limnological News, 1: 1-6.

Larsen, K. 1955. Fish population analysis in some small Danish trout streams by means of DC electro-fishing. Meddelelser fra Danmarks Fiskeri - og Havundersøgelser. Ny Serie: Bind 1,10: 1-69.

Lorenzen, K., Cowx, I.G., Entsua-Mensah, R. E. M., Lester, N. P., Koehn, J. D., Randall, R.G., So, N., Bonar S.A., Bunnell, D.B., Venturelli, P., Bower, S. D. \& Cooke, S. J. 2016. Stock assessment in inland fisheries: a foundation for sustainable use and conservation. Revierws in Fish Biology and Fisheries, 26: 405-440.

Lucas, M.C. \& Marmulla, G. 2000. An assessment of anthropogenic activities on and rehabilitation of river fisheries: current state and future direction. In I.G. Cowx, ed. Management and Ecology of River Fisheries, pp. 261-278. Fishing News Books, Blackwell Science, Oxford.

Lusk, S. 1996. Development and status of populations of Barbus barbus in the waters of the Czech Republic. Folia Zoologica, 45: 39-46.

Lusk, S., Halačka, K., Lusková, V. \& Prazak, O. 1996. Fish assemblages of the "Soutok" area in southern Moravia, Czech Republic. Acta-Universitatis Carolinae Biologica, 40: 147-156.

Lusk, S., Halačka, K. \& Lusková, V. 2003. Rehabilitating the floodplain of the lower River Dyje for fish. River Research and Applications, 19: 281-288.

Lyach, R. \& Čech, M. 2017. Do otters target the same fish species and sizes as anglers? A case study from a lowland trout stream (Czech Republic). Aquatic Living Resources, 30: 11 .

Lyach, R. \& Čech, M. 2017. The effect of cormorant predation on newly established Atlantic salmon population. Folia Zoologica, 66 (3): 167-175. 
Lyach, R., Blabolil, P. \& Čech, M. 2018. Great Cormorants Phalacrocorax carbo feed on larger fish in late winter. Bird study, 65: 249-256.

Lyach, R. \& Čech, M. 2018a. A new trend in Central European recreational fishing: More fishing visits but lower yield and catch. Fisheries Research, 201: 131-137.

Lyach, R. \& Čech, M. 2018b. Do recreational fisheries metrics vary on differently sized fishing grounds? Fisheries Management and Ecology, 25(5): 356-365.

Lyach, R. \& Remr, J. 2019a. The effect of a large-scale fishing restriction on angling harvest: a case study of grayling Thymallus thymallus in the Czech Republic. Aquatic Living Resources, 32.

Lyach, R. \& Remr, J. 2019b. The effects of environmental factors and fisheries management on recreational catches of perch Perca fluviatilis in the Czech Republic. Aquatic Living Resources, 32.

Lyle, J.M., Coleman, A.P. M., West, L., Campbell, D. \& Henry, G.W. 2002. New largescale survey methods for evaluating sport fisheries. In T.J. Pitcher, C.E. Hollingworth, eds. Recreational Fisheries: Ecological, Economic and Social Evaluation, pp. 207-226. Blackwell Science, Oxford, UK.

Lynch, A.J., Cooke, S.J., Deines, A.M., Bower, S.D., Bunnell, D.B., Cowx, I.G., Nguyen, V.M., Nohner, J., Phouthavong, K., Riley, B., Rogers, M.W., Taylor, W.W., Woelmer, W., Youn, S.-J. \& Beard, T.D. Jr. 2016. The social, economic, and environmental importance of inland fish and fisheries. Environmental Reviews, 24 (2): 115-121. [online]. [Cited on 2 March 2020]. https://doi.org/10.1139/er-2015-0064

Lynch, A.J., Cowx, I.G., Fluet-Chouinard, E., Glaser, S.M., Phang, S.C., Beard, T.D., Bower, S.D., Brooks, J.L, Bunnell, D.B., Claussen, J.E., Cooke, S.J., Kao Y.-C., Lorenzen K., Myers, B.J.E., Reid, A.J., Taylor, J.J. \& Youn, S. 2017. Inland fisheries - Invisible but integral to the UN Sustainable Development Agenda for ending poverty by 2030. Global Environmental Change, 47: 167-173. [online]. [Cited on 2 March 2020]. https://doi.org/10.1016/j.gloenvcha.2017.10.005

Marine Institute. 1997. A National Survey of Water-based Leisure Activities, Dublin, Ireland: Marine Institute.

Marttunen, M. \& Vehanen, T. 2004. Toward Adaptive Management: The Impacts of Different Management Strategies on Fish Stocks and Fisheries in a Large Regulated Lake. Environmental Management, 33: 840-854.

Matena, J., Kubecka, J. \& Peterka, J. 1999. Quantitative assessment of pikeperch larvae in the Lipno Reservoir. Bulletin Fish. Res. Inst. Vodnany, 1/2: 75-84.

Matulić, D., Šprem, N., Piria, M., Tomljanović, T., Treer, T., Safner, R. \& Aničić, I. 2010. Analysis of Recreational Fisheries in the Croatian Areas of the Sava and Danube Rivers. Agriculturae conspectus scientificus, 75 (4): 183-190.

Millane, M., Shephard, S., White, J., Ó Maoiléidigh, N., O’Higgins, K., O’Malley, P., Roche, W., Poole, R., Rogan, G., Bond, N. \& Gargan, P.G. 2017. Estimating salmonid angling exploitation rates from systems monitored by fish counters, and potential application to fisheries management in Ireland. In G. Harris, ed. Sea Trout: Science $E$ Management. Proceedings of the 2nd International Sea Trout Symposium, pp. 167-184.

Mills, K.E., Pershing, A.J., Sheehan, T.F. \& Mountain, D. 2013. Climate and ecosystem linkages explain widespread declines in North American Atlantic salmon populations. Global Change Biology, 19 (10): 3046-3061.

Milner, N.J., Davidson, I., Evans, R., Locke, V. \& Wyatt, R. 2001. The use of rod catches to estimate salmon runs in England and Wales. Paper for Atlantic Salmon Trust workshop, Lowestoft.

Ministry of Food, Agriculture and Fisheries. 2010. Angling in Denmark, Copenbagen, Denmark (in Danish), 28 pp. [online]. [Cited 8 June 2020]. http://fvm.dk/fileadmin/user_ upload/FVM.dk/Dokumenter/Servicemenu/Publikationer/Lystfiskeri_i_Danmark.pdf 
Mitchell, M., Vanberg, J. \& Sipponen, M. 2010. Commercial inland fishing in member countries of the European Inland Fisheries Advisory Commission (EIFAC): Operational environments, property rights regimes and socio-economic indicators. EIFAC Ad Hoc Working Party on Socio-Economic Aspects of Inland Fisheries. 113 pp.

Møller, P.R., Beck, M. \& Carl, H. 2012. Dyndsmerling. In H. Carl, P.R. Møller, eds. Atlas over danske ferskvandsfisk (in Danish), pp. 313-321. Natural History Museum of Denmark.University of Copenhagen.

Morales-Nin, B. \& Lobon-Cervia, J. (forthcoming). Pesca recreativa en España. Editorial CSIC. Madrid.

Moriarty, C. \& Dekker, W., eds. 1997. Management of the European eel. Fish. Bulletin, 15.

Mrakovčić, M., Brigić, A., Buj, I., Ćaleta, M., Mustafić, P. \& Zanella, D. 2006. Red book of freshwater fish of Croatia. Ministry of Culture, State Institute for Nature Protection, Republic of Croatia. (in Croatian, with English Introduction)

Mrakovčić, M., Čaldarović, O., Safner, R., Oraić, D., Opačak, A., Lenhardt, M., Škrijelj, R., Mikavica, D. \& Herstad, T-J. 2005. Management of freshwater fisheries on bordering rivers: pilot study with a holistic regional approach. Croatian Ministry of Agriculture, Forestry and Water Management with Norwegian partner Akvaplan-niva AS, Zagreb, Croatia.

NASCO. 2009. NASCO Guidelines for the Management of Salmon Fisheries. CNL (09) 43.

Neuvonen, T., \& Sievänen, M. 2011. Luonnon virkistyskäyttö, 2010. Metlan työraportteja 212. 90 pp. (In Finnish)

The National Academies of Sciences, Engineering, and Medicine. 2017. Review of the Marine Recreational Information Program. Washington, DC: The National Academies Press. [online]. [Cited 2 March 2020]. https://doi.org/10.17226/24640

Natural Resources Institute Finland. 2018. Fisheries and bunting statistics [online]. [Cited 2 March 2020]. https://stat.luke.fi/en/kala-ja-riista.

Nielsen, E.E., Hansen, M.M. \& Loeschcke, V. 1997. Analysis of microsatellite DNA from old scale samples of Atlantic salmon Salmo salar: A comparison of genetic composition over 60 years. Molecular Ecology, 6 (5): 487-492.

Nielsen, E.E., Hansen, M.M. \& Bach, L.A. 2001. Looking for a needle in a haystack: discovery of indigenous Atlantic salmon (Salmo salar L.) in stocked populations. Conservation Genetics, 2: 219-232.

Newman, S. 2014. Inland fisheries and the common implementation policy. Directorate General for Internal Policies, Policy Department B: Structural and Cohesion Policies, Fisheries.

NRC. 2006. Review of the Recreational Fisheries Survey Methods. National Research Council, Washington, DC.

NSAD. 2015a. The Economic Contribution of Pike Angling in Ireland. National Strategy for Angling Development.

NSAD. 2015b. National Strategy for Angling Development. In: Inland Fisheries Ireland [online]. Citywest, Dublin. [Cited 1 June 2016]. www.fisheriesireland.ie/AnglingInformation/national-strategy-for-angling-development.html

Official Statistics of Finland (OSF). 2017. Recreational fishing. In: Natural Resources Institute Finland [online]. Helsinki, Finland. [Cited 2 March 2020]. https://stat.luke.fi/ en/recreational-fishing

Official Statistics of Finland (OSF). 2018. Commercial inland fishery. In: Natural Resources Institute Finland [online]. Helsinki, Finland. [Cited 2 March 2020]. https:// stat.luke.fi/en/commercial-inland-fishery

Official Statistics of Finland (OSF). 2019. Commercial marine fishery. In: Natural Resources Institute Finland [online]. Helsinki, Finland. [Cited 2 March 2020]. https:// stat.luke.fi/en/commercial-marine-fishery

Olesen, H.J. \& Storr-Paulsen, M. 2015. Eel, cod and seatrout harvest in Danish recreational fishing during 2012. DTU Aqua report No. 293. 
O’Neill, C.E. \& Davis, J. 1991. Alternative Definitions of Demand for Recreational Angling in Northern Ireland, Journal of Agricultural Economics, 42 (2): 174-179.

Ovaskainen, V. 1999. Virkistyskalastuksen taloudellisesta arvottamisesta. Pohjanlahden vaelluskalojen tila- ja tulevaisuus - Kalantutkimuspäivät 1999. Kala ja riistaraportteja,167: 15-18. (In Finnish)

PACEC. 2017. An Analysis of the Value of Wild Fisheries in Scotland [online]. Report prepared for Marine Scotland, Aberdeen. [Cited 2 March 2020]. https://www2.gov.scot/ Resource/0051/00514801.pdf

Palm, S., Romakkaniemi, A., Dannewitz, J., Jokikokko, E., Pakarinen, T., Huusko, R., Broman, A. \& Sutela, T. 2019. Tornionjoen lohi-, meritaimen- ja vaellussiikakannat - ybteinen ruotsalais-suomalainen biologinen selvitys sopivien kalastussääntöjen arvioimiseksi vnodelle 2019. Swedish University of Agricultural Sciences and Natural Resources Institute Finland. (In Finnish)

Parkkila, K. 2005. Simojoen lohen saalismäärän lisä̈̈ntymisen taloudellinen arviointi contingent valuation-menetelmällä (Estimating the willingness to pay for catch improvements in the river Simojoki - an application of contingent valuation method) [online]. (Master's thesis). Department of Economics and Management, University of Helsinki. [Cited 2 March 2020] (in Finnish) https://helda.helsinki.fi/bitstream/ handle/10138/20953/simojoen.pdf?sequence $=2$

Parkkila, K., Arlinghaus, R., Artell, J., Gentner, B., Haider, W., Aas, Ø., Barton, D., Roth, E. \& Sipponen, M. 2010. Methodologies for assessing socio-economic benefits of European inland recreational fisheries [online]. EIFAC Occasional Paper No. 46. Ankara, FAO. 102 pp. [Cited 2 March 2020]. http://www.fao.org/3/i1723e/i1723e.pdf

Parkkila, K., Haltia, E. \& Karjalainen, T. 2011. Iijoen lohikannan palauttamistoimien hyödyt virkistyskalastajille - pilottitutkimus ehdollisen arvottamisen menetelmällä. Riista- ja kalatalous - Selvityksiä, 4/2011. (In Finnish)

Pedersen, S., Heinimaa, P. \& Pakarinen, T. 2012. Workshop on Baltic Sea Trout, Helsinki, Finland, 11-13 October 2011. DTU Aqua Report No. 248.

Pellikka, J. \& Eskelinen, P. 2019. Vapaa-ajankalastajien profiilit. Luonnonvara- ja biotalouden tutkimus, xx/2019. (In Finnish)

Pinello, D., Gee, J. \& Dimech, M. 2017. Handbook for fisheries socio-economic sample survey - principles and practice [online]. FAO Fisheries and Aquaculture Technical Paper No. 613. Rome, FAO. 136 pp. [Cited 2 March 2020]. http://www.fao.org/3/a-i6970e.pdf

Piria M., Simonović P., Zanella D., Ćaleta M., Šprem N., Paunović M., Tomljanović T., Gavrilović A., Pecina M., Špelić I., Matulić D., Rezić A., Aničić I., Safner R. \& Treer, T. 2019. Long-term analysis of fish assemblage structure in the middle section of the Sava River - The impact of pollution, flood protection and dam construction. Science of the Total Environment, 651: 143-153

Piria, M., Simonović, P., Nikolić,V., Ristovska, M., Apostolou, A., Adrović, A., Povž, M., Zanella, D., Mrdak, D., Milošević, D., Vardakas, L., Koutsikos, N., Kalogianni, E., Gregori, A., Kostov, V., Škrijelj, R., Korro, K., Bakiu, R., Tarkan, A.S. \& Joy, M.K. 2018. Alien freshwater fish species in the Balkans - vectors and pathways of introduction. Fish and Fisheries, 19: 138-169.

Pivnička, K. \& Rybáŕ, M. 2001. Long-term trends in sport fishery yield from selected reservoirs in the Labe watershed (1958-1998). Czech Journal of Animal Science, 46: 89-94.

Pivnička, K., Švátora, M., Křŕžek, J. \& Sýkora, P. 2005. Fish assemblages in the Berounka river and its tributaries (Úhlava and Mže) in 1975-2004 - Environmental parameters, fishery statistics, and electroshocker data. Acta Universitatis Carolinae Environmentalica, 19: 33-89.

Pohja-Mykrä, M.K., Matilainen, A-M.K., Kujala, S.M., Hakala, O.H., Harvio, V., Törmä, H.K. \& Kurki, S.P. 2018. Erätalouteen liittyvän yritystoiminnan nykytila ja kehittämisedellytykset. Valtioneuvoston selvitys- ja tutkimustoiminnan julkaisusarja 40/2018. (In Finnish) 
Pollock, K.H., Jones, C.M. \& Brown, T.L. 1994. Angler Surveys and Their Application to Fisheries Management. American Fisheries Society Special Publication 25, Bethesda, MD.

Pokki, H., Artell, J., Mikkola, J., Orell, P. \& Ovaskainen,V. 2018.Valuing recreational salmon fishing at a remote site in Finland: A travel cost analysis. Fisheries Research, 208: 145-156.

Pont, D., Valentini, A., Rocle, M., Maire, A., Delaigue, O., Jean, P. \& Dejean, T. (forthcoming). The future of fish-based ecological assessment of European rivers: from traditional EU Water framework Directive compliant methods to eDNA metabarcodingbased approaches. Journal of Fish Biology [online]. [Cited 2 March 2020]. https://doi. org/10.1111/jfb.14176

Pöyry. 2015. Oulujärven kalataloustarkkailu v. 2015. (In Finnish) http://www.kfrs.fi/ binary/file/-/id/13/fid/184/

Radford, A., Riddington, G., Anderson, J. \& Gibson, H. 2014. The Economic Impact of Game and Coarse Angling in Scotland [online]. Report prepared for the Scottish Executive, Edinburgh. [Cited 2 March 2020]. https://www.eaa-europe.org/files/theeconomy-corse-scotland-2004_7922.pdf

Rasmussen, G. \& Geertz-Hansen, P. 1998. Stocking of fish in Denmark. In I.G. Cowx, ed. Stocking and Introduction of Fish, pp. 14-21. Fishing News Books, Blackwell Science, Oxford.

Rasmussen, G. \& Geertz-Hansen, P. 2001. Fisheries management in inland and coastal waters in Denmark from 1987 to 1999. Fisheries Management and Ecology, 8: 311-322.

Rasmussen, G. \& Pedersen, S. 2018. Sea Trout (Salmo trutta L.) in Denmark. In J. LobónCerviá, N. Sanz, eds. Brown Trout: Biology, Ecology and Management, 1st edition, pp. 483-521.

Říha, M., Kubečka, J., Mrkvička, T., Prchalová, M., Čech, M., Draštík, V., Frouzová, J., Hladík, M., Hohausová, E., Jarolím, O., Jůza, T., Kratochvíll, M., Peterka, J., Tušer, M. \& Vašek, M. 2008. Dependence of beach seine net efficiency on net length and diel period. Aquatic Living Resources, 21: 411-418.

Riista- ja kalatalouden tutkimuslaitos. 2009. Data Analysis to Support the Development of a Baltic Sea Action Plan [online]. Helsinki, Finland. [Cited 2 March 2020]. In Finnish with English summary. https://ec.europa.eu/fisheries/sites/fisheries/files/docs/body/ baltic_sea_salmon_en.pdf

Salojärvi, K. 1991. Stock-recruitment relationships in the vendace (Coregonus albula L.) in Lake Oulujärvi, northern Finland. Aqua Fennica, 21: 153-161.

Salojärvi, K. 1992. The role of compensatory processes in determining the yield from whitefish (Coregonus lavaretus L. s.1.) stocking in inland waters in northern Finland. Finnish Fisheries Research, 13: 1-30.

Schwinn, M., Baktoft, H., Aarestrup, K. \& Koed, A. 2019. Artificial lakes delay the migration of brown trout Salmo trutta smolts: a comparison of migratory behaviour in a stream and through an artificial lake. Journal of Fish Biology [online]. [Cited 2 March 2020]. https://doi.org/10.1111/jfb.13950

Sievänen, T. \& Neuvonen, M., eds. 2011. Luonnon virkistyskäyttö 2010. Metlan työraportteja 212. (in Finnish)

Simonović, P., Piria, M., Zuliani, T., Ilić, M., Marinković, N., Kračun-Kolarević, M. \& Paunović, M. 2017. Characterization of sections of the Sava River based on fish community structure. Science of the Total Environment, 574: 264-271.

Simonović, P., Povž, M., Piria, M., Treer, T., Adrović, A., Škrijelj, R., Nikolić, V. \& Simić, V. 2015. Ichthyofauna of the River Sava System In R. Milačič et al., eds. The Sava River, The Handbook of Environmental Chemistry 31, pp. 361-400. Springer-Verlag Berlin Heidelberg.

Simonsen, P., Kjellerup, L., Koed, A. \& Nielsen, E. E. 2004. National management plan for salmon. Denmark: Miljøministeriet, Skov- og Naturstyrelsen. (in Danish). 
Sipponen, M. 1999. The Finnish inland fisheries system: the outcomes of private ownership of fishing rights and changes in administrative practices. Biological Research Reports from the University of Jyväskylä, 73: 1-81.

Skov, C., Aarestrup, K., Sivebæk, F., Pedersen, S., Vrålstad, T. \& Berg, S. 2011. Nonindigenous signal crayfish Pacifastacus leniusculus is now common in Danish streams: Preliminary status for national distribution and protective actions. Biological Invasions, 13: 1269-1274.

Skov, C., Jepsen, N., Baktoft, H., Jansen, T., Pedersen, S. \& Koed, A. 2014. Cormorant predation on PIT-tagged lake fish. Journal of Limnology, 73: 177-186.

Skov, C., Jansen, T. \& Arlinghaus, R. 2017. 62 years of population dynamics of European perch (Perca fluviatilis) in a mesotrophic lake tracked using angler diaries: The role of commercial fishing, predation and temperature. Fisheries Research, 195: 71-79 [online]. [Cited 2 March 2020]. https://doi.org/10.1016/j.fishres.2017.06.016

Skov, C. 2018. Pike stocking for lake restoration. In C. Skov \& P.A. Nilsson, eds. Biology and Ecology of Pike, pp. 269-288. CRC Press.

Skov, C., Berg, S., Eigaard, O.R., Jessen, T.K. \& Skov, P.V. 2019. Danish fisheries and aquaculture: past, present and future. Fisheries [online]. [Cited 2 March 2020]. https:// doi.org/10.1002/fsh.10330

Small, I. 1991. Exploring data provided by angling for salmonids in the British Isles. In I. G. Cowx, ed. Catch effort sampling strategies, pp 81-91. Fishing News Books, Oxford.

Šmejkal, M., Ricard, D., Prchalová, M., Říha, M., Muška, M., Blabolil, P., Čech, M., Vašek, M., Jůza, T., Monteoliva Herreras, A., Encina, L., Peterka, J. \& Kubečka, J. 2015. Biomass and Abundance Biases in European Standard Gillnet Sampling. PLoS ONE, 10(3): e0122437.

Solomon, D.T. \& Potter, E.C.E. 1992. The measurement and Evaluation of the Exploitation of Atlantic Salmon. Atlantic Salmon Trust, Pitlochry, UK.

Sparrevohn, C.R. \& Storr-Paulsen, M. 2010. Eel and cod catches in Danish recreational fishing: Survey design and 2009 catches. DTU Aqua Report, No. 217-2010.

Sparrevohn, C.R., Storr-Paulsen, M. \& Nielsen, J. 2011. Eel and cod catches in Danish recreational fishing: Survey design and 2009 catches. DTU Aqua Report, No. 240-2011.

Sparrevohn, C.R. \& Storr-Paulsen, M. 2012. Using interview-based recall surveys to estimate cod Gadus morhua and eel Anguilla anguilla harvest in Danish recreational fishing. ICES Journal of Marine Science, 69: 323-330.

Spurný, P., Mareš, J., Kopp, R., Fiala, J. \& Vítek, T. 2009. Socioekonomická studie sportovního rybolovu v České republice 2009. Mendelova Universita v Brně, Oddělení rybářství a hydrobiologie, Brno.

Spurný, P., Mareš, J., Kopp, R., Fiala, J. \& Vítek, T. 2013. Socioekonomická studie sportovního rybolovu v České republice 2013. Mendelova Universita v Brně, Oddělení rybářství a hydrobiologie, Brno.

Spurný, P., Mareš, J., Kopp, R., Grmela, J., Mareš, L. \& Malý, O. 2017. Socioekonomická studie sportovního rybolovn v České republice 2017. Mendelova Universita v Brně, Oddělení rybářství a hydrobiologie, Brno.

Suuronen, P. \& Bartley, D.M. 2014. Challenges in managing inland fsheries - using the ecosystem approach. Boreal Environmental Research, 19: 245-255.

TDI. 2013. Socio-Economic Study of Recreational Angling in Ireland. Final Report.

Thodsen, H., Tornbjerg, H., Rasmussen, J.J., Bøgestrand, J., Blicher-Mathiesen, G., Larsen, S.E., Ovesen, N.B., Windolf, J. \& Kjeldgaard, A. 2019. Vandløb 2017. NOVANA. Aarhus Universitet, DCE - Nationalt Center for Miljø og Energi. Videnskabelig rapport No. 306 [online]. [Cited 2 March 2020]. http://dce2.au.dk/pub/ SR306.pdf

Toivonen, A., Roth, E., Navrud, S., Gudbergsson, G., Appelblad, H., Bengtsson, B. \& Tuunainen, P. 2004. The economic value of recreational fisheries in Nordic countries. Fisheries Management and Ecology, 11: 1-14. 
Treer, T. \& Kubatov, I. 2017. The co-existence of recreational and artisanal fisheries in the central parts of the Danube and Sava rivers. Croatian Journal of Fisheries, 75: 116-127.

UNEP. 2010. Blue Harvest: Inland Fisheries as an Ecosystem Service. World Fish Center, Penang, Malaysia.

Urho, L., Koljonen, M-L., Saura, A., Savikko, A., Veneranta, L. \& Janatuinen, A., Kalat. (Pisces), Julk., Hyvärinen, E., Juslén, A., Kemppainen, E., Uddström, A. \& Liukko, U.-M. 2019. Suomen lajien uhanalaisuus- Punainen kirja 2019. The 2019 Red List of Finnish Species, pp. 549-555. Ympäristöministeriö ja Suomen ympäristökeskus. Helsinki. (In Finnish with an English summary)

Vainikka, A. \& Hyvärinen, P. 2012. Ecologically and evolutionarily sustainable fishing of the pikeperch Sander lucioperca: Lake Oulujärvi as an example. Fisheries Research, 113: 8-20.

Vainikka, A., Jakubavičiūtė, E. \& Hyvärinen, P. 2017. Synchronous decline of three morphologically distinct whitefish (Coregonus lavaretus) stocks in Lake Oulujärvi with concurrent changes in the fish community. Fisheries Research, 196: 34-46.

Van der Hammen, T., de Graaf, M. \& Lyle, J.M. 2016. Estimating catches of marine and freshwater recreational fisheries in the Netherlands using an online panel survey. ICES Journal of Marine Science, 73: 441-450.

Vehanen, T., Hyvärinen, P. \& Huusko, A. 2007. Food consumption and prey orientation of piscivorous brown trout (Salmo trutta L) and pikeperch (Stizostedion lucioperca) in a large regulated lake. Journal of Applied Ichthyology, 14: 15-22.

Vehanen, T., Marttunen, M., Tervo, H., Kylmälä, P. \& Hyvärinen, P. 2002. Management of Fisheries in a Large Lake - for Fish and Fishermen. In I.G. Cowx, ed. Management and Ecology of Lake and Reservoir Fisheries, pp. 299-311. Fishing News Books Blackwell.

Venturelli, P., Hyder, K. \& Skov, C. 2017. Angler apps as a source of recreational fisheries data: Opportunities, challenges and proposed standards. Fish and Fisheries, 18: 578-595.

Vesterinen (Artell), J., Pouta, E., Huhtala, A. \& Neuvonen, M. 2010. Impacts of changes in water quality on recreation behavior and benefits in Finland. Journal of Environmental Management, 91: 984-994.

Vostradovský, J. \& Tichý, J. 1999. History of fish stock development, fishery management and research on the Lipno Reservoir. Bulletin VURH Vodnany, 35: 48-65.

Warwick, R.M. 1986. A new method for detecting polluting effects on marine macrobentic communities. Mar. Biol., 92: 557-562.

Whelan, B.J. \& Marsh, G. 1988. An Economic Evaluation of Irish Angling. Economic and Social Research Institute and the Central Fisheries Board, Dublin. 



\section{Other sources of information}

\section{BIBLIOGRAPHY FOR THE ERRIFF RIVER CASE STUDY (CHAPTER 7.2)}

Costelloe, M., Costelloe, J., Coghlan, N., O’Donohoe, G. \& O’Connor, B. 1998. Distribution of the larval stages of Lepeophtheirus salmonis in three bays on the west coast of Ireland. ICES Journal of Marine Science, 55 (2): 181-187 [online]. [Cited 2 March 2020]. http://icesjms.oxfordjournals.org/content/55/2/181.full.pdf

De Eyto, E., White, J., Boylan, P., Clarke, B., Cotter, D., Doherty, D., Gargan, P., Kennedy, R., McGinnity, P., Ó Maoiléidigh, N. \& O’Higgins, K. 2015. The fecundity of wild Irish Atlantic salmon Salmo salar L. and its application for stock assessment purposes. Fisheries Research, 164: 159-169.

Finstad, B., Bjorn, P.A., Todd, C.D., Whoriskey, F., Gargan, P.G., Forde, G. \& Revie, C.W. 2010. The effects of sea Lice on Atlantic Salmon and other salmonid species. In Ø. Aas, S. Einum, A. Klemetsen, J. Skurdal, eds. Atlantic Salmon Ecology, pp. 253-276. Wiley-Blackwell.

Gargan, P., Poole, R., Tully, O. \& Forde, G. 1997. Recaptures of marked sea trout distant from their natal systems in western Ireland. In A.H. McVicar, ed. Report on the Workshop on the Interactions between Salmon Lice and Salmonids, appendix 62. Edinburgh, UK.

Gargan, P.G., Whelan, K.F. \& Whelan, B.J. 1997. An illustrative grilse survival model for an Irish salmon fishery. In P. Hickley, H. Tompkins, eds. Recreational Fisheries - Social, Economic and Management Aspects, pp. 106-115. FAO/EIFAC Fishing News Books.

Gargan, P.G. 2000. The impact of the salmon louse (Lepeophtheirus salmonis) on wild salmonids in Europe and recommendations for effective management of sea lice on marine salmon farms. In P. Gallagher, C. Orr, eds. Aquaculture and the Protection of Wild Salmon Workshop Proceedings, pp. 37-46. Simon Fraser University, Vancouver, British Columbia, Canada.

Gargan, P., Stafford, J. \& Ó’Maoiléidigh, N. 2001. The relationship between salmon rod catch, stock size, rod exploitation and rod effort on the Erriff Fishery, Western Ireland. In R. Shelton, ed. The Interpretation of Rod and Net Catch Data, pp. 68-75 [online]. The Atlantic Salmon Trust, Pitlochry. [Cited 2 March 2020]. http://www.environmentdata. org/download/file/ast:83/ast:83/1/0/OBJ/PDF/NA

Gargan, P.G., Tully, O. \& Poole, R. 2003. The relationship between sea lice infestation, sea lice production and sea trout survival in Ireland, 1992-2001. In D. Mills, ed. Salmon on the Edge, pp. 119-135. Blackwell Science, Oxford, UK.

Gargan, P., Poole, R. \& Forde, G. 2006. A Review of the Status of Irish Sea Trout Stocks. In G.S. Harris, N.J.Milner, eds. Sea Trout: Biology, Conservation and Management. Proceedings of First International Sea Trout Symposium, Cardiff, July 2004, pp. 25-44 [online]. Blackwell Scientific Publications, Oxford. [Cited 2 March 2020]. http:// onlinelibrary.wiley.com/doi/10.1002/9780470996027.fmatter/pdf

Gargan, P.G., Forde, G., Hazon, N., Russell, D.J.F. \& Todd, C.D. 2012. Evidence for sea lice-induced marine mortality of Atlantic salmon (Salmo salar) in western Ireland from experimental releases of ranched smolts treated with emamectin benzoate. Canadian Journal of Fisheries and Aquatic Sciences, 69 (2): 343-353.

Gargan, P.G., Kelly, F.L., Shephard, S. \& Whelan, K.F. 2016. Temporal variation in sea trout Salmo trutta life history traits in the Erriff River, western Ireland. Aquaculture Environment Interactions, 8: 675-689 [online]. [Cited 2 March 2020]. DOI: 10.3354/aei00211 
Gargan, P.G., Shephard, S. \& Macintyre, C. 2017. Assessment of the increased mortality risk and population regulating effect of sea lice (Lepeophtheirus salmonis) from marine salmon farms on wild sea trout in Ireland and Scotland. In G. Harris, ed. Sea Trout: Science E Management. Proceedings of the 2nd International Sea Trout Symposium, pp. 507-522.

ICES. 1997. Report of the Workshop on the interactions between Salmon lice and salmonids, Edinburgh, United Kingdom, 11-15 November 1996 [online]. Copenhagen, Denmark. [Cited 2 March 2020]. http://www.ices.dk/sites/pub/Publication\%20Reports/ Expert\%20Group\%20Report/Anadromous\%20and\%20Catadromous\%20Fish\%20 Committee/1997/1997_M4.pdf

Millane, M., Shephard, S., White, J., Ó Maoiléidigh, N., O’Higgins, K., O’Malley, P., Roche, W., Poole, R., Rogan, G, Bond, N. \& Gargan, P.G. 2017. Estimating salmonid angling exploitation rates from systems monitored by fish counters, and potential application to fisheries management in Ireland. In G. Harris, ed. Sea Trout: Science $\mathcal{E}$ Management. Proceedings of the 2nd International Sea Trout Symposium, pp. 167-184.

O'Farrell, M.M., Whelan, K.F. \& Whelan, B.J. 1989. A preliminary appraisal of the fecundity of migratory trout (Salmo trutta) in the Erriff Catchment, western Ireland. Polish Archives of Hydrobiology, 36 (2): 273-81.

O'Farrell, M.M., Whelan, K.F., Joyce, T. \& Whelan, B.J. 1990. The performance of the River Erriff salmon fisheries. Proceedings of the Institute of Fisheries Management 20th Annual Study Course, pp. 129-148.

O'Farrell, M.M., Whelan, K.F., Poole, R., Gargan, P., Peirce, R.P., Moore, T, \& Lubberhuizen, J. 1993. Western Ireland Migratory Trout (Salmo trutta): Smolt Production, Characteristics and Timing of Migration. ICES CM 1993/M: 52 [online]. [Cited 2 March 2020]. http://www.ices.dk/sites/pub/CM\%20Doccuments/1993/M/1993_M52.pdf

Poole, W.R., Byrne, C.J., Dillane, M.G., Whelan, K.F. \& Gargan, P.G. 2002. The Irish sea trout enhancement programme: A review of the broodstock and ova production programmes. Fisheries Management and Ecology, 9: 1-14.

Shephard, S., MacIntyre, C. \& Gargan, P.G. 2016. Aquaculture and environmental drivers of salmon lice Lepeophtheirus salmonis infestation and body condition in sea trout (Salmo trutta L.). Aquaculture Environment Interactions, 8: 597-610 [online]. [Cited 2 March 2020]. http://www.int-res.com/articles/aei2016/8/q008p597.pdf

Shephard, S. \& Gargan, P.G. 2017. Quantifying the contribution of sea lice from aquaculture to declining annual returns in a wild Atlantic salmon population. Aquaculture Environment Interactions, 9: 181-192 [online]. [Cited 2 March]. http://www.int-res. com/articles/aei2017/9/q009p181.pdf

Shephard, S., Davidson, I.C., Walker, A.M., \& Gargan, P.G. 2018. Length-based indicators and reference points for assessing data-poor stocks of diadromous trout Salmo trutta. Fisheries Research, 199: 36-43.

Thorstad, E.B., Todd, C.D., Uglem, I., Bjørn, P.A., Gargan, P.G., Vollset, K.W., Halttunen, E., Kålås, S., Berg, M. \& Finstad, B. 2015. Effects of salmon lice Lepeophtheirus salmonis on wild sea trout Salmo trutta-a literature review. Aquaculture Environment Interactions, 7: 91-113 [online]. [Cited 2 March 2020]. http://www.int-res.com/articles/ aei2015/7/q007p091.pdf

Tully, O., Poole, W.R. \& Whelan, K.F. 1993. Infestation parameters for Lepeophtheirus salmonis (Kroyer) (Copepoda: Caligidae) parasitic on sea trout, Salmo trutta L., off the west coast of Ireland during 1990 and 1991. Aquaculture Research, 24 (4): 545-555.

Tully, O., Gargan, P.G., Poole, W.R. \& Whelan, K.F. 1999. Spatial and temporal variation in the infestation of sea trout (Salmo trutta L.) by the caligid copepod Lepeophtheirus salmonis (Kroyer) in relation to sources of infestation in Ireland.Parasitology, 119: 41-51.

Wild Salmon and Sea Trout Statistics. Central Fisheries Board (2001-2009) [online]. [Cited 2 March 2020]. http://www.fisheriesireland.ie/Salmon-Management/wild-salmon-andsea-trout-statistics.html

Wild Salmon and Sea Trout Statistics. Inland Fisheries Ireland (2010-2016). [online]. [Cited 2 March 2020]. http://www.fisheriesireland.ie/Salmon-Management/wildsalmon-and-sea-trout-statistics.html 

Inland fisheries are important sources of ecosystem services contributing to human diet, health, well-being and economies. The evaluation of the importance and value of inland fisheries is one of the biggest challenges for its development. To develop the inland fisheries data collection, we reviewed the current status of data collection in European countries and provided five detailed country examples. The level and methods of inland fisheries data collection in Europe were highly variable. Some countries did not collect any data on recreational fishing, or it was collected only from specific areas, or only the number of licenses sold was recorded. Data collection from catches of diadromous species was most common and harmonized among countries and in particular, Atlantic salmon Salmo salar were recorded. When data from other fish species were also nationally collected, the methods used included postal or telephone recall surveys using a sample of citizens of the country. More detailed surveys were used to assist national surveys, or were used independently, in specific sites of importance using various methods, like postal surveys targeted to fishing license holders, online reporting of catches, or catch reports and logbooks. Many countries provided fishing license buyers with catch return forms or logbooks to be filled at fishing occasions and/or returned in the end of the fishing season.

Commercial inland fisheries did not exist, or were very limited, in many European countries. In countries where commercial fishing was important, in most cases the fishers were registered and obliged to report their catches. The reliability of self-reporting of commercial catches was questioned in some cases. There was a trend towards web-based online reporting of inland fisheries data, which some countries were already using. The specific country examples give detailed description of data collection, focusing on: 1) country-wide postal survey (Finland) and 2) web-based survey and development of citizen science approach (Denmark). Example 3) from Ireland focuses on recreational salmonid fishing and conservation limits. There are two examples based on logbook returns: 4) one strict system, which is considered to work well (Czech Republic) and 5) one less controlled system, currently not producing reliable results, and under development (Croatia). Case studies were provided in each country example. Finally, the authors discuss the important aspects of inland fisheries data collection and review the methods to provide recommendations. 